University of Tennessee Health Science Center UTHSC Digital Commons

\title{
Design of Lipid and Polymeric Carriers for Nucleic Acid Delivery
}

\author{
Lin Zhu \\ University of Tennessee Health Science Center
}

Follow this and additional works at: https://dc.uthsc.edu/dissertations

Part of the Pharmaceutics and Drug Design Commons

\section{Recommended Citation}

Zhu, Lin , "Design of Lipid and Polymeric Carriers for Nucleic Acid Delivery" (2010). Theses and Dissertations (ETD). Paper 324. http://dx.doi.org/10.21007/etd.cghs.2010.0384.

This Dissertation is brought to you for free and open access by the College of Graduate Health Sciences at UTHSC Digital Commons. It has been accepted for inclusion in Theses and Dissertations (ETD) by an authorized administrator of UTHSC Digital Commons. For more information, please contact jwelch30@uthsc.edu. 


\title{
Design of Lipid and Polymeric Carriers for Nucleic Acid Delivery
}

\begin{abstract}
The objectives of the study were to investigate and develop lipid and polymeric carriers for nucleic acid delivery. These included: i) to develop novel cationic lipids for plasmid, oligonucleotide, and siRNA delivery; ii) to develop a novel polymeric delivery system, polyethylene glycol (PEG) based bio-conjugate, for oligonucleotide delivery; iii) to develop a novel bio-conjugate delivery system for siRNA delivery.
\end{abstract}

In Chapter 2, we discussed the barriers and strategies of nucleic acid delivery, as well as summarized the commonly used lipids, polymers, and the corresponding carriers in terms of their characteristics, applications, advantages and limitations.

Cationic lipids are most commonly used transfection reagents in delivery of nucleic acids to target cells in vitro. In Chapter 3, we synthesized a series of pyridinium lipids which contain a heterocyclic ring and a nitrogen atom. The structure-activity relationship (SAR) and formulation of corresponding cationic liposomes were studied for gene and siRNA delivery. The pyridinium lipids were mixed with a co-lipid, such as 1,2-dioleoyl-sn-glycero-3-phosphoethanolamine (DOPE) and cholesterol, to prepare cationic liposomes by sonication. These liposomes were mixed with plasmid DNA and transfected into CHO cells. Several factors including hydrophobic anchor chain length, anchor chain type, configuration of double bond, linker type, co-lipid type, cationic lipid/co-lipid molar ratio, charge ratio (N/P), concentration of serum, and cell type had significant influence on transfection efficiency and cytotoxicity. Pyridinium lipids with amide linker showed higher transfection efficiency compared to their ester counterparts. Liposomes prepared at a 1:1 molar ratio of pyridinium lipid and co-lipid showed higher transfection efficiency. Pyridinium lipids based on a hydrophobic anchor chain length of 16 showed higher transfection efficiency and lower cytotoxicity. The trans-isomers of pyridinium lipids showed higher transfection efficiency than the cis-isomers at the same fatty acid chain length. In the presence of serum, C16:0 and Lipofectamine significantly decreased their transfection efficiencies, which were completely lost at a serum concentration of $30 \%$ and higher, while $\mathrm{C} 16: 1$ trans-isomer still had high transfection efficiency under these conditions. The optimized formulation was further investigated in delivery of siRNAs and showed equal or higher gene silencing effect at the low dose of siRNAs compared to Lipofectamine 2000.

To avoid use of polycations, in Chapter 4, we conjugated galactosylated poly(ethylene glycol) (Gal-PEG) to ODN via an acid labile ester linkage of $\beta$-thiopropionate. The conjugate was purified by RP-HPLC and verified by polyacrylamide gel electrophoresis. To determine the biodistribution and pharmacokinetic parameters of Gal-PEG-ODN, ODN was radiolabeled by ${ }^{33} \mathrm{P}$ before the conjugation reaction. Following tail vein injection into rats, Gal-PEG- ${ }^{33} \mathrm{P}-\mathrm{ODN}$ rapidly cleared from circulation and

$60.2 \%$ of the injected dose accumulated in the liver at $30 \mathrm{~min}$ post-injection, which was significantly higher than that deposited after injection of ${ }^{33} \mathrm{P}-\mathrm{ODN}$. The plasma concentration versus time profile of Gal-PEG- ${ }^{33} \mathrm{P}-\mathrm{ODN}$ was biphasic, with $4.38 \pm 0.36 \mathrm{~min}$ as $\mathrm{t}_{1 / 2}$ of distribution and $118.61 \pm 22.06 \mathrm{~min}$ as $\mathrm{t}_{1 / 2}$ of elimination. Prior administration of excess Gal-BSA decreased the hepatic uptake of Gal-PEG- ${ }^{33} \mathrm{P}-\mathrm{ODN}$ from $60.2 \%$ to $35.9 \%$, suggesting galactose triggers the asialoglycoprotein receptor-mediated endocytosis of Gal-PEG- ${ }^{33} \mathrm{P}-\mathrm{ODN}$ by hepatocytes. A large proportion of the injected Gal-PEG- ${ }^{33} \mathrm{P}-\mathrm{ODN}$ was taken up by the hepatocytes as evidenced by determination of radioactivity in the digested liver cells upon liver perfusion and separation by centrifugation on a Nycodenz gradient.

Although the potency and specificity of siRNA was demonstrated, so far, siRNA has not been successfully used as a clinical therapeutic due to its short circulation time in blood stream, non specific tissue or cell 
targeting, and insufficient intracellular transport. In Chapter 5, a similar strategy was used to design siRNA conjugates. To target to hepatocytes and hepatic stellate cells, galactose and M6P were used as the ligands respectively to synthesize Gal-PEG-siRNA and M6P-PEG-siRNA. In this study the cleavable disulfide bond was introduced between siRNA and PEG to ensure siRNA dissociation from the conjugate in the reducing environment in cytoplasm. After conjugation reaction, the conjugate was purified by ion exchange HPLC and verified by gel retardation assay. After treatment with DTT, the conjugated siRNA was disassociated from its conjugate and verified by gel retardation assay. To evaluate the gene silencing ability of siRNA conjugate, an effective luciferase siRNA sequence was designed and conjugated with Gal-PEG and M6P-PEG. Then Gal-PEG-siRNA and M6P-PEG-siRNA were transfected with luciferase expression HepG2 cells and rat HSCs respectively. We found both conjugates could down-regulate the luciferase gene expression for about $40 \%$ without any transfection reagents, while the gene down-regulation level reached more than $98 \%$ with the help of cationic liposomes at the same dose.

In conclusion, we synthesized a series of pyridinium lipids and studied their SAR and corresponding liposomal formulations. We found pyridinium lipids showed high transfection efficiency and had the potential to be used as transfection reagents in vitro. The polymeric conjugate delivery systems, Gal-PEG-ODN, Gal-PEG-siRNA and M6P-PEG-siRNA were successfully designed and developed. The in vitro and in vivo studies showed that the conjugate delivery systems could effectively deliver nucleic acids into the target cells, release their cargo, and manipulate the target gene expression. These research works strengthened the development of lipid and polymeric carriers as the effective nucleic acid delivery systems.

\section{Document Type}

Dissertation

\section{Degree Name}

Doctor of Philosophy $(\mathrm{PhD})$

\section{Program}

Pharmaceutical Sciences

\section{Research Advisor}

Ram I. Mahato, Ph.D.

\section{Keywords}

delivery, lipid, nucleic acid, PEG, polymer, siRNA

\section{Subject Categories}

Medicine and Health Sciences | Pharmaceutics and Drug Design | Pharmacy and Pharmaceutical Sciences 
DESIGN OF LIPID AND POLYMERIC CARRIERS FOR NUCLEIC ACID DELIVERY

\author{
A Dissertation \\ Presented for \\ The Graduate Studies Council \\ The University of Tennessee \\ Health Science Center \\ In Partial Fulfillment \\ Of the Requirements for the Degree \\ Doctor of Philosophy \\ From The University of Tennessee
}

By

Lin Zhu

December 2010 
Portions of Chapter 3 C 2008 by American Chemical Society for Bioconjugate Chemistry.

Portions of Chapter 4 (C) 2008 by American Chemical Society for Bioconjugate Chemistry.

All other material (C) 2010 by Lin Zhu.

All rights reserved. 


\section{DEDICATION}

This dissertation is dedicated to

my parents, Mr. Xianzhong Zhu and Mrs. Jinhua Li, my wife Mrs. Ying Tu, for their endless love and support. 


\section{ACKNOWLEDGEMENTS}

My sincerest gratitude goes to my major professor Dr. Ram I Mahato, for the opportunities, valuable advice, motivation, guidance and support given to me during the course of this research work.

I would like to thank my other committee members, Dr. Ramareddy V. Guntaka, Dr. Bernd Meibhom, Dr. Duane D. Miller, and Dr. Lawrence M. Pfeffer for their guidance, suggestions, and help throughout my research work.

I feel so lucky that I have been working with a nice and helpful group in the past five years, I would like to give my sincere thanks to Dr. Ajit Narang, Dr. Kun Cheng, Dr. Zhaoyang Ye, Dr. Guofeng Cheng, Dr. Xiangxu Jia, Dr. Yong Cheng, Dr. Daniel De Paula, Mr. Ravikiran Panakanti, Mr. Feng Li, Ms. Ningning Yang, Mr. Michael K. Danquah, Mr. Hao Wu, and Ms. Rubi Mahato.

My special thanks go to Dr. Yan Lu for her hard working in the synthesis of all pyridinium lipids and kind help in writing the manuscript.

I would like to thank the University of Tennessee Health Science Center for providing the opportunity and financial assistance to pursue a Doctor of Philosophy degree, and all the faculty and staff in Department of Pharmaceutical Sciences for their help and support during my graduate study.

I would also like to thank American Chemical Society for Bioconjugate Chemistry for letting me include my published materials in my dissertation. 


\begin{abstract}
The objectives of the study were to investigate and develop lipid and polymeric carriers for nucleic acid delivery. These included: i) to develop novel cationic lipids for plasmid, oligonucleotide, and siRNA delivery; ii) to develop a novel polymeric delivery system, polyethylene glycol (PEG) based bio-conjugate, for oligonucleotide delivery; iii) to develop a novel bio-conjugate delivery system for siRNA delivery.

In Chapter 2, we discussed the barriers and strategies of nucleic acid delivery, as well as summarized the commonly used lipids, polymers, and the corresponding carriers in terms of their characteristics, applications, advantages and limitations.

Cationic lipids are most commonly used transfection reagents in delivery of nucleic acids to target cells in vitro. In Chapter 3, we synthesized a series of pyridinium lipids which contain a heterocyclic ring and a nitrogen atom. The structure-activity relationship (SAR) and formulation of corresponding cationic liposomes were studied for gene and siRNA delivery. The pyridinium lipids were mixed with a co-lipid, such as 1,2dioleoyl-sn-glycero-3-phosphoethanolamine (DOPE) and cholesterol, to prepare cationic liposomes by sonication. These liposomes were mixed with plasmid DNA and transfected into CHO cells. Several factors including hydrophobic anchor chain length, anchor chain type, configuration of double bond, linker type, co-lipid type, cationic lipid/co-lipid molar ratio, charge ratio (N/P), concentration of serum, and cell type had significant influence on transfection efficiency and cytotoxicity. Pyridinium lipids with amide linker showed higher transfection efficiency compared to their ester counterparts. Liposomes prepared at a 1:1 molar ratio of pyridinium lipid and co-lipid showed higher transfection efficiency. Pyridinium lipids based on a hydrophobic anchor chain length of 16 showed higher transfection efficiency and lower cytotoxicity. The trans-isomers of pyridinium lipids showed higher transfection efficiency than the cis-isomers at the same fatty acid chain length. In the presence of serum, C16:0 and Lipofectamine significantly decreased their transfection efficiencies, which were completely lost at a serum concentration of $30 \%$ and higher, while $\mathrm{C} 16: 1$ trans-isomer still had high transfection efficiency under these conditions. The optimized formulation was further investigated in delivery of siRNAs and showed equal or higher gene silencing effect at the low dose of siRNAs compared to Lipofectamine 2000.

To avoid use of polycations, in Chapter 4, we conjugated galactosylated poly(ethylene glycol) (Gal-PEG) to ODN via an acid labile ester linkage of $\beta$ thiopropionate. The conjugate was purified by RP-HPLC and verified by polyacrylamide gel electrophoresis. To determine the biodistribution and pharmacokinetic parameters of Gal-PEG-ODN, ODN was radiolabeled by ${ }^{33} \mathrm{P}$ before the conjugation reaction. Following tail vein injection into rats, Gal-PEG- ${ }^{33} \mathrm{P}-\mathrm{ODN}$ rapidly cleared from circulation and $60.2 \%$ of the injected dose accumulated in the liver at 30 min post-injection, which was significantly higher than that deposited after injection of ${ }^{33} \mathrm{P}-\mathrm{ODN}$. The plasma concentration versus time profile of Gal-PEG- ${ }^{33} \mathrm{P}-\mathrm{ODN}$ was biphasic, with $4.38 \pm 0.36$ min as $t_{1 / 2}$ of distribution and $118.61 \pm 22.06$ min as $t_{1 / 2}$ of elimination. Prior
\end{abstract}


administration of excess Gal-BSA decreased the hepatic uptake of Gal-PEG- ${ }^{33} \mathrm{P}-\mathrm{ODN}$ from $60.2 \%$ to $35.9 \%$, suggesting galactose triggers the asialoglycoprotein receptormediated endocytosis of Gal-PEG $-{ }^{33} \mathrm{P}-\mathrm{ODN}$ by hepatocytes. A large proportion of the injected Gal-PEG- ${ }^{33} \mathrm{P}-\mathrm{ODN}$ was taken up by the hepatocytes as evidenced by determination of radioactivity in the digested liver cells upon liver perfusion and separation by centrifugation on a Nycodenz gradient.

Although the potency and specificity of siRNA was demonstrated, so far, siRNA has not been successfully used as a clinical therapeutic due to its short circulation time in blood stream, non specific tissue or cell targeting, and insufficient intracellular transport. In Chapter 5, a similar strategy was used to design siRNA conjugates. To target to hepatocytes and hepatic stellate cells, galactose and M6P were used as the ligands respectively to synthesize Gal-PEG-siRNA and M6P-PEG-siRNA. In this study the cleavable disulfide bond was introduced between siRNA and PEG to ensure siRNA dissociation from the conjugate in the reducing environment in cytoplasm. After conjugation reaction, the conjugate was purified by ion exchange HPLC and verified by gel retardation assay. After treatment with DTT, the conjugated siRNA was disassociated from its conjugate and verified by gel retardation assay. To evaluate the gene silencing ability of siRNA conjugate, an effective luciferase siRNA sequence was designed and conjugated with Gal-PEG and M6P-PEG. Then Gal-PEG-siRNA and M6P-PEG-siRNA were transfected with luciferase expression HepG2 cells and rat HSCs respectively. We found both conjugates could down-regulate the luciferase gene expression for about $40 \%$ without any transfection reagents, while the gene down-regulation level reached more than $98 \%$ with the help of cationic liposomes at the same dose.

In conclusion, we synthesized a series of pyridinium lipids and studied their SAR and corresponding liposomal formulations. We found pyridinium lipids showed high transfection efficiency and had the potential to be used as transfection reagents in vitro. The polymeric conjugate delivery systems, Gal-PEG-ODN, Gal-PEG-siRNA and M6PPEG-siRNA were successfully designed and developed. The in vitro and in vivo studies showed that the conjugate delivery systems could effectively deliver nucleic acids into the target cells, release their cargo, and manipulate the target gene expression. These research works strengthened the development of lipid and polymeric carriers as the effective nucleic acid delivery systems. 


\section{TABLE OF CONTENTS}

CHAPTER 1. GENERAL INTRODUCTION ............................................................

\section{CHAPTER 2. LIPID AND POLYMERIC CARRIER MEDIATED NUCLEIC ACID}

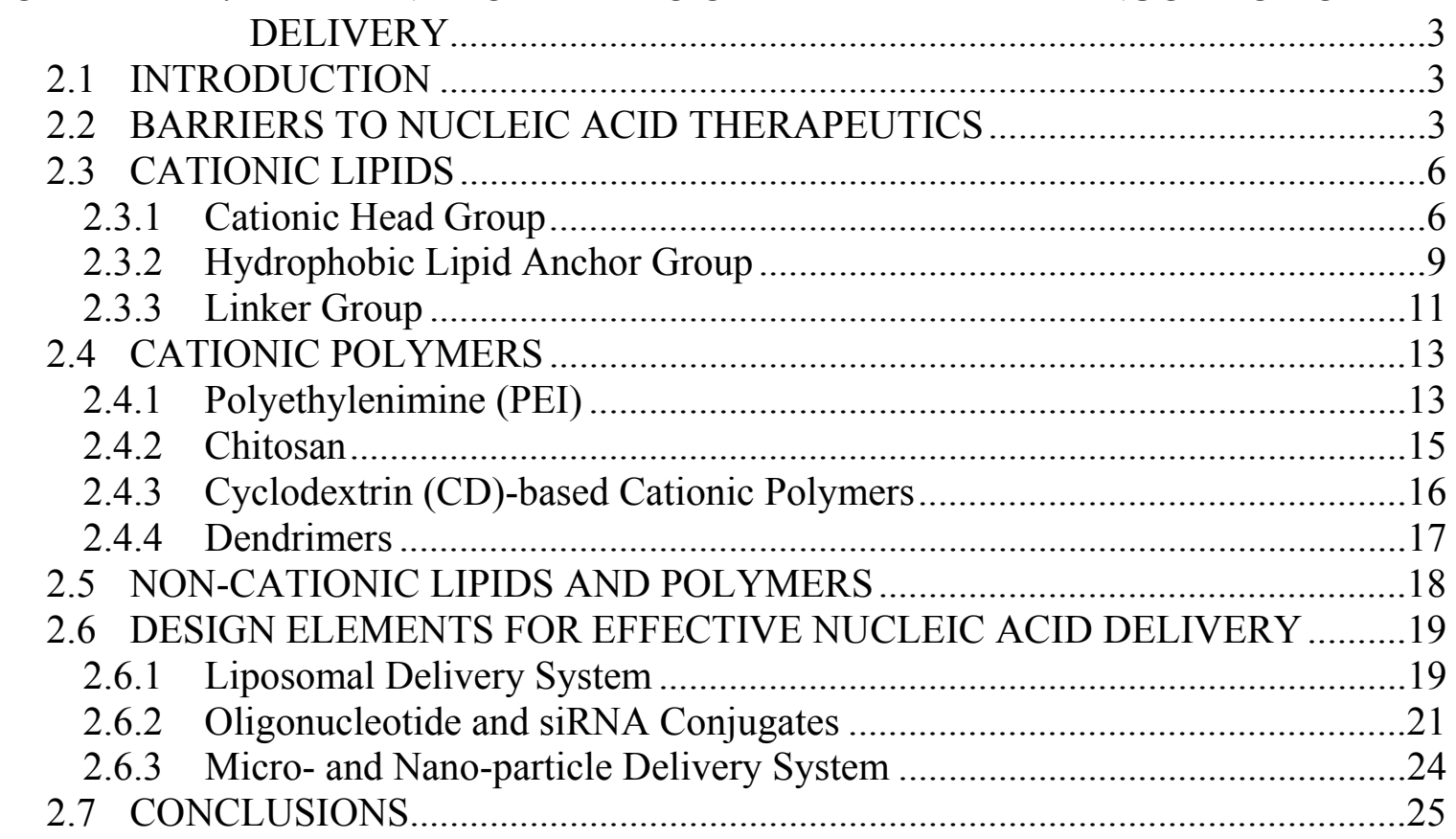

\section{CHAPTER 3. STRUCTURAL AND FORMULATION FACTORS INFLUENCING PYRIDINIUM LIPID-BASED NCLEIC ACID DELIVERY ..................26}

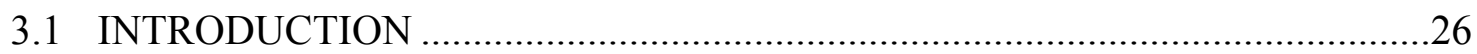

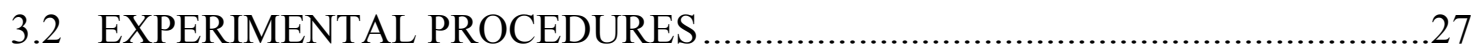

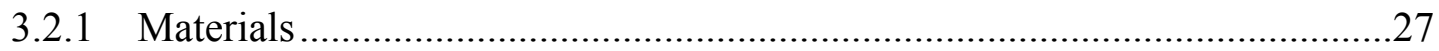

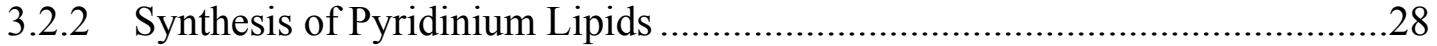

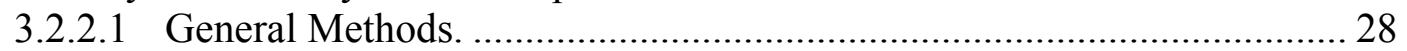

3.2.2.2 Synthesis of Pyridinium Amide Cationic Lipids 4-13 .......................... 28

3.2.2.3 Synthesis of Pyridinium Ester Cationic Lipids 14-18 ........................... 33

3.2.3 Determination of Lipid Phase Transition Temperature and Melting Point....34

3.2.4 Preparation of Pyridinium Liposomes and Lipoplexes .................................34

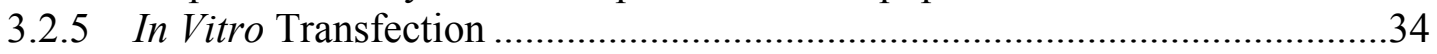

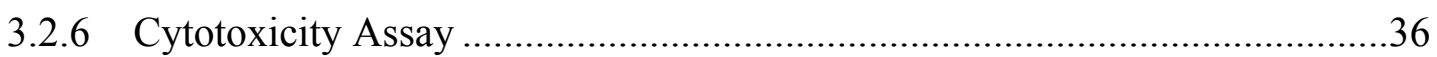

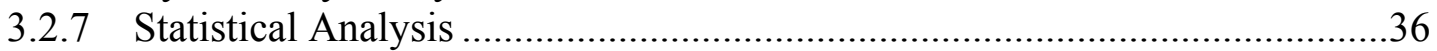

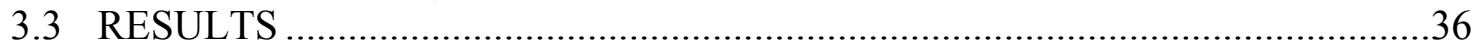

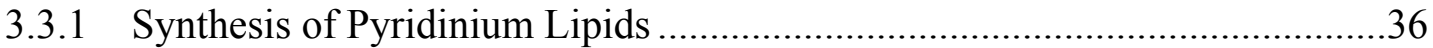

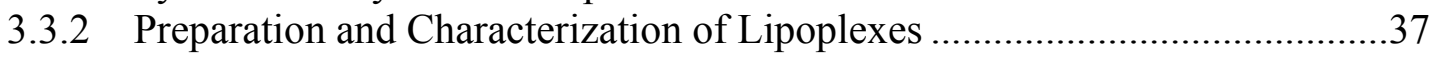

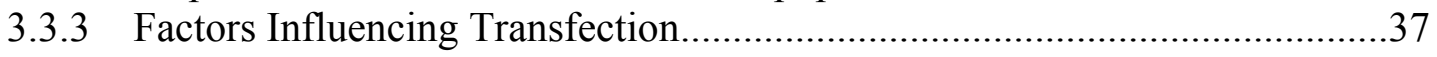

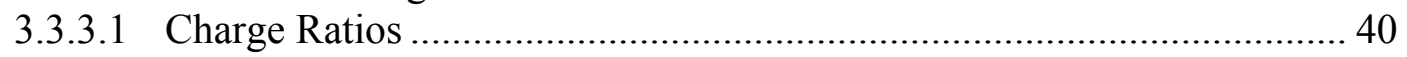

3.3.3.2 Type of Linkers ............................................................................. 40

3.3.3.3 Cationic Lipid:Co-lipid Molar Ratios ............................................... 40 


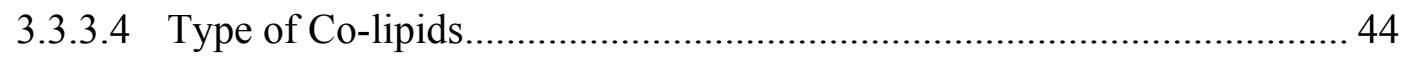

3.3.3.5 Alkyl Chain Length .............................................................................. 44

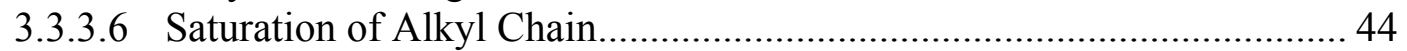

3.3.3.7 Configuration of Alkyl Chain.................................................................. 44

3.3.3.8 Influence of Serum on Gene Transfer .................................................... 49

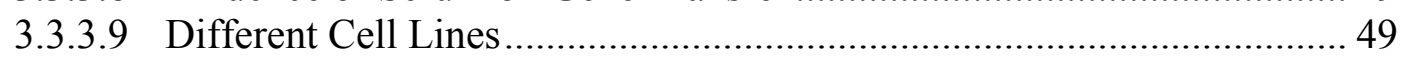

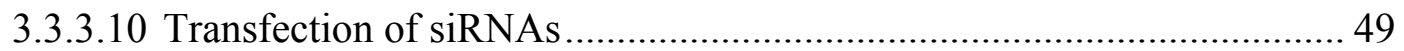

3.3.3.11 Cellular Uptake Study of siRNAs Using Pyridinium Lipids .................. 54

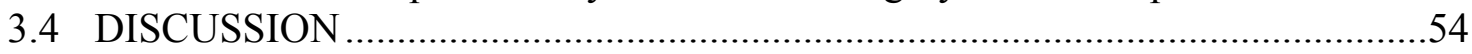

\section{CHAPTER 4. SITE-SPECIFIC DELIVERY OF OLIGONULCLEOTIDES TO HEPATOCYTES AFTER SYSTEMIC ADMINSTRATION ...................59}

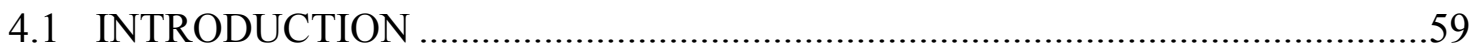

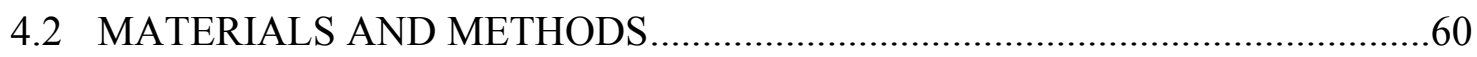

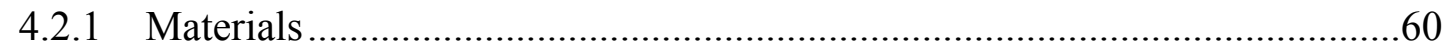

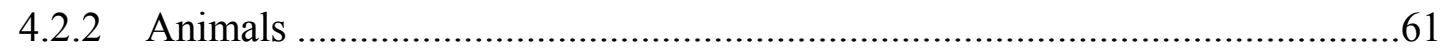

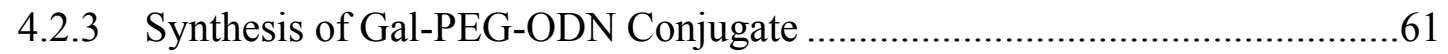

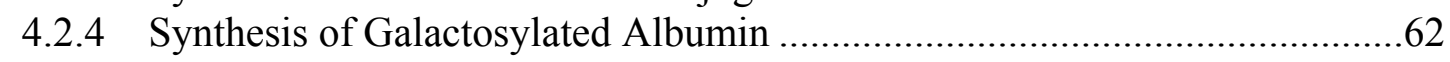

4.2.5 Radiolabeling of Oligonucleotides ............................................................62

4.2.6 Dissociation and Stability ......................................................................62

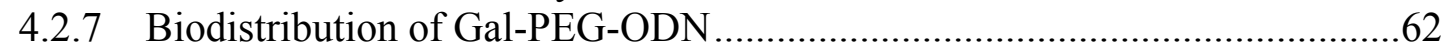

4.2.8 Determination of Pharmacokinetic Profiles ...................................................63

4.2.9 Competition in Hepatic Uptake of Gal-PEG-ODN ………………...................64

4.2.10 Hepatic Cellular Distribution of Gal-PEG-ODN ………………....................64

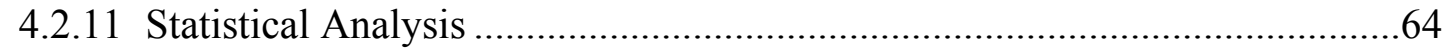

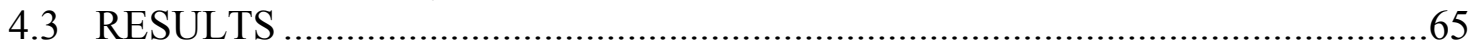

4.3.1 Synthesis and Characterization of Gal-PEG and Gal-PEG-ODN ..................65

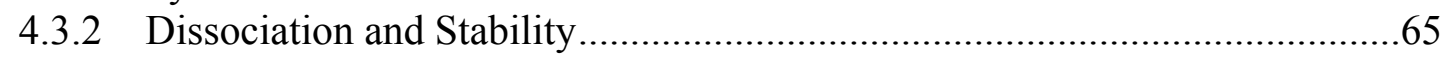

4.3.3 Biodistribution of Gal-PEG-ODN Conjugate …………………..................72

4.3.4 Competition in Hepatic Uptake of Gal-PEG- ${ }^{33}$ P-ODN ..................................72

4.3.5 Hepatic Cellular Localization ...................................................................76

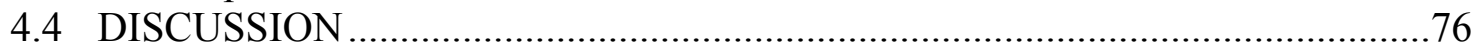

\section{CHAPTER 5. TARGETED DELIVERY OF SIRNA TO HEPATOCYTES AND} HEPATIC STELLATE CELLS.............................................................. 80

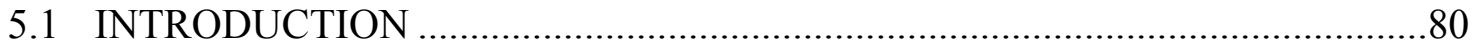

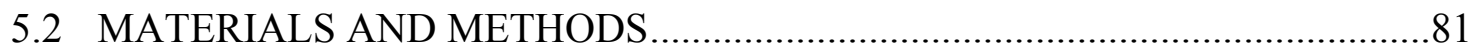

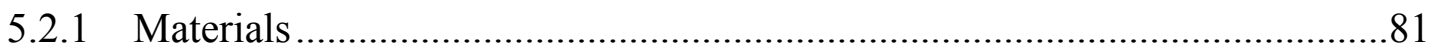

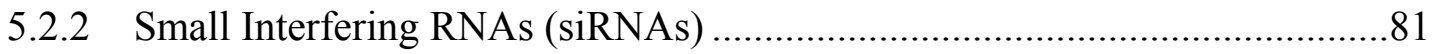

5.2.3 Synthesis of Gal-PEG-siRNA and M6P-PEG-siRNA …………..................82

5.2.3.1 Synthesis of Ligands (Gal and M6P) ………....................................... 82

5.2.3.2 Synthesis of Gal-PEG-OPSS and M6P-PEG-OPSS ............................... 82

5.2.3.3 Synthesis of Gal-PEG-siRNA and M6P-PEG-siRNA ………................. 82

5.2.3.4 Characterization of Gal-PEG-OPSS and M6P-PEG-OPSS .................... 83

5.2.3.5 Cell Cultures and Transfections ............................................................. 83 


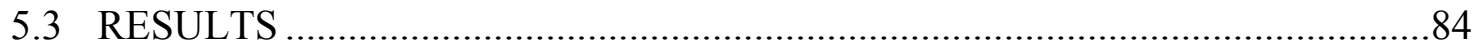

5.3.1 Synthesis of Gal-PEG-siRNA and M6P-PEG-siRNA ………………….......84

5.3.2 Dissociation of siRNAs from Gal-PEG-siRNA and M6P-PEG-siRNA ........90

5.3.3 Gene Down-regulation Study ………………...........................................90

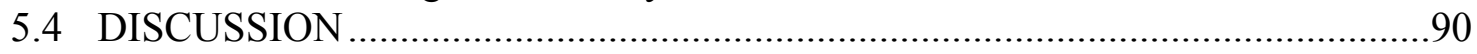

CHAPTER 6. SUMMARY AND PRESPECTIVES ...................................................95

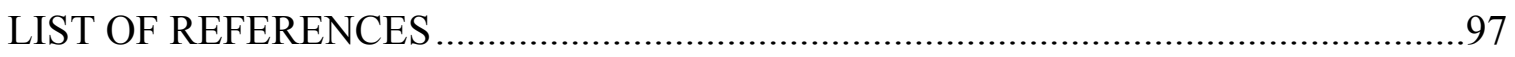

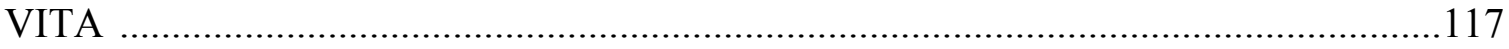




\section{LIST OF TABLES}

Table $2.1 \quad$ The structures of commonly used cationic lipids ................................... 8

Table 3.1 Energy minimized structures and melting points of pyridinium lipids......29

Table 3.2 Determination of lipid phase transition temperature $\left({ }^{\circ} \mathrm{C}\right)$ by DSC .......... 38

Table 3.3 Particle size and $\zeta$-potential of pyridinium cationic liposome and

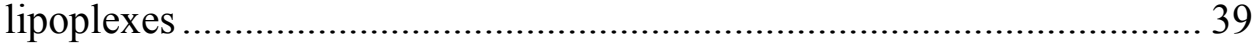

Table 4.1 Tissue uptake rate index and clearance of ${ }^{33} \mathrm{P}-\mathrm{ODN}$ and Gal-PEG- ${ }^{33} \mathrm{P}-$ ODN after systemic administration into rats 


\section{LIST OF FIGURES}

Figure 2.1 The barriers and strategies of nucleic acid delivery ................................ 5

Figure 2.2 Influence of serum on transfection of $\mathrm{CHO}$ cells by pyridinium liposomes ……....................................................................................

Figure 2.3 Influence of configuration (cis vs. trans) of pyridinium lipids on transfection efficiency............................................................................. 10

Figure 2.4 Influence of linker type (ester vs. amide) of pyridinium lipids on GFP (A) and luciferase (B) plasmids transfection ........................................... 12

Figure 2.5 The structures of commonly used cationic polymers .............................. 14

Figure 2.6 Conjugation of TFO to cholesterol (A) and HPMA (B) ......................... 22

Figure 2.7 Synthesis scheme (A), biodistribution (B), and hepatic localization (C)

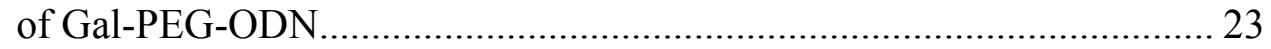

Figure $3.1 \quad$ Synthesis scheme of pyridinium lipids ………..................................... 30

Figure 3.2 Effect of charge ratios on the transfection (A) and cytotoxicity (B) of $\mathrm{CHO}$ cells at $48 \mathrm{~h}$ after transfection of lipoplexes ...................................... 41

Figure 3.3 Effect of linker type on GFP gene (A) and luciferase gene (B) transfection efficiency and cytotoxicity (C) at $48 \mathrm{~h}$ after transfection of

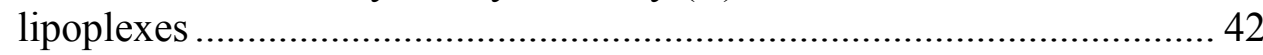

Figure 3.4 Effect of cationic lipid/co-lipid molar ratios on transfection efficiency (A) and cytotoxicity (B)

Figure 3.5 Effect of co-lipid type on transfection efficiency (A) and cytotoxicity (B) 45

Figure 3.6 Effect of fatty acid chain length on transfection efficiency (A) and cytotoxicity (B)..... 46

Figure 3.7 Effect of degree of saturation on transfection efficiency (A) and cytotoxicity (B)

Figure 3.8 Effect of alkyl chain configuration on transfection efficiency (A) and cytotoxicity (B) 48

Figure 3.9 Influence of serum on gene transfer. 50 
Figure 3.10 Transfection efficiency (A) and cytotoxicity (B) in hepatocarcinoma cells

Figure 3.11 Transfection efficiency (A) and cytotoxicity (B) in prostate cancer cells

Figure 3.12 Gene silencing of luciferase siRNA in luciferase engineered prostate cancer cells (C4-2) using pyridinium cationic liposomes

Figure 3.13 Cellular uptake of Alexa Fluor ${ }^{\circledR}$ Red Fluorescent siRNA in CHO cells using pyridinium cationic liposomes

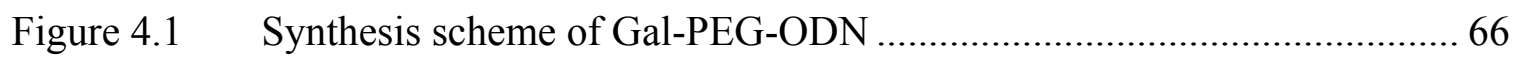

Figure 4.2 Characterization of p-aminophenyl $\beta$-D-galactopyranoside with ESIMS and ${ }^{1} \mathrm{H}$ NMR.

Figure 4.3 Characterization of Gal-PEG-acrylate with MALDI-TOF-MS and ${ }^{1} \mathrm{H}$ NMR 68

Figure 4.4 Identification of Gal-PEG-ODN by PAGE.

Figure 4.5 HPLC chromatograms of ODN (A), PEG (B), reaction mixture (C), during purification (D) and after purification (E) of Gal-PEG-ODN ....... 70

Figure 4.6 Dissociation and stability study of Gal-PEG- ${ }^{33}$ P-ODN ......................... 71

Figure 4.7 Accumulation (A) and concentration (B) of Gal-PEG- ${ }^{33} \mathrm{P}-\mathrm{ODN}$ after tail vein injection into rats at a dose of $0.2 \mathrm{mg} \mathrm{ODN} / \mathrm{Kg}$ of body weight

Figure 4.8 Plasma data was analyzed using a two compartment model with WinNonlin Professional (version 5.0.1) software. 74

Figure 4.9 Effect of Gal-BSA on biodistribution of Gal-PEG- ${ }^{33} \mathrm{P}-\mathrm{ODN}$ after systemic administration into rats ............................................................. 77

Figure 4.10 Hepatic cellular localization of ${ }^{33}$ P-ODN and Gal-PEG ${ }^{33}$ P-ODN.......... 78

Figure 5.1 Synthesis scheme of Gal-PEG-siRNA and M6P-PEG-siRNA .................. 85

Figure 5.2 Characterization of p-aminophenyl-6-phospho- $\alpha$-D-mannopyranoside with ESI-MS and ${ }^{1} \mathrm{H}$ NMR 86 
Figure 5.3 Characterization of Gal-PEG-OPSS (A) and M6P-PEG-OPSS (B) with

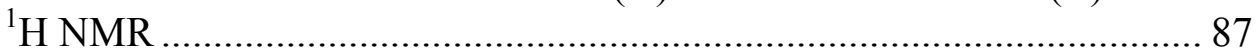

Figure 5.4 Purification of Gal-PEG-siRNA and M6P-PEG-siRNA by Ion Exchange Chromatography.................................................................... 88

Figure 5.5 Identification of siRNA conjugates by gel retardation assay.................... 89

Figure 5.6 In vitro gene down regulation effects of Gal-PEG-siRNA and M6PPEG-siRNA...... 


\section{LIST OF ABBREVIATIONS}

$\begin{array}{ll}\text { ACN } & \text { Acetonitrile } \\ \text { apoB } & \text { Apolipoprotein B } \\ \text { BBB } & \text { Blood brain barrier } \\ \text { BGSC } & \text { Bis-guanidiniumspermidine-cholesterol } \\ \text { BSA } & \text { Bovine serum albumin } \\ \text { CD } & \text { Cyclodextrin } \\ \text { CHO } & \text { Chinese hamster ovary } \\ \text { CL } & \text { Cationic liposome } \\ \text { CNS } & \text { Central nervous system } \\ \text { D }_{2} \mathrm{O} & \text { Deuterium oxide } \\ \text { Da } & \text { Dalton } \\ \text { DAB } & \text { Butylenediamine } \\ \text { DC-Chol } & \text { 3- }- \text {-[N-(N,N'-dimethylaminoethane) carbamoyl] cholesterol } \\ \text { DD } & \text { Degree of deacetylation } \\ \text { DDAB } & \text { Imethyldioctadecylammonium bromide } \\ \text { DHB } & \text { 2,5-Dihydroxybenzoic acid } \\ \text { DMEM } & \text { Dulbecco's modified Eagle's medium } \\ \text { DMF } & \text { Dimethylformamide } \\ \text { DMRIE } & \text { N-[1-(2,3-dimyristyloxy) propyl]-N,N-dimethyl-N-(2- } \\ & \text { hydroxyethyl) ammonium bromide } \\ \text { DMSO } & \text { Dimethyl sulfoxide } \\ \text { DODAC } & \text { N,N-Dioleyl-N,Ndimethylammonium chloride } \\ \text { DOGS } & \text { Dioctadecyl amidoglyceryl spermine } \\ \text { DOPE } & \text { 1,2-Dioleoyl-sn-glycero-3-phosphoethanolamine } \\ \text { DOSPA } & \text { 2,3-Dioleyloxy-N-[2-spermine carboxamide] ethyl-N,N-dimethyl- } \\ & \text { 1-propanammonium trifluoroacetate } \\ \text { DOTAP } & \text { 1,2-Dioleoyl-3-trimethylammonium-propane } \\ \text { DOTMA } & \text { N-[1-(2,3-dioleoyloxy)propel]-N,N,N-trimethylammonium } \\ \text { DP } & \text { Degree of polymerization } \\ \text { dsRNA } & \text { Double-stranded RNA } \\ \text { DTT } & \text { Dithiothreitol } \\ \text { ECM } & \text { Extracellular matrix } \\ \text { EPR } & \text { Enhanced permeability and retention } \\ \text { EtBr } & \text { Ethidium bromide } \\ \text { FBS } & \text { Fetal bovine serum } \\ \text { Gal } & \text { Galactose } \\ \text { GFP } & \text { Green fluorescent protein } \\ \text { GSH } & \text { L-glutathione } \\ \text { HBsAg } & \text { Hepatitis B surface antigen } \\ \text { HBV } & \text { Hepatitis B virus } \\ \text { H } & \text { Intercalated hexagonal structure } \\ \mathrm{H}_{\mathrm{II}} & \text { Inverted hexagonal structure } \\ \text { HRMS } & \\ & \\ & \end{array}$




$\begin{array}{ll}\text { HSCs } & \text { Hepatic stellate cells } \\ \text { IFN } & \text { Interferon } \\ \text { IGF2R } & \text { Insulin-like growth factor-II receptor } \\ \text { IL } & \text { Interleukin } \\ \text { LHRH } & \text { Luteinizing hormone-releasing hormone } \\ \text { L }_{\alpha} & \text { Lamellar structure } \\ \text { M6P } & \text { Mannose-6-phosphate } \\ \text { MALDI-TOF } & \text { Matrix Assisted Laser Desorption/Ionization Time-of-Flight } \\ \text { miRNA } & \text { Micro RNA } \\ \text { MLV } & \text { Large Multilamellar vesicular } \\ \text { mRNA } & \text { Message RNA } \\ \text { MTT } & \text { 3-[4,5-Dimethylthiazol-2-yl]-2,5-diphenyltetrazolium bromide } \\ \text { MWCO } & \text { Molecular weight cut off } \\ \text { N/P } & \text { Nitrogen to phosphate } \\ \text { NHS } & \text { N-hydroxysuccinimidyl } \\ \text { NPC } & \text { Non-parenchymal cells } \\ \text { ODN } & \text { Oligonucleotide } \\ \text { OEI } & \text { Oligoethylenimine } \\ \text { OPSS } & \text { (Ortho-pyridyl) disulfide } \\ \text { PAA } & \text { Poly(amino acid) } \\ \text { PAGE } & \text { Polyacrylamide gel electrophoresis } \\ \text { PAMAM } & \text { Polyamidoamine } \\ \text { papM6P } & \text { p-Aminophenyl-6-phospho- } \alpha \text {-D-mannopyranoside } \\ \text { PBS } & \text { Phosphate buffered saline } \\ \text { PDI } & \text { Polydispersity index } \\ \text { PEC } & \text { Polyelectrolyte complex } \\ \text { PEG } & \text { Poly(ethylene glycol) } \\ \text { PEI } & \text { Polyethylenimine } \\ \text { PHP } & \text { Poly(4-hydroxy-L-proline ester) } \\ \text { PLGA } & \text { Poly(lactic-co-glycolic acid) } \\ \text { PLL } & \text { Poly-L-Lysine } \\ \text { pnpM } & \text { p-Nitrophenyl- } \alpha \text {-D-mannopyranoside } \\ \text { pnpM6P } & \text { p-Nitrophenyl-6-phospho- } \alpha \text {-D-mannopyranoside } \\ \text { PPI } & \text { Polypropylenimine } \\ \text { ppm } & \text { Parts per million } \\ \text { PS } & \text { Phosphorothioate } \\ \text { PSD } & \text { Particle size distribution } \\ \text { PVP } & \text { Polyvinyl pyrrolidone } \\ \text { RISC } & \text { RNA-induced silencing complex } \\ \text { RLU } & \text { Relative light unit } \\ \text { RNAi } & \text { RNA interfering } \\ \text { RP-HPLC } & \text { Reverse phase-high performance liquid chromatography } \\ \text { SD } & \text { Standard deviation } \\ \text { SDS } & \text { Soding RNA } \\ \text { shRNA } & \text { sirecyl sulfate } \\ \text { siRNA } & \end{array}$


SNALP

SOD

SPDP

SPLP

SUV

TCA

TFO

TLC

TMS

VEGF
Stable nucleic-acid-lipid particle

Superoxide dismutase

$\mathrm{N}$-succinimidyl-3-(2-pyridyl dithio)-propionate

Stabilized plasmid lipid particles

Small unilamellar vesicle

Trichloroacetic acid

Triplex-forming oligonucleotide

Thin layer chromatography

Tetramethylsilane

Vascular endothelial growth factor 


\section{CHAPTER 1. GENERAL INTRODUCTION}

Plasmid DNAs, oligonucleotides (ODNs), and siRNAs are negatively charged macromolecules. Although the applications and therapeutic outcomes of these genetic molecules are much different, there are some similarities in their physicochemical and hydrodynamic properties. They are fairly unstable and have very low cellular uptake without transfection reagents. Although cationic liposomes are commonly used transfection reagents, their performance has to be improved with respect to the transfection ability and cytotoxicity. Cationic lipids or polymers are not suitable for in vivo delivery of nucleic acids because of their non-specific binding with plasma proteins and other tissues via ionic interaction, leading to systemic toxicity. In contrast, target ligand containing polyethylene glycol (PEG) based carriers have better characteristics, especially for enhanced circulation time and cell specific delivery of nucleic acids. Therefore, we hypothesized that:

(i) Pyridinium lipids can effectively transfect nucleic acids (plasmid DNA and siRNA) into cells.

(ii) Galactosylated oligonulceotides will be efficiently delivered to hepatocytes after systemic administration.

(iii) Gal-PEG (or M6P-PEG) conjugation to siRNAs will enhance their uptake by HepG2 cells and HSCs.

We proposed the following specific aims:

AIM I: Can pyridinium lipids effectively transfect nucleic acids into cells? Since pyridinium cationic lipids were reported to have high transfection efficiency and low cytotoxicity, in Chapter 3, we designed a series of novel pyridinium lipids. Therefore, we proposed to determine:

(i) Synthesis and characterization of pyridinium lipids.

(ii) Physicochemical characterization of pyridinium cationic liposomes and their lipoplexes.

(iii) In vitro transfection and cytotoxicity of pyridinium lipid based lipoplexes and siRNA complexes.

AIM II: Can galactosylated oligonulceotides be efficiently delivered to hepatocytes after systemic administration? Galactosylated poly L-Lysine (PLL)/ODN complexes were reported to specifically deliver ODNs to hepatocytes. To avoid nonspecific binding with plasma proteins, in Chapter 4, we designed a non-cationic oligonucleotide conjugate. Therefore, we proposed to determine:

(i) Conjugation and purification of Gal-PEG-ODN.

(ii) In vitro characterization of Gal-PEG-ODN.

(iii) In vivo biodistribution and pharmacokinetic profiles of Gal-PEG-ODN. 
AIM III: Can Gal-PEG (or M6P-PEG) conjugation to siRNAs enhance their uptake by HepG2 cells and HSCs. Cationic lipid or cationic polymer/siRNA complexes can significantly enhance siRNAs' cellular uptake, but their positive surface may induce complement system activation and cytotoxicity. To specifically deliver siRNAs to hepatic cells, we designed PEG based siRNA conjugates. Therefore, we proposed to determine:

(i) Conjugation and purification of Gal-PEG-siRNA and M6P-PEG-siRNA.

(ii) In vitro characterization of Gal-PEG-siRNA and M6P-PEG-siRNA.

(iii) In vitro gene silencing effects of Gal-PEG-siRNA and M6P-PEG-siRNA. 


\section{CHAPTER 2. LIPID AND POLYMERIC CARRIER MEDIATED NUCLEIC ACID DELIVERY}

\section{$2.1 \quad$ INTRODUCTION}

Gene therapy is defined as the insertion of genes into cells to replace, correct or makeup the defective genes for treating acquired and genetic disorders. Gene therapy can help us target the origin of the disorder instead of using drugs to alleviate symptoms. In the last decade, the spectrum of functional genetic materials used in gene therapy was dramatically broadened and diversified. Notably, gene therapy caught the world's eyes again when the two Nobel Prize Laureates, Andrew Fire and Craig Mello, demonstrated the mechanism and application of RNA interfering (RNAi) $(1,2)$ in 2006. This is inspite of the fact that accidental deaths of virus based genetic therapeutics occurred during clinical trials and frustrated enthusiastic scientists all over the world. RNAi which was first observed in plants (3), is recognized as a naturally occurring process by which cells can regulate gene expression. RNAi molecules typically refer to double-stranded RNA (dsRNA) (2), small interfering RNA (siRNA) (19-23 base-pairs) (4), short hairpin RNA (shRNA) (5) and micro RNA (miRNA) (6). Although they are structurally different, all of them could induce the sequence specific gene silencing by either degradation or inhibition of the target mRNA via perfect or mismatched binding in the presence of RNA-induced silencing complex (RISC).

Plasmid DNA, oligonucleotide (ODN), and siRNA are the most commonly investigated nucleic acids for gene therapy. The applications and therapeutic outcomes of genetic molecules may vary depending on their mechanisms in the gene expression pathway. They manipulate not only genomic DNA at the transcriptional level, but also mRNA and protein synthesis at the post-transcriptional level. Antisense oligonucleotides and siRNAs have undergone for clinical trials (7). These molecules are typically macromolecules with big hydrodynamic size and negative charge in aqueous solution. Naturally occurring genetic molecules are usually fragile and easily degraded by endoand exonucleases. Harsh environmental factors including heat, oxidants, acids, and alkali can also cause damage in their structures.

\subsection{BARRIERS TO NUCLEIC ACID THERAPEUTICS}

It is extremely difficult to achieve the expected biological effects of nucleic acids by traditional delivery strategies due to many biological barriers. Besides instability, several obstacles have to be surpassed before these genetic molecules take action at the desired sites. First of all, these macromolecules should go across the biological barriers including extracellular, cellular and intracellular biological membranes. For the systemic administration of plasmid DNAs or ODNs, the molecules have to go sequentially across the vasculature wall, intercellular tissue junction, and cytoplasm membrane of the target cells, escape from endosome, and then enter the nucleus. For the systemic administration of siRNAs or miRNAs, these molecules should also overcome most of these biological 
barriers except nuclear membrane. For local administration, one or two more biological barriers may be involved. If the target site is located in central nervous system (CNS), the tight junctions between endothelial cells of CNS vessels, the so called Blood Brain Barrier (BBB) have to be surpassed. Second, various enzymes and proteins are involved in nucleic acid delivery process, which may degrade nucleic acids or trigger immune system. Unmodified siRNAs have been reported to be unstable in the presence of high concentration of FBS (8). The conserved sequence of nucleic acids could be recognized and bound by immune molecules and engulfed by the immune cells or activate the complement system $(9,10)$. In some cases the therapeutic effects became negligible or null after multiple administrations of genetic materials (11). Third, the low efficacies caused by non-specific biodistribution always come along with in vivo studies. Kidney plays an important role in the disposition of these macromolecules post systemic administration. In general, macromolecules with the molecular weight of less than 50,000 $\mathrm{Da}$ are susceptible to glomerular filtration (12). Cy3 labeled siRNAs were predominantly accumulated in the kidney, whereas no accumulation was detected in other organs in 20 min post i.v. injection (13). The macromolecules that are too large to go through the glomerular pore will likely accumulate in the liver because of its loose structure in the endothelium and high blood perfusion (12). However, hydrodynamic injection could accumulate macromolecules in the highly perfused internal organs, e.g. the liver, regardless of their molecular size $(14,15)$.

Considering these barriers (Figure 2.1), a successful in vivo delivery strategy should be designed to satisfy the following major criteria: (i) the method should protect the genetic molecules from degradation by nucleases; (ii) it should help the genetic molecules cross the cell membrane, escape from endosome, and finally enter either nucleus or cytoplasm depending on their mechanisms; (iii) it should have no or less side effects caused by either genetic molecules or the method itself; (iv) it should prolong the circulation time and prevent non specific disposition of genetic molecules to facilitate their delivery to the target cells. For the in vitro delivery, the first three criteria have to be satisfied.

Current strategies include physical approaches and design of delivery systems. Temporary destabilization of cell membrane by a physical force can facilitate the intracellular gene transfer, which includes needle injection (16), coated microneedle (17), electroporation $(18,19)$, gene gun (20), ultrasound (21), and hydrodynamic delivery $(14,15)$.

The nucleic acid delivery systems can be generally classified to two categories, viral vectors versus nonviral vectors. Viral vectors exhibited high efficiency at delivering both DNAs and RNAs to numerous cell lines and in some cases gave long-term gene expression after once administration because of their infection and self replication potency. However, the safety issues such as immunogenicity and insertion mutagenesis, and manufacturing issues such as the limitation in the size of the inserted DNA fragments and difficulty in the scale-up procedures of commonly used viral vectors, are the serious problems and have caused wide public concerns $(7,9)$. In contrast, nonviral vectors, 


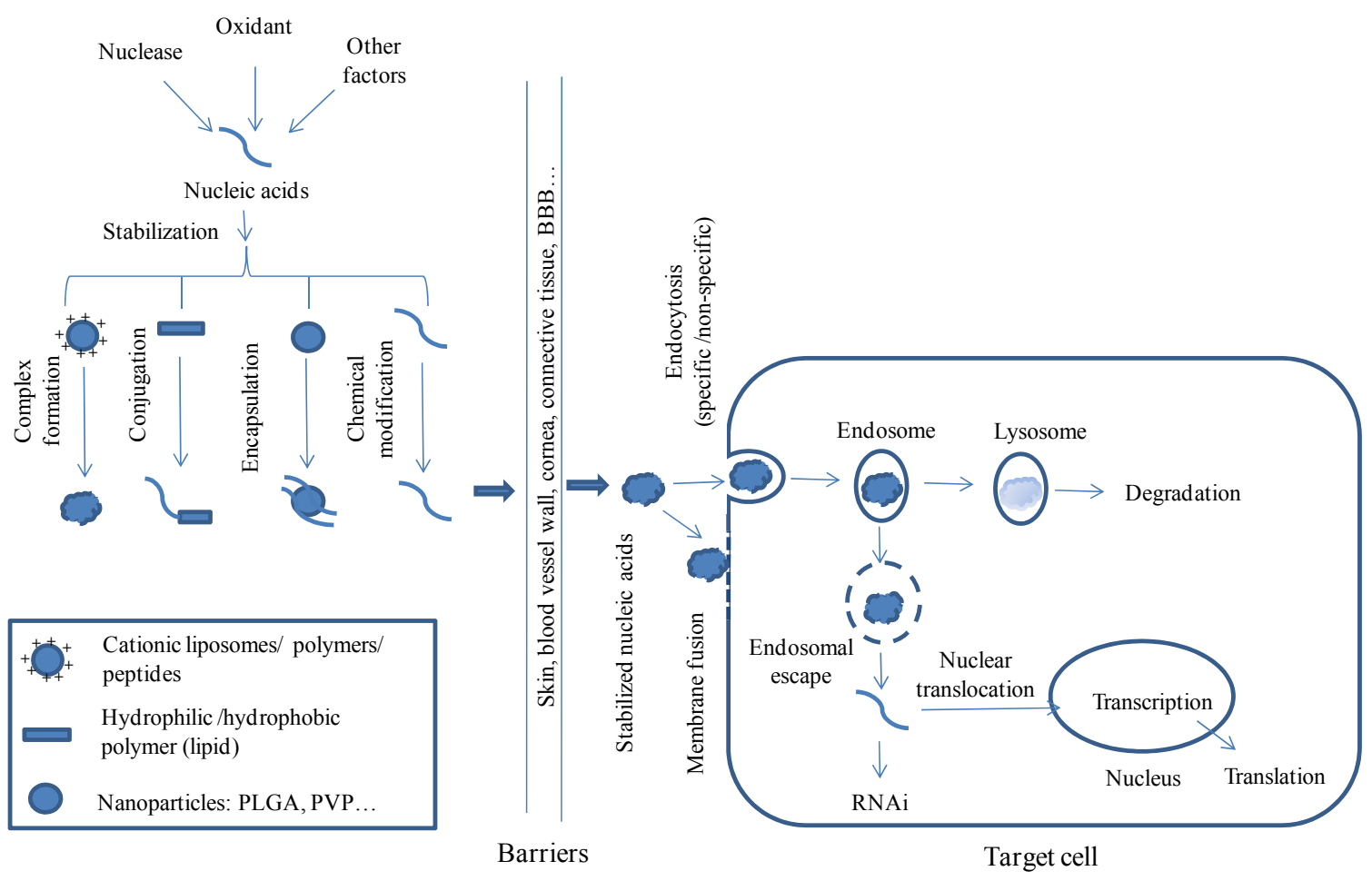

Figure 2.1 The barriers and strategies of nucleic acid delivery. 
including cationic liposomes (lipids), cationic polymers, cationic proteins (peptides), dendrimers, non-cationic polymers, nanoparticles, and bioconjugates, are usually safe and ease in manufacture. Although significant progress has been made in the design and applications of various nonviral delivery systems, the efficiency of nonviral approaches are still much less compared to viral vectors. In this article we are going to briefly discuss the most popularly used nonviral carriers and their components including lipids and polymers in terms of their characteristics, applications, advantages and limitations.

\subsection{CATIONIC LIPIDS}

Cationic lipids are the most commonly used materials for nucleic acid delivery. Significant progress has been made in the design and functionalization of cationic lipids since the introduction of $\mathrm{N}$-[1-(2,3-dioleoyloxy)propel]-N,N,N-trimethylammonium (DOTMA) (22). DOTMA contains a quaternary ammonium group which can condense nucleic acids via electrostatic interaction to form a nano-sized particle, and two oleoyl chains which facilitate the formation of liposomes and fusion with cell membrane. Other most commonly used cationic lipids for nucleic acid delivery include 2,3-dioleyloxy-N[2-spermine carboxamide] ethyl-N,N-dimethyl-1-propanammonium trifluoroacetate (DOSPA, Lipofectamine); 1,2-dioleoyl-3-trimethylammonium-propane (DOTAP); N-[1(2,3-dimyristyloxy) propyl]-N,N-dimethyl-N-(2-hydroxyethyl) ammonium bromide (DMRIE), 3- $\beta$-[N-(N,N'-dimethylaminoethane) carbamoyl] cholesterol (DC-Chol) (23); dioctadecyl amidoglyceryl spermine (DOGS, Transfectam); and imethyldioctadecylammonium bromide (DDAB) (24-28). A few such lipids have also been tested in initial clinical studies. However, many of the cationic lipids used in early clinical trials such as DC-Chol, DMRIE, and GL-67, although effective in vitro, have proven inefficient in vivo, especially when compared with viral vectors $(28,29)$. Some other promising cationic lipids have also been extensively studied. For example, various types of pyridinium lipids containing one or more pyridinium cationic head groups which were designed by Mahato's (30) and other groups $(31,32)$, showed high transfection efficiency and low cytotoxicity even at the high concentration of serum in the transfection medium (30) (Figure 2.2).

Although the reported cationic lipids are structurally different, most of them contain three basic components, the cationic polar head group, the hydrophobic domain, and the linker connecting the polar group with hydrophobic group (Table 2.1). Since the three parts of a cationic lipid significantly influence the transfection efficiency and cytotoxicity of the lipoplexes formed by cationic lipids (liposomes) and nucleic acids, understanding these structural parameters is essential for the rational design of efficient cationic lipid-based transfection reagents.

\subsubsection{Cationic Head Group}

The positively charged hydrophilic head group of cationic lipids usually consists of monoamine group including tertiary amine or quaternary amine, polyamine group, 


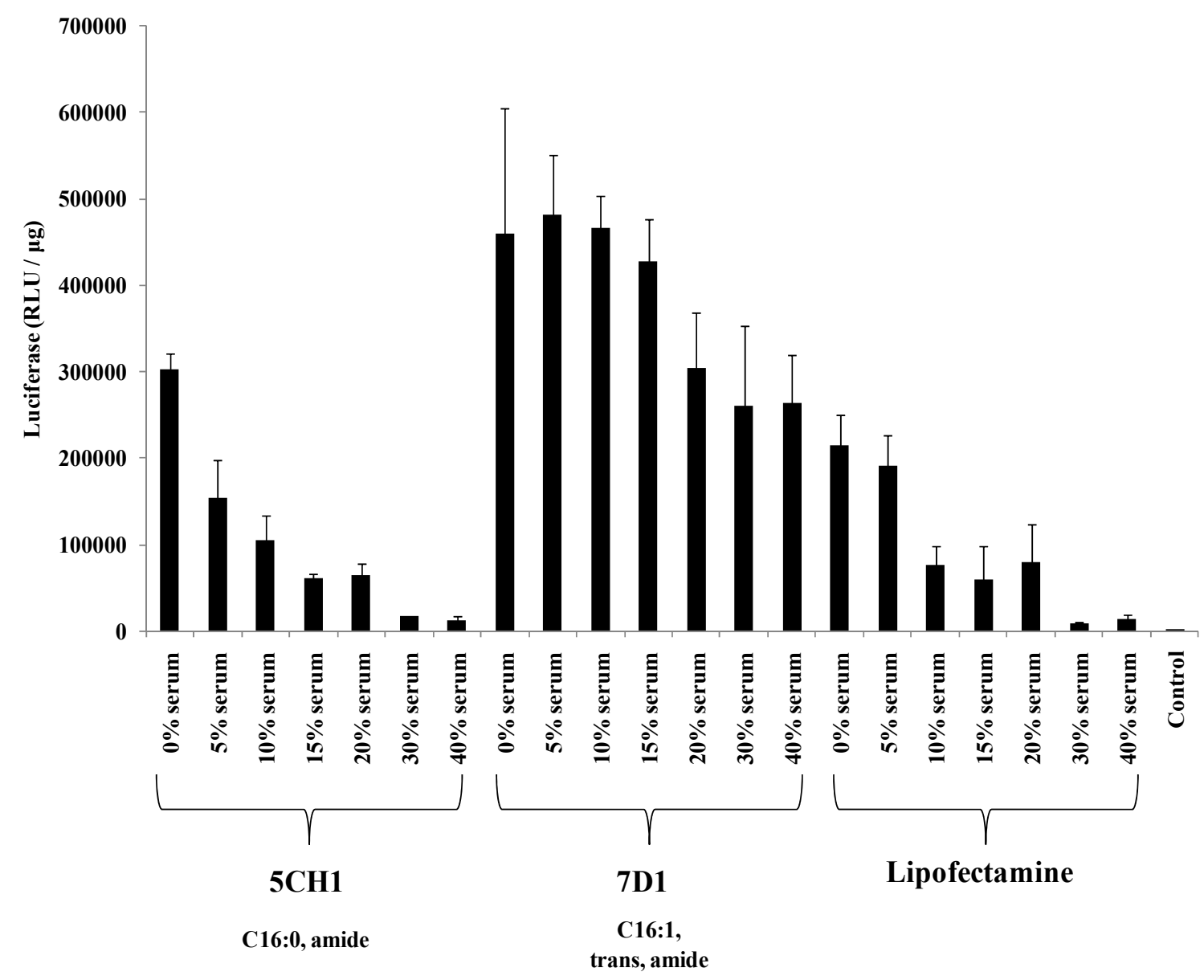

Figure 2.2 Influence of serum on transfection of CHO cells by pyridinium liposomes.

Lipids 5 (C16:0, amide linker) and 7 (C16:1, amide linker, trans-isomer) were used to prepare cationic liposomes with co-lipid cholesterol and DOPE at the molar ratio of 1:1. Lipoplexes were formed by mixing with luciferase plasmid at the charge ratio of $3: 1$ $(+/-)$. Luciferase gene expression in $\mathrm{CHO}$ cells was determined at $48 \mathrm{~h}$ after transfection. The dose of pcDNA3-Luc plasmid was $0.2 \mu \mathrm{g} /$ well for $4 \times 10^{4}$ cells. D: DOPE. CH: cholesterol. 


\begin{tabular}{|c|c|c|c|c|}
\hline Name & Cationic head & Linker & Hydrophobic anchor chain & Structural components \\
\hline DOTMA & & & & $\begin{array}{l}\text { Monoamine, ether linker, two unsaturated } \\
\text { fatty acid chains }\end{array}$ \\
\hline DOTAP & & & & $\begin{array}{l}\text { Monoamine, ester linker, two unsaturated } \\
\text { fatty acid chains }\end{array}$ \\
\hline $\begin{array}{l}\text { DC- } \\
\text { Cholesterol }\end{array}$ & & & & Monoamine, carbamate linker, cholesterol \\
\hline $\begin{array}{l}\text { Pyridinium } \\
\quad \text { lipid }\end{array}$ & & & & $\begin{array}{l}\text { Pyridinium ring, amid linker, unsaturated } \\
\text { fatty acid chains }\end{array}$ \\
\hline SAINT 2 & & & & $\begin{array}{l}\text { Pyridinium ring, aliphatic linker, two } \\
\text { unsaturated fatty acid chains }\end{array}$ \\
\hline DOGS & & & & $\begin{array}{l}\text { Polyamine, amid linker, two saturated fatty } \\
\text { acid chains }\end{array}$ \\
\hline DOSPA & & & & $\begin{array}{l}\text { Polyamine, ether linker, two unsaturated } \\
\text { fatty acid chains }\end{array}$ \\
\hline BGSC & & & & Polyamine, carbamate linker, cholesterol \\
\hline
\end{tabular}


amidinium group, or guanidinium group (such as bis-guanidiniumspermidine-cholesterol (BGSC)) (33). Recently, various heterocyclic cationic lipids have been studied and used for nucleic acid delivery. Pyridinium heterocyclic ring in the cationic amphiphile, first introduced in the 1940s, has been shown to have antiseptic and antibiotic properties. A series of pyridinium lipids have been developed, and some of them have been reported to reach or surpass the performance of commercially available transfection reagents both in vitro and in vivo $(30,31,34)$. In addition to pyridinium cationic lipids, other types of heterocylic head groups have also been investigated in the design of cationic lipids, such as imidazole, piperizine, and amino acid $(35,36)$. The main function of cationic head groups is to interact with negatively charged DNA or RNA molecules via electrostatic interaction to form the slight positively charged condensed particles, leading to enhanced cellular uptake (37) and endosomal escape (38).

\subsubsection{Hydrophobic Lipid Anchor Group}

The hydrophobic domains usually contain either simple aliphatic hydrocarbon chains such as fatty acid chains of various lengths and unsaturation states, or steroids such as cholesterol, which helps in forming liposomes and exchanging lipids of cell membrane (12). Previous studies suggested that the type and length of aliphatic chain influenced the transfection efficiency (30). Most effective cationic lipids have two linear fatty acid chains such as DOTMA, DOTAP and SAINT-2. In general, cationic lipids containing one hydrocarbon chain and more than two hydrophobic chains might cause either toxic or poor transfection $(39,40)$ although tetraalkyl lipid chain surfactants, the dimer of N,N-Dioleyl-N,Ndimethylammonium chloride (DODAC), has shown enhanced gene transfer over DODAC (41).

The degree of unsaturation and configuration of the hydrophobic chain also influence the transfection efficiency and cytotoxicity (31). The degree of unsaturation in the lipid structure affected the fusogenicity of the lipid $\left(\mathrm{L}_{\alpha}\right.$ to $\mathrm{H}_{\mathrm{II}}$ transition) $(42,43)$. The double bond in the fatty acid chain decreased the phase transition temperature of the lipids (30). The decrease in phase transition temperature increased fusogenicity, leading to an increase in transfection efficiency (44). To investigate the relevance of configuration of double bond and cationic lipids' performance, we synthesized new pyridinium cationic lipids with one double bond (cis or trans) in the hydrophobic carbon chain. All the trans-oriented lipids regardless of their hydrophobic chain lengths (C16:1, C18:1, and C20:1) enhanced the transfection efficiency compared to their cis-oriented counterparts (30) (Figure 2.3). This trend was in good agreement with the previous report by Van der Woude et al. (31). The influence of aliphatic chain length on the performance of cationic lipids was a little bit complicated in the reported studies. Felgner et al. reported that the transfection efficiency increased with the decrease in the hydrophobic chain length from $\mathrm{C} 18$ to $\mathrm{C} 14$ in the DOTMA derivatives (45). In the study of pyridinium cationic lipids, we found that the unsaturated lipid C16:1 had better transfection effect compared to C18:1 and C20:1 (30,34). A similar trend was also found in DOTAP derivatives (35). However, it was found that transfection efficiencies were higher for the lipids with longer alkyl chain $(\mathrm{C} 18>\mathrm{C} 16>\mathrm{C} 14>\mathrm{C} 12)$ in the study of trilysine-based 


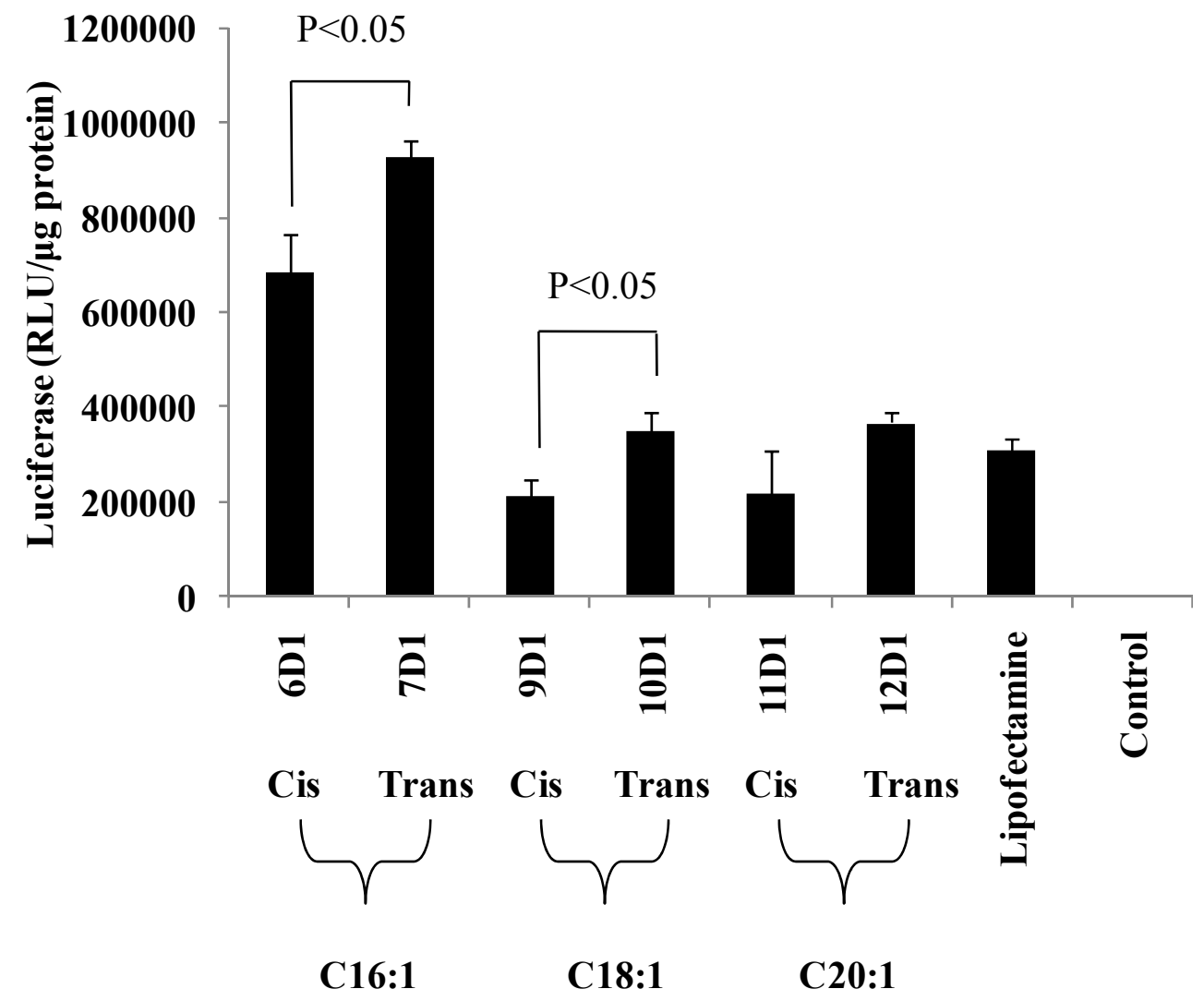

Figure 2.3 Influence of configuration (cis vs. trans) of pyridinium lipids on transfection efficiency.

Lipids 6 (C16:1, amide linker, cis-isomer), 7 (C16:1, amide linker, trans-isomer), 9 (C18:1, amide linker, cis-isomer), 10 (C18:1, amide linker, trans-isomer), 11 (C20:1, amide linker, cis-isomer) and 12 (C20:1, amide linker, trans-isomer) were used to prepare cationic liposomes with DOPE at the molar ratio of 1:1. Lipoplexes were formed by mixing with luciferase plasmid at the charge ratio of $3: 1(+/-)$. Luciferase gene expression in $\mathrm{CHO}$ cells was determined at $48 \mathrm{~h}$ after transfection. The dose of pcDNA3-Luc plasmid was $0.2 \mu \mathrm{g} / \mathrm{well}$ for $4 \times 10^{4}$ cells. D: DOPE. 
Gemini surfactants with $€$,є-linkage (46). Takahashi et al. also reported the polyamidoamine (PAMAM) dendron-bearing lipids with longer alkyl chain length showed higher transfection efficiency compared to their short chain counterparts (47). The conflict facts with respect to hydrophobic chain length indicated that the transfection ability of cationic lipids is strongly determined by both cationic head group and its compatible hydrophobic lipid anchor length. A hypothesis based on "dimensionless packing parameter, $\mathrm{P}=\mathrm{V} / \mathrm{a} \cdot \mathrm{l}$ " $(48,49)$ may explain why these experimental data showed conflict. Here, "V" denotes the hydrophobic chain volume, "a" the optimal crosssectional head group area and "l" the length of the hydrophobic tails. When $1 / 2<\mathrm{P} \leq 1$, the DNA/cationic liposomes complexes will undergo lamellar organization, $\mathrm{L}_{\alpha}$; while when $\mathrm{P}>1$, the complexes will prefer inverted structures, $\mathrm{H}_{\mathrm{II}}$. $\mathrm{L}_{\alpha}$ phase was more stable and resulted in a lower transfection potential compared to $\mathrm{H}_{\text {II }}$ phase which had a higherorder inverted hexagonal structure and was believed to have the ability to fusion with plasma membrane and trigger the endosomal escape resulting in higher transfection efficiency $(50,51)$.

\subsubsection{Linker Group}

Stability, biodegradability, and transfection efficiency of a cationic lipid greatly depend on the structure of the linker that binds the polar head to the hydrophobic anchor chains (52). Most commonly used linkers include ethers, esters, amides, or carbamates. Ether linker was reported to be stable and non-biodegradable when used as the linkage in cationic lipids. An enhanced gene transfection of cholesterol-based cationic lipids was observed when ether was used as the linker compared to those of the lipids based on either ester or urethane linkers (53). Both esters and amides are biodegradable linkages and shown high transfection efficiency in pyridinium cationic lipids (32). However, pyridinium cationic lipids with amides linkage were reported to be chemically stable with higher melting point but lower phase transition temperature, resulting in higher transfection efficiency compared to their ester-bond counterparts (30) (Figure 2.4); in contrast esters were not stable chemically, but showed less toxic (54). Carbamate group structurally shares the properties of both ester and amide and showed high transfection efficiency and low toxicity when used as the linker in DC-Chol (27) and BGSC (33). Since cleavable lipids have low cytotoxicity and could facilitate nucleic acid release from lipoplexes after cleavage, the design of new types of linkages are of interest, such as photo-sensitive (55), $\mathrm{pH}$-sensitive (56), and redox-sensitive linkages (57).

Although the above three basic components of cationic lipids have been studied extensively, it should be mentioned that the performance of a cationic lipid in the nucleic acid delivery is contributed by the entire molecule rather than the three independent parts. In summary, transfection efficiency of cationic lipids greatly depends on (i) the extent of DNA or RNA condensation, (ii) enhanced cellular uptake due to ionic and/or hydrophobic interaction with negatively charged biological surfaces, and (iii) membrane fusion via transient membrane destabilization to achieve delivery into the cytoplasm while avoiding degradation in the lysosomal compartment. However, for siRNAs, the 
(A)

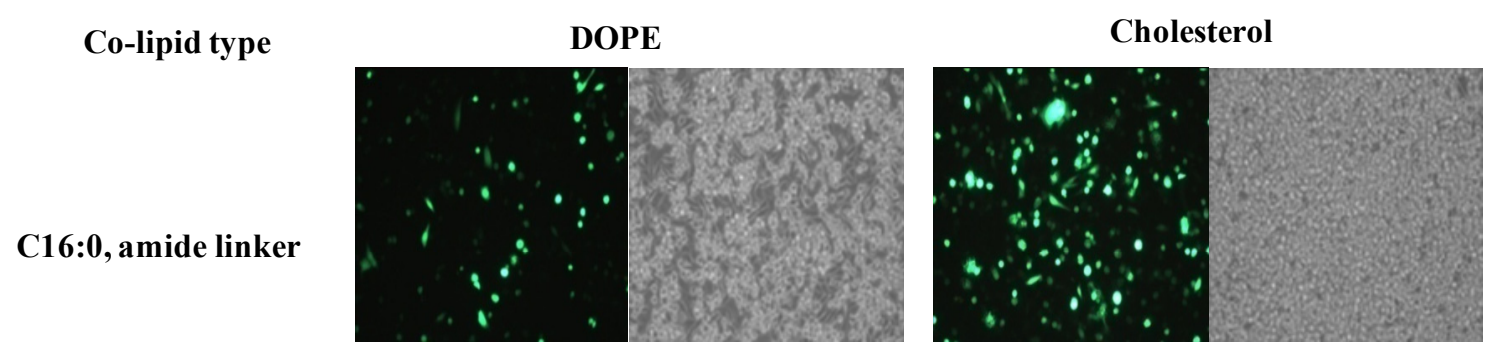

C16:0, ester linker
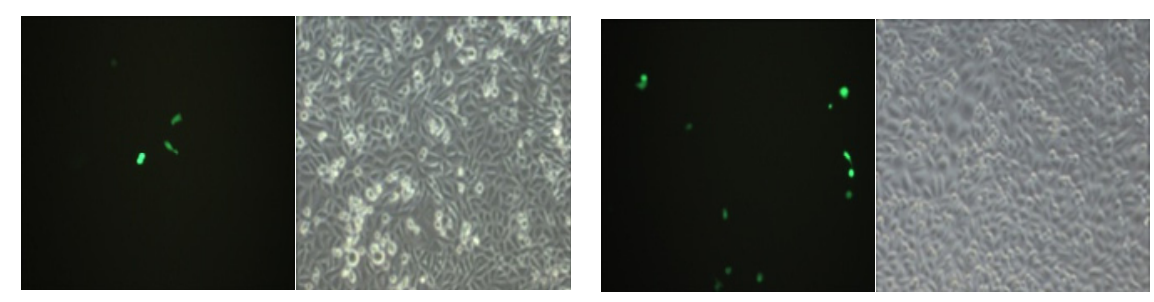

(B)

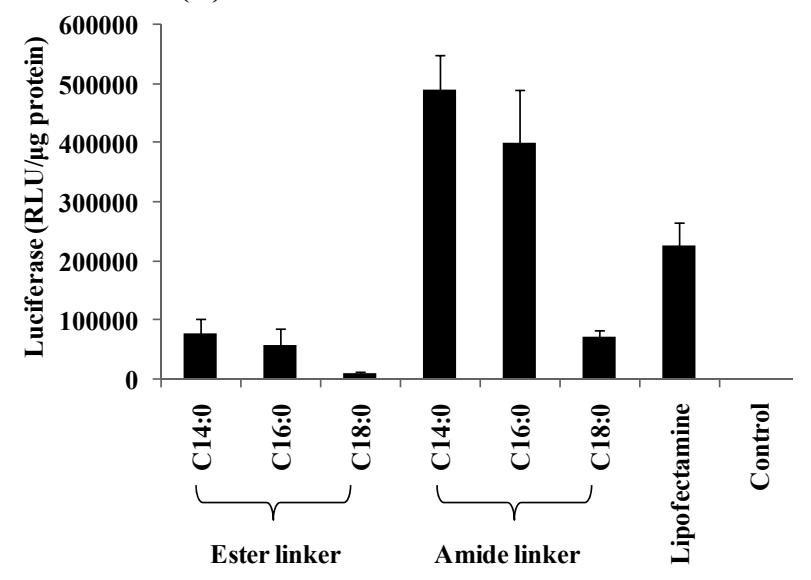

Figure 2.4 Influence of linker type (ester vs. amide) of pyridinium lipids on GFP (A) and luciferase (B) plasmids transfection.

(A) C16:0 lipid with amide linker and C16:0 lipid with ester linker were used to prepare cationic liposomes with co-lipid DOPE and cholesterol at the molar ratio of 1:1. Lipoplexes were formed by mixing with GFP plasmid at the charge ratio of 3:1 (+/-). GFP gene expression in $\mathrm{CHO}$ cells was observed at $48 \mathrm{~h}$ after transfection using fluorescence microscopy. The dose of pCMS-EGFP plasmid was $0.4 \mu \mathrm{g} /$ well for $4 \times 10^{4}$ cells. (B) lipids with easter linker and lipids with amide linker were used to prepare cationic liposomes with DOPE at the molar ratio of 1:1. Lipoplexes were formed by mixing with luciferase plasmid at the charge ratio of 3:1 (+/-). Luciferase gene expression in $\mathrm{CHO}$ cells was determined at $48 \mathrm{~h}$ after transfection. The dose of pcDNA3-Luc plasmid was $0.2 \mu \mathrm{g} /$ well for $4 \times 10^{4}$ cells. 
complete condensation may not be achieved easily and the stability of siRNA/lipid complexes is relatively low compared to that of plasmid DNA/lipid complexes (58). In this condition, other mechanisms such as temporary destabilization or pore forming of cell membrane may play the key role in siRNA transfer.

\subsection{CATIONIC POLYMERS}

Cationic polymers are also commonly used for the nucleic acid delivery. Cationic polymers readily form complexes with nucleic acids via electrostatic interactions and create a net positive charge under appropriate conditions. This facilitates cell attachment, subsequent internalization by endocytosis or membrane fusion, and endosomal escape by proton sponge (59). The structures of the cationic polymers are much different. These include linear polymers such as chitosan and linear poly(ethyleneimine) (LPEI), branched polymers such as branched poly(ethyleneimine) (BPEI), circle-like polymers such as cyclodextrin, net-work (cross-linked) type polymers such as cross-linked poly(amino acid) (PAA), and dendrimers (Figure 2.5). To overcome the cytotoxicity of cationic polymers, the biodegradable polymers were designed, e.g. poly(4-hydroxy-L-proline ester) (PHP), poly(amino-ester), PAA. The design of the new functional polymers has become a hot area in formulation and drug delivery. To understand the properties and application of these polymers in nucleic acid delivery, in the following section we reviewed the mostly used cationic polymers.

\subsubsection{Polyethylenimine (PEI)}

Polyethylenimine is one of the most widely used synthetic carriers for nucleic acid delivery (59). Based on its structure, PEI exists as either linear PEI or branched PEI. PEI is a highly positively charged polymer. Linear PEI contains all secondary amines in its backbone except the terminal groups. In contrast, branched PEI contains primary, secondary and tertiary amino groups at the estimated ratio of 1:1:1 (60). The different types of amine groups have different $\mathrm{pKa}$ values and could be protonated in different levels at the given $\mathrm{pH}$. This confers PEI a superior buffering capacity over a wide range of $\mathrm{pH}$ during the effective delivery of its cargoes into the target cells via endocytosis pathway. After endocytosis, unprotonated amines would be protonated at acidic $\mathrm{pH}$ in endosome, and this increases the influx of protons, chloride ions and water into the endosomes. The increased osmotic pressure causes endosome to swell and rupture, by which the endosomal content is released $(59,61)$. This is widely accepted "proton sponge" hypothesis $(62,63)$. PEI's buffering capacity may protect its cargoes from degradation and lead to early endosomal escape during the endosomes' maturation process and their subsequent fusion with the lysosome. The transfection efficiency and cytotoxicity of PEI strongly depend on its molecular weight. Increase in its molecular weight results in the increase of its transfection efficiency as well as its cytotoxicity, mainly necrosis probably caused by strong aggregation (64) and adherence on cell membrane (65). Serveral studies have done to determine the effect of PEI molecular weight on transfection efficiency (6668 ). It was believed that the most suitable molecular weight of PEI for complexation 
Linear polymers

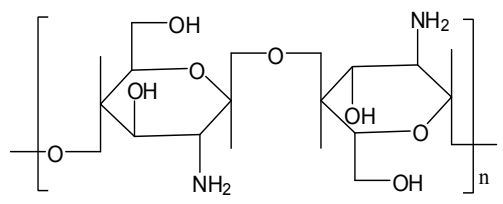

Chitosan

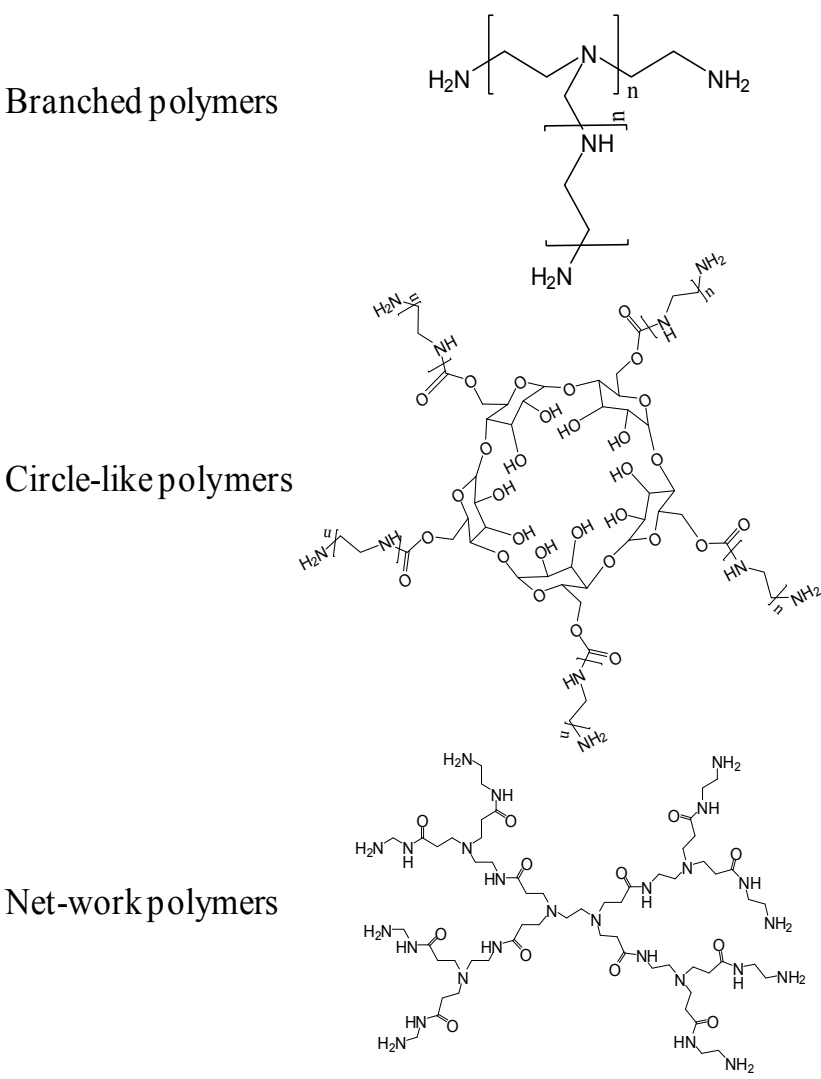<smiles>CC(CCN)NCCC(C)(C)N</smiles>

Linear PEI

Branched PEI

Oligoethylenimine modified cyclodextrin

\section{Figure 2.5 The structures of commonly used cationic polymers.}


with DNA segments was between 5 and $25 \mathrm{kDa}(68)$, although some groups reported that high (800 kDa) (64) and low (2 kDa) (67) molecular weight PEIs also showed good transfection at their preferring $\mathrm{N} / \mathrm{P}$ ratios.

In addition to the effect of molecular weights, the different behaviors were found between branched PEI and linear PEI. Branched PEI has relatively higher DNA condensing capacity compared to linear PEI. Kircheis et al. found that the DNA complexes formed by $25 \mathrm{kDa}$ branched PEI was about $180 \mathrm{~nm}$ while the complexes formed by $22 \mathrm{kDa}$ linear PEI aggregated at the same N/P ratio and ionic strength (69). It was also reported that high content of primary amines made PEI polyplexes more stable (70). Based on these studies, branched PEI is more effective than linear PEI in the in vitro transfection. However, stronger association with the bound nucleic acids might cause the difficulty to de-assemble and release its cargoes after endosomal escape (38). In contrast, linear PEI has relatively lower condensation capability as well as its kinetic instability under salt conditions (71), resulting in the more efficient dissociation. Linear PEI is less cytotoxic than its branched counterparts (71). These characteristics make linear PEI more effective in the in vivo delivery (71-73). Although both branched and linear PEI were widely used, the nature of PEI still has to be improved to satisfy the safety and effectiveness requirements of in vivo nucleic acid delivery (74). Recently, more and more studies have been focused on the improvement of PEI's properties $(72,75)$.

\subsubsection{Chitosan}

Chitosan is produced from the naturally occurring chitin which is the structural element in the exoskeleton of crustaceans and cell walls of fungi. Partial deacetylation of chitin exposes amine groups of chitosan makes it a cationic polymer. Chitosan is a linear polysaccharide polymer, which is composed of D-glucosamine (deacetylated unit) and Nacetyl-D-glucosamine (acetylated unit) linked with randomly distributed $\beta-(1,4)$ glycosidic bonds. Biodegradability, biocompatibilities, low immunogenicity, and low cytotoxicity render chitosan one of the most prominent carriers for nucleic acid delivery (76-78). The size and zeta potential, morphology, stability, and biological effect of its polyplexes, are strongly dependent on chitosan's molecular weight, degree of deacetylation, N/P ratio and $\mathrm{pH}(79,80)$. Increase in molecular weight of chitosan increased the size of polyplexes, resulting in the increase of transfection efficiency $(81,82)$.

MacLaughlin et al. studied the wide range molecular weight chitosans from 7 to $540 \mathrm{kDa}$ and found that the particle size of chitosan/DNA complexes prepared at the N/P ratio of $6: 1$ with a plasmid concentration of $100 \mu \mathrm{g} / \mathrm{mL}$ significantly increased from 100 $\mathrm{nm}$ to $500 \mathrm{~nm}$ along with the increase of chitosan's molecular weight (82). A similar trend was found by Katas et al. when they used chitosan hydrochloride to condense siRNAs (78). Huang et al. also reported that low molecular weight chitosan was less efficient in condensing plasmid DNA and corresponding polyplexes were less stable during dilution compared to its high molecular weight counterparts (83). This may be because the high molecular weight chitosan interacts with DNA molecules by not only 
via electrostatic interaction but also via effective chain entanglement (84). However, in some cases high molecular weight could not guarantee high gene transfection and silencing since the strong interaction force inside polyplexes might hinder the release of loaded nucleic acids $(85,80)$. These facts emphasized the importance of a fine balance between extracellular protection and intracellular release to obtain expected biological effects. Since the positive charge of chitosan comes from deacetylation, the degree of deacetylation is important for nucleic acid delivery. The commonly used chitosans are highly deacetylated, probably $80 \%$ or above $(77,78,82)$, to expose more charge for condensing nucleic acids. Low deacetylation caused low transfection efficiency (83), although the similar condensation effect as high degree of deacetylation could be achieved at a relatively high N/P ratio. Liu et al. studied chitosan's protonation and its complexation with DNA at different $\mathrm{pHs}$ and found that amine groups were almost completely protonated at the $\mathrm{pH}$ below its $\mathrm{pKa}$ (about 6.5), resulting in the increased electrostatic interaction between chitosan and DNA (87). In contrast, the amine groups were hardly protonated at the $\mathrm{pH}$ above 7.5 , resulting in poor DNA condensation (88). However, the low transfection efficiency was observed at the $\mathrm{pH}$ below 6.5 , due to the hindrance of endosomal escape and cargo release, although chitosan could be highly protonated (88). In addition to charge density, other characteristics also influence the performance of chitosan, including solubility (89), degradation (90), and crystallinity (91). The proper modification of chitosan with other polymers or ligands could improve its performance in the delivery of nucleic acids.

\subsubsection{Cyclodextrin (CD)-based Cationic Polymers}

Cyclodextrins are a naturally occurring cyclic oligosaccharides constituted by 6-8 $(+)$ glucopyranoside units, linked by $\alpha-1,4-$ linkages, and well known as $\alpha-, \beta-$, or $\gamma-C D$, respectively. They are topologically represented as torus-like macro-rings with the relatively hydrophobic inner cavities, where various molecules can be encapsulated and form supramolecular inclusion complexes (92). Therefore, CDs and their derivatives have been extensively studied for understanding the mechanism of molecular recognition and as drug carriers to enhance the solubilization, stabilization and absorption (93). Since nucleic acids are negatively charged hydrophilic macromolecules, they cannot be trapped into native CD's cavities like small molecules. To use CDs for nucleic acid delivery, they have to be incorporated by cations or modified by other cationic polymers. Davis' group developed a linear $\beta$-CD containing cationic polymer by polymerization of a bifunctional $\beta$-CD monomer, (2-aminoethanethio)- $\beta$-CD derivative, via the cationic linkages, dimethylsuberimidate (94). Another modification was available by conjugating multiple oligoethylenimine (OEI) arms onto the $\alpha-\mathrm{CD}$ core to form a star-shaped cationic polymer (95). These kinds of modifications of CDs were reported to enhance the in vitro transfection efficiency and lower the cytotoxicity.

The most important feature of CD-containing polymers is their capability to form the inclusion complexes which can be used as the functional moieties for further modifications. Grafting PEG-adamantane on the $\beta$-CD moieties of DNA polyplexes was reported to stabilize polyplexes, decrease cytotoxicity, and enhance transfection 
efficiency (96). Recently, a new class of cationic supramolecules, CD-based polyrotaxanes, had been designed for gene delivery $(97,98)$. The new cationic polyrotaxane composed of multiple OEI grafted $\beta$-CDs that were threaded on PPO block and blocked on the two ends of a Pluronic (PEO-PPO-PEO) triblock copolymer (99). Cationic polyrotaxanes effectively condensed plasmid DNA to nanoparticles and showed low cytotoxicity and high transfection efficiency in BHK-21 and MES-SA cells (98).

\subsubsection{Dendrimers}

Dendrimer consists of a central core molecule, from which a number of highly branched arms "grow" to form a tree-like structure with a manner of symmetry or asymmetry. Dendrimers have unique architecture and properties which make dendritic polymers the focus of much research in drug and gene delivery as well as diagnostics and bioengineering. Dendritic polymers could be constructed by stepwise synthesis using a divergent or convergent method (100). The most popularly used dendrimers are Polyamidoamine (PAMAM) and polypropylenimine (PPI) dendrimers. PAMAM dendrimers are synthesized commonly starting from a core molecule, ethylenediamine or ammonia, then esterizing the core with methylacrylate followed by amidation of the ester with ethylenediamine. The resulting polymer after one reaction circle is termed as a generation (e.g. G2, G3 ...). If the reactions terminate just after esterization, the term "half generation" (e.g. G2.5, G3.5...) will be given to the dendritic polymer.

For PPI dendrimers, the branched PPI units will grow from the core molecule, butylenediamine (DAB), by Michael addition followed by hydrogenation of nitrile groups (100). Because of their unique architecture dentrimers adopt a planar-elliptical shape or spherical shape depending on the number of generations. Usually the inner structure is loose due to the low density of molecules compared to the compact structure in the outer layer due to the high density of molecules. The space inside the dendrimer is favorable for small molecules to be encapsulated in. However it seems impossible for nucleic acids due to their large size. Commonly, the cationic dendrimers with the outside positive surface are suitable to condense and carry the negatively charged nucleic acids like other cationic polymers. Dendrimer interacts with biological membranes by its pore forming ability which may induce the small, transient pores near the contact site. The pore forming ability depends on the charge density and the generation of dendrimer. The higher the charge density or generation, the higher the transfection efficiency (100). However, large dendrimers with the high generations commonly show higher cytotoxicity than the dendrimers with low generations (101). In general the toxicity of dendrimers is lower than that of PEI, PLL or DEAE-dextran (74). Another important aspect of dendrimer is its $\mathrm{pH}$ buffering capacity which can cause endosome disruption and facilitate the dendrimer/nucleic acid complex release (61). Since dendrimers show higher transfection efficiency and low cytotoxicity, dendrimer-based transfection reagents have already been commercialized, including PolyFect and SuperFect (QIAGEN), Starburst ${ }^{\circledR}$ PAMAM dendrimers (Dendritic Nanotechnologies), Priostar ${ }^{\circledR}$ dendrimers (Starpharma), and Astramol ${ }^{\mathrm{TM}}$ (DSM). 
Dendrimers to have similar or superior performance compared to cationic polymers or lipids $(102,103)$. However, only about $1 \%$ of PAMAM dendrimers (G3 and G4) was detected in blood circulation compared to more than $60 \%$ of dendrimers accumulated in the liver at $1 \mathrm{~h}$ after intravenous injection into rats (104). To use dendrimers as in vivo delivery system, some improvement has to be made to decrease their non specific distribution and increase their efficacies. Conjugation of hydrophilic $\alpha$ CD to G2 to G4 PAMAM dendrimers significantly increased their transfection efficiency and decreased their cytotoxicity caused by highly dense positive charge even at the high $\mathrm{N} / \mathrm{P}$ ratio (105). Taratula reported that coating of PPI dendrimer (G5) /siRNA nanoparticles with PEG-luteinizing hormone-releasing hormone (LHRH) peptide could stabilize the siRNA complexes in the presence of plasma. These targeted particles were efficiently accumulated in the tumor area compared to non-targeted particles (106). Quaternization of primary amino groups especially external amine was also explored in high generation of PPI dendrimers to reduce their cytotoxicity (107). However, the transfection efficiency might be decreased due to the insufficient surface charge (108).

\subsection{NON-CATIONIC LIPIDS AND POLYMERS}

Non-cationic polymers or lipids cannot condense nucleic acids via electrostatic interaction and in most cases they work as the constituents in the cationic vectors. For example, DOPE and cholesterol are the two most commonly used neutral co-lipids for preparing cationic liposomes. The incorporation of fusogenic lipids such as DOPE can improve endosomal escape by membrane fusion between the liposomal and endosomal bilayers $(109,110)$. DOPE has been shown to be a major driving force in promoting transfection efficiency of SAINT-2 cationic lipids, as it undergoes $\mathrm{L}_{\alpha}$ to $\mathrm{H}_{\text {II }}$ transition when dispersed in a physiological buffer (111). The use of cholesterol as a co-lipid has been reported to show enhanced in vivo gene expression, as cholesterol containing liposomes could efficiently interact with the cell membrane in the presence of serum (112).

Some new materials have been created by conjugating lipids to polymers. Branched PEI-cholesterol water soluble lipopolymer was synthesized by Han et al. (113) and Wang et al. (114). These branched PEI-cholesterol conjugates self-assemble into cationic micelles with diameter of approximately $50 \mathrm{~nm}$ in aqueous buffer and showed enhanced transgene expression and low cytotoxicity compared to PEI control in CT-26 colon adenocarcinoma and $293 \mathrm{~T}$ human embryonic kidney transformed cells $(113,114)$. PEG based non-cationic polymers or lipids are another widely used constituent in the cationic liposomal or polymeric carriers. PEGylation of cationic lipids or polymers can be done by either surface modification or incorporation of pegylated moieties into liposome preparation. PEGylation of Stabilized Plasmid Lipid Particle (SPLP) or Stable Nucleic-Acid-Lipid Particle (SNALP) could neutralize the positively charged surface of cationic lipids and provide a neutral, hydrophilic coating to the particle's exterior using a diffusible PEG-lipid conjugate, PEG2000-C-DMA, resulting in the long circulation time and low immune response $(115,116)$. Systemic administration of anti-HBV siRNAs 
containing pegylated SNALP significantly inhibited HBV DNA and HBsAg expression in a HBV mouse model (116).

Besides the above discussion, non-ionic polymers were designed and used independently in the nucleic acid delivery. Pluronic ${ }^{\circledR}$, also called poloxamer, is a series of block copolymers based on ethylene oxide and propylene oxide. It is widely used in drug and gene delivery (117). Enhanced gene expression was observed post injection of plasmid DNA with SP1017 which is the combination of Pluronics L61 and F127 into rats' skeletal muscle compared to another non-ionic polymer, polyvinyl pyrrolidone (PVP) (118). Further study showed that SP1017 could improve DNA distribution inside muscular tissue resulting in increased bioavailability, although Pluronic did not increase the in vitro gene transfection and expression since it interacted with DNA via weak force such as hydrogen bonds rather than strong electrostatic interaction (118). Another frequently reported non-ionic polymer was poly(lactic-co-glycolic acid) (PLGA) or its derivatives, by which nucleic acids could be encapsulated into the core or absorbed on the surface of PLGA nanoparticles $(119,120)$.

Bioconjugation technology to deliver oligonulceotides or siRNAs is also being widely investigated. Oligonucleotides and siRNAs are easier to be conjugated with lipids or polymers since they are relatively small compared to plasmids (121), which can loose their supercoiled configuration. Bioconjugation of ODN and siRNA is discussed in the following section.

\subsection{DESIGN ELEMENTS FOR EFFECTIVE NUCLEIC ACID DELIVERY}

To achieve efficient delivery of nucleic acids, in general, a delivery system has to be designed based on the cargo's properties and desired therapeutic effect using lipids, polymers, or their combination.

\subsubsection{Liposomal Delivery System}

Liposomes, the microscopic bubbles of amphiphilic lipids surrounding an aqueous interior, which have a history of roughly 40 years, have been proven to be a unique tool for studying both structural and dynamic aspects of natural membranes $(122,123)$. Given their biocompatibility, biodegradability, low toxicity and immunogenicity, liposomes have attracted attention in the past three decades as pharmaceutical carriers of great potential (124). Liposomal delivery system is the most widely used carrier for in vitro and in vivo nucleic acid delivery. Although in some cases cationic lipids are used alone, most cationic lipids are used to prepare cationic liposomes which contain at least two components, the cationic lipid and neutral co-lipid. The selection of co-lipids is important, as they can significantly influence the overall performance of cationic liposomes. We used DOPE and cholesterol as the co-lipid to prepare pyridinium-lipid based cationic liposomes respectively to transfer plasmid DNA in CHO cells and found that both DOPE and cholesterol could enhance transgene expression when used with each favorite 
cationic lipids (30). The cationic lipids are usually considered to be transfection inefficient if they cannot work well with co-lipids to improve gene transfection. However, Mukherjee et al. proposed a different strategy that involved combination of co-lipids (DOPE, cholesterol and DOPC) in equimolar ratio. This approach could improve the transfection efficiencies of cationic lipids which had been proven transfection inefficient when formulated with each of these co-lipids alone (125).

There is a strong relationship between the morphology of lipoplexes and their performance. A few models were introduced to predict and mimic the morphologies of lipoplexes, including external model (DNA is adsorbed onto the surface of cationic liposomes), internal model (DNA is surrounded by cationic liposomes), beads (cationic liposomes) on a string (DNA) model, and globular model (126). It was recently agreed that the "phase models" of lipoplexes were more helpful in understanding their transfection abilities, including the lamellar structure $\left(\mathrm{L}_{\alpha}\right)$, the inverted hexagonal structure $\left(\mathrm{H}_{\mathrm{II}}\right)$, and the intercalated hexagonal structure $\left(\mathrm{H}_{\mathrm{I}}\right)(126)$. Many excellent research or review papers have been published in terms of these issues $(51,111,126,127)$. In general, $\mathrm{L}_{\alpha}$ phase lipoplexes are relatively stable and have low transfection activity, while $\mathrm{H}_{\mathrm{II}}$ phase lipoplexes are instable and show high propensity of lipid fusion resulting in high transfection efficiency. Besides liposomal components, the charge ratio (N/P ratio) of cationic lipids/nucleic acids, preparation methods, ionic strength, and temperature, may also influence the lipoplex formation and its morphology. Charge ratio was one of the mostly studied issues and found to significantly influence the morphology of lipoplexes and their transfection abilities. At the high N/P ratio, the lipid/DNA complex was found to adopt a globular structure with the effective condensation (128), while at the low N/P ratio, the beads on a string structure could be formed along with the addition of DNAs (129). Highly condensed positively charged particles are easier for cells to take up. However, if the concentration of cationic liposomes is too high, it may cause cytotoxicity. The size of lipoplexes was also reported to have the influence on transfection efficiency. So far the effect of size was controversial since the conflicting results were reported in the previous studies. However it was believed that large lipoplexes were more efficient to transfect nucleic acids in vitro since large particles led to faster sedimentation, the maximum contact with cell membrane, and easier dissociation of lipoplexes post endocytosis. In contrast, the small size particle was much safer and appropriate for in vivo delivery of nucleic acids (126).

To design an in vivo liposomal delivery system, surface modification of cationic liposomes was reported to be effective. Sato et al. successfully used vitamin A-coupled cationic liposomes to specifically deliver siRNAs to hepatic stellate cells in fibrotic rats, by which they almost completely resolved liver fibrosis and prolonged rats' lives (130). Since PEG chain could sterically stabilize the liposomes and prevent early capturing by macrophages, pegylated cationic liposomes were used for in vivo delivery of nucleic acids (131-133). Systemic administration of SNALP/APOB-specific siRNAs in cynomolgus monkeys could silence APOB mRNA expression more than $90 \%$ and this effect lasted for 11 days (133). 


\subsubsection{Oligonucleotide and siRNA Conjugates}

Since oligonucleotides and siRNAs are readily modified by other functional molecules to improve their stability and pharmacokinetic behaviors (134), the conjugation reaction was widely used to link nucleic acid with functional lipids $(135,136)$, polymers $(134,137)$, and nanoparticles $(138)$. ODN or siRNA can be covalently linked with functional molecules via non-degradable or degradable linkage, such as acid-labile ester $(134,139)$ and reducible disulfide bond $(140,141)$. Both 3'- and 5'-terminus of single strand oligos were used for conjugation $(134,142)$. For siRNAs, however, it was known that antisense strand of siRNA worked as the template in RISC for RNAi. It was further shown that 5'-terminus of antisense strand is more important than 3'-terminus and determines RNAi activity (143-145). Therefore, the 3'- and 5'-end of sense strand are preferred for conjugation (121).

Cholesterol is commonly used lipid for ODN and siRNA conjugation. After conjugation, the hydrophobicity will be increased resulting in the change of in vivo distribution. Cheng et al. conjugated triplex-forming oligonucleotide (TFO) with cholesterol at its 3'-terminus via disulfide bond and found that conjugation with cholesterol had little effect on the triplex-forming ability of the TFO with target duplex DNA and enhanced hepatic uptake of ODNs after i.v. injection into rats (135) (Figure 2.6A). To make apolipoprotein B (apoB) siRNA conjugate, Soutschek et al. linked cholesterol with the phosphorothioated antisense RNA oligo at 3 '-terminus via aminocaproic acid-pyrrolidine linkage followed by annealing with the complementary sense strand oligo. Systemic administration of siRNA-cholesterol resulted in silencing of apoB mRNA in liver and jejunum as well as reduction of the total cholesterol level (136). Water soluble polymers with the functional terminal groups were alos used to conjugate with nucleic acids, such as PEG $(134,141)$ and HPMA (137) (Figure 2.6B). We conjugated galactosylated poly (ethylene glycol) (Gal-PEG) to ODN via an acid-labile ester linkage of $\beta$-thiopropionate. Gal-PEG-ODN was found stable when incubated it with rat serum, while the ester linkage was cleaved and ODN dissociated from the conjugate when environmental $\mathrm{pH}$ was 5.5. Systemic administration of Gal-PEG-ODN significantly enhanced cellular uptake of ODNs in hepatocytes since galactose residue is the specific ligand for asialoglycoprotein receptors on the surface of hepatocytes, while the accumulation of ODNs in liver was significantly inhabited by pre-injection of BASGal (134) (Figure 2.7).

Pegylated siRNA was studied by Park's group $(141,146)$ and Katoka's group. $(139,147)$ Like pegylated ODN, pegylation could protect siRNA from nuclease digestion, prolong its systemic circulation, and confer targeting effect if a targeting ligand is attached to PEG. In Park's study, N-Succinimidyl 3-(2-pyridyldithio)propionate (SPDP), a hetero-functional coupling reagent, was first reacted with $\mathrm{NH}_{2}$ at 3 '-terminus of the sense strand to produce a 2-pyridyl disulfide activated siRNA which could further react with sulfhydryl group in PEG to form a disulfide bond. In their study, the peptides were used as ligands, e.g. vascular endothelial growth factor (VEGF) (141) and LHRH (146). In contrast, Katoka used acid-labile linkage between siRNA and PEG and lactose residue as a ligand (139). Both Park and Katoka reported that pegylated siRNA could 


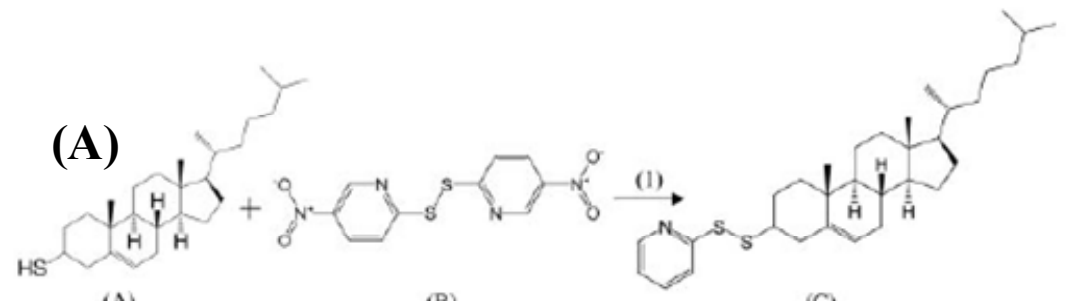

(A)

(B)

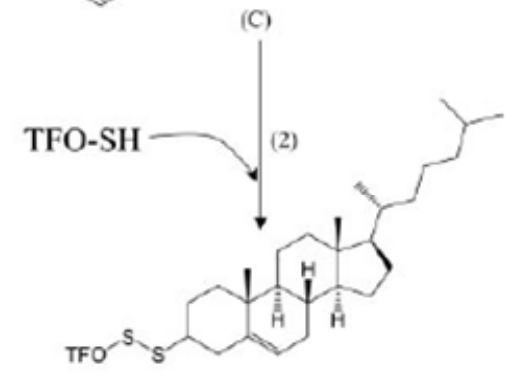

(A) Thiocholesterol
(B) Bis-(5-nitro-2-pyridyl)-disulphide
(C) 2-(5'-Nitropyridyl)-3-cholesterol disulphide
(D) TFO-Cholesterol

(D)
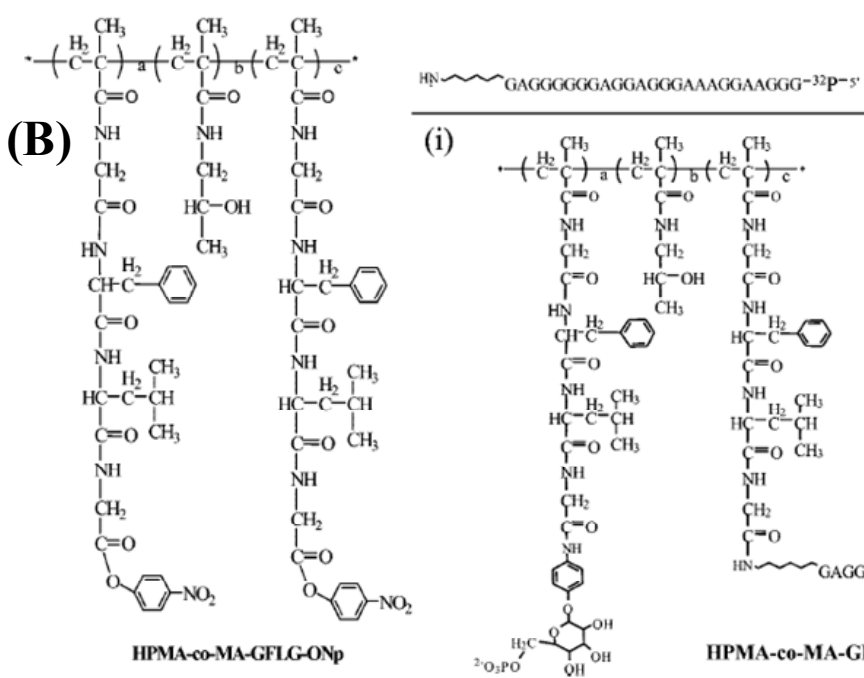

(i)

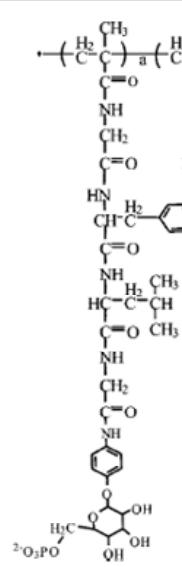

$\mathrm{CH}^{\mathrm{H}_{3}} \mathrm{H}^{\mathrm{H}_{3}} \mathrm{C}^{\mathrm{H}}$

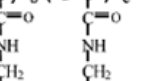

$\mathrm{C}_{\mathrm{C}}^{\mathrm{H}_{2}}$

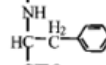

Y $=0$

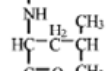

Y $=0 \mathrm{CH}$

$\mathrm{NH}^{\mathrm{H}}$

$\mathrm{c}_{\mathrm{c}}^{\mathrm{H}}=\mathrm{O}$

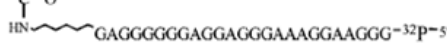

HPMA-co-MA-GFLG-M6P-co-GFLG-TFO

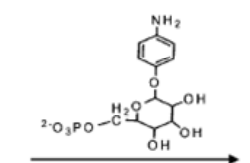

(ii)

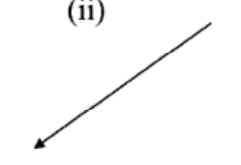

Figure 2.6 Conjugation of TFO to cholesterol (A) and HPMA (B).

(A) Thiocholesterol was reacted with bis-(5-nitro-2-pyridyl)-disulfide in pyridine at room temperature for $2 \mathrm{~h}$ to form 2-(5'-nitropyridyl)-3-cholesterol disulfide. Then, 2-(5'nitropyridyl)-3-cholesterol disulfide was conjugated to TFO-SH in DMF under $\mathrm{N}_{2}$ protection at $40{ }^{\circ} \mathrm{C}$ for $24 \mathrm{~h}$. (B) Poly(HPMA-co-MA-GFLG-ONP) and TFO-NH $\mathrm{NH}_{2}$ were reacted in the presense of $N, N^{\prime}$-diisopropylethylamine (DIPEA) in DMSO at room temperature, followed by reaction with p-Aminophenyl-6-phospho- $\alpha$-Dmannopyranoside (papM6P) in the presense of DIPEA. 
(A)
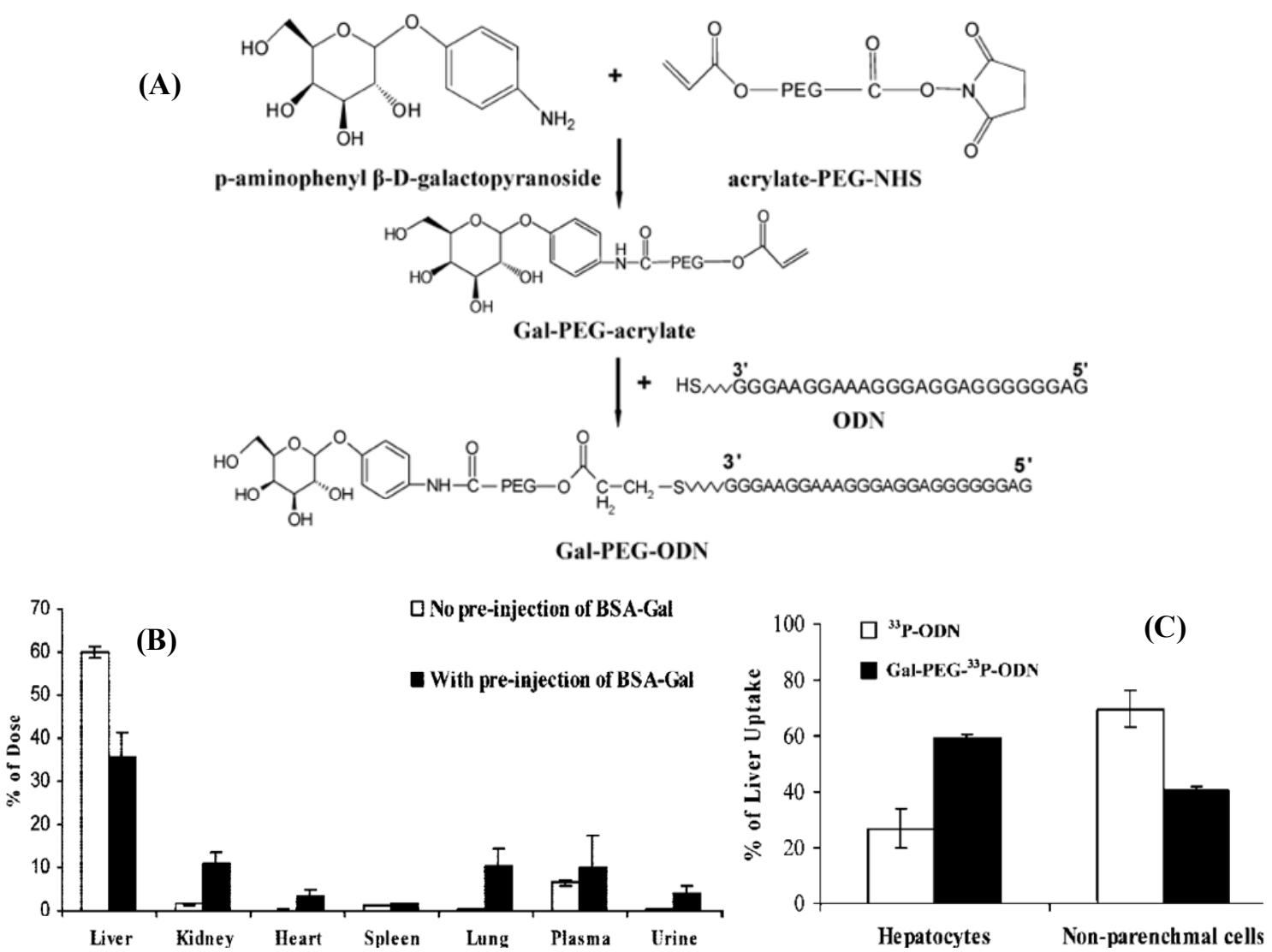

Figure 2.7 Synthesis scheme (A), biodistribution (B), and hepatic localization (C) of Gal-PEG-ODN.

(A) p-Aminophenyl $\beta$-D-galactopyranoside reacted with acrylate-PEG-NHS in DMF. Then Gal-PEG-acrylate was conjugated to reduced 3'-thiol ODN by Michael addition in nuclease free water. (B) Gal-BSA $(10 \mathrm{mg} / \mathrm{Kg})$ was injected intravenously into rats 2 minutes before injection of Gal-PEG- ${ }^{33} \mathrm{P}-\mathrm{ODN}$ at a dose of $0.2 \mathrm{mg} / \mathrm{Kg}$. At 30 minute post injection, rats were sacrificed, major organs were isolated and radioactivity was determined. (C) The liver was perfused by collagenase/pronase digestion at $30 \mathrm{~min}$ post injection of ${ }^{33} \mathrm{P}-\mathrm{ODN}$ or Gal-PEG- ${ }^{33} \mathrm{P}-\mathrm{ODN}$ at a dose of $0.2 \mathrm{mg} / \mathrm{Kg}$. Parenchymal (hepatocytes) and non-parenchymal cells were separated and the associated radioactivity was measured. 
spontaneously form polyelectrolyte complex (PEC) micelles with PEI (148) or pegylated polyplexes with poly(L-lysine) (PLL) (147) via electrostatic interaction. After complex formation the negatively charged siRNAs would be buried in the core and completely covered by hydrophilic PEG shell. This kind of nanoparticles were found to be significantly accumulated in the tumor region in an in vitro three-dimensional tumor model (147) and tumor bearing mice after systemic administration (148) due to enhanced permeability and retention (EPR).

Although siRNA conjugates have been studied recently, it is still too early to see their benefits in the clinic. Most of these studies are still in their early stage and focused on the design and preparation. The therapeutic and side effects have to be thoroughly tested since the conjugate, in a sense, is more like a new drug molecule which has the different structure as its "parents".

\subsubsection{Micro- and Nano-particle Delivery System}

Poly(D,L-lactide-co-glycolide) (PLGA) is a FDA approved polymer which is widely used in formulation and drug delivery $(149,150)$. Nucleic acids /PLGA particles could be made by conventional microsphere-making techniques, such as double emulsion $(\mathrm{W} / \mathrm{O} / \mathrm{W})(119,151)$ and spray-drying techniques $(120,152)$. However, by these methods, the encapsulation efficiency of nucleic acids in PLGA particles was as low as less than 1 $\mu \mathrm{g} / \mathrm{mg}(120,153)$ because the hydrophilicity of nucleic acids was not compatible with hydrophobic core of PLGA particles. Besides that, the hostile condition of preparation and the decrease in $\mathrm{pH}$ during the hydrolysis of PLGA also inactivated the loaded nucleic acids (154). Thus, encapsulation efficiency and the stability of nucleic acids are significantly influenced by preparation methods. Condensation of nucleic acids by cationic polymers before encapsulation in PLGA particles was reported to increase the encapsulation efficiency and protect the loaded nucleic acids from degradation. Capan et al. found complex formation with PLL (N/P 3:1 and 8:1) dramatically increased the encapsulation efficiency of supercoiled DNAs in PLGA/DNA micro particles (155). It was reported that other cationic materials, e.g. PEI, DOTMA, DC-Chol, or CTAB, could be used to make cationic PLGA/DNA nanospheres by a modified O/W emulsion solvent -evaporation method (152). Murata et al. prepared a long-term sustained release PLGA microspheres encapsulating anti-VEGF siRNA / cationic polymer complexes (arginine or branched PEI) using the $\mathrm{W} / \mathrm{O} / \mathrm{W}$ in-water drying method and observed the inhibition of tumor growth (119). The alternative strategy to improve the encapsulation efficiency was to synthesize new PLA grafted cationic polymers (156). The hydrophobicity and molecular weight of PLGA also have profound influence on the encapsulation efficiency of hydrophilic nucleic acids $(153,154)$. Besides low encapsulation efficiency and inactivation of macromolecules, the slow drug release rate and burst release may hinder its application in the delivery of nucleic acids. 


\subsection{CONCLUSIONS}

The success of gene therapy is highly dependent on the delivery systems because of the unique nature of genetic materials compared to that of small molecules. Cationic lipids and polymers are widely used as transfection reagents for plasmid DNA, oligonucleotide and siRNA. Each of them has its advantages and disadvantages. The in vivo nucleic acid delivery is a complicated process and influenced by many factors. For example, cationic lipids are excellent transfection reagents and can efficiently transfect nucleic acids in vitro, while they exhibited low efficacies when administered intravenously (11) because of the induction of immune response and non specific distribution. However, cationic lipid-formulated plasmid DNA vaccine was reported to significantly enhance the antigen-specific antibody responses compared to naked plasmid DNA vaccine via intramuscular injection, possibly due to the induction of inflammatory cytokines like IFN- $\gamma$, IL-12, and IL-6 $(157,158)$. PEGylation can significantly decrease non specific distribution and unexpected immune response. The cleavable linkage between PEG moiety and the cationic lipid or polymer is preferred since positively charged surface has to be exposed to trigger the endocytosis and endosomal escape. Modification of gene carriers with ligands may be another efficient way to impart the cell specific delivery. The interaction, either electrostatic or other forces, between nucleic acids and cationic carriers should be strong enough to make sure the lipo(poly)-plexes stable before cellular internalization. Thereafter, the complexes commonly locate in endosomes. The endosomal escape is an important step for a gene medicine to take action. The endosomal escape could be enhanced by "proton sponge effect" or lipid fusion. Then the loaded nucleic acids should be dissociated from the complexes and released in the cytoplasm or be translocated into nucleus. Any problems in each step may cause the whole delivery process fail. In this area, a great deal of work needs to be done so that we could have a comprehensive understanding of nucleic acid delivery process. The commonly used cationic carriers could also be used for siRNA delivery. However, siRNA is a short molecule compared to DNA and has different behaviors when mixing with cationic carriers. The optimized delivery condition for DNA may not be suitable for ODN or siRNA delivery (58). A variety of specific delivery systems have been developed to effectively target siRNAs to malignant cells. For example, lipid or polymer based siRNA conjugates have shown to be effective in vitro and in vivo (121). Since most siRNA conjugates are not positively charged, they are more suitable for in vivo delivery.

The side effects of lipid or polymeric carriers have to be thoroughly studied although they were reported safer than viral vectors. The therapeutic applications of these carriers are still limited although some exciting progress has been achieved in various research areas, including the increased understanding of the biological processes involved in nucleic acid delivery, the technology to increase the chemical stability and therapeutic efficacy of nucleic acid, and the innovative design of new functional materials and delivery systems. To design a perfect lipid or polymeric nucleic acid delivery system, we still have a long way to go. 


\section{CHAPTER 3. STRUCTURAL AND FORMULATION FACTORS INFLUENCING PYRIDINIUM LIPID-BASED NCLEIC ACID DELIVERY*}

\subsection{INTRODUCTION}

Cationic liposomes are the most commonly used synthetic carriers for delivery of oligonucleotides, siRNAs and plasmid DNA. The three basic components of a cationic lipid, which affect gene expression or silencing, include (i) a hydrophobic lipid anchor group, such as fatty acid chains of various lengths and unsaturation states, or cholesterol, which helps in forming liposomes and exchanging lipids in cell membrane (12), (ii) linker group, such as an ester, ether, amide, or carbamate, which binds the polar group to the lipid moiety and determines the stability and biodegradability of the cationic lipid (159), and (iii) a positively charged hydrophilic head group, such as mono- or poly-amine group, which interacts with pDNA via electrostatic interaction, leading to its condensation and enhanced the cellular uptake $(37,114)$. Understanding of these structural parameters is essential for the rational design of efficient cationic lipid-based transfection reagents. Transfection efficiency of cationic liposomes greatly depends on (i) the extent of DNA condensation, (ii) increased cellular uptake due to ionic and/or hydrophobic interaction with negatively charged biological surfaces, and (iii) membrane fusion via transient membrane destabilization to achieve delivery into the cytoplasm while avoiding degradation in the lysosomal compartment $(52,160)$.

Significant progress has been made in the design and function of cationic lipids since the introduction in 1987 of the transfection reagent Lipofectin, which is a 1:1 w/w mixture of the cationic lipid $N$-[1-(2,3-dioleoyloxy)propel]- $N, N, N$-trimethylammonium (DOTMA) and DOPE (22). Many cationic lipids bearing either a single tertiary or quaternary ammonium head group or which contain protonatable polyamines linked to dialkyl or cholesterol anchors have been designed for transfection of a variety of cell types in culture $(24,27,45)$. Commercially available cationic lipids used as liposomes or alone for gene delivery include DOTMA (Lipofectin); 2,3-dioleyloxy- $N$-[2-spermine carboxamide] ethyl- $N, N$-dimethyl-1-propanammonium trifluoroacetate (DOSPA, Lipofectamine), 1,2-bis(oleoyloxy)-3-(trimethylammonio) propane (DOTAP), $N$-[1-(2,3dimyristyloxy)propyl]- $N, N$-dimethyl- $N$-(2-hydroxyethyl) ammonium bromide (DMRIE), $3 \beta$-[N-(N,N'-dimethylaminoethane) carbamoyl] cholesterol (DC-Chol), and dioctadecyl amidoglyceryl spermine (DOGS, Transfectam) and dimethyldioctadecylammonium bromide (DDAB) $(22-26,158,160,161)$. A few such compounds have also been used in initial clinical studies. However, many of the cationic lipids used in early clinical trials such as DC-Chol, DMRIE, and GL-67, although effective in vitro, have proven inefficient in vivo, especially when compared with viral vectors $(28,29)$.

Various heterocyclic cationic lipids had been studied and used for gene delivery.

* Adapted with permission from American Chemical Society. Zhu, L., Lu, Y., Miller, D. D., and Mahato, R. I. (2008) Structural and formulation factors influencing pyridinium lipid-based gene transfer. Bioconjug Chem 19, 2499-512. 
Some of them showed higher transfection efficiency and lower cytotoxicity compared to cationic lipids with linear primary amines or polyamines as the head group (162). Pyridinium heterocyclic ring in the cationic amphiphile was first introduced in 1940s, which had antiseptic and antibiotic properties $(26,163)$. Upon the invention of pyridinium-based cationic lipids, a series of these lipids have been developed and some of them have been reported to reach or surpass the transfection efficiency of commercial cationic lipid formulations, both in vitro and vivo, while maintaining low cytotoxicity $(31,32,34,164,165)$.

In this study, we synthesized a series of pyridinium lipids containing a heterocyclic positively charged ring linked to different types of fatty acids via ester or amide spacers. Following purification and characterization of these cationic lipids using ${ }^{1} \mathrm{H}$ NMR, ${ }^{13} \mathrm{C}$ NMR and mass spectrometry, cationic liposomes were prepared using DOPE or cholesterol as a co-lipid, followed by determination of particle size and zeta potential. Reporter gene expression and cytotoxicity were determined after transfection of Chinese Hamster Ovary (CHO) cells, hepatocarcinoma (CRL1830) cells and prostate cancer (C4-2) cells with green fluorescent protein (GFP) or luciferase expression plasmid DNA after complex formation with cationic liposomes. Factors influencing gene transfer, including charge ratio (N/P) between cationic liposomes and pDNA, cationic lipid / colipid ratio, linker type, fatty acid carbon chain length, degree of saturation, configuration of double bond, the presence of serum and cell type were studied. The pyridinium lipid was also tested in the delivery of siRNA and gene silencing study.

\subsection{EXPERIMENTAL PROCEDURES}

\subsubsection{Materials}

1,2-Dioleoyl-sn-glycero-3-phosphoethanolamine (DOPE) was purchased from Avanti Polar Lipids (Alabaster, AL). Alexa Fluor ${ }^{\circledR}$ Red fluorescent siRNA, firefly luciferase siRNA (sense strand: CUU ACG CUG AGU ACU UCG A[dt][dt], antisense strand:UCG AAG UAC UCA GCG UAA G[dt][dt]), Lipofectamine, Lipofectmine 2000, G418, DMEM and RPMI1640 were purchased from Invitrogen Corporation (Carlsbad, CA). Heat-inactivated fetal bovine serum (FBS) and penicillin (10000 units/mL penicillin G sodium)-streptomycin solution $(10000 \mu \mathrm{g} / \mathrm{mL}$ streptomycin sulfate) in $0.85 \%$ saline were purchased from Mediatech, Inc. (Herndon, VA). Luciferase Assay Kit and Cell Culture Lysis Reagent $5 \times(\mathrm{CCLR})$ were procured from Promega Corporation (Madison, WI). QIAfilter plasmid maxi kit was purchased from Qiagen, Inc. (Valencia, CA); BCA protein assay kit from Pierce (Rockland, IL); pCMS-EGFP plasmid was procured from BD Biosciences Clontech (Palo Alto, CA) and pcDNA3-Luc plasmid was a kind gift from Expression Genetics, Inc. (Huntsville, AL). All reagents used for lipid synthesis were purchased from Sigma-Aldrich Chemical Co. (St. Louis, MO) and Fisher Scientific (Pittsburgh, PA) and were used without further purification. 


\subsubsection{Synthesis of Pyridinium Lipids}

\subsubsection{General Methods.}

Routine thin layer chromatography (TLC) was performed on aluminum backed Uniplates. (Analtech, Newark, DE). ${ }^{1} \mathrm{H}$ NMR spectra were obtained on a Bruker AX 300 (Billerica, MA) or Varian Inova-500 (Palo Alto, CA) spectrometer. Chemical shifts for ${ }^{1} \mathrm{H}$ NMR were reported as parts per million (ppm) relative to tetramethylsilane (TMS) in deuterated chloroform $\left(\mathrm{CDCl}_{3}\right)$ as internal standard. ${ }^{13} \mathrm{C}$ NMR spectra were obtained on a Bruker AX 300 spectrometer, operating at $75.5 \mathrm{MHz}$. To make sure the final results reliable we used two mass spectrometers, conventional mass and high-resolution mass (HRMS) to characterize the synthesized pyridinium lipids. Conventional mass spectral data was collected on a Bruker ESQUIRE electrospray/ion trap instrument in positive and negative ion modes. High-resolution mass measurements were obtained using a Micromass Q-TOF2 mass spectrometer. HRMS samples were dissolved in 50\% acetonitrile, $0.1 \%$ Formic acid, and were infused by syringe $(0.4 \mu \mathrm{L} / \mathrm{min})$. To make the paper easier to be read we only list the HRMS data.

Pyridinium amide cationic lipids 4-13 and pyridinium ester cationic lipids 14-18 were synthesized as described by Illies et al. (32) and their visual structures with minimized energy were simulated with the Chem3D Pro software, version 10.0 (CambridgeSoft Corp., Cambridge, MA) using MM2 molecular mechanics routine toward a $0.1 \mathrm{rms}$ gradient, which are shown in Table 3.1. Figure 3.1 outlines a synthesis route via the corresponding pyrylium salts. Mesityl oxide was monoacylated with fatty acid chloride in the presence of aluminum chloride to yield pyrylium chloroaluminate, which was subsequently converted into more stable hexafluorophosphate 1 , for using as a key intermediate to react with different primary amines, yielding aminoethylpyridinium hexafluorophosphate 2 and hydroxyethylpyridinium hexafluorophosphate 3 . Acylation of these pyridinium salts with different types of fatty acid chlorides afforded the final pyridinium amide cationic lipids 4-13 and pyridinium ester cationic lipids 14-18, which were purified with chromatography on silica gel and recrystallized from ethanol.

\subsubsection{Synthesis of Pyridinium Amide Cationic Lipids 4-13}

Aminoethylpyridinium hexafluorophosphate 2, compounds 4 and 5 were synthesized as described by Ilies et al.(32) and the spectra were the same as those reported previously.

4, 6-Dimethyl-2-tetradecyl-1-[2-(9Z)-hexadec-9-enoylamidoethyl] pyridinium hexafluorophosphate 6. Yield: $89.9 \% ;{ }^{1} \mathrm{H}$ NMR $\left(\mathrm{CDCl}_{3}\right), \delta$, ppm: $7.41(\mathrm{~s}, 1 \mathrm{H}, \mathrm{H}-5$ pyridinium), $7.38(s, 1 \mathrm{H}, \mathrm{H}-3$ pyridinium), $6.75(t, 1 \mathrm{H}, J=6.0 \mathrm{~Hz}), 5.33(m, 2 \mathrm{H}, \mathrm{J}=5.4$ $\mathrm{Hz}), 4.56(t, 2 \mathrm{H}, J=6.9 \mathrm{~Hz}), 3.63\left(d t, 2 \mathrm{H}, J=6.9 \mathrm{~Hz}, 6.6 \mathrm{~Hz}, \mathrm{CONHCH}_{2}\right), 3.17(t, 2 \mathrm{H}, J$ $\left.=7.5 \mathrm{~Hz}, \mathrm{C} \alpha \mathrm{Py}-\underline{\mathrm{C}}_{2}\right), 2.90$ ( $s, 3 \mathrm{H}, \mathrm{CH}_{3} \alpha$-Pyridinium), 2.55 ( $s, 3 \mathrm{H}, \underline{\mathrm{CH}}_{3} \gamma$-Pyridinium), $2.18\left(t, 2 \mathrm{H}, J=7.5 \mathrm{~Hz}, \mathrm{NHCOC}_{2}\right), 1.99(4 \mathrm{H}, b r), 1.72$ (quint., $2 \mathrm{H}, \mathrm{C} \alpha \mathrm{Py}-\mathrm{CH}_{2} \underline{\mathrm{CH}}_{2}$ ), $1.47\left(m, 2 \mathrm{H}, \mathrm{NHCOCH}_{2} \mathrm{CH}_{2}\right), 1.25\left(s, 38 \mathrm{H}, \mathrm{CH}_{2}\right.$ from both of alkyl chains $), 0.88(t, 6 \mathrm{H}$, $\mathrm{C}_{3}$ of alkyl chains); ${ }^{13} \mathrm{C}$ NMR $\left(300 \mathrm{M}, \mathrm{CDCl}_{3}\right), 175.23(\mathrm{C}=\mathrm{O}), 159.07,158.14$, 
Table 3.1 Energy minimized structures and melting points of pyridinium lipids.

\begin{tabular}{|c|c|c|c|c|c|c|}
\hline $\begin{array}{l}\text { Carbon chain } \\
\text { legnth and type }\end{array}$ & $\begin{array}{c}\text { Compound } \\
\text { ID }\end{array}$ & Amide & M.P. & $\begin{array}{c}\text { Compound } \\
\text { ID }\end{array}$ & Ester & M.P. \\
\hline C14:0 & 4 & & $73.6^{\circ} \mathrm{C}$ & 14 & & $72.3^{\circ} \mathrm{C}$ \\
\hline C15:0 & & & & 15 & & $81.7^{\circ} \mathrm{C}$ \\
\hline C16:0 & 5 & & $80.7^{\circ} \mathrm{C}$ & 16 & & $77.1^{\circ} \mathrm{C}$ \\
\hline C18:0 & 8 & & $83.8^{\circ} \mathrm{C}$ & 17 & & $74.4^{\circ} \mathrm{C}$ \\
\hline C18:0, branch & 13 & & $-16.3^{\circ} \mathrm{C}$ & & & \\
\hline $\mathrm{C} 16: 1$, cis-9 & 6 & & $36.8^{\circ} \mathrm{C}$ & & & \\
\hline C16:1, trans-9 & 7 & & $63.5^{\circ} \mathrm{C}$ & & & \\
\hline C18:1, cis-9 & 9 & & $50^{\circ} \mathrm{C}$ & 18 & & $48.7^{\circ} \mathrm{C}$ \\
\hline C18:1, trans-9 & 10 & & $64.8^{\circ} \mathrm{C}$ & & & \\
\hline $\mathrm{C} 20: 1$, cis- 11 & 11 & & $50.4^{\circ} \mathrm{C}$ & & & \\
\hline $\mathrm{C} 20: 1$, trans-11 & 12 & & $69.4^{\circ} \mathrm{C}$ & & & \\
\hline
\end{tabular}




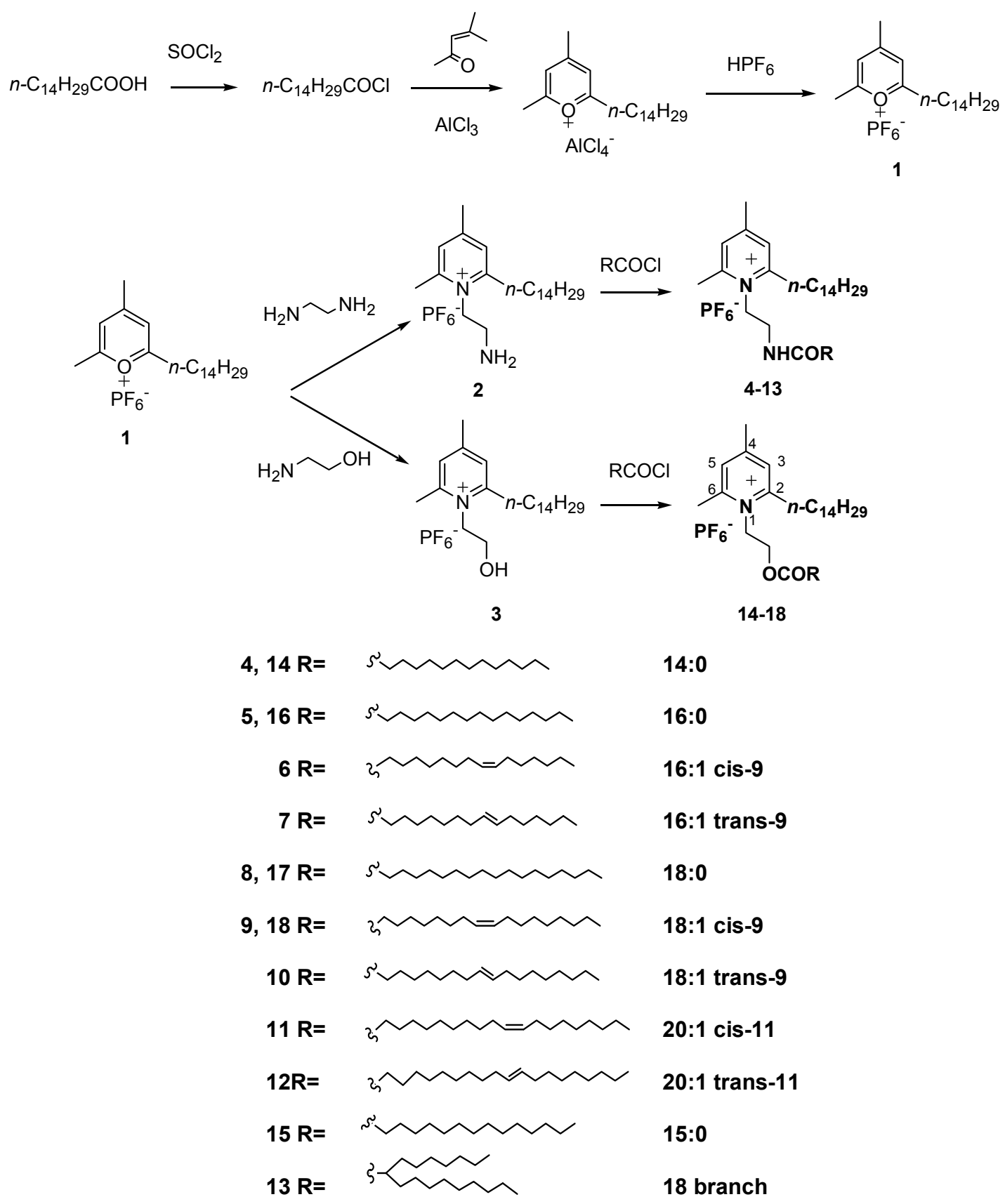

Figure 3.1 Synthesis scheme of pyridinium lipids. 
155.05 (C-2, C-4 and C-6 pyridium), 130.41, $130.28(\mathrm{CH}=\mathrm{CH}), 128.68,127.32(\mathrm{C}-3$ and C-5 pyridium), 50.55 ( $\left.\mathrm{C \alpha Py}-\underline{\mathrm{C}} \mathrm{H}_{2}\right), 38.25\left(\mathrm{C} \beta \mathrm{Py}-\underline{\mathrm{CH}}_{2}\right), 35.97,33.25,32.59,32.57,31.92$, $31.75,29.70,29.69,29.65,29.64,29.63,29.63,29.59,29.39,29.34,29.29,29.29,29.24$, 29.21, 29.06, 29.03, 28.84, 25.40, 22.67, 22.63, 21.73, 21.51, 14.05, 14.05; HRMS calcd for $\mathrm{C}_{39} \mathrm{H}_{71} \mathrm{~N}_{2} \mathrm{O}^{+}, \mathrm{Mr}=583.5566$, found 583.5568 .

4, 6-Dimethyl-2-tetradecyl-1-[2-(9E)-hexadec-9-enoylamidoethyl] pyridinium hexafluorophosphate 7. Yield: $81.5 \%$; ${ }^{1} \mathrm{H} \mathrm{NMR}\left(300 \mathrm{M}, \mathrm{CDCl}_{3}\right), \delta$, ppm: $7.42(s, 1 \mathrm{H}$, $\mathrm{H}-5$ pyridinium), $7.37(s, 1 \mathrm{H}, \mathrm{H}-3$ pyridinium), $6.75(t, 1 \mathrm{H}, J=6.0 \mathrm{~Hz}), 5.37(m, 2 \mathrm{H})$, $4.55(t, 2 \mathrm{H}, J=6.6 \mathrm{~Hz}), 3.62\left(d t, 2 \mathrm{H}, J=6.6 \mathrm{~Hz}, 6.3 \mathrm{~Hz}, \mathrm{CONHCH}_{2}\right), 3.17(t, 2 \mathrm{H}, J=7.5$ $\left.\mathrm{Hz}, \mathrm{C} \alpha \mathrm{Py}-\mathrm{CH}_{2}\right), 2.90$ (s, 3H, $\underline{\mathrm{CH}}_{3} \alpha$-Pyridinium), 2.54 (s, 3H, $\mathrm{CH}_{3} \gamma$-Pyridinium), 2.17 ( $t$, $2 \mathrm{H}, J=7.5 \mathrm{~Hz}, \mathrm{NHCOC}_{2}$ ), 1.95 (4H, br), 1.72 (quint., $2 \mathrm{H}, \mathrm{CaPy}-\mathrm{CH}_{2} \mathrm{CH}_{2}$ ), 1.46 (quint., $\left.2 \mathrm{H}, \mathrm{NHCOCH}_{2} \mathrm{CH}_{2}\right), 1.25\left(s, 38 \mathrm{H}, \underline{\mathrm{CH}}_{2}\right.$ from both of alkyl chains), $0.87\left(t, 6 \mathrm{H}, \mathrm{CH}_{3}\right.$ of alkyl chains); ${ }^{13} \mathrm{C} \mathrm{NMR}\left(300 \mathrm{M}, \mathrm{CDCl}_{3}\right), 174.67(\mathrm{C}=\mathrm{O}), 158.47,157.54,154.51$ (C-2, C4, C-6 pyridinium), 129.37, $129.25(\mathrm{CH}=\mathrm{CH}), 128.11,126.72$ (C-3 and $\mathrm{C}-5$ pyridium), $49.97\left(\mathrm{C} \alpha \mathrm{Py}-\underline{\mathrm{CH}}_{2}\right), 37.64\left(\mathrm{C} \beta \mathrm{Py}-\underline{\mathrm{CH}}_{2}\right), 36.38,32.67,31.35,31.21,29.17,29.11,29.09$, 29.08, 29.07, 29.02, 28.82, 28.77, 28.72, 28.70, 28.69, 28.65, 28.60, 28.55, 28.49, 28.40, 26.66, 26.65, 24.83, 22.09, 22.06, 21.14, 20.92, 13.49, 13.48; HRMS calcd for $\mathrm{C}_{39} \mathrm{H}_{71} \mathrm{~N}_{2} \mathrm{O}^{+}, \mathrm{Mr}=583.5566$, found 583.5562.

4, 6-Dimethyl-2-tetradecyl-1-(2-octadecanoylamidoethyl) pyridinium hexafluorophosphate 8. Yield: $87.5 \% ;{ }^{1} \mathrm{H} \mathrm{NMR}\left(\mathrm{CDCl}_{3}\right), \delta$, ppm: $7.41(\mathrm{~s}, 1 \mathrm{H}, \mathrm{H}-5$ pyridinium), $7.38(s, 1 \mathrm{H}, \mathrm{H}-3$ pyridinium $), 6.77(t, 1 \mathrm{H}, J=6.0 \mathrm{~Hz}), 5.37(\mathrm{~m}, 2 \mathrm{H}, \mathrm{J}=$ $19.2 \mathrm{~Hz}), 4.55(t, 2 \mathrm{H}, J=6.9 \mathrm{~Hz}), 3.62\left(d t, 2 \mathrm{H}, J=6.9\right.$ and $\left.6.0 \mathrm{~Hz}, \mathrm{CONHCH}_{2}\right), 3.17(t$, $\left.2 \mathrm{H}, J=7.2 \mathrm{~Hz}, \mathrm{C} \alpha \mathrm{Py}-\mathrm{CH}_{2}\right), 2.90\left(s, 3 \mathrm{H}, \mathrm{CH}_{3} \alpha\right.$-Pyridinium), $2.54\left(s, 3 \mathrm{H}, \mathrm{C}_{3} \gamma-\right.$ Pyridinium), 2.17 ( $\left.t, 2 \mathrm{H}, \mathrm{NHCOCH}_{2}\right), 1.95\left(4 \mathrm{H}, b r\right.$, ), 1.72 (quint., $2 \mathrm{H}, \mathrm{C \alpha Py}-\mathrm{CH}_{2} \mathrm{CH}_{2}$ ), 1.48 (quint., $\left.2 \mathrm{H}, \mathrm{NHCOCH}_{2} \mathrm{CH}_{2}\right), 1.25\left(\mathrm{~s}, 50 \mathrm{H}, \mathrm{C}_{2}\right.$ from both of alkyl chains), 0.88 ( $t$, $6 \mathrm{H}, \underline{\mathrm{CH}}_{3}$ of alkyl chains); ${ }^{13} \mathrm{C} \mathrm{NMR}\left(300 \mathrm{M}, \mathrm{CDCl}_{3}\right), 175.15(\mathrm{C}=\mathrm{O}), 159.00,158.06$, 155.03 (C-2, C-4, C-6 pyridinium), 128.64, 127.24 (C-3 and C-5 pyridium), 50.49 (CaPy- $\left.\underline{\mathrm{CH}}_{2}\right), 38.17\left(\mathrm{C} \beta \mathrm{Py}-\underline{\mathrm{CH}}_{2}\right), 35.94,33.19,31.89,31.88,29.67,29.66,29.66,29.65$, 29.64, 29.63, 29.63, 29.62, 29.61, 29.61, 29.60, 29.55, 29.49, 29.35, 29.33, 29.32, 29.31, 29.30, 29.26, 29.25, 29.22, 29.02, 25.37, 22.63, 22.63, 21.67, 21.42, 14.01, 14.01;

HRMS calcd for $\mathrm{C}_{41} \mathrm{H}_{77} \mathrm{~N}_{2} \mathrm{O}^{+}, \mathrm{Mr}=613.6036$, found 613.6036 .

\section{4, 6-Dimethyl-2-tetradecyl-1-(2-oleoylamidoethyl) pyridinium}

hexafluorophosphate 9. Yield: $62.3 \% ;{ }^{1} \mathrm{H} \mathrm{NMR}\left(\mathrm{CDCl}_{3}\right), \delta$, ppm: $7.41(s, 1 \mathrm{H}, \mathrm{H}-5$ pyridinium), $7.38(\mathrm{~s}, 1 \mathrm{H}, \mathrm{H}-3$ pyridinium), $6.77(t, 1 \mathrm{H}, J=6.0 \mathrm{~Hz}, \mathrm{CON} \underline{\mathrm{H}}), 5.33(2 \mathrm{H}, t$, $\underline{\mathrm{HC}}=\mathrm{C} \underline{\mathrm{H}}), 4.56(t, 2 \mathrm{H}, J=6.9 \mathrm{~Hz}), 3.63\left(d t, 2 \mathrm{H}, J=6.9\right.$ and $\left.6.0 \mathrm{~Hz}, \mathrm{CONHC}_{2}\right), 3.17(t$, $\left.2 \mathrm{H}, J=7.5 \mathrm{~Hz}, \mathrm{C} \alpha \mathrm{Py}-\underline{\mathrm{C}}_{2}\right), 2.90\left(s, 3 \mathrm{H}, \mathrm{CH}_{3} \alpha\right.$-Pyridinium), $2.55\left(s, 3 \mathrm{H}, \mathrm{C}_{3} \gamma-\right.$ Pyridinium), $2.18\left(t, 2 \mathrm{H}, \mathrm{NHCOC}_{2}\right), 1.99$ ( $\left.q, 4 \mathrm{H}\right), 1.72$ (quint., $2 \mathrm{H}, \mathrm{C \alpha Py}-\mathrm{CH}_{2} \underline{\mathrm{CH}}_{2}$ ), 1.47 (quint., $\left.2 \mathrm{H}, \mathrm{NHCOCH}_{2} \mathrm{CH}_{2}\right), 1.25\left(s, 42 \mathrm{H}, \mathrm{C}_{2}\right.$ from both of alkyl chains), 0.88 ( $t$, $6 \mathrm{H}, \mathrm{CH}_{3}$ of alkyl chains); ${ }^{13} \mathrm{C} \mathrm{NMR}\left(300 \mathrm{M}, \mathrm{CDCl}_{3}\right), 175.20(\mathrm{C}=\mathrm{O}), 159.07,158.13$, 155.05 (C-2, C-4, C-6 pyridinium), 129.95, $129.81(\mathrm{CH}=\mathrm{CH}), 128.68,127.31(\mathrm{C}-3$ and C-5 pyridium), $50.55\left(\mathrm{C \alpha Py}-\underline{\mathrm{CH}}_{2}\right), 38.24\left(\mathrm{C} \beta \mathrm{Py}-\underline{\mathrm{CH}}_{2}\right), 35.96,33.24,31.91,31.90,29.78$, 29.75, 29.68, 29.67, 29.66, 29.64, 29.63, 29.58, 29.51, 29.38, 29.33, 29.32, 29.29, 29.28, 
29.28, 29.26, 29.25, 29.24, 29.18, 29.06, 27.23, 25.39, 22.66, 21.71, 21.49, 14.05, 14.05; HRMS calcd for $\mathrm{C}_{41} \mathrm{H}_{75} \mathrm{~N}_{2} \mathrm{O}^{+}, \mathrm{Mr}=611.5879$, found 611.5872 .

4, 6-Dimethyl-2-tetradecyl-1-[2-(9E)-Octadec-9-enoylamidoethyl] pyridinium hexafluorophosphate 10. Yield: $56.5 \% ;{ }^{1} \mathrm{H} \mathrm{NMR}\left(\mathrm{CDCl}_{3}\right), \delta$, ppm: $7.42(s, 1 \mathrm{H}, \mathrm{H}-5$ pyridinium), $7.37(s, 1 \mathrm{H}, \mathrm{H}-3$ pyridinium $), 6.76(t, 1 \mathrm{H}, J=6.3 \mathrm{~Hz}), 5.37(t, 2 \mathrm{H}, \underline{\mathrm{HC}}=\mathrm{C} \underline{\mathrm{H}}$, $\mathrm{J}=19.2 \mathrm{~Hz}), 4.57(t, 2 \mathrm{H}, J=6.9 \mathrm{~Hz}), 3.63\left(d t, 2 \mathrm{H}, J=6.9\right.$ and $\left.6.3 \mathrm{~Hz}, \mathrm{CONHC}_{2}\right), 3.17$ $\left(t, 2 \mathrm{H}, J=7.8 \mathrm{~Hz}, \mathrm{C} \alpha \mathrm{Py}-\mathrm{C}_{2}\right), 2.90\left(s, 3 \mathrm{H}, \mathrm{CH}_{3} \alpha\right.$-Pyridinium), $2.56\left(s, 3 \mathrm{H}, \mathrm{C}_{3} \gamma-\right.$ Pyridinium), $2.18\left(t, 2 \mathrm{H}, \mathrm{NHCOC}_{2}\right), 1.99(b r, 4 \mathrm{H}), 1.74$ (quint., $2 \mathrm{H}, \mathrm{C \alpha \textrm {Py }}-\mathrm{CH}_{2} \mathrm{C}_{2}$ ), 1.46 (quint., $\left.2 \mathrm{H}, \mathrm{NHCOCH}_{2} \mathrm{CH}_{2}\right), 1.25\left(s, 42 \mathrm{H}, \mathrm{CH}_{2}\right.$ from both of alkyl chains), 0.87 ( $t$, $6 \mathrm{H}, \mathrm{CH}_{3}$ of alkyl chains); ${ }^{13} \mathrm{C}$ NMR $\left(300 \mathrm{M}, \mathrm{CDCl}_{3}\right), 175.14(\mathrm{C}=\mathrm{O}), 158.98,158.06$, 155.02 (C-2, C-4, C-6 pyridinium), 130.36, $130.21(\mathrm{CH}=\mathrm{CH}), 128.63,127.23(\mathrm{C}-3$ and C-5 pyridium), $50.47\left(\mathrm{C \alpha Py}-\mathrm{CH}_{2}\right), 38.16\left(\mathrm{C} \beta \mathrm{Py}-\mathrm{CH}_{2}\right), 35.91,33.17,32.54,32.51,31.86$, $31.84,29.62,29.63,29.62,29.61,29.60,29.59,29.58,29.53,29.42,29.34,29.28,29.23$, 29.24, 29.20, 29.18, 29.15, 29.01, 28.98, 25.34, 22.60, 22.61, 21.65, 21.41, 13.99, 13.99; HRMS calcd for $\mathrm{C}_{41} \mathrm{H}_{75} \mathrm{~N}_{2} \mathrm{O}^{+}, \mathrm{Mr}=611.5879$, found 611.5870 .

4, 6-Dimethyl-2-tetradecyl-1-[2-(11Z)-eicos-11-enoylamidoethyl] pyridinium hexafluorophosphate 11. Yield: $79.8 \% ;{ }^{1} \mathrm{H}$ NMR $\left(\mathrm{CDCl}_{3}\right), \delta$, ppm: $7.41(s, 1 \mathrm{H}, \mathrm{H}-5$ pyridinium), $7.38(\mathrm{~s}, 1 \mathrm{H}, \mathrm{H}-3$ pyridinium $), 6.78(t, 1 \mathrm{H}, J=6.3 \mathrm{~Hz}), 5.34(\mathrm{~m}, 2 \mathrm{H}$, $\underline{\mathrm{HC}}=\mathrm{C} \underline{\mathrm{H}}), 4.56(t, 2 \mathrm{H}, J=6.6 \mathrm{~Hz}), 3.63\left(d t, 2 \mathrm{H}, J=6.6\right.$ and $\left.6.3 \mathrm{~Hz}, \mathrm{CONHC}_{2}\right), 3.17(t$, $\left.2 \mathrm{H}, J=7.8 \mathrm{~Hz}, \mathrm{C \alpha Py}-\mathrm{C}_{2}\right), 2.90$ ( $s, 3 \mathrm{H}, \mathrm{C}_{3} \alpha$-Pyridinium), $2.55\left(s, 3 \mathrm{H}, \mathrm{CH}_{3} \gamma-\right.$ Pyridinium), $2.18\left(t, 2 \mathrm{H}, \mathrm{NHCOCH}_{2}\right), 1.99(b r, 4 \mathrm{H}), 1.72$ (quint., $2 \mathrm{H}, \mathrm{CaPy}-\mathrm{CH}_{2} \mathrm{CH}_{2}$ ), 1.57-1.42 ( $\left.m, 2 \mathrm{H}, \mathrm{NHCOCH}_{2} \mathrm{CH}_{2}\right), 1.25$ ( $s, 46 \mathrm{H}, \mathrm{C}_{2}$ from both of alkyl chains), 0.88 ( $t$, $6 \mathrm{H}, \mathrm{CH}_{3}$ of alkyl chains); ${ }^{13} \mathrm{C} \mathrm{NMR}\left(300 \mathrm{M}, \mathrm{CDCl}_{3}\right), 175.23(\mathrm{C}=\mathrm{O}), 159.06,158.13$, 155.06 (C-2, C-4, C-6 pyridinium), 129.90, $129.90(\mathrm{CH}=\mathrm{CH}), 128.69,127.31$ (C-3 and C-5 pyridium), $50.54\left(\mathrm{C \alpha Py}-\mathrm{CH}_{2}\right), 38.23\left(\mathrm{C} \beta \mathrm{Py}-\mathrm{CH}_{2}\right), 35.97,33.24,31.92,31.90,29.81$, 29.80, 29.78, 29.69, 29.67, 29.65, 29.64, 29.59, 29.54, 29.52, 29.50, 29.39, 29.35, 29.32, $29.30,29.29,29.29,29.28,29.24,29.06,27.25,27.23,25.41,24.78,22.66,21.72,21.49$, 14.05, 14.05; HRMS calcd for $\mathrm{C}_{43} \mathrm{H}_{79} \mathrm{~N}_{2} \mathrm{O}^{+}, \mathrm{M} r=639.6192$, found 639.6193 .

4, 6-Dimethyl-2-tetradecyl-1-[2-(11E)-eicos-11-enoylamidoethyl] pyridinium hexafluorophosphate 12. Yield: $58.8 \% ;{ }^{1} \mathrm{H} \mathrm{NMR}\left(\mathrm{CDCl}_{3}\right), \delta, \mathrm{ppm}: 7.41(s, 1 \mathrm{H}, \mathrm{H}-5$ pyridinium), $7.38(s, 1 \mathrm{H}, \mathrm{H}-3$ pyridinium $), 6.78(t, 1 \mathrm{H}, J=6.0 \mathrm{~Hz}), 5.38(t, 2 \mathrm{H}, \underline{\mathrm{HC}}=\mathrm{C} \underline{\mathrm{H}})$, $4.57(t, 2 \mathrm{H}, J=6.6 \mathrm{~Hz}), 3.64\left(d t, 2 \mathrm{H}, J=6.9\right.$ and $\left.6.0 \mathrm{~Hz}, \mathrm{CONHC}_{2}\right), 3.17(t, 2 \mathrm{H}, J=7.8$ $\left.\mathrm{Hz}, \mathrm{C} \alpha \mathrm{Py}-\underline{\mathrm{CH}}_{2}\right), 2.90$ ( $s, 3 \mathrm{H}, \underline{\mathrm{CH}}_{3} \alpha$-Pyridinium), 2.56 ( $s, 3 \mathrm{H}, \underline{\mathrm{CH}}_{3} \gamma$-Pyridinium), 2.18 ( $t$, $2 \mathrm{H}, \mathrm{NHCOC}_{2}$ ), 1.96 (br, 4H), 1.71 (quint., $2 \mathrm{H}, \mathrm{C} \alpha \mathrm{Py}-\mathrm{CH}_{2} \mathrm{CH}_{2}$ ), 1.48 (quint., $2 \mathrm{H}$, $\left.\mathrm{NHCOCH}_{2} \underline{\mathrm{CH}}_{2}\right), 1.25$ ( $s, 42 \mathrm{H}, \mathrm{C}_{2}$ from both of alkyl chains), $0.87\left(t, 6 \mathrm{H}, \mathrm{C}_{3}\right.$ of alkyl chains); ${ }^{13} \mathrm{C}$ NMR $\left(300 \mathrm{M}, \mathrm{CDCl}_{3}\right), 175.27(\mathrm{C}=\mathrm{O}), 159.11,158.16,155.04(\mathrm{C}-2, \mathrm{C}-4, \mathrm{C}-$ 6 pyridinium), 130.36, $130.36(\mathrm{C}=\mathrm{C}), 128.68,127.35$ (C-3 and $\mathrm{C}-5$ pyridium $), 50.59$

$\left(\mathrm{C \alpha Py}-\underline{\mathrm{CH}}_{2}\right), 38.27\left(\mathrm{C} \beta \mathrm{Py}-\underline{\mathrm{CH}}_{2}\right), 35.98,33.28,32.60,31.92,31.91,29.70,29.69,29.69$, 29.68, 29.68, 29.67, 29.67, 29.66, 29.65, 29.64, 29.59, 29.49, 29.49, 29.39, 29.35, 29.32, 29.30, 29.29, 29.19, 29.07, 25.40, 25.40, 22.66, 22.66, 21.74, 21.54, 14.05, 14.05; HRMS calcd for $\mathrm{C}_{43} \mathrm{H}_{79} \mathrm{~N}_{2} \mathrm{O}^{+}, \mathrm{Mr}=639.6192$, found 639.6196. 
4, 6-Dimethyl-2-tetradecyl-1-[2-(2-heptyl-undecanoyl)-amidoethyl] pyridinium hexafluorophosphate 13. Yield: $77.3 \% ;{ }^{1} \mathrm{H} \mathrm{NMR}\left(\mathrm{CDCl}_{3}\right), \delta$, ppm: 7.41 (s, 1H, H-5 pyridinium), 7.37 (s, 1H, H-3 pyridinium), $6.78(1 \mathrm{H}, \mathrm{t}, 1 \mathrm{H}, J=6.3 \mathrm{~Hz}), 4.55(\mathrm{t}$, $2 \mathrm{H}, J=6.6 \mathrm{~Hz}), 3.66\left(\mathrm{dt}, 2 \mathrm{H}, J=6.6\right.$ and $\left.6.6 \mathrm{~Hz}, \mathrm{CONHCH}_{2}\right), 3.22(\mathrm{t}, 2 \mathrm{H}, J=6.9 \mathrm{~Hz}$, $\mathrm{C} \alpha \mathrm{Py}-\mathrm{C}_{2}$ ), 2.93 (s, 3H, $\underline{\mathrm{C}}_{3} \alpha$-Pyridinium), 2.55 (s, 3H, $\underline{\mathrm{C}}_{3} \gamma$-Pyridinium), 2.12 (quint., $1 \mathrm{H}, \mathrm{NHCOC} \underline{\mathrm{H}}$ ), 1.71 (quint., $2 \mathrm{H}, \mathrm{C} \alpha \mathrm{Py}-\mathrm{CH}_{2} \underline{\mathrm{C}}_{2}$ ), 1.46 (quint., $\left.4 \mathrm{H}, \mathrm{NHCOCH}\left(\mathrm{C}_{2}\right)_{2}\right)$, 1.25 and 1.23 (s, s, $46 \mathrm{H}, \mathrm{CH}_{2}$ from both of alkyl chains), 0.88-0.84 (m, 9H, $\mathrm{CH}_{3}$ of alkyl chains); ${ }^{13} \mathrm{C}$ NMR $\left(300 \mathrm{M}, \mathrm{CDCl}_{3}\right), 178.24(\mathrm{C}=\mathrm{O}), 159.01,158.01,155.21(\mathrm{C}-2, \mathrm{C}-4, \mathrm{C}-6$ pyridinium), 128.71, 127.25 (C-3 and $\mathrm{C}-5$ pyridium), 50.51 ( $\left.\mathrm{C} \alpha \mathrm{Py}-\mathrm{CH}_{2}\right), 47.17$

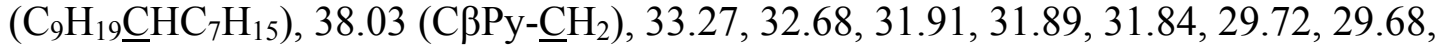
29.67, 29.66, 29.65, 29.65, 29.61, 29.61, 29.60, 29.53, 29.42, 29.34, 29.33, 29.30, 29.71, $29.11,29.06,27.45,27.38,27.42,26.77,22.65,22.62,21.65,21.44,14.04,14.04$; HRMS calcd for $\mathrm{C}_{41} \mathrm{H}_{77} \mathrm{~N}_{2} \mathrm{O}^{+}, \mathrm{Mr}=613.6035$, found 613.6037 .

\subsubsection{Synthesis of Pyridinium Ester Cationic Lipids 14-18}

Hydroxyethylpyridinium hexafluorophosphate 3, compounds 14 and 16 were synthesized as the described method (32) and the spectra are the same as those reported in ref. 25.

4, 6-Dimethyl-2-tetradecyl-1-(2-pentadecanoylhydroxyethyl) pyridinium hexafluorophosphate 15. Yield: $72.0 \% ;{ }^{1} \mathrm{H} \mathrm{NMR}\left(\mathrm{CDCl}_{3}\right), \delta$, ppm: $7.44(\mathrm{~s}, 1 \mathrm{H}, \mathrm{H}-5$ pyridinium), 7.39 (s, $1 \mathrm{H}, \mathrm{H}-3$ pyridinium), 4.80 (t, $\left.2 \mathrm{H}, J=5.7 \mathrm{~Hz}, \mathrm{COOC} \underline{\mathrm{H}}_{2}\right), 4.47$ (t, $2 \mathrm{H}$, $J=5.7 \mathrm{z}$ ), 3.04 (t, $\left.2 \mathrm{H}, J=7.8 \mathrm{~Hz}, \mathrm{C} \alpha \mathrm{Py}-\mathrm{C}_{2}\right), 2.87$ (s, 3H, $\underline{\mathrm{H}}_{3} \delta$-Pyridinium), 2.55 (s, $3 \mathrm{H}, \mathrm{CH}_{3} \gamma$-Pyridinium), 2.25 (t, $\left.2 \mathrm{H}, J=7.5 \mathrm{~Hz}, \mathrm{COC}_{2}\right), 1.79(\mathrm{cv}, 2 \mathrm{H}, J=7.5 \mathrm{~Hz}),$, (cv, $\left.2 \overline{\mathrm{H}}, \mathrm{COCH}_{2} \mathrm{CH}_{2}\right), 1.25,1.26\left(\mathrm{~s}, 44 \mathrm{H}, \mathrm{CH}_{2}\right.$ from both of alkyl chains), $0.88(\mathrm{t}, 6 \mathrm{H}$, $\mathrm{C}_{3}$ of alkyl chains $) ;{ }^{13} \mathrm{C}$ NMR $\left(300 \mathrm{M}, \mathrm{CDCl}_{3}\right), 173.00(\mathrm{C}=\mathrm{O}), 158.63,158.56,155.43$ (C-2, C-4, C-6 pyridinium), 128.81, 126.90 (C-3 and C-5 pyridium), $60.68\left(\mathrm{C} \alpha \mathrm{Py}-\underline{\mathrm{CH}}_{2}\right)$, $49.94\left(\mathrm{C} \beta \mathrm{Py}-\mathrm{CH}_{2}\right), 33.76,33.38,31.92,29.68,29.68,29.67,29.67,29.66,29.66,29.65$, 29.65, 29.64, 29.60, 29.59, 29.59, 29.58, 29.45, 29.36, 29.35, 29.34, 29.22, 29.19, 29.06, 28.37, 24.64, 22.67, 21.77, 21.63, 14.06, 14.06; HRMS calcd for $\mathrm{C}_{38} \mathrm{H}_{70} \mathrm{NO}_{2}{ }^{+}, \mathrm{Mr}=$ 572.5406 , found 572.5404 .

4, 6-Dimethyl-2-tetradecyl-1-(2-octadecanoylhydroxyethyl) pyridinium hexafluorophosphate 17. Yield: $70.1 \% ;{ }^{1} \mathrm{H} \mathrm{NMR}\left(\mathrm{CDCl}_{3}\right), \delta$, ppm: $7.43(s, 1 \mathrm{H}, \mathrm{H}-5$ pyridinium), $7.40(s, 1 \mathrm{H}, \mathrm{H}-3$ pyridinium $), 4.81\left(t, 2 \mathrm{H}, J=6.0 \mathrm{~Hz}, \mathrm{COOC} \underline{\mathrm{H}}_{2}\right), 4.49(t, 2 \mathrm{H}$, $J=6.0 \mathrm{z}), 3.06\left(t, 2 \mathrm{H}, J=7.5 \mathrm{~Hz}, \mathrm{C} \alpha \mathrm{Py}-\underline{\mathrm{CH}}_{2}\right), 2.89$ ( $s, 3 \mathrm{H}, \mathrm{C}_{3} \alpha$-Pyridinium), 2.57 ( $s$, $3 \mathrm{H}, \underline{\mathrm{CH}}_{3} \gamma$-Pyridinium), $2.26\left(t, 2 \mathrm{H}, J=7.5 \mathrm{~Hz}, \mathrm{COC}_{2}\right.$ ), 1.81 (quint., $2 \mathrm{H}, \mathrm{C} \alpha \mathrm{Py}-$ $\mathrm{CH}_{2} \mathrm{CH}_{2}$ ), 1.49 (quint., $2 \mathrm{H}, \mathrm{COCH}_{2} \mathrm{CH}_{2}$ ), 1.26, 1.27 (s, 50H, $\mathrm{C}_{2}$ from both of alkyl chains $), 0.88\left(t, 6 \mathrm{H}, \underline{\mathrm{CH}}_{3}\right.$ of alkyl chains); ${ }^{13} \mathrm{C} \mathrm{NMR}\left(300 \mathrm{M}, \mathrm{CDCl}_{3}\right), 173.00(\mathrm{C}=\mathrm{O})$, 158.64, 158.55, 155.43 (C-2, C-4, C-6 pyridinium), 128.80, 126.90 (C-3 and C-5 pyridium), $60.68\left(\mathrm{C \alpha Py}-\underline{\mathrm{CH}}_{2}\right), 49.95\left(\mathrm{C} \beta \mathrm{Py}-\underline{\mathrm{CH}}_{2}\right), 33.76,33.38,31.92,31.92,29.70$, 29.69, 29.69, 29.69, 29.68, 29.68, 29.67, 29.66, 29.65, 29.65, 29.64, 29.60, 29.58, 29.45, $29.35,29.35,29.34,29.22,29.19,29.06,28.37,24.65,24.65,22.67,22.67,21.77,21.63$, 14.05, 14.05; HRMS calcd for $\mathrm{C}_{41} \mathrm{H}_{76} \mathrm{NO}_{2}{ }^{+}, \mathrm{Mr}=614.5875$, found 614.5880. 
4, 6-dimethyl-2-tetradecyl-1-(2-oleoylhydroxyethyl) pyridinium

hexafluorophosphate 18. Yield 69.5\%; ${ }^{1} \mathrm{H}$ NMR $\left(\mathrm{CDCl}_{3}\right), \delta$, ppm: $7.43(\mathrm{~s}, 1 \mathrm{H}, \mathrm{H}-5$ pyridinium), $7.39(\mathrm{~s}, 1 \mathrm{H}, \mathrm{H}-3$ pyridinium $), 5.33(\mathrm{~m}, 2 \mathrm{H}, \mathrm{CH}$ from double bond in oleyl group), $4.80\left(t, 2 \mathrm{H}, J=6.0 \mathrm{~Hz}, \mathrm{COOC}_{2}\right), 4.47(t, 2 \mathrm{H}, J=6.0 \mathrm{~Hz}), 3.05(t, 2 \mathrm{H}, J=7.5$ $\left.\mathrm{Hz}, \mathrm{C} \alpha \mathrm{Py}-\mathrm{C}_{2}\right), 2.87$ ( $s, 3 \mathrm{H}, \underline{\mathrm{CH}}_{3} \alpha$-Pyridinium), 2.55 ( $s, 3 \mathrm{H}, \mathrm{C}_{3} \gamma$-Pyridinium), 2.25 (t, $2 \mathrm{H}, J=7.8 \mathrm{~Hz}, \mathrm{COCH}_{2}$ ), 1.99 (q, 4H), 1.79 (quint., $2 \mathrm{H}, \mathrm{CaPy}-\mathrm{CH}_{2} \mathrm{CH}_{2}$ ), 1.48 (quint., $2 \mathrm{H}$, $\left.\mathrm{COCH}_{2} \mathrm{CH}_{2}\right), 1.26\left(s, 44 \mathrm{H}, \mathrm{CH}_{2}\right.$ from both of alkyl chains $), 0.88\left(t, 6 \mathrm{H}, \mathrm{CH}_{3}\right.$ of alkyl chains); ${ }^{13} \mathrm{C}$ NMR (300 M, $\left.\overline{\mathrm{CDCl}}_{3}\right), 172.99(\mathrm{C}=\mathrm{O}), 158.75,158.62,155.52(\mathrm{C}-2, \mathrm{C}-4, \mathrm{C}-6$ pyridinium), 130.15, $129.59(\mathrm{CH}=\mathrm{CH}), 128.76,126.90(\mathrm{C}-3$ and $\mathrm{C}-5$ pyridium $), 60.70$ $\left(\mathrm{C} \alpha \mathrm{Py}-\underline{\mathrm{CH}}_{2}\right), 50.09$ (CßPy- $\left.\mathrm{CH}_{2}\right), 33.75,33.42,31.92,31.90,29.76,29.68,29.68,29.67$, $29.67,29.65,29.63,29.57,29.51,29.44,29.35,29.34,29.33,29.29,29.20,29.19,29.12$, 29.07, 29.02, 28.41, 27.25, 27.16, 24.64, 22.66, 21.79, 14.04, 14.04; HRMS calcd for $\mathrm{C}_{41} \mathrm{H}_{74} \mathrm{NO}_{2}{ }^{+}, \mathrm{Mr}=612.5719$, found 612.5725.

\subsubsection{Determination of Lipid Phase Transition Temperature and Melting Point}

Differential Scanning Calorimetry (DSC) studies were carried out to find the phase transition temperature and melting point with a DSC Q2000, TA Instruments (UK). About $5 \mathrm{mg}$ of pyridinium lipid or lipid mixture was scanned from 0 to $100{ }^{\circ} \mathrm{C}$ at a scan rate of $2{ }^{\circ} \mathrm{C} / \mathrm{min}$. Data were analyzed using Universal Analysis software provided by TA instruments.

\subsubsection{Preparation of Pyridinium Liposomes and Lipoplexes}

A pyridinium lipid was dissolved in chloroform with a co-lipid, DOPE or Chol, at the molar ratio of $1: 1,2: 1$ and $4: 1$ to reach a final concentration of $1 \mathrm{mg} / \mathrm{mL}$ for the charged species. The solvent was removed by rotary evaporation and further dried under vacuum overnight to generate a thin lipid film. The lipid film was hydrated in sterile water at $60{ }^{\circ} \mathrm{C}$, vortexed, and sonicated to yield cationic liposomes. Pyridinium liposomes were characterized for DNA condensation efficiency, particle size, and $\zeta$ potential as described previously (114). Briefly, DNA condensation was determined by $0.6 \%$ agarose gel electrophoresis at $10 \mathrm{~V} / \mathrm{cm}$ for $100 \mathrm{~min}$ in $1 \times \mathrm{TBE}$ buffer, followed by ethidium bromide (EtBr) staining. The particle size and $\zeta$-potential of cationic liposomes and lipoplexes were determined at $25^{\circ} \mathrm{C}$ by dynamic light scattering using Malvern Zetasizer ${ }^{\circledR}$ (Malvern Instruments, UK).

\subsubsection{In Vitro Transfection}

CHO cells were seeded in 24-well plates, and maintained in $0.5 \mathrm{~mL}$ of RPMI 1640 medium containing $10 \%$ fetal bovine serum (FBS) under $5 \% \mathrm{CO}_{2}$ at $37{ }^{\circ} \mathrm{C}$ for $24 \mathrm{~h}$. The cell number was about $4 \times 10^{4}$ cells per well. GFP or luciferase expression plasmid (pCMS-EGFP or pDNA3-Luc) and cationic liposomes (different formulations) were diluted to $25 \mu \mathrm{l}$ by Opti-MEM® I Medium, respectively, and incubated for $5 \mathrm{~min}$ at room 
temperature. Lipoplexes were prepared by mixing plasmid and liposomes in equal volume, and incubated for $20 \mathrm{~min}$ at room temperature to allow complex formation. Immediately before transfection, the media was removed, and cells were washed gently with sterile Phosphate Buffered Saline (PBS). Lipoplexes were added to each well, diluted to $0.5 \mathrm{~mL}$ by Opti-MEM ${ }^{\circledR}$ I Medium, and the plate was incubated under $5 \% \mathrm{CO}_{2}$ at $37^{\circ} \mathrm{C}$ for $6 \mathrm{~h}$. Following transfection, the culture medium was replaced with RPMI 1640 medium containing 10\% FBS. GFP gene expression was observed under fluorescence microscopy (Olympus, Japan).

For luciferase expression, the cells were collected and lysed. The cell lysate were measured for luciferase gene expression by Luciferase Assay Kit (Promega, Madison, WI). The total protein concentration was measured by bicinchoninic acid (BCA) Protein Assay Reagent (Pierce, Rockford, IL). Luciferase activity was normalized by the total protein content and expressed as relative light unit (RLU) per $\mu \mathrm{g}$ of protein (RLU/ $\mu \mathrm{g}$ protein).

To determine whether the presence of serum in the culture media affects the transfection efficiency of pyridinium lipids, we used RPMI 1640 culture medium containing $0,5,10,15,20,30$ and $40 \%$ FBS for transfection of CHO cells with pyridinium lipid-based lipoplexes and their transfection efficiencies were determined. To determine the effect of cell types on gene transfer, two more cell lines were used to determine transfection efficiency and cytotoxicity. Hepatocarcinoma cells (CRL 1830) were seeded with $0.5 \mathrm{~mL}$ of DMEM medium containing $10 \% \mathrm{FBS}$ under $5 \% \mathrm{CO}_{2}$ at 37 ${ }^{\circ} \mathrm{C}$. Prostate cancer cells (C4-2) cells seeded with RPMI 1640 medium containing 10\% FBS under $5 \% \mathrm{CO}_{2}$ at $37{ }^{\circ} \mathrm{C}$. The cell number was about $4 \times 10^{4}$ cells per well for 24 well plate for both of them. Luciferase expression and cytotoxicity were measured at the end of the transfection.

To determine the cellular uptake of siRNA using pyridinium lipids, the Alexa Fluor ${ }^{\circledR}$ Red fluorescent siRNA was mixed with pyridinium liposome (7D1) at the charge ratio of 3:1 (+/-) to produce the siRNA/cationic liposome (CL) complexes according to the same procedure of the lipoplexes. After addition of the siRNA/CL complexes into the $\mathrm{CHO}$ cells, we took the picture using fluorescence microscopy at $2 \mathrm{~h}, 4 \mathrm{~h}$, and $24 \mathrm{~h}$.

To make luciferase expression prostate cancer (C4-2) cells, cells were seeded in cell culture plate $24 \mathrm{~h}$ before being transfected with $\mathrm{pRc} / \mathrm{CMV} 2-\mathrm{Luc}$ plasmid (from Dr. Shu Wang, National University of Singapore) for $18 \mathrm{~h}$. Two days after transfection, cells were transferred into a T-25 cell culture flask and selected with $600 \mu \mathrm{g} / \mathrm{mL}$ G418. The resulting bioluminescent cells were maintained in media containing $300 \mu \mathrm{g} / \mathrm{mL}$ G418. To determine the gene silencing of siRNA using pyridinium lipids, luciferase siRNA was mixed with pyridinium liposome (7D1) at the charge ratio of $3: 1(+/-)$ to produce the siRNA/CL complexes according to the same procedure of the lipoplexes. The luciferase engineered C4-2 cells was seeded in the 24-well plate $24 \mathrm{~h}$ at the density of $4 \times 10^{4}$ cells per well before transfection of luciferase siRNA. The siRNA/CL complexes were transfected into $\mathrm{C} 4-2$ cells using the same protocol as the plasmid. The luciferase level was measured after $48 \mathrm{~h}$. 


\subsubsection{Cytotoxicity Assay}

The cytotoxicity of lipoplexes at $48 \mathrm{~h}$ post-transfection was determined using 3[4,5-dimethylthiazol-2-yl]-2,5-diphenyltetrazolium bromide (MTT) assay in CHO cells. Briefly $5 \mathrm{mg} / \mathrm{mL}$ stock solution of MTT in PBS was diluted 1:10 with complete growth medium. Four hours before the end of transfection study, cell culture medium was removed and replaced by MTT medium to achieve a final concentration of $0.5 \mathrm{mg} / \mathrm{mL}$ MTT. The plate was then incubated at $37{ }^{\circ} \mathrm{C}$ in $5 \% \mathrm{CO}_{2}$ for $4 \mathrm{~h}$. The medium was removed, blotted dry, and $200 \mu \mathrm{L}$ of DMSO was added to each well to dissolve the formazan crystals. Finally the plate was read spectrophotometrically at $560 \mathrm{~nm}$ using a microplate reader (Bio-Rad, Hercules, CA). The relative cell viability was calculated as $[\mathrm{Abs}]_{\text {sample }} /[\mathrm{Abs}]_{\mathrm{control}} \times 100 \%$.

\subsubsection{Statistical Analysis}

Data were expressed as the mean \pm standard deviation (SD). The difference between any two groups was determined by ANOVA. $\mathrm{P}<0.05$ was considered statistically significant.

\subsection{RESULTS}

\subsubsection{Synthesis of Pyridinium Lipids}

The goal of this study was to synthesize a series of pyridinium lipids to determine the structure-activity relationship for enhanced gene delivery. All of these cationic lipids contain a heterocyclic pyridinium ring linked to a single alkyl chain fatty acid of different alkyl chain lengths (C14, C15, C16, C18 and C20), types (cis and trans isomers) and branched chain via ester and amide spacers. We synthesized not only the saturated and unsaturated even number carbon chain length but also carbon chain length of 15 (odd number) saturated analog and branched carbon chain saturated analog. Synthesis scheme of pyridinium lipids is shown in Figure 3.1. Briefly, mesityl oxide was monoacylated to yield pyrylium chloroaluminates, which were converted into pyrylium hexafluorophosphates (1) by hexafluorophosphoric acid. Pyrylium hexafluorophosphate was used as a key intermediate for reaction with different primary amines to form a pyridinium heterocyclic ring with different linkers in the final structure. Acylation of these pyridinium salts with different lengths and types of fatty acid chlorides afforded the final pyridinium lipids. Intermediate and final products of these pyridinium lipids were characterized by ${ }^{1} \mathrm{H}$ NMR, ${ }^{13} \mathrm{C}$ NMR and high-resolution mass spectrometry, and these results are included in the methods section.

The structures with minimized energy of these lipids are listed in Table 3.1. Two side chains are much closer in energy minimized structures of unsaturated lipids than those of saturated lipids, which may facilitate the formation of lipid bilayers in 
liposomes. The melting points of these lipids are listed in Table 3.1. More than half of these pyridinium lipids have melting points of more than $60^{\circ} \mathrm{C}$. Increase in fatty acid chain length increased the melting point. Saturated lipids have higher melting points than unsaturated lipids except branched one. For unsaturated lipids, melting point of transisomer is higher than that of cis-isomer of the same fatty acid chain length. Lipid phase transition temperatures of pure pyridinium lipids and lipid mixture are listed in Table 3.2. The lipids with amide linker showed lower phase transition temperature compared to lipids with ester linker. Increase in hydrophobic carbon chain length increased the phase transition temperature. At the same carbon chain length the phase transition temperature of trans isomer was higher than that of cis isomer. Phase transition temperature was higher when formulated with cholesterol than that when formulated with DOPE. Higher phase transition temperature makes liposome preparation difficult by rehydration of lipid films and extrusion. Therefore, probe sonication was used to produce small unilamellar vesicles (SUV) at $60^{\circ} \mathrm{C}$. Sterile water was used as the suspension medium in cationic liposome preparation so as to prevent cationic liposome aggregation in long term storage in electrolytical buffer.

\subsubsection{Preparation and Characterization of Lipoplexes}

Transfection efficiency of lipoplexes is known to depend on the particle size and surface charge of liposomes and lipoplexes $(166,167)$. Therefore, we determined the mean particle size, particle size distribution (PSD) and $\zeta$-potential of pyridinium liposomes prepared using different co-lipids and molar ratios of cationic lipid/co-lipid. The mean particle size of these liposomes was about $97.98 \pm 4.31 \mathrm{~nm}$, with the polydispersity index (PDI) of $0.32 \pm 0.03$, and $\zeta$-potential was $41.33 \pm 4.10 \mathrm{mv}$ (Table 3.3). This suggests little difference in particle size and $\zeta$-potential among different liposome preparations. Pyridinium liposomes were stable and no aggregation was observed at $4{ }^{\circ} \mathrm{C}$ during the experimental period. Lipoplexes were formed by simple mixing pyridinium liposomes and plasmid DNA. The degree of DNA condensation increased with the increase in charge ratio. However, migration of some free DNA was seen when lipoplexes were prepared at $0.5 / 1$ to $2.5 / 1(+/-)$. At the charge ratio of $3: 1(+/-)$ or above plasmid DNA was completely condensed in all the formulations, as evidenced by no band shift upon agarose gel electrophoresis of lipoplexes (data not shown). Upon lipoplex formation, the particle size, polydispersity index and $\zeta$-potential of lipoplexes were determined and found to be $124.33 \pm 2.08 \mathrm{~nm}, 0.17 \pm 0.02$ and $28.07 \pm 5.12 \mathrm{mv}$, respectively. Particle size distribution of lipoplexes $(<200 \mathrm{~nm})$ was more than $90 \%$ at $0 \mathrm{~h}$ and more than $80 \%$ after $10 \mathrm{~h}$. There was no significant change in the particle size, particle size distribution and $\zeta$-potential even at $10 \mathrm{~h}$ post-incubation at room temperature, suggesting these lipoplexes are fairly stable on storage.

\subsubsection{Factors Influencing Transfection}

The effect of various structure and formulation parameters on in vitro transfection efficiency of pyridinium lipids in $\mathrm{CHO}$ cells was examined as a function of linker (ester 
Table 3.2 Determination of lipid phase transition temperature $\left({ }^{\circ} \mathrm{C}\right)$ by DSC.

\begin{tabular}{|c|c|c|c|c|}
\hline \multirow{2}{*}{$\begin{array}{l}\text { Type of hydrophobic } \\
\text { anchor chain }\end{array}$} & \multicolumn{2}{|c|}{ Linker } & \multicolumn{2}{|c|}{$\begin{array}{l}\text { Lipid, amide linker/Co-lipid } \\
\text { (molar ratio 1:1) }\end{array}$} \\
\hline & Ester & Amide & DOPE & CHOL \\
\hline C14:0 & $45.5-47.5$ & $38.9-44.9$ & $18.2-21.4$ & $32.9-35.2$ \\
\hline C16:0 & $63.5-66.1$ & $39.3-41.4$ & $37.8-40.0$ & $40.2-42.1$ \\
\hline $\mathrm{C} 16: 1$, cis & & $29.7-31.1$ & & \\
\hline $\mathrm{C} 16: 1$, trans & & $35.7-36.7$ & & \\
\hline C18:0 & $73.4-74.1$ & $45.4-48.7$ & $24.2-26.3$ & $42.1-46.5$ \\
\hline $\mathrm{C} 18: 1$, cis & & $31.4-32.1$ & & \\
\hline $\mathrm{C} 18: 1$, trans & & $34.1-37.9$ & & \\
\hline $\mathrm{C} 20: 1$, cis & & $36.7-39.6$ & & \\
\hline $\mathrm{C} 20: 1$, trans & & $37.4-41.3$ & & \\
\hline
\end{tabular}

Values are "onset to peak temperature".

N/A: no significant phase transition temperature was observed. 
Table 3.3 Particle size and $\zeta$-potential of pyridinium cationic liposome and lipoplexes.

\begin{tabular}{cccc}
\hline Parameters & $\begin{array}{c}\text { Pyridinium cationic } \\
\text { liposomes }\end{array}$ & Lipoplexes (0h) & Lipoplexes (10h) \\
\hline Particle size (nm) & $97.98 \pm 4.31$ & $124.33 \pm 2.08$ & $128.33 \pm 1.53$ \\
PDI & $0.32 \pm 0.03$ & $0.17 \pm 0.02$ & $0.15 \pm 0.02$ \\
PSD $(<200 \mathrm{~nm})$ & $>95 \%$ & $>90 \%$ & $>80 \%$ \\
$\zeta$-potential $(\mathrm{mv})$ & $41.33 \pm 4.10$ & $28.07 \pm 5.12$ & $31.17 \pm 5.50$ \\
\hline
\end{tabular}

PDI: polydispersion index; PSD: particle size distribution 
vs. amide), hydrophobic carbon chain length (14, 16 and 18) and type (single vs. double), configuration of double bond (cis-isomer vs. trans-isomer), co-lipid type (DOPE vs. Chol), cationic lipid/co-lipid molar ratio $(1: 1,2: 1$ and $4: 1)$ and cationic lipid/DNA (+/-) charge $(1: 1,3: 1$ and $5: 1)$ ratio. Lipofectamine is one of the most commonly used transfection reagents and thus we selected this as the positive control for screening of our pyridinium lipids. Our purpose was to optimize our own cationic liposome formulations, not the transfection conditions of Lipofectamine. Therefore, we formulated Lipofectamine/plasmid complexes at 3/1 (+/-) charge ratio, which is in the range of the recommended conditions by the manufacturer. Transfection efficiency was reported as relative light units (RLU) per $\mu \mathrm{g}$ of total protein content.

\subsubsection{Charge Ratios}

Pyridinium lipid (C16:0, amide linker) was mixed with Chol at the cationic lipid/co-lipid ratio of 1:1 to prepare cationic liposomes, and lipoplexes were prepared by mixing with luciferase plasmid at the charge ratio of 1:1, 3:1 and 5:1 (+/-). Luciferase gene expression (Figure 3.2A) and cytotoxicity (Figure 3.2B) in CHO cells were determined at $48 \mathrm{~h}$ post-transfection. Luciferase gene expression levels increased with increasing lipid/DNA charge ratios from 1:1 to 5:1, while cell viability decreased slightly with increase in charge ratio to 5:1 (+/-). Compared to Lipofectamine, much higher transfection efficiency was observed at the charge ratios of 3:1 and 5:1(+/-) groups but there was no significant difference between 3:1 and 5:1. Further, there was no significant difference in cytotoxicity between pyridinium liposomes and Lipofectamine.

\subsubsection{Type of Linkers}

Pyridinium lipids (C16:0 with ester and amide linkers) were used to prepare liposomes with DOPE and Chol at the cationic lipid/co-lipid molar ratio of 1:1. Following transfection of CHO cells with lipoplexes $(3: 1,+/-)$, GFP positive CHO cells were visualized under fluorescence microscopy at $48 \mathrm{~h}$ post-transfection. The cationic lipids with amide linkers significantly increased transfection efficiency in all liposomal formulations in $\mathrm{CHO}$ cells compared to their counterparts with ester linker, as evidenced by much higher levels of green fluorescence. This trend was confirmed by luciferase gene expression. (Figure 3.3).

\subsubsection{Cationic Lipid:Co-lipid Molar Ratios}

Pyridinium lipid with C16:0 fatty acid chain and amide linker was used to formulate liposomes with cholesterol at cationic lipid/co-lipid molar ratio of 1:1, 2:1 and $4: 1$, and lipoplexes were prepared at the charge ratio of $3: 1(+/-)$. At $48 \mathrm{~h}$ post-transfection, luciferase gene expression (Figure 3.4A) and cytotoxicity (Figure 3.4B) were measured. Pyridinium liposomes prepared at 1:1 and 2:1 cationic lipid/co-lipid molar ratios showed higher transfection efficiency compared to 4:1 molar ratio and Lipofectamine. Cell viability slightly decreased when the molar ratio of pyridinium lipid to Chol increased but no difference compared to Lipofectamine. So we decided to select 1:1 cationic lipid/colipid molar ratio to prepare liposomes for further studies. 


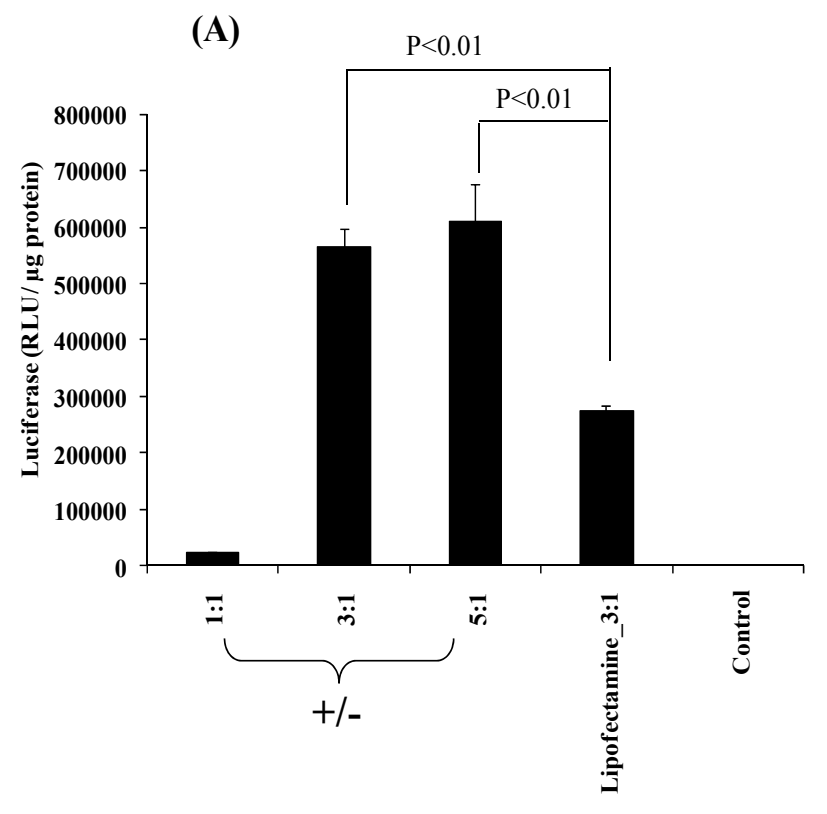

(B)

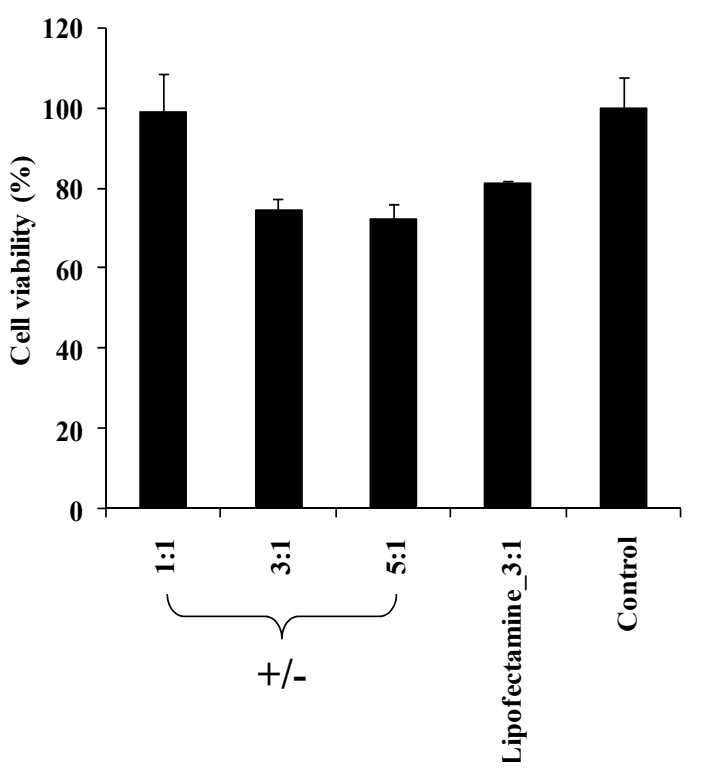

Figure 3.2 Effect of charge ratios on the transfection (A) and cytotoxicity (B) of CHO cells at $48 \mathrm{~h}$ after transfection of lipoplexes.

Pyridinium lipid 5 (C16:0, amide linker, trans-isomer) was mixed with cholesterol (Chol) at the cationic lipid/co-lipid ratio of 1:1 to prepare cationic liposomes, and lipoplexes were prepared by mixing with luciferase plasmid at the charge ratio of 1:1, 3:1 and 5:1 (+/-). Luciferase gene expression and cytotoxicity in $\mathrm{CHO}$ cells were determined after $48 \mathrm{~h}$ post-transfection. The dose of pcDNA3-Luc plasmid was $0.2 \mu \mathrm{g} /$ well for $4 \times$ $10^{4}$ cells. 
(A)

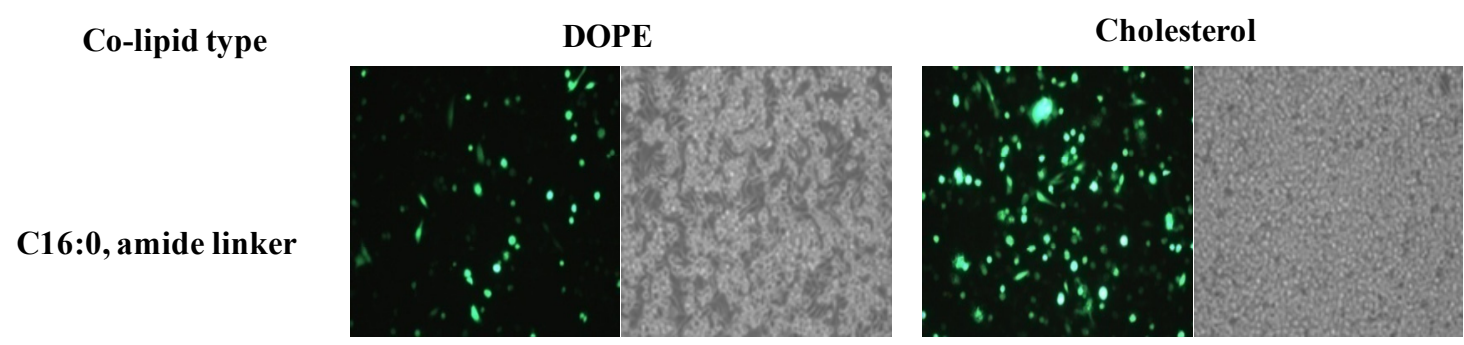

C16:0, ester linker
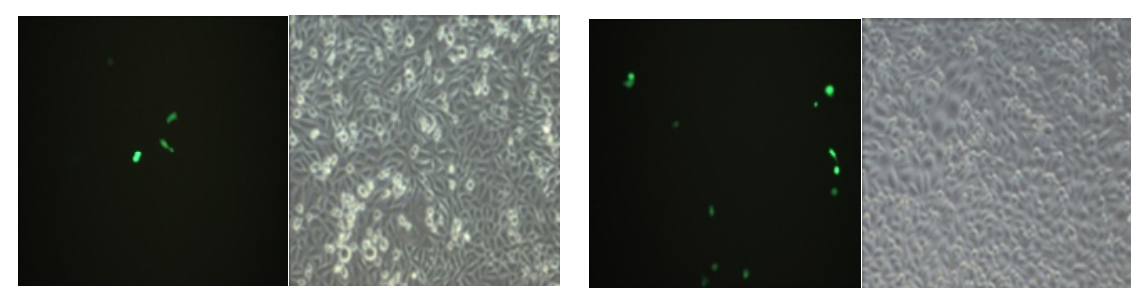

(B)
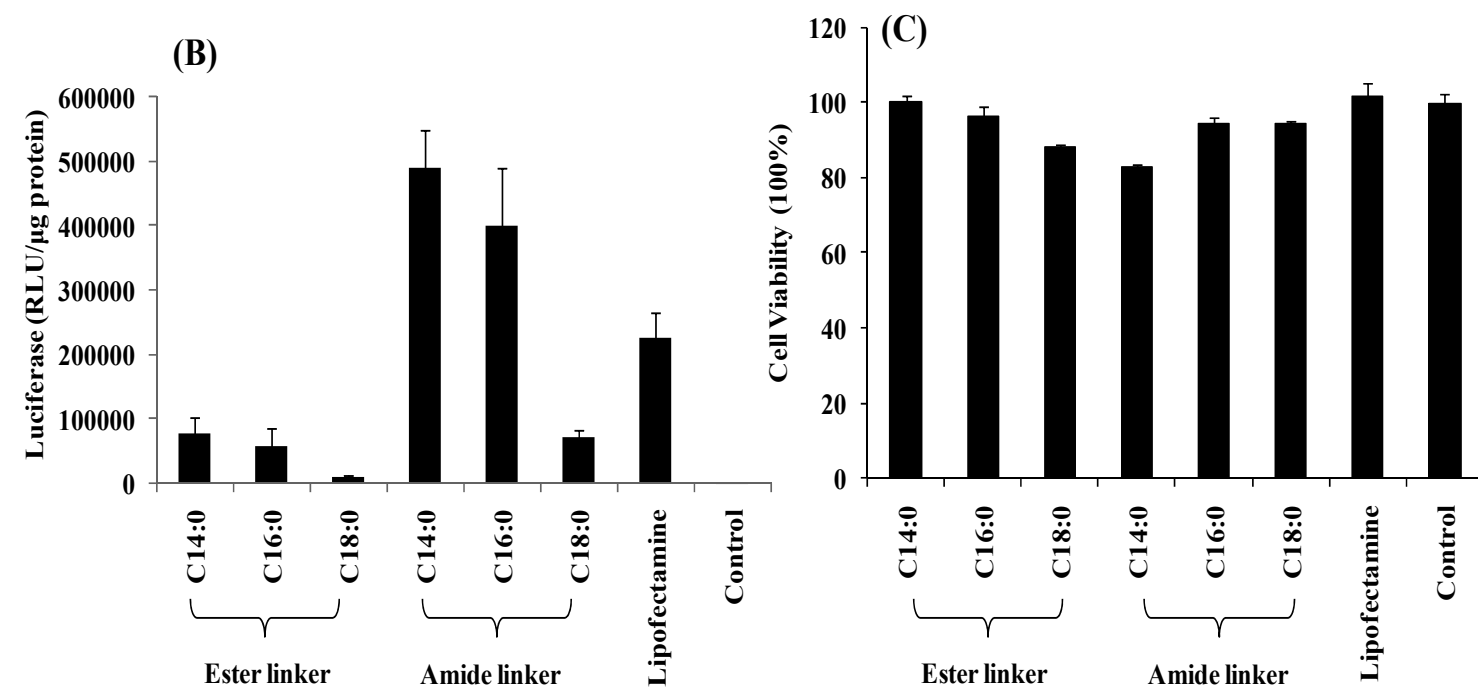

Figure 3.3 Effect of linker type on GFP gene (A) and luciferase gene (B) transfection efficiency and cytotoxicity $(C)$ at $48 \mathrm{~h}$ after transfection of lipoplexes. For 2.3A, C16:0 lipid with amide linker and C16:0 lipid with ester linker were used to prepare cationic liposomes with co-lipid DOPE and cholesterol at the molar ratio of 1:1. Lipoplexes were formed by mixing with GFP plasmid at the charge ratio of 3:1 (+/-). GFP gene expression was observed at $48 \mathrm{~h}$ after transfection under fluorescence microscopy and normal light as control. The dose of pCMS-EGFP plasmid was 0.4 $\mu \mathrm{g} /$ well for $4 \times 10^{4}$ cells.

For 2.3B and 2.3C, Lipids with easter linker and lipids with amide linker were used to prepare cationic liposomes with DOPE at the molar ratio of 1:1. Lipoplexes were formed by mixing with luciferase plasmid at the charge ratio of 3:1 (+/-). Luciferase gene expression (B) and cytotoxicity (C) in CHO cells were determined at $48 \mathrm{~h}$ after transfection. The dose of pcDNA3-Luc plasmid was $0.2 \mu \mathrm{g} /$ well for $4 \times 10^{4}$ cells. 

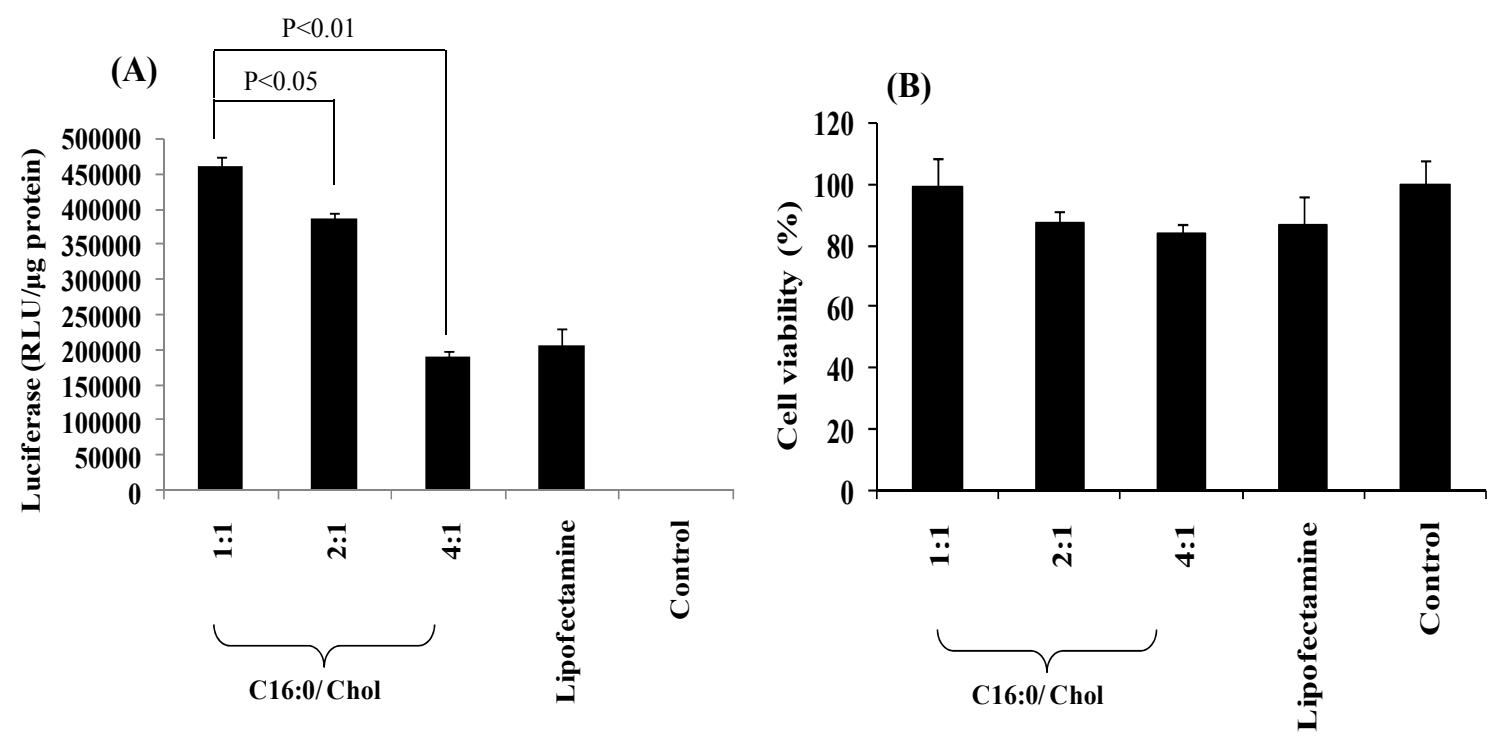

Figure 3.4 Effect of cationic lipid/co-lipid molar ratios on transfection efficiency (A) and cytotoxicity (B).

Lipid 5 (C16:0, amide linker) was used to prepare cationic liposomes with co-lipid cholesterol (Chol) at the molar ratio of 1:1, 2:1 and 4:1. Lipoplexes were formed by mixing with luciferase plasmid at the charge ratio of 3:1 (+/-). Luciferase gene expression and cytotoxicity in $\mathrm{CHO}$ cells were determined at $48 \mathrm{~h}$ after transfection. The dose of pcDNA3-Luc plasmid was $0.2 \mu \mathrm{g} /$ well for $4 \times 10^{4}$ cells. 


\subsubsection{Type of Co-lipids}

Pyridinium lipids with amide linker but different fatty acid chain (C16:0 and C18:0) were used to prepare liposomes by mixing with DOPE and Chol at the molar ratio of 1:1, and lipoplexes were prepared at the charge ratio of $3: 1(+/-)$. After $48 \mathrm{~h}$ posttransfection, luciferase gene expression (Figure 3.5A) and cytotoxicity (Figure 3.5B) were measured. Chol as a co-lipid showed higher transfection efficiency in C16:0 amide lipid, on the contrary DOPE as a co-lipid showed higher transfection efficiency in C18:0 amide lipid. Both of the formulations showed higher gene transfer than Lipofectamine/pDNA complexes formulated at 3:1 (+/-) charge ratio. No difference in cytotoxicity between pyridinium liposomes and Lipofectamine.

\subsubsection{Alkyl Chain Length}

Pyridinium lipids with amide linker and different alkyl chain length (C14:0, $\mathrm{C} 16: 0$ and $\mathrm{C} 18: 0)$ were used to formulate liposomes with cholesterol at cationic lipid/colipid molar ratio of 1:1. At $48 \mathrm{~h}$ post-transfection of $\mathrm{CHO}$ cells with lipoplexes, luciferase level was determined at 3:1 (+/-) charge ratio (Figure 3.6A). Cytotoxicity data was shown in Figure 3.6B. Pyridinium lipid with $\mathrm{C} 14: 0$ and $\mathrm{C} 16: 0$ showed much higher transfection efficiency compared to $\mathrm{C} 18: 0$ and also higher than Lipofectamine at 3:1 (+/-) ratio. There was no difference in cytotoxicity compared to Lipofectamine for all the formulations except C14:0 lipid with amide linker, which showed the lowest level of cell viability. We also found that odd number (C15:0) and C18:0 branched carbon chain analogs could not increase the transfection efficiency (data not shown).

\subsubsection{Saturation of Alkyl Chain}

Pyridinium lipids (C16:0 and $\mathrm{C} 16: 1)$ were used to prepare cationic liposomes using Chol as a co-lipid at 1:1 molar ratio. At $48 \mathrm{~h}$ post-transfection of $\mathrm{CHO}$ cells with lipoplexes $(3: 1,+/-)$, luciferase gene expression (Figure 3.7A) and cytotoxicity (Figure 3.7B) were measured. The trans-isomer showed slightly higher transfection efficiency than saturated lipid, and much higher transfection efficiency than its counterpart cisisomer. No significant difference in cell viability between pyridinium lipids and Lipofectamine.

\subsubsection{Configuration of Alkyl Chain}

Pyridinium lipids with different alkyl chain length (C16:1, C18:1 and C20:1) and different configuration (cis and trans) of double bond were used to formulate cationic liposomes with DOPE at the molar ratio of 1:1. At $48 \mathrm{~h}$ post-transfection of $\mathrm{CHO}$ cells with lipoplexes $(3: 1,+/-)$, luciferase gene expression (Figure 3.8A) and cytotoxicity (Figure 3.8B) were measured. The liposomes formulated with trans configuration lipids showed higher transfection efficiency compared to their counterpart lipids with cis configuration at the same fatty acid chain length. C16:1 trans isomer has much higher transfection efficiency than C18:1 and C20:1 trans isomers at the same type of 
(A)

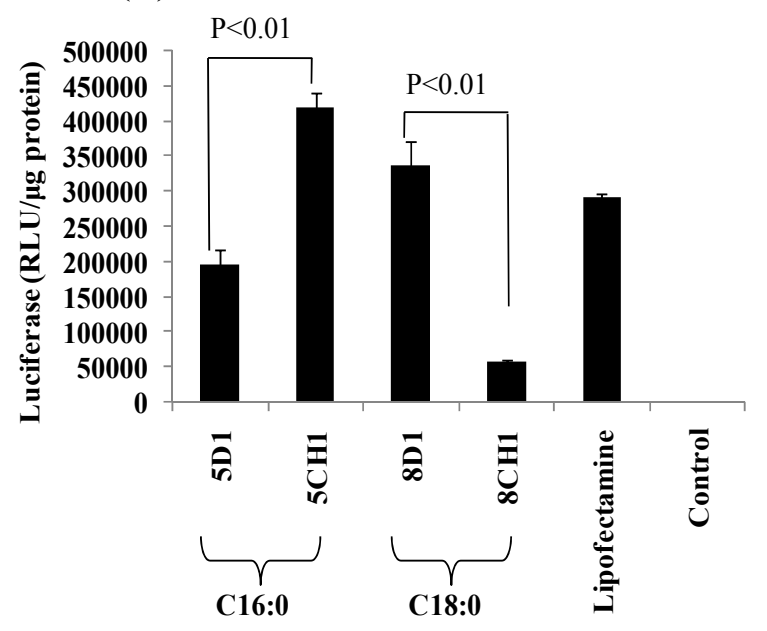

(B)

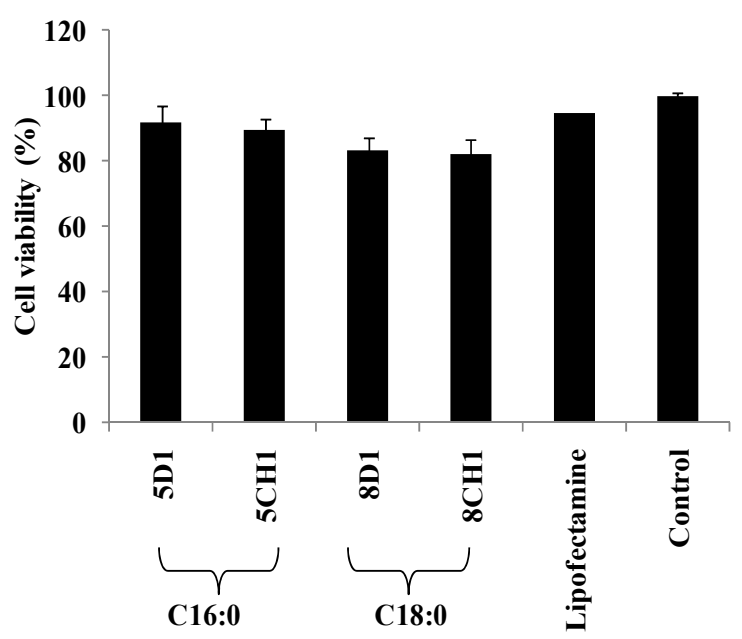

\section{Figure 3.5 Effect of co-lipid type on transfection efficiency (A) and cytotoxicity}

(B).

Lipids 5 (C16:0, amide linker) and 8 (C18:0, amide linker) were used to prepare cationic liposomes with co-lipid DOPE and cholesterol (Chol) at the molar ratio of 1:1.

Lipoplexes were formed by mixing with luciferase plasmid at the charge ratio of 3:1

$(+/-)$. Luciferase gene expression and cytotoxicity in $\mathrm{CHO}$ cells were determined at $48 \mathrm{~h}$ after transfection. The dose of pcDNA3-Luc plasmid was $0.2 \mu \mathrm{g} / \mathrm{well}$ for $4 \times 10^{4}$ cells. 


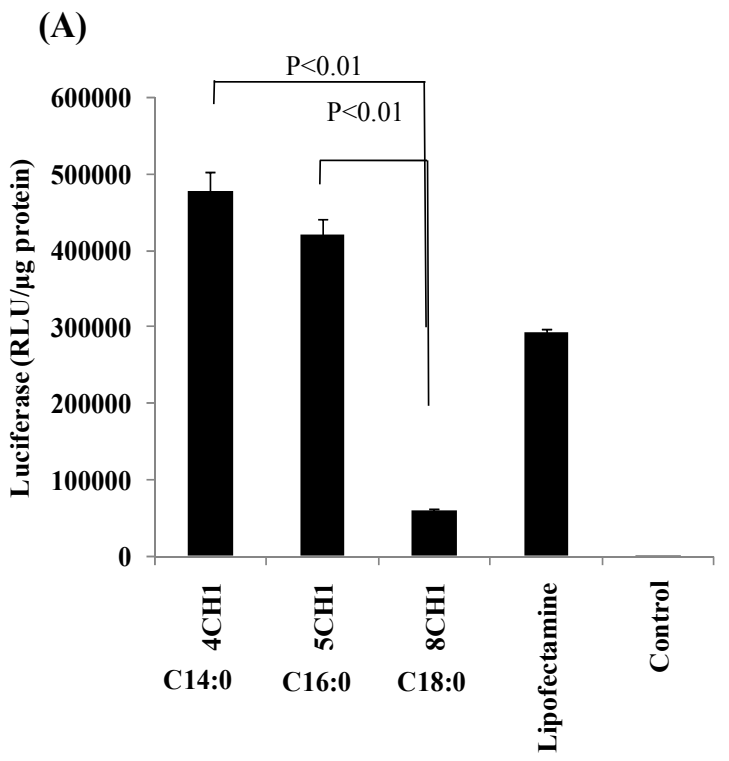

(B)

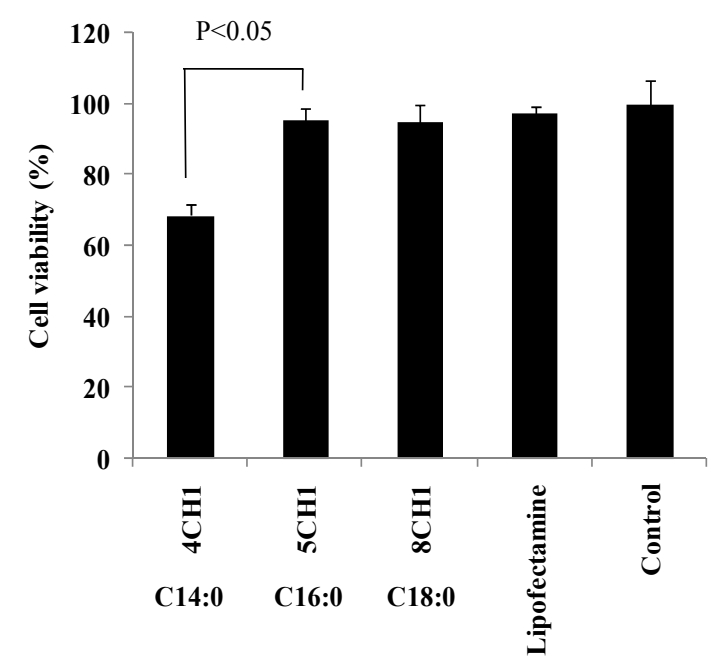

Figure 3.6 Effect of fatty acid chain length on transfection efficiency (A) and cytotoxicity (B).

Lipids 4 (C14:0, amide linker), 5 (C16:0, amide linker) and 8 (C18:0, amide linker) were used to prepare cationic liposomes with co-lipid cholesterol (Chol) at the molar ratio of 1:1. Lipoplexes were formed by mixing with luciferase plasmid at $3: 1(+/-)$ charge ratio. Luciferase gene expression and cytotoxicity in CHO cells were determined at $48 \mathrm{~h}$ after transfection. The dose of pcDNA3-Luc plasmid was $0.2 \mu \mathrm{g} /$ well for $4 \times 10^{4}$ cells. 
(A)

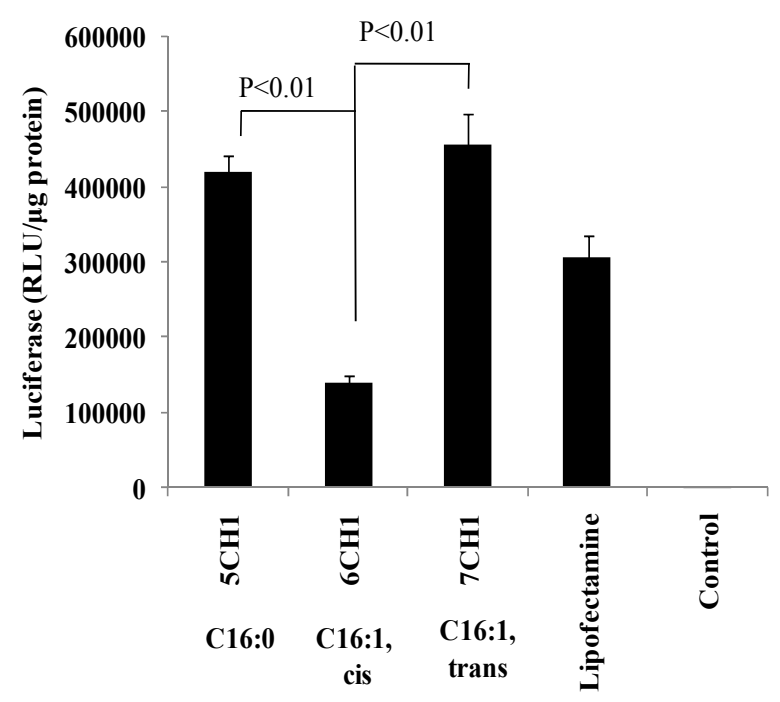

(B)

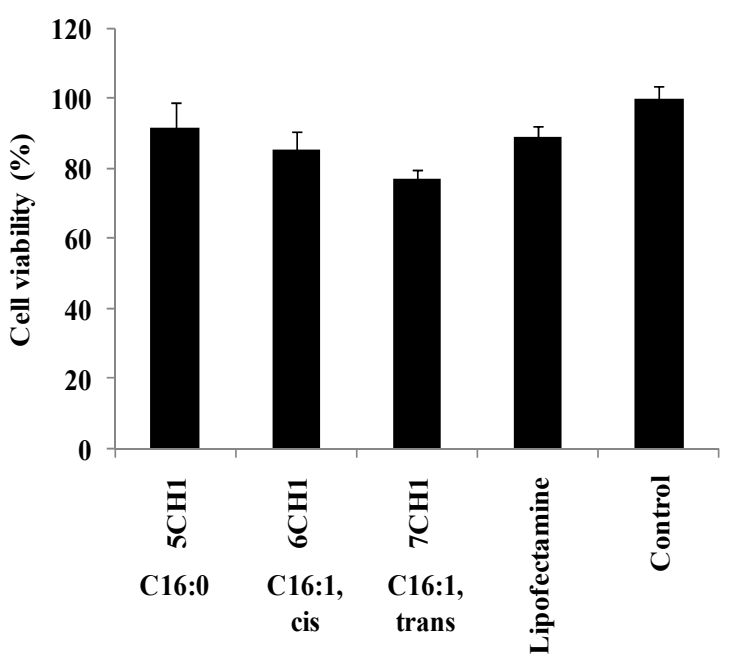

Figure 3.7 Effect of degree of saturation on transfection efficiency (A) and cytotoxicity (B).

Lipids 5 (C16:0, amide linker), 6 (C16:1, amide linker, cis-isomer) and 7 (C16:1, amide linker, trans-isomer) were used to prepare cationic liposomes with co-lipid cholesterol (Chol) at the molar ratio of 1:1. Lipoplexes were formed by mixing with luciferase plasmid at the charge ratio of 3:1 (+/-). Luciferase gene expression and cytotoxicity in $\mathrm{CHO}$ cells were determined at $48 \mathrm{~h}$ after transfection. The dose of pcDNA3-Luc plasmid was $0.2 \mu \mathrm{g} /$ well for $4 \times 10^{4}$ cells. 
(A)

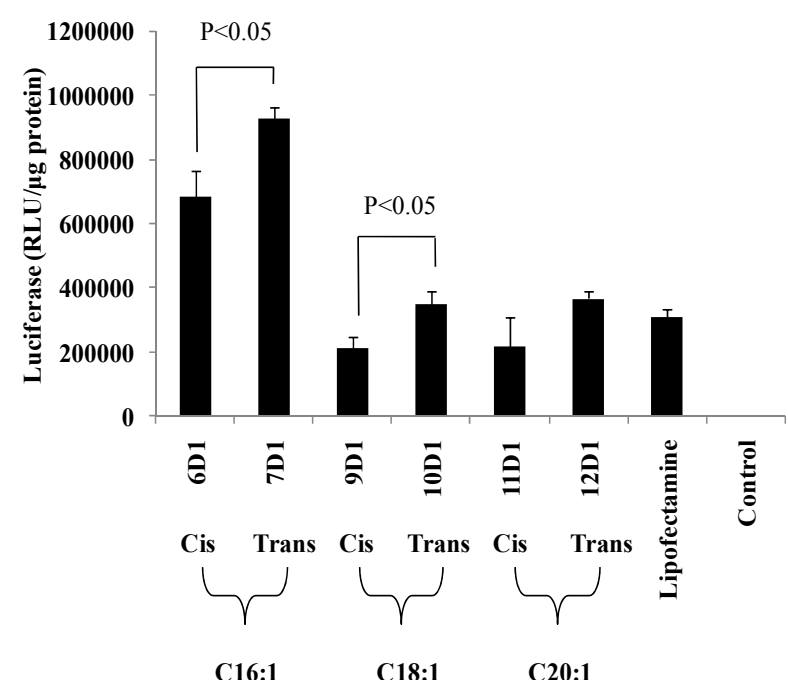

(B)

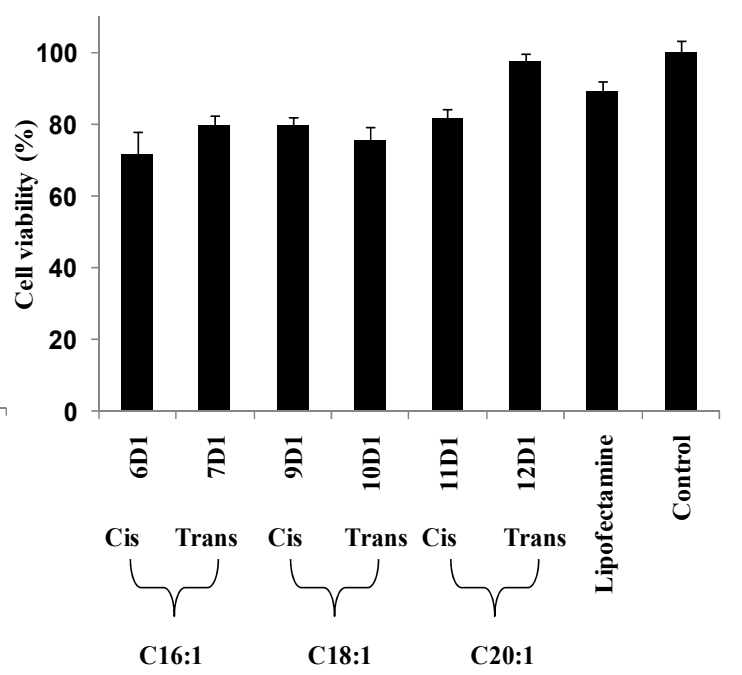

Figure 3.8 Effect of alkyl chain configuration on transfection efficiency (A) and cytotoxicity (B).

Lipids 6 (C16:1, amide linker, cis-isomer), 7 (C16:1, amide linker, trans-isomer), 9 (C18:1, amide linker, cis-isomer), 10 (C18:1, amide linker, trans-isomer), 11 (C20:1, amide linker, cis-isomer) and 12 (C20:1, amide linker, trans-isomer) were used to prepare cationic liposomes with co-lipid DOPE at the molar ratio of 1:1. Lipoplexes were formed by mixing with luciferase plasmid at the charge ratio of 3:1 (+/-). Luciferase gene expression and cytotoxicity in $\mathrm{CHO}$ cells were determined at $48 \mathrm{~h}$ after transfection. The dose of pcDNA3-Luc plasmid was $0.2 \mu \mathrm{g} /$ well for $4 \times 10^{4}$ cells. 
formulations. No significant difference in cell viability between all formulations and Lipofectamine.

\subsubsection{Influence of Serum on Gene Transfer}

Since serum is known to interfere with the transfection of lipoplexes, we transfected $\mathrm{CHO}$ cells with the lipoplexes prepared using two most potent pyridinium lipid-based liposome formulations (C16:0, amide: cholesterol at 1:1 molar ratio $(5 \mathrm{CH} 1)$ and C16:1, amide, trans: DOPE at 1:1 molar ratio (7D1)) in the presence of serum $(0,5$, 10, 15, 20, 30 and 40\%). As shown in Figure 3.9, the formulation 7D1 showed significantly higher transfection efficiency compared to the formulation $5 \mathrm{CH} 1$ and Lipofectamine (formulated at 3:1,+/- charge ratio) at each serum concentration. The transfection efficiencies were decreased with increase in serum concentration. At the serum concentration of $30 \%$ and higher, $5 \mathrm{CH} 1$ and Lipofectamine lost their transfection ability when formulated at 3/1 (+/-) charge ratio, while 7D1 still kept high transfection efficiency. The luciferase gene expression in 7D1 treated cells at the serum concentration of $40 \%$ showed incredibly similar level compared to those of $5 \mathrm{CH} 1$ and Lipofectamine in the serum free medium.

\subsubsection{Different Cell Lines}

Two pyridinium lipid formulations (5CH1 and 7D1) based on cationic/co-lipid molar ratio of $1: 1$ and complex formation at 3:1 (+/-) charge ratio were tested in two additional cell lines, CRL 1830 and C4-2. At $48 \mathrm{~h}$ post-transfection, luciferase gene expression and cytotoxicity in CRL 1830 (Figure 3.10) and C4-2 (Figure 3.11) were measured. Both formulations worked very well in these two cell lines as evidence by more than 5-10 times of luciferase level compared to Lipofectamine when formulated at $3 / 1(+/-)$ charge ratio. There was no significant difference in cell viability between all formulations and Lipofectamine. These results suggest that the order of magnitude to which pyridinium lipid based formulations exceeds Lipofectamine 3/1 (+/-) formulation is cell type dependent. Nevertheless, in all cases, much higher transfection efficiency was obtained when transfection was carried out using pyridinium lipid with C16 fatty acid chain and amide linker.

\subsubsection{Transfection of siRNAs}

Since siRNA was widely used to silence the target gene in the cell culture, the transfection ability of pyridinium lipids was tested in the delivery of luciferase siRNA into the luciferase expression C4-2 cells. The pyridinium lipid formulation (7D1) was prepared using DOPE as the co-lipid at the molar ratio of 1:1. The luciferase siRNA/cationic liposome complexes were prepared at 3:1 (+/-) charge ratio and transfected into luciferase expression C4-2 cells. Lipofectamine 2000 was used at the same charge ratio as the pyridinium cationic liposomes and as the positive control. At 48 $\mathrm{h}$ post-transfection, luciferase gene expression (Figure 3.12) was measured. Based on the data, both pyridinium lipids and Lipofectamine 2000 could transfect luciferase siRNAs into luciferase gene expression C4-2 cells and down-regulate the luciferase gene 


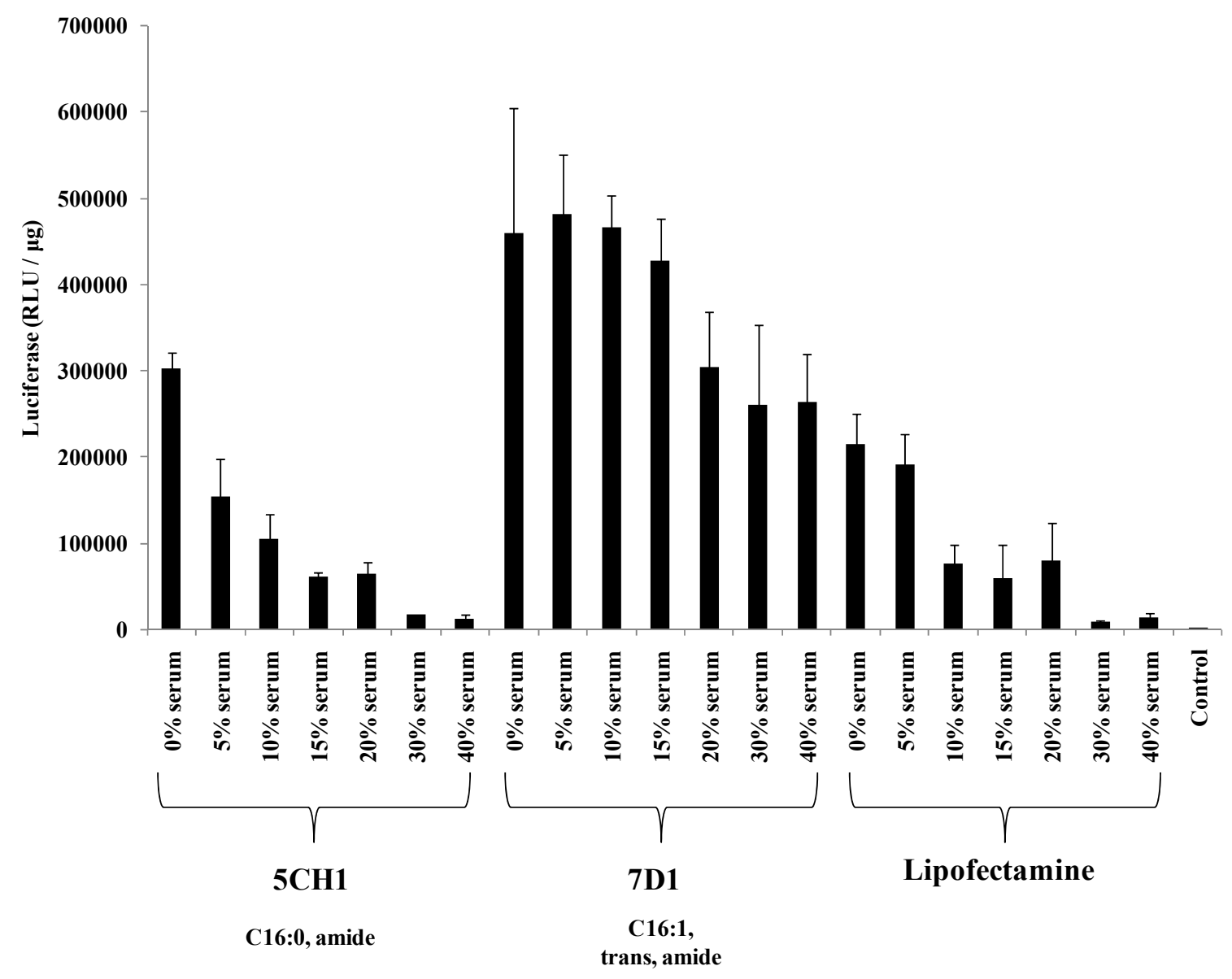

Figure 3.9 Influence of serum on gene transfer.

Lipids 5 (C16:0, amide linker) and 7 (C16:1, amide linker, trans-isomer) were used to prepare cationic liposomes with co-lipid DOPE and cholesterol at the molar ratio of 1:1. Lipoplexes were formed by mixing with luciferase plasmid at the charge ratio of 3:1 $(+/-)$. Luciferase gene expression and cytotoxicity in $\mathrm{CHO}$ cells were determined at $48 \mathrm{~h}$ after transfection. The dose of pcDNA3-Luc plasmid was $0.2 \mu \mathrm{g} / \mathrm{well}$ for $4 \times 10^{4}$ cells. 


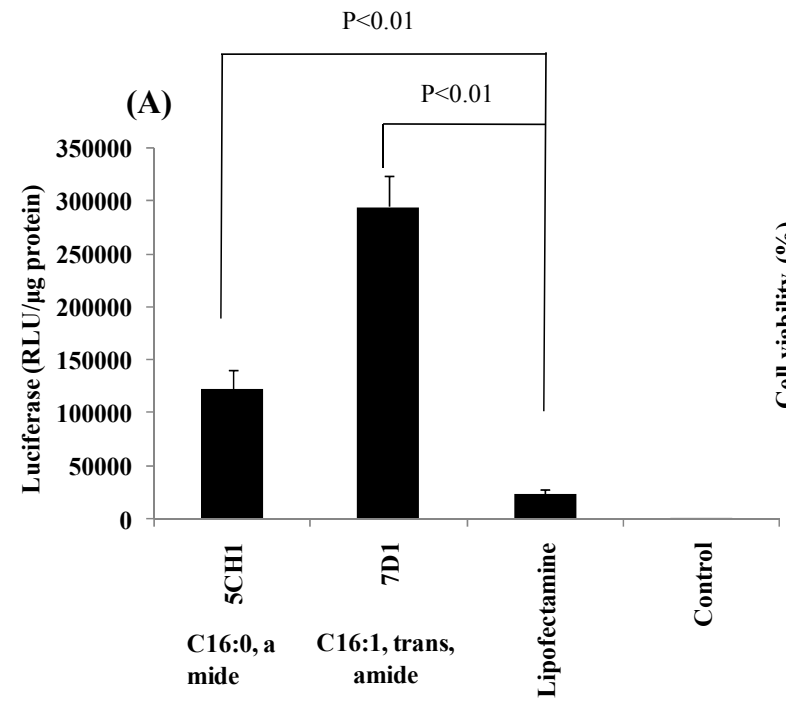

(B)

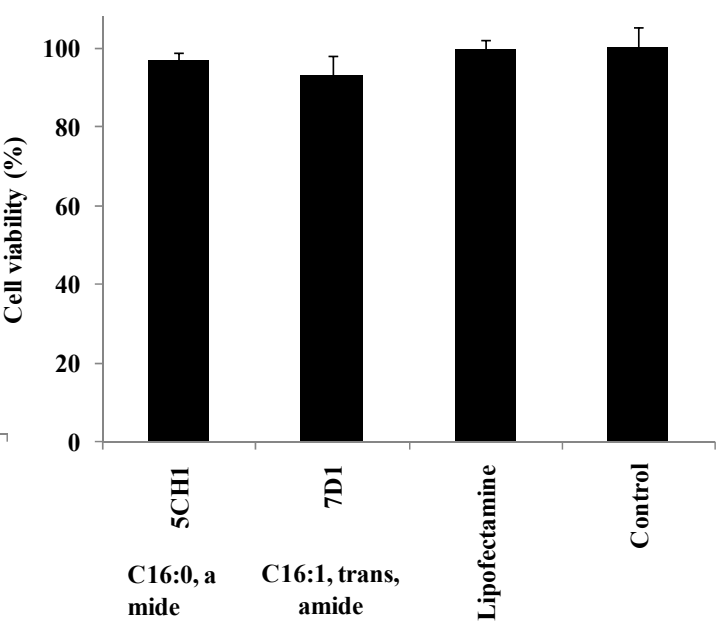

Figure 3.10 Transfection efficiency (A) and cytotoxicity (B) in hepatocarcinoma cells.

Lipids 5 (C16:0, amide linker) and 7 (C16:1, amide linker, trans-isomer) were used to prepare cationic liposomes with co-lipid DOPE and cholesterol at the molar ratio of 1:1. Lipoplexes were formed by mixing with luciferase plasmid at the charge ratio of 3:1 $(+/-)$. Luciferase gene expression and cytotoxicity in CRL 1830 cells were determined at $48 \mathrm{~h}$ after transfection. The dose of pcDNA3-Luc plasmid was $0.2 \mu \mathrm{g} /$ well for $4 \times 10^{4}$ cells. 


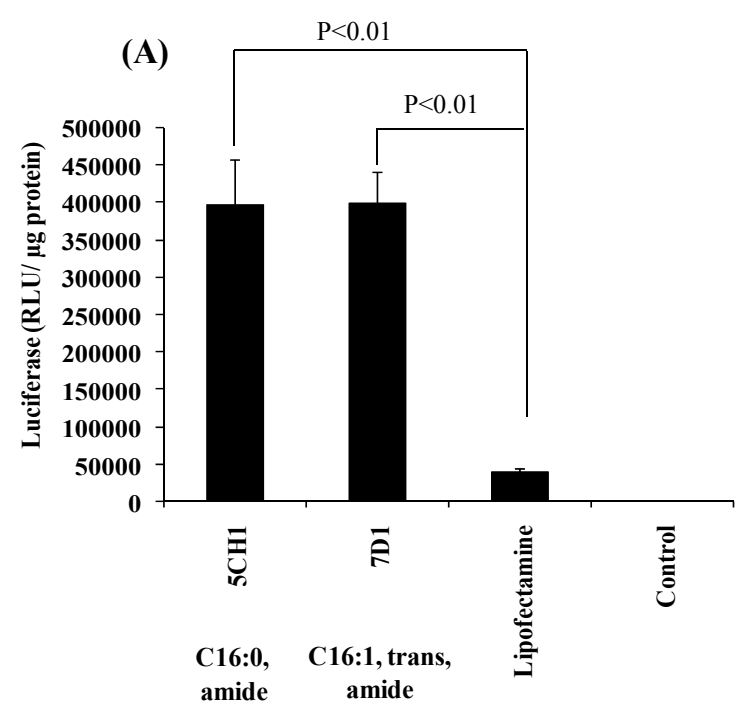

(B)

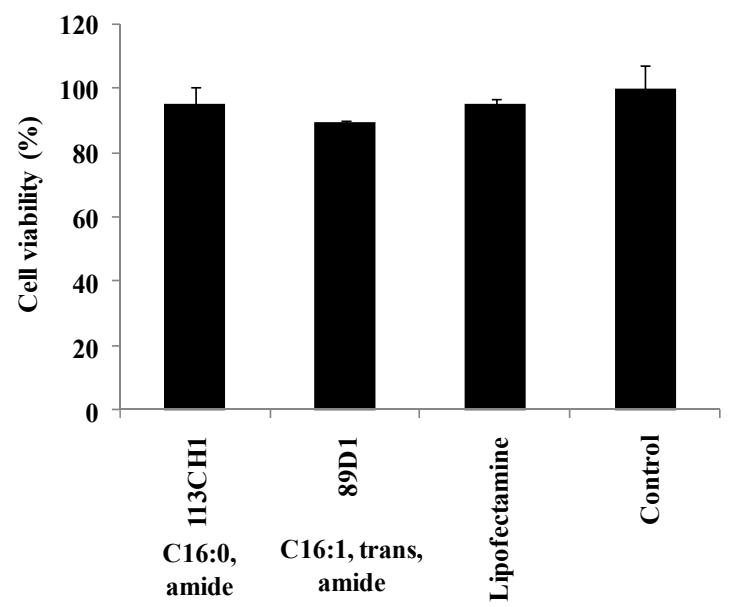

Figure 3.11 Transfection efficiency (A) and cytotoxicity (B) in prostate cancer cells.

Lipids 5 (C16:0, amide linker) and 7 (C16:1, amide linker, trans-isomer) were used to prepare cationic liposomes with co-lipid DOPE and cholesterol at the molar ratio of 1:1. Lipoplexes were formed by mixing with luciferase plasmid at the charge ratio of 3:1 $(+/-)$. Luciferase gene expression and cytotoxicity in C4-2 cells were determined at $48 \mathrm{~h}$ after transfection. The dose of pcDNA3-Luc plasmid was $0.2 \mu \mathrm{g} /$ well for $4 \times 10^{4}$ cells. 


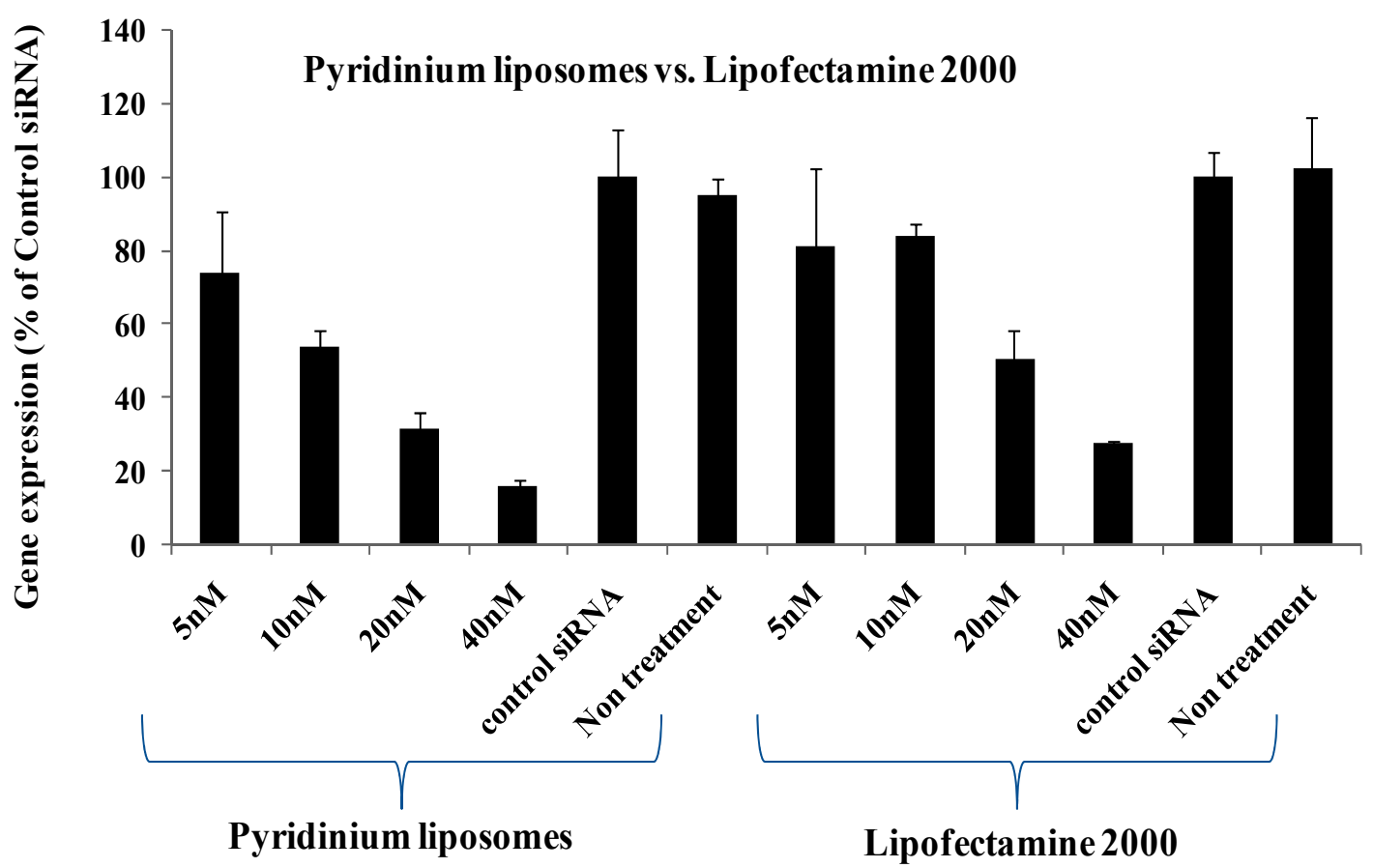

Figure 3.12 Gene silencing of luciferase siRNA in luciferase engineered prostate cancer cells (C4-2) using pyridinium cationic liposomes.

Lipids 7 (C16:1, amide linker, trans-isomer) were used to prepare cationic liposomes with co-lipid DOPE at the molar ratio of 1:1. Lipoplexes were formed by mixing with siRNAs at the charge ratio of 3:1 (+/-). Luciferase gene expression in C4-2 cells was determined at $48 \mathrm{~h}$ after transfection. The doses of Luc siRNA were 5, 10, 20, and $40 \mathrm{nM}$.

Lipofectamine 2000 was used as the positive control. 
expression even at the low dose of siRNAs. Transfection using pyridinium cationic liposomes showed relatively high gene down-regulation rate compared to Lipofectamine 2000 .

\subsubsection{Cellular Uptake Study of siRNAs Using Pyridinium Lipids}

The pyridinium lipid formulation (7D1) was prepared using DOPE as the co-lipid at the molar ratio of 1:1. The Alexa Fluor ${ }^{\circledR}$ Red Fluorescent siRNA/cationic liposome complexes were prepared at 3:1 (+/-) charge ratio and added into CHO cells. The photo was taken by fluorescence microscopy at 2, 4 and $24 \mathrm{~h}$ after addition of siRNA/CL complexes (Figure 3.13). Compared to free siRNAs at $24 \mathrm{~h}$, complexation with pyridinium cationic liposomes significantly increased the cellular uptake of fluorescent siRNA even at $2 \mathrm{~h}$ after addition of siRNA/pyridinium cationic lipid.

\subsection{DISCUSSION}

The structural and formulation factors, such as lipid/DNA ratio, co-lipid type, and cationic lipid/co-lipid ratio have been shown to influence gene transfer efficiency both in vitro and in vivo $(45,166,168)$. Pyridinium lipids have been shown to display higher transfection efficiency in cells that are not easily transfected by other cationic lipids, such as lipofectin, and transfect relatively a large number of cells (31). Therefore, here we report the effect of these parameters on the transfection efficiency of a series of pyridinium lipids.

In general, transfection efficiency increases with increase in the charge ratio of lipoplexes until it becomes too toxic to the cells. To determine the structure-activity relationship of pyridinium lipid, we first determined the effect of cationic lipid/plasmid charge ratio on the transfection efficiency to find the best charge ratio for further evaluations. Based on our transfection data, lipoplexes prepared at the charge ratio of 3:1 $(+/-)$ showed much higher transfection efficiency compared to 1:1 (+/-), but no significant difference compared to 5:1 (+/-). There is no significant difference between pyridinium lipids and Lipofectamine in cytotoxicity. Therefore, the charge ratio was fixed to $3: 1$ in all the following experiments.

Melting point, phase transition temperature, biodegradability and transfection efficiency are known to depend on the structure of the linker that binds to the polar head group to the hydrophobic lipid chains (52). Therefore, we determined the effect of amide and ester linkers on transfection efficiency and cytotoxicity. We used these linkers because they are biodegradable and thus could reduce the cytotoxicity of pyridinium lipids (32). As shown in Figure 3.3, the lipid with amide linker showed higher transfection efficiency compared to their counterparts with the ester linker regardless of the fatty acid chain length. The high transfection efficiency of amide linker lipids may be caused by their lower phase transition temperature (Table 3.2) which makes liposomal bilayer structure more stable in aqueous solution during transfection process and storage. 

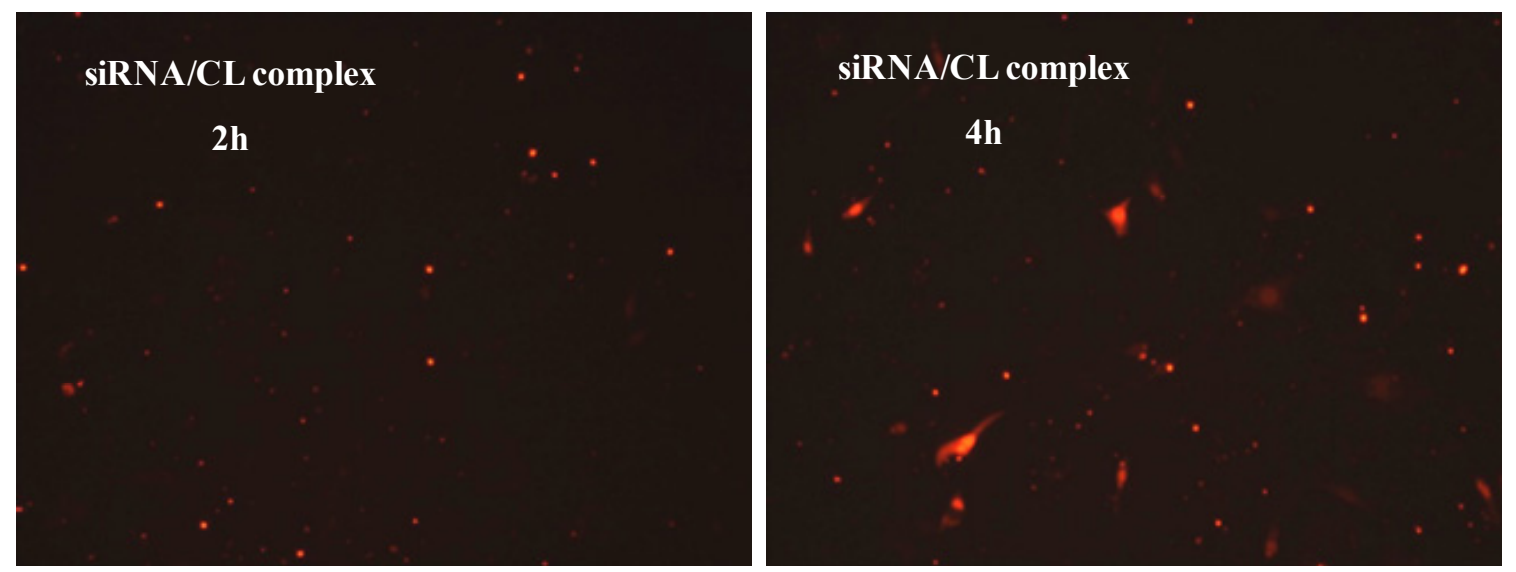

siRNA/CL complex

24h

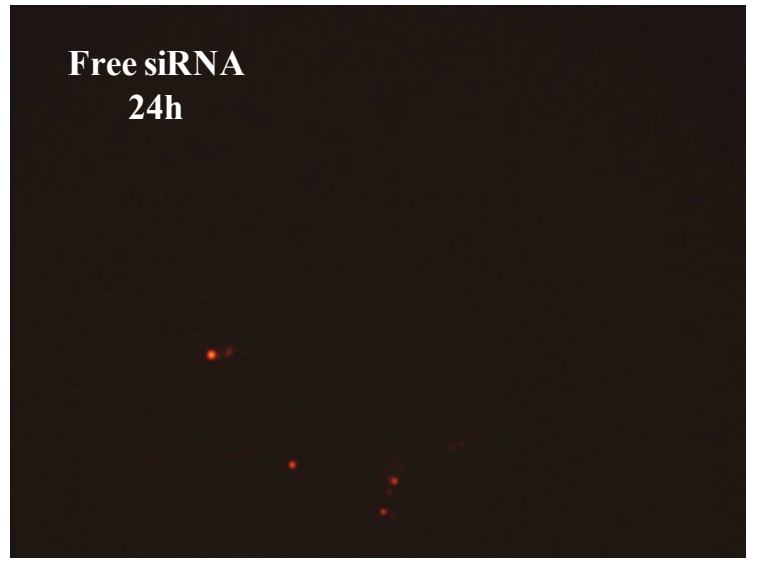

Figure 3.13 Cellular uptake of Alexa Fluor ${ }^{\circledR}$ Red Fluorescent siRNA in CHO cells using pyridinium cationic liposomes.

Lipids 7 (C16:1, amide linker, trans-isomer) were used to prepare cationic liposomes with co-lipid DOPE at the molar ratio of 1:1. Lipoplexes were formed by mixing with siRNAs at the charge ratio of $3: 1(+/-)$. The photo was taken by fluorescence microscopy at 2,4 and $24 \mathrm{~h}$ after addition of siRNA/CL complexes. 
The molar ratio of a cationic lipid to co-lipid is known to affect the phase transition temperature of cationic liposomes and the structure of lipoplexes. Therefore, we prepared cationic liposomes using pyridinium lipid and cholesterol at the molar ratio of $1: 1,2: 1$ and $4: 1$, as cholesterol has been reported to be superior to DOPE for pyridinium lipids (34). Luciferase gene expression (Figure 3.4A) and cytotoxicity (Figure 3.4B) were influenced by the molar ratio of pyridinium lipid to Chol, with the highest transfection efficiency for the liposomes prepared at 1:1 cationic lipid/co-lipid molar ratio. Increase in the amount of Chol slightly decreased cytotoxicity of pyridinium liposomes. So we fixed cationic lipid/co-lipid molar ratio to $1: 1$ in other experiments. These results are in good agreements with the work of Illies et al. (34).

DOPE and Chol are the most commonly used co-lipids in liposome preparation. The incorporation of fusogenic lipids such as DOPE improves the endosomal release by membrane fusion between the liposomal and endosomal bilayers $(109,110)$. It had been also proved that DOPE could be a major driving force in promoting transfection of SAINT-2 based lipoplexes via the transformation of the lamellar DOPE-containing complex as prepared in water to the hexagonal phase when dispersed in a physiological salt solution (111). The use of Chol as a co-lipid has been reported to show enhanced in vivo gene expression, as Chol-containing liposomes efficiently interact with the cell membrane in the presence of serum (112). Based on our data, the use of both DOPE and Chol as co-lipids showed higher transfection efficiency of pyridinium lipids compared to Lipofectamine when lipoplexes were prepared at 3/1 (+/-) charge ratio. The selection of co-lipid was dependent on the type of cationic lipids.

The hydrophobic chain length influences the shape of amphiphiles and supramolecular associations generated through the self-assembling process (32). Therefore, we synthesized a series of pyridinium lipids with different length of fatty acids to determine the influence of alkyl chain length on gene transfer. Pyridinium lipids with C14:0 and C16:0 fatty acid and amide linker formulated with Chol showed higher transfection efficiency compared to C18:0 lipid with the same linker (Figure 3.6A). Since C14:0 was more toxic than $\mathrm{C} 16: 0$ but had similar transfection efficiency, we only synthesized C16:1, C18:1 and C20:1 for further evaluation. As shown in Figure 3.8A, C16:1 showed higher transfection efficiency compared to C18:1 and C20:1. Ilies et al. (2006) reported similar results (32). Van der Woude et al. (31) also reported significant reduction in transfection efficiency and cytotoxicity with elongation of the alkyl chain length to C18:0 (SAINT-5) relative to that of C16:0 (SAINT-1). Srilakshmi et al. (169) demonstrated that the transfection efficiency of cationic lipids was anchor-dependent when they studied the cationic lipids containing hydrophobic anchor chain ranging from $\mathrm{C} 12$ to $\mathrm{C} 18$. In their study, the lipid containing 16-carbon chain showed better transfection efficiency among these compounds, while lipids containing less than 14carbon anchor chain did not show any transfection, indicating that a minimum of 14carbon anchor length is essential for imparting transfection properties to their cationic lipids (170). Cationic lipids containing less than 14-carbon anchor chain do not form stable lipoplexes that are required for efficient cellular uptake of plasmid DNA. Noncondensed plasmid DNA present in the lipoplexes either gets degraded by the serum proteins and/or enters into a non-productive pathway (170). On the contrary, the carbon 
anchor chain will promote strong interaction between DNA and cationic lipid by hydrophobic strength besides electrostatic interaction, which will decrease the release of DNA from cationic liposomes, leading to further decrease in gene expression (164). A balance between the stability of the liposome in the medium and endosomal DNA release into the cytoplasm is important for efficient transfection efficiency (171).

The degree of un-saturation and configuration of hydrophobic anchor chain can affect the transfection efficiency and cytotoxicity (31). The degree of un-saturation in lipid structure affects the fusogenicity of the lipid $\left(\mathrm{L}_{\alpha} / \mathrm{H}_{\mathrm{II}}\right.$ transition) $(42,43)$. Increase in the chain length of saturated hydrophobic anchors increases the phase transition temperature: $45.5,63.5$ and 73.4 for $\mathrm{C} 14: 0, \mathrm{C} 16: 0$ and $\mathrm{C} 18: 0$ of pyridinium lipids with ester linkages; and 38.9, 39.3 and 45.4 for C14:0, C16:0 and C18:0 of pyridinium lipids with amide linkers (Table 3.2). The increase in phase transition temperature decreases fusogenicity, leading to decrease in transfection efficiency (44). Double bond in the fatty acid carbon chain will also decrease the melting point (Table 3.1). To investigate the relevance of cis versus trans orientation, we synthesized new lipids with one double bond (cis or trans) in the hydrophobic carbon chain. As apparent in Figures 3.7A and 3.8A trans-orientation (C16:1, C18:1 and C20:1) enhances the transfection efficiency compared to cis-oriented alkyl chains of the same length. This trend is in good agreement with the previous report by Van der Woude et al. (31). Based on our results shown in Figures 3.5A, 3.7A and 3.8A, we conclude that the trans-isomer worked better than cis and saturated lipids.

The stability of the lipoplexes in the presence of serum is important for their in vivo efficacies $(172,173)$. Increase in serum concentration significantly decreased the transfection efficiency (Figure 3.9). Serum contains nucleases and other enzymes, which would degrade plasmid DNA, and also contains proteins, such as albumin, which would inhibit the cellular association of the lipoplex (174). However, our lipid trans-isomer C16:1 showed excellent performance even at the serum concentration of $30 \%$ and above which Lipofectamine totally lost its transfection ability when lipoplexes were formulated at 3/1 (+/-) charge ratio. This finding suggests that C16:1 trans-isomer-based liposomes can be used for in vivo gene delivery. Gopal et al. (164) also demonstrated good transfection efficiency of glutamide-containing pyridinium lipids in the presence serum.

Since pyridinium lipids could interact with the negatively charged molecules and form the condensed particles which facilitate the cellular uptake, it was expected to be used to deliver and enhance the cellular uptake of siRNAs. To study the silencing effect of luciferase siRNAs, we used luciferase expression cells. The data in Figure 3.12 showed that pyridinium lipids enhanced the gene down-regulation rate higher than commercial product Lipofectamine 2000, which is specifically designed for siRNA delivery. The photos in Figure 3.12 showed that complexation with siRNAs increased the speed and extent of the cellular uptake compared to free siRNAs.

A major issue of interest is obviously the understanding why pyridinium cationic lipid could improve transfection. Since a couple of papers have shown that the lipid with one or more pyridinium ring could significantly improve the transfection efficiency and 
decrease the cytotoxicity. Obviously the pyridinium positively charged head group plays an important role in the improvement of transfection efficiency. It had been proved that the antimicrobial activity of alkyl pyridinium salts was associated with the cell leakage (175). This antimicrobial activity increased with increase in number of pyridinium head groups. The multiheaded pyridinium amphiphiles were more active as compared to their trimethylammonium counterparts (176). Woude et al. reported that alkyl pyridinium cationic lipid (SAINT-2) could increase the membrane permeability although this effect is not high to assure the lower cytotoxicity compared to DOTMA (31). Tucker et al. reported that pre-incubation of the sponge toxin (a kind of alkyl pyridinium compound) with cells could make a transit perforation on the cytoplasm membrane and facilitate cDNA transmembrane movement (177). The permeabilization of pyridinium cationic lipids was further proved by the evidence of the more efficient tissue penetration of pyridinium-based lipoplexes compared to lipoplexes formed by DOTAP in vivo (165). The pore on the surface of cell membrane evoked increases in intracellular $\mathrm{Ca}^{2+}$, collapsed membrane potentials and reduced input resistance $(177,178)$. DOSPA is a polycation which is the component of Lipofectamine. It was reported that polycation could form positively charged loops fixed on DNA molecules. These loops interact with negatively charged lipids on plasma membranes, which probably induce effective nonspecific endocytosis and subsequent cell transformation (179). Pore-forming ability combined with ionic attraction, membrane association and endocytosis, may explain why some of our newly synthesized pyridinium cationic lipids showed relatively higher transfection efficiency compared to Lipofectamine and Lipofectamine 2000.

In conclusion, we have demonstrated that a number of structural and formulation parameters including hydrophobic carbon chain lengths, double bond configuration in the unsaturated aliphatic hydrocarbon tails, cationic lipid/co-lipid ratios, cationic lipid/DNA charge ratios and cell types play important roles in gene transfer and cytotoxicity of these pyridinium lipids. Important findings include: (a) higher transfection efficiencies of pyridinium lipids with the amide linkers compared to their ester counterparts; (b) higher transfection efficiency at 1:1 molar ratio of pyridinium lipid and co-lipid compared to 2:1 and 4:1; (c) efficient transfection with C16 chain length pyridinium lipids; (d) better transfection efficiencies in the presence and absence of serum, compared to that of Lipofectamine, a widely used commercially available liposomal transfection kit; (e) higher transfection efficiencies of pyridinium lipids with the trans orientation in the hydrophobic anchor chain compared to those with cis orientation; (f) C16:1 trans-isomer pyridinium lipids were more efficient in transfection efficiency in the presence of high concentration of serum compared with Lipofectamine when lipoplexes were prepared at 3/1 (+/-) charge ratio; and (g) pyridinium lipids could efficiently deliver siRNAs and showed good gene silencing effect. 


\section{CHAPTER 4. SITE-SPECIFIC DELIVERY OF OLIGONULCLEOTIDES TO HEPATOCYTES AFTER SYSTEMIC ADMINSTRATION*}

\subsection{INTRODUCTION}

Oligonucleotides (ODNs) have attracted much attention as a new class of therapeutic agents that can be used for gene modulation. However, in vivo gene silencing by ODNs has not yet been successful because of several obstacles, including the nonspecific interaction with plasma proteins, wide distribution and poor stability against enzymatic degradation. Since phosphodiester ODNs have extremely short half-lives due to degradation by nucleases, phosphorothioate (PS) ODNs are commonly used. PS ODNs are fairly stable in vivo, but readily bind to serum proteins, leading to undesirable biological events. To address these problems, a variety of delivery systems composed of cationic lipids $(12,45,180)$ and cationic polymers $(181-183)$ have been developed. Some of these delivery systems substantially enhanced the enzymatic stability and uptake into the target cells in vitro (184). However, most of these cationic carriers are inefficient in vivo because of their non-specific biodistribution in the body.

We and others have shown that ODNs are cleared rapidly from the circulation and accumulated to most of the peripheral tissues, with the highest accumulation in the liver and kidney $(12,185-188)$. The asialoglycoprotein receptor is located on parenchymal liver cells (e.g., hepatocytes) and recognizes terminal galactose (189) or lactose residues $(190,191)$. Therefore, we previously used galactosylated poly(L-lysine) (Gal-PLL) for complex formation with ODNs and demonstrated enhanced hepatic uptake of ODNs, which was influenced by the particle size, zeta potential, sugar substitution, and molecular weight of both polycations and ODNs (192). Although the uptake of GalPLL/ODN complexes by hepatocytes was significantly higher than that of naked ODNs, the difference of their distribution to different liver cells was only moderate. To avoid the use of polycations, Rajur et al. (1997) covalently conjugated ODNs to asialoorosomucoid via a disulfide bond using sulfosuccinimidyl 6-[3'-(2-pyridyldithio) propionamido] hexanoate (sulfo-LC-SPDP), but the authors did not test the conjugate in vivo (193).

PEGylation is known to significantly enhance the ODN stability against exonucleases and reduce renal clearance compared to unmodified ODNs (194). The in vivo activity of a drug depends in part on its rate of excretion and degradation. PEGylation should promote the bioactivity of an ODN by increasing plasma residence time and decreasing nuclease degradation. PEGylation also shield the inherent negative charge of ODN, thereby possibly facilitating cellular uptake of the conjugated drug. Additionally, PEGylation could potentially diminish the immunostimulatory effects of the ODNs (126). Keeping these benefits in mind, Bonora etal. (1997) conjugated ODNs

* Adapted with permission from American Chemical Society. Zhu, L., Ye, Z., Cheng, K., Miller, D. D., and Mahato, R. I. (2008) Site-specific delivery of oligonucleotides to hepatocytes after systemic administration. Bioconjug Chem 19, 290-8. 
to poly(ethylene glycol) (PEG) through a covalent linkage (195). However, these PEGODN conjugates were less effective, since PEG could not be cleaved early from the ODNs in the cytoplasm. Therefore, Oishi et al. conjugated ODN to acrylated or lactosylated PEG through a pH-responsive ester $(139,196)$. However, these authors did not determine the biodistribution of Lac-PEG-ODN and used in conjunction with a cationic polymer like linear polyethyleneimine (PEI), which is likely to promote nonspecific interaction with plasmaproteins and uptake by phagocytic cells.

In this study, we used fully phosphorothioate G-rich ODN, which is fairly stable, but binds to serum proteins (197). To minimize binding to plasma proteins, enhance stability and prolong circulation time, we conjugated Gal-PEG to ODN using an acid labile linker. Gal-PEG is expected to enhance ODN delivery to the hepatocytes whose inflammation and injury lead to progression of liver fibrosis (198). In this study, we conjugated ODN to Gal-PEG via an acid labile ester linkage and used without any cationic polymers or lipids to avoid cytotoxicity and non-specific interaction. Following conjugation and in vitro characterization, we determined the biodistribution of Gal-PEG-

${ }^{33} \mathrm{P}-\mathrm{ODN}$ at whole body, organ (liver) and cellular (liver cells) levels after tail vein injection into rats.

\subsection{MATERIALS AND METHODS}

\subsubsection{Materials}

25 mer ODN (5' GAG GGG GGA GGA GGG AAA GGA AGG G 3') modified with a sulfhydryl group at the 3'-end was purchased from Invitrogen Corporation (Carlsbad, CA). $\left[\gamma-{ }^{33} \mathrm{P}\right]$ ATP was obtained from MP Biomedicals (Irvine, CA) and T4 polynucleotide kinase (T4-PNK) from New England Biolabs (Beverly, MA). Bio-Gel P6DG gel was purchased from Bio-Rad Laboratories (Hercules, CA). PD-10 desalting columns were obtained from Pharmacia Fine Chemicals AB (Uppsala, Sweden).

Soluene $^{\circledR}-350$ (tissue solubilizer) and Hionic-Fluor (scintillation fluid) were purchased from Perkin Elmer (Boston, MA). Isoflurane was obtained from Baxter Health Corporation (Deerfield, IL). Type IV collagenase was purchased from Worthington Biochemical Corporation (Lakewood, NJ). Nycodenz ${ }^{\mathrm{TM}}$ AG was obtained from Greiner Bio-One Inc. (Longwood, FL). PE-60 polyethylene tube was purchased from Becton Dickinson and Company (Sparks, MD) and heparin solution was procured from American Pharmaceutical Partners, Inc. (Los Angeles, CA). Acrylate-PEG-NHS (MW: $3486 \pm 500 \mathrm{Da}$ ) was purchased from Nektar Therapeutics (Huntsville, AL). Bovine serum albumin (BSA) (fraction V, purity $>98 \%$ ) was purchased from USB Corporation (Cleveland, $\mathrm{OH}$ ). Palladium (10 wt \% on activated carbon), thiophosgene, Brilliant Blue R Staining Solution, dithiothreitol (DTT), p-nitrophenyl $\beta$-D-galactopyranoside, Dimethylformamide (DMF), 2,5-Dihydroxy benzoic acid (DHB), methylene blue, deuterium oxide $\left(\mathrm{D}_{2} \mathrm{O}\right)$, triethylamine (TEA, HPLC grade), and pronase were purchased from Sigma-Aldrich Chemicals Limited (St. Louis, MO). Dialysis tubing (MWCO 1000 Da) was purchased from Spectrum Laboratories, Inc. (Houston, TX). Amicon Centricon 
filter devices (MWCO $10000 \mathrm{Da}$ ) were purchased from Millipore Corporation. (Billerica, MA). Hydrogen peroxide $\left(\mathrm{H}_{2} \mathrm{O}_{2}\right)$, acetic acid, acetonitrile (ACN, HPLC grade) and water (HPLC grade) were purchased from Fisher Chemical (Fair Lawn, NJ). $\mathrm{Ca}^{2+} / \mathrm{Mg}^{2+}$-free Hank's balanced salt solution (Cellgro) was purchased from Media Tech (Washington, DC).

\subsubsection{Animals}

Male Sprague-Dawley rats weighing 140-160 g were purchased from Harlan Co. (San Diego, CA) and were housed individually under the controlled light (12/12 h) and temperature conditions and had free access to food and water.

\subsubsection{Synthesis of Gal-PEG-ODN Conjugate}

p-Nitrophenyl $\beta$-D-galactopyranoside $(200 \mathrm{mg}$ ) was reduced with $200 \mathrm{mg}$ of $10 \%$ palladium on activated carbon under hydrogen $(1 \mathrm{~atm})$ in $30 \mathrm{~mL}$ of a 1:1 (v/v) ethanolwater mixture for $2 \mathrm{~h}$, as described by Monsigny et al. (199). The product, paminophenyl $\beta$-D-galactopyranoside, was concentrated by solvent removal under vacuum and characterized using ${ }^{1} \mathrm{H}$ NMR and mass spectrometry after dissolving in $\mathrm{D}_{2} \mathrm{O}$, and the NMR spectra were recorded on a Bruker ARX-300 MHz spectrometer at $25^{\circ} \mathrm{C}$. Chemical shifts were recorded in ppm relative to $\mathrm{D}_{2} \mathrm{O}(\delta 4.79,1 \mathrm{H})$. Electron spray ionization (ESI) mass spectra were obtained after dissolving the product in methanol on an ESQUIRE-LC Ion Trap LC/MS system. Acrylate polyethylene glycol N-hydroxysuccinimidyl (NHS) ester (acrylate-PEG-NHS) (58 mg) and $p$-aminophenyl $\beta$-D-galactopyranoside (43.4 mg) were dissolved separately in $0.4 \mathrm{~mL}$ of DMF, mixed together and stirred for $6 \mathrm{~h}$, then dialyzed in $500 \mathrm{~mL}$ water for $48 \mathrm{~h}$ with MWCO 1000. The product, galactose (Gal)-PEGacrylate was characterized by ${ }^{1} \mathrm{H}$ NMR after dissolving the product in $\mathrm{D}_{2} \mathrm{O}$. The molecular weight of Gal-PEG-ODN was determined using Matrix Assisted Laser Desorption/Ionization Time-of-Flight (MALDI-TOF) mass spectrometry with DHB as a matrix.

Modified ODNs were treated with $0.2 \mathrm{M}$ DTT in $0.1 \mathrm{M}, \mathrm{pH} 9.0$ glycine buffer containing $0.1 \mathrm{M} \mathrm{NaCl}$ for $3 \mathrm{~h}$ at room temperature to generate a 3'-thiol functional group. Excess DTT was removed by extraction with ethyl acetate, and ODN was precipitated by adding 2.6 volume of ethanol after addition of sodium acetate $(\mathrm{NaOAc})$ to $0.3 \mathrm{M}$. The mixture was kept at $-30{ }^{\circ} \mathrm{C}$ overnight and centrifuged at $13000 \mathrm{~g}$ for $30 \mathrm{~min}$. The ODN with 3'-thiol functional group and Gal-PEG-acrylate were dissolved in $0.4 \mathrm{~mL}$ water at a molar ratio of 1:100, stirred under nitrogen protection at room temperature for $6 \mathrm{~h}$, and then centrifuged the mixture by Amicon Centricon filter device (MWCO $10000 \mathrm{Da}$ ) at 2, $500 \mathrm{~g}$ for $30 \mathrm{~min}$. The upper solution of the filter device was collected and lyophilized. The formation of Gal-PEG-ODN was verified on $20 \%$ native polyacrylamide gel electrophoresis at $8 \mathrm{~V} / \mathrm{cm}$ for $100 \mathrm{~min}$ at room temperature, followed by gel staining with methylene blue. The reaction mixtures and the purity of intermediate and final products were monitored by Reverse Phase-High Performance Liquid Chromatography (RP- 
HPLC), which was carried on a reverse phase C18 column $(250 \mathrm{~mm} \times 4.6 \mathrm{~mm}$, Alltech, Deerfield, IL) by an HPLC system (Waters, Milford, MA) with detection at $260 \mathrm{~nm}$ using a gradient of $5 \%-80 \% \mathrm{ACN}$ in $0.1 \mathrm{M}$ triethylammonium acetate at a flow rate of 1.0 $\mathrm{mL} / \mathrm{min}$ at $56^{\circ} \mathrm{C}$.

\subsubsection{Synthesis of Galactosylated Albumin}

Gal-BSA was synthesized from p-aminophenyl $\beta$-D-galactopyranoside and BSA (MW $66 \mathrm{kDa}$ ) using a modified method described by Sando and Karson (200). After conjugation Gal-BSA was purified by PD-10 column and identified by sodium dodecyl sulfate polyacrylamide gel electrophoresis (SDS-PAGE) followed by staining with Brilliant Blue R Staining Solution. The molar ratio of galactose and BSA was about 15 . Sugar (galactose) content was determined by the resorcinol-sulfuric acid method as described by Monsigny et al. (201).

\subsubsection{Radiolabeling of Oligonucleotides}

The 25 mer ODN or Gal-PEG-ODN was labeled by adding $\gamma-{ }^{33} \mathrm{P}$ to the 5 ' end using $\left[\gamma-{ }^{33} \mathrm{P}\right]$ ATP and T4-PNK, using the manufacturer's protocol. Briefly, $1 \mu \mathrm{g}$ of ODN or Gal-PEG-ODN was mixed with $5 \mu$ l of T4-PNK buffer, $2 \mu \mathrm{L}$ of T4-PNK, and $4 \mu \mathrm{L}$ of $\left[\gamma_{-}{ }^{33} \mathrm{P}\right] \mathrm{ATP}$. The reaction mixture was incubated at $37^{\circ} \mathrm{C}$ for $60 \mathrm{~min}$, followed by incubation at $70{ }^{\circ} \mathrm{C}$ for $10 \mathrm{~min}$ to stop the reaction. Unincorporated $\left[\gamma_{-}{ }^{33} \mathrm{P}\right]$ ATP was removed from radiolabeled ODN or Gal-PEG-ODN by size exclusion chromatography with Bio-Gel P-6DG gel. Radioactivity was measured on TRI-CARB ${ }^{\circledR} 2000$ liquid scintillation analyzer (PACKARD Instrument Company, Meridon, CT). The incorporation efficiency of the purified ${ }^{33} \mathrm{P}-\mathrm{ODN}$ was determined by trichloroacetic acid (TCA) precipitation method and the value was more than $95 \%$. The specific activity of ${ }^{33} \mathrm{P}-\mathrm{ODN}$ was about $5 \times 10^{5} \sim 10 \times 10^{5} \mathrm{cpm} / \mu \mathrm{g}$.

\subsubsection{Dissociation and Stability}

To determine whether ODNs can dissociate from Gal-PEG-ODN conjugate after endocytosis, this conjugate was incubated at $37^{\circ} \mathrm{C}$ in Tris $\mathrm{HCl}$ buffer of $\mathrm{pH} 5.5$ for 1, 2 and $4 \mathrm{~h}$. In addition we also incubated this conjugate in the rat serum at $37^{\circ} \mathrm{C}$ to determine its stability. These samples were then detected by $20 \%$ polyacrylamide gel electrophoresis and autoradiography.

\subsubsection{Biodistribution of Gal-PEG-ODN}

The animal protocol was approved by the Animal Care and Use Committee (ACUC), Department of Comparative Medicine, University of Tennessee Health Science Center, Memphis, TN 38163. Male Sprague-Dawley rats weighing 140-160 g were used 
in this study and 4 rats were used for each time point. Unlabeled and Gal-PEG- $-{ }^{33} \mathrm{P}-\mathrm{ODN}$ were mixed in saline to give a final concentration of $1 \mathrm{mg} / \mathrm{mL}$ and specific activity of $1 \times$ $10^{6} \mathrm{cpm} / \mathrm{mL}$. Rats were anesthetized by inhalation of isoflurane and Gal-PEG- ${ }^{33} \mathrm{P}-\mathrm{ODN}$ or ${ }^{33} \mathrm{P}-\mathrm{ODN}$ was injected via tail vein at a dose of $0.2 \mathrm{mg} / \mathrm{Kg}$ body weight. At $2.5,5,15$, $30,90,240$ and $1440 \mathrm{~min}$ post injection, $0.5 \mathrm{~mL}$ blood was collected by cardiac puncture in heparinized tubes, and urine was collected directly from the bladder using 0.26 gauge needle syringe. The animals were then sacrificed and major tissues (liver, kidney, spleen, heart, lung and muscle) were collected, washed, blotted dry, weighed and stored at $-80{ }^{\circ} \mathrm{C}$. The radioactivity of urine sample was counted directly after adding $10 \mathrm{~mL}$ of scintillation fluid. Two hundred microliters of plasma and $200 \mathrm{mg}$ of each tissue were incubated with $2 \mathrm{~mL}$ tissue solubilizer for $3 \mathrm{~h}$ at $55^{\circ} \mathrm{C}$ and overnight at $37^{\circ} \mathrm{C}$ in shaker. Four hundred microliters of $\mathrm{H}_{2} \mathrm{O}_{2}$ was added and incubated at $55^{\circ} \mathrm{C}$ for another $30 \mathrm{~min}$. Ten milliliters of scintillation fluid was added to each sample and the radioactivity was counted using a liquid scintillation counter.

\subsubsection{Determination of Pharmacokinetic Profiles}

Plasma data was analyzed using WinNonlin Professional (version 5.0.1, Pharsight Corporation, Mountainview, CA). The Gal-PEG- ${ }^{33} \mathrm{P}-\mathrm{ODN}$ plasma concentration data versus time were fitted using one- and two-compartment models, and pharmacokinetic parameters were calculated area under the curve (AUC), $\mathrm{C}_{\max }, \mathrm{T}_{\max }$ and Clearance (CL). The data were best fitted to a two compartment model where

$$
C_{t}=A e^{-\alpha t}+B e^{-\beta t}
$$

and $\mathrm{C}_{\mathrm{t}}$ equals concentration at time $\mathrm{t}, \mathrm{A}$ and $\mathrm{B}$ are the $\mathrm{y}$-axis intercepts, and $\alpha$ and $\beta$ are the hybrid constants for distribution and elimination, respectively. Tissue distribution data of Gal-PEG- ${ }^{33} \mathrm{P}-\mathrm{ODN}$ were analyzed in terms of clearance and tissue uptake rate index using biexponential equations as described previously. (12) The change in the amount of radioactivity in a tissue with time can be described as follows:

$$
d T(t) / t=C L_{\text {in }} C(t)-K_{\text {out }} T(t)
$$

where $\mathrm{T}(\mathrm{t})(\%$ of dose/g) represents the amount of radioactivity in $1 \mathrm{~g}$ of the tissue, $\mathrm{C}(\mathrm{t})(\%$ of dose $/ \mathrm{mL})$ is the plasma concentration of radioactivity, $\mathrm{CL}_{\mathrm{in}}\left(\mathrm{mLh}^{-1} \mathrm{~g}^{-1}\right)$ is the tissue uptake rate index from the plasma to the tissue, and $\mathrm{K}_{\text {out }}\left(\mathrm{h}^{-1}\right)$ is the rate constant for efflux from the tissue. In the present study, the efflux process can be considered negligible during the initial time points up to $90 \mathrm{~min}$. Hence, eq 1 integrates to

$$
C L_{\text {in }}=T\left(t_{1}\right) \int_{0}^{t_{1}} C\left(t_{1}\right) d t=T\left(t_{1}\right) / A U C_{0-t_{1}}
$$

where $t_{1}(h)$ is the sampling time. According to Eq. 4-2, the tissue uptake rate index is calculated using the amount of radioactivity in the tissue and the area under the plasma 
concentration-time curve (AUC). Then, the organ clearance $\left(\mathrm{CL}_{\text {org }}\right)$ is expressed as follows:

$$
C L_{\text {org }}=C L_{i n} W
$$

where $\mathrm{W}(\mathrm{g})$ is the total weight of the organ. When the tissue uptake process followed nonlinear kinetics, $\mathrm{CL}_{\text {in }}$ values would represent an average value for the overall experimental period. Total body clearance $\left(\mathrm{CL}_{\text {total }}\right)$ was calculated from $\mathrm{AUC}$ for infinite time $\left(\mathrm{AUC}_{\infty}\right)$ by the following equation:

$$
C L_{\text {total }}=\text { dose } / A U C_{\infty}
$$

The tissue uptake clearance and index were calculated using the values up to 30 min after injection, assuming that ODNs were fairly stable within this period.

\subsubsection{Competition in Hepatic Uptake of Gal-PEG-ODN}

Two minutes before the injection of Gal-PEG- ${ }^{33} \mathrm{P}-\mathrm{ODN}$ at a dose of $0.2 \mathrm{mg} / \mathrm{kg}$ (specific activity: $1 \times 10^{6} \mathrm{cpm} / \mathrm{mL}$ ), rats received $10 \mathrm{mg} / \mathrm{Kg}$ of Gal-BSA via tail vein injection. At 30 min post injection, blood and urine were collected; other major organs were harvested as described above for radioactive measurement.

\subsubsection{Hepatic Cellular Distribution of Gal-PEG-ODN}

To determine the effect of conjugation with Gal-PEG on the hepatic uptake of ODNs, the liver was isolated and perfused in situ with $\mathrm{Ca}^{2+} / \mathrm{Mg}^{2+}$-free Hanks' balanced salt solution containing $0.1 \%$ pronase and $0.05 \%$ collagenase at $30 \mathrm{~min}$ post intravenous injection of ${ }^{33} \mathrm{P}-\mathrm{ODN}$ or Gal-PEG- ${ }^{33} \mathrm{P}-\mathrm{ODN}$ into rats as described previously (197). Briefly, rats $(200-250 \mathrm{~g})$ were anesthetized by inhalation of isoflurane, and $100 \mathrm{IU}$ of heparin was injected via tail vein, the abdomen was opened, and the portal vein was cannulated with PE-60 polyethylene tube. The liver was pre-perfused with $2 \mathrm{~mL}$ diluted heparin solution, then with $200 \mathrm{~mL} \mathrm{Ca}{ }^{2+} / \mathrm{Mg}^{2+}$-free Hank's balanced salt solution and finally with Hank's balanced salt solution containing $0.05 \%$ type IV collagenase and $0.1 \%$ pronase for additional $250 \mathrm{~mL}$. All the perfusion solutions were incubated at $37{ }^{\circ} \mathrm{C}$. After perfusion, different liver cell types were separated by Nycodenz gradient (202) and radioactivity was measured. The contributions of various cell types to the total liver uptake were calculated as percentage of total hepatic uptake.

\subsubsection{Statistical Analysis}

Data were expressed as the mean \pm standard deviation (SD). The difference between any two groups was determined by ANOVA. $\mathrm{P}<0.05$ was considered statistically significant. 


\subsection{RESULTS}

Chronic injury and inflammation of hepatocytes often lead to liver fibrosis and loss of sinusoidal fenestrae, suggesting that liposomal and nanoparticulate delivery systems may not be good for ODN delivery to the hepatocytes. Therefore, we synthesized Gal-PEG and conjugated to ODN by $\beta$-thiopropionate, an acid-labile linkage which is easily cleaved at acidic $\mathrm{pH}$, leading to endosomal release of ODNs after endocytosis (196). Following synthesis and characterization, we determined the biodistribution at whole body, organ (liver) and cellular (liver cells) levels after systemic administration of Gal-PEG- ${ }^{33} \mathrm{P}-\mathrm{ODN}$ in rats.

\subsubsection{Synthesis and Characterization of Gal-PEG and Gal-PEG-ODN}

The synthesis scheme of Gal-PEG-ODN conjugate is shown in Figure 4.1. pNitrophenyl $\beta$-D-galactopyranoside was reduced to $p$-aminophenyl $\beta$-Dgalactopyranoside. ESI-MS and ${ }^{1} \mathrm{H}$ NMR results of this intermediate product are shown in Figure 4.2. ESI-MS (positive ion mode): $294.1\left([\mathrm{M}+\mathrm{Na}]^{+}\right)$(Figure 4.2A); ${ }^{1} \mathrm{H}$ NMR $\left(\mathrm{D}_{2} \mathrm{O}\right): \delta 6.73(\mathrm{~d}, 1 \mathrm{H}), 6.90(\mathrm{~d}, 1 \mathrm{H}), 5.35(\mathrm{~s}, 1 \mathrm{H}), 3.76-4.09(\mathrm{~m}, 4 \mathrm{H}), 3.61(\mathrm{~m}, 2 \mathrm{H})$ (Figure 4.2B). Gal-PEG-acrylate was synthesized from NHS-PEG-acrylate and identified by MALDI-TOF MS and ${ }^{1} \mathrm{H}$ NMR. For MALDI-TOF MS, DHB was used as a matrix at the weight ratio of 1:2 (Gal-PEG-acrylate/DHB). Molecular weight of Gal-PEG-acrylate was $3758 \mathrm{Da}$ after conjugation between acrylate-PEG-NHS (MW $3486 \mathrm{Da}$ ) and paminophenyl $\beta$-D-galactopyranoside (MW $271 \mathrm{Da}$ ) (Figure 4.3A). ${ }^{1} \mathrm{H}$ NMR $\left(\mathrm{D}_{2} \mathrm{O}\right): \delta$ $7.35(\mathrm{~d}, 2 \mathrm{H}), 7.12(\mathrm{~d}, 2 \mathrm{H}), 5.54(\mathrm{~s}, 1 \mathrm{H}), 3.48-3.92(\mathrm{~m}, 538 \mathrm{H}), 5.93(\mathrm{~d}, 2 \mathrm{H}), 6.17(\mathrm{t}, 1 \mathrm{H})$, $6.40(\mathrm{~d}, 1 \mathrm{H})$ (Figure 4.3B). Gal-PEG was then conjugated to ODN by Michael addition from p-aminophenyl $\beta$-D-galactopyranoside and Gal-PEG-acrylate. Gal-PEG-ODN was also identified by native polyacrylamide gel electrophoresis (PAGE) and staining with methylene blue (Figure 4.4). For the purification process, the RP-HPLC was used to monitor the mixtures and the purity of the intermediate and final products. From the HPLC chromatograms of ODNs, PEG and Gal-PEG-ODN conjugate shown in Figure 4.5, almost all PEG and ODNs were removed from the conjugate after purification. G-rich ODNs used in this study has the tendency to form G-quartets, which may decrease the recovery of the conjugate.

\subsubsection{Dissociation and Stability}

To determine the dissociation and stability of Gal-PEG- ${ }^{33} \mathrm{P}-\mathrm{ODN}$, the radioactivity of the samples was measured after gel electrophoresis and autoradiography at $0,1,2$ and 4 h post-incubation of the conjugate in Tris $\mathrm{HCl}$ buffer of $\mathrm{pH} 5.5$ and rat serum, respectively. In the $\mathrm{pH} 5.5$ buffer, the band of Gal-PEG- ${ }^{33} \mathrm{P}-\mathrm{ODN}$ gradually disappeared along the incubation time, while the band of the ${ }^{33} \mathrm{P}-\mathrm{ODN}$ was still there even up to $4 \mathrm{~h}$ (Figure 4.6). In contrast, this conjugate was fairly stable in rat serum for at 


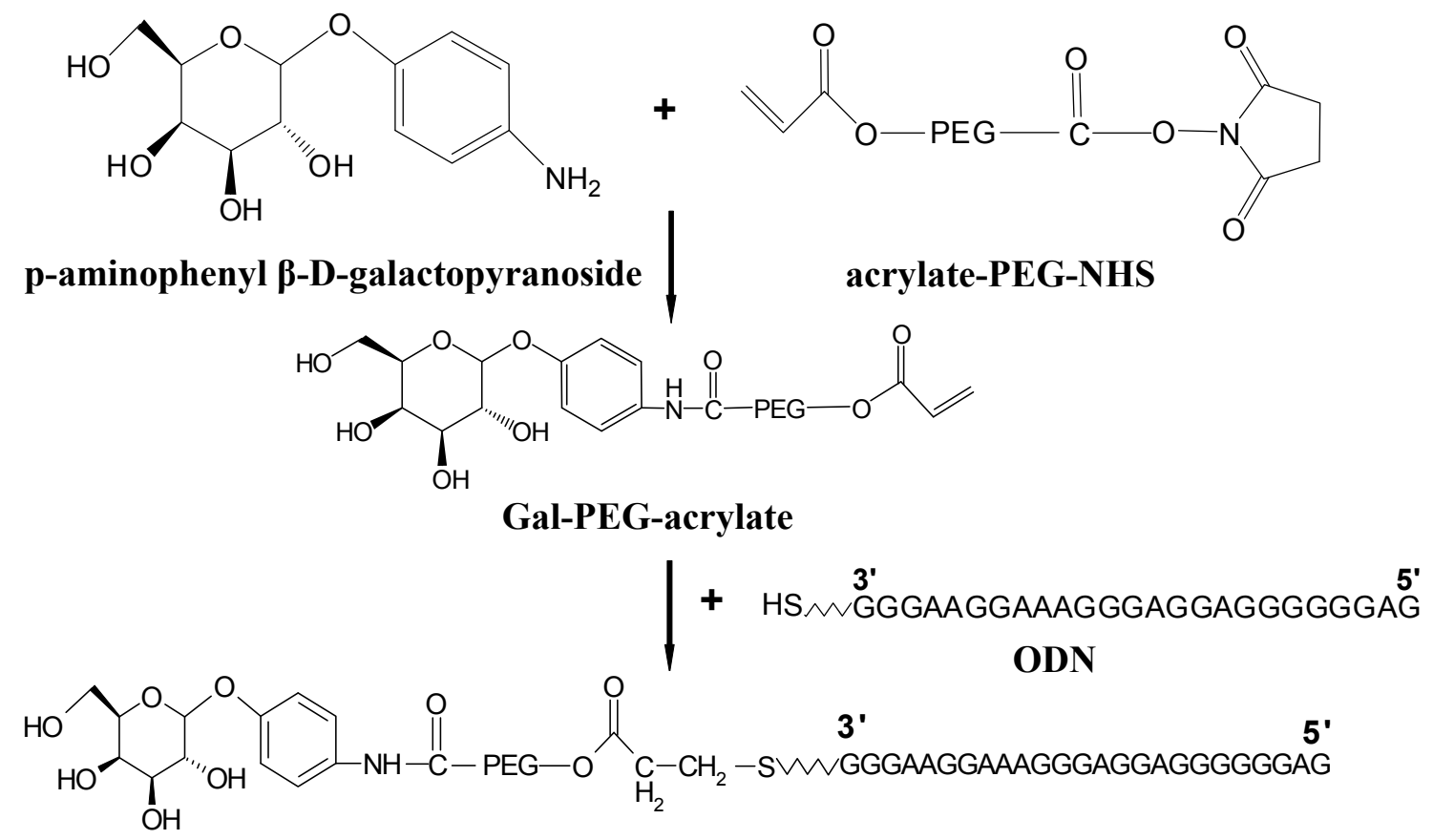

\section{Gal-PEG-ODN}

Figure 4.1 Synthesis scheme of Gal-PEG-ODN.

$\mathrm{p}$-Nitrophenyl $\beta$-D-galactopyranoside was reduced to $\mathrm{p}$-aminophenyl $\beta$-Dgalactopyranoside, which was reacted with easy going group, NHS, of acrylate-PEGNHS, resulted in Gal-PEG-acrylate. Then Gal-PEG-acrylate was conjugated to 3'-thiol ODN by Michael addition. 
A)

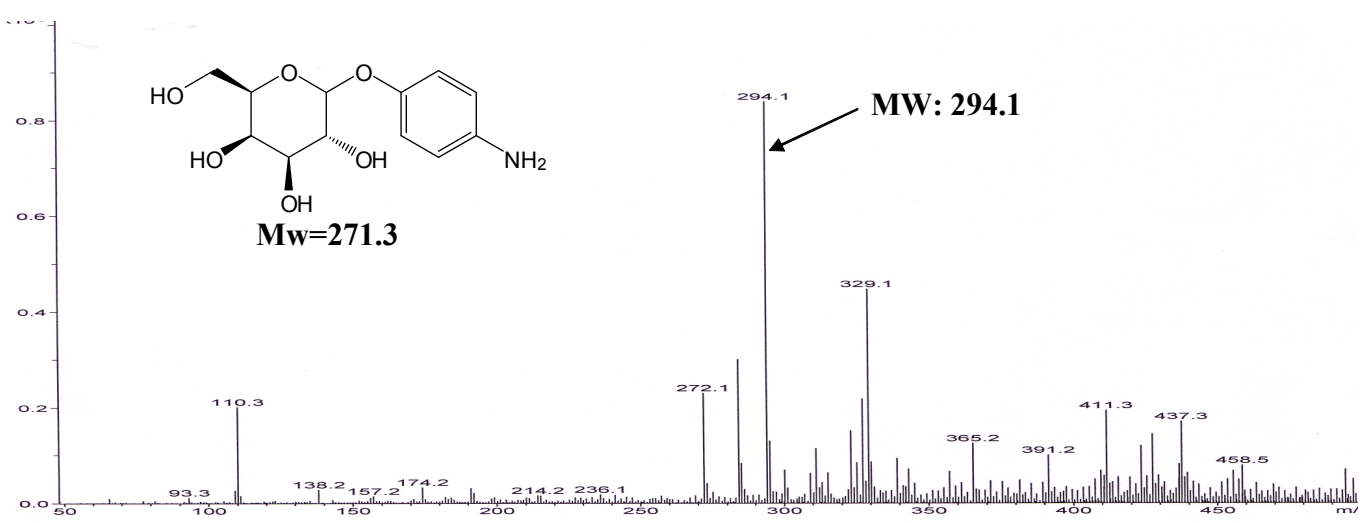

B)

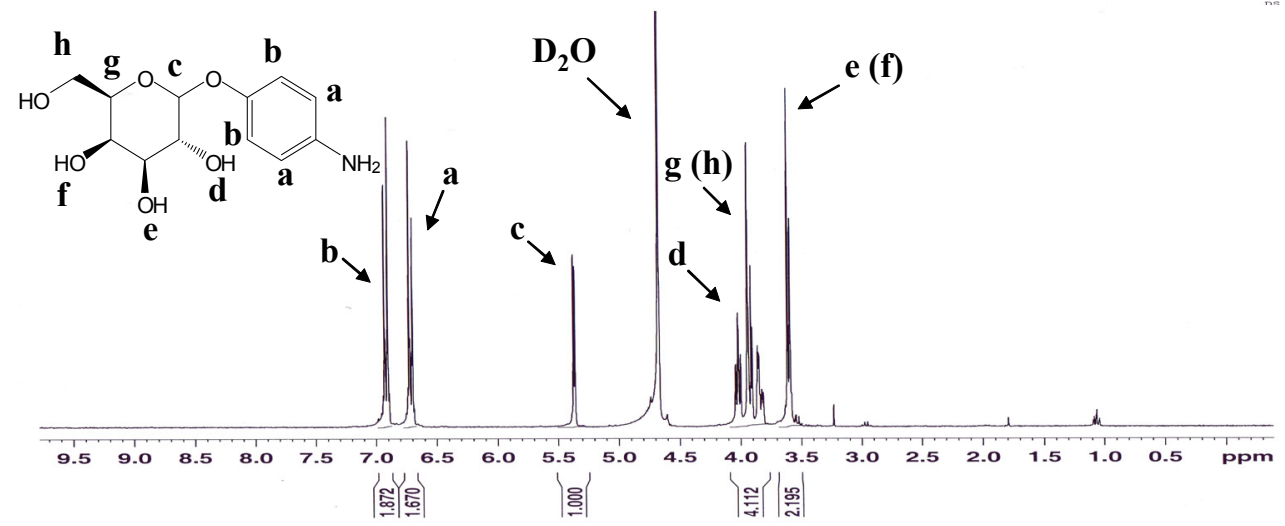

Figure 4.2 Characterization of p-aminophenyl $\beta$-D-galactopyranoside with ESIMS and ${ }^{1}$ H NMR.

Electron spray ionization mass spectra (A) were obtained after dissolving the product in methanol on an ESQUIRE-LC Ion Trap LC/MS system. For ${ }^{1} \mathrm{H}$ NMR (B), samples were dissolved in $\mathrm{D}_{2} \mathrm{O}$ and the spectra were recorded on a Bruker ARX-300 MHz NMR spectrometer at $25^{\circ} \mathrm{C}$. 
A)

B)
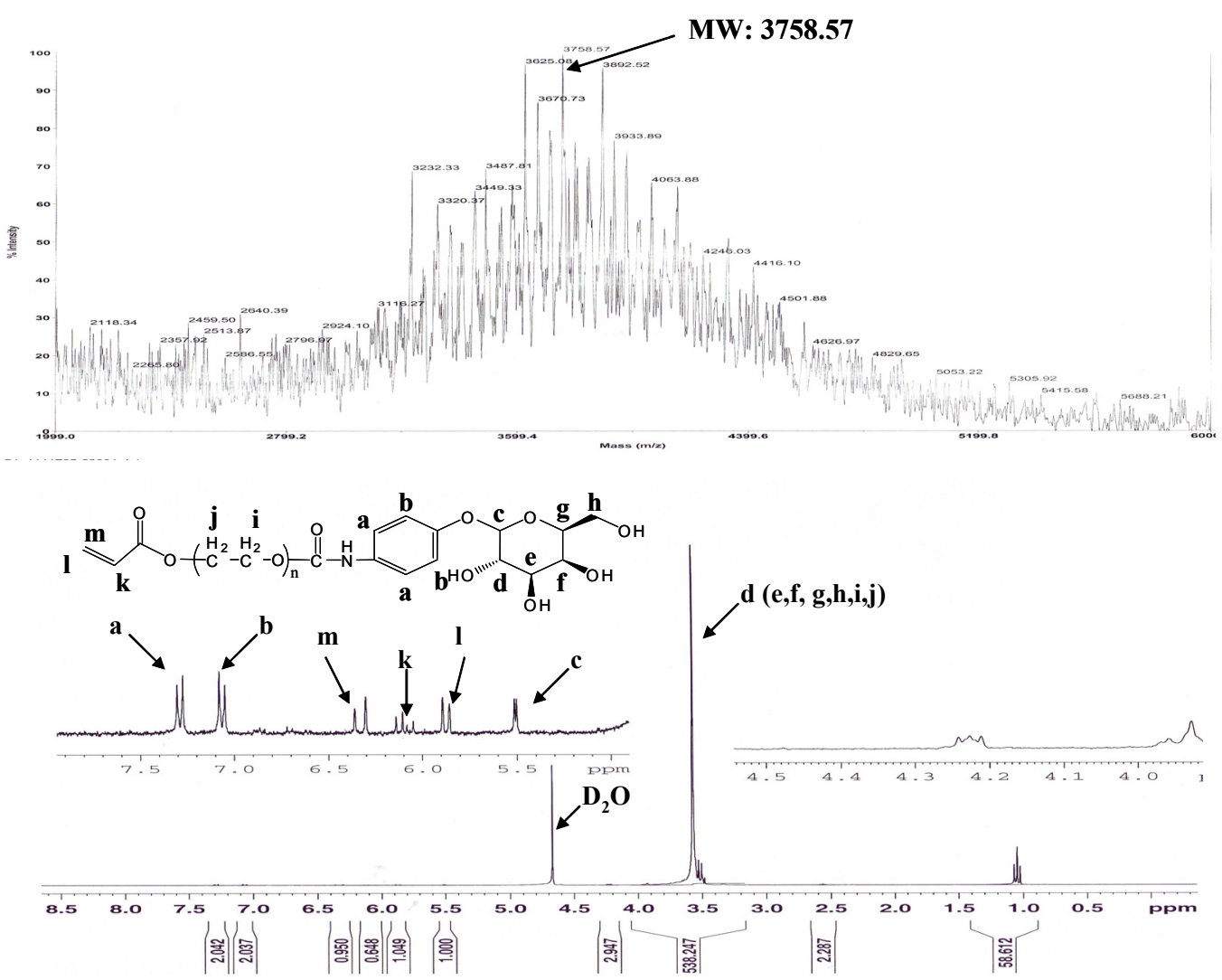

Figure 4.3 Characterization of Gal-PEG-acrylate with MALDI-TOF-MS and ${ }^{1} \mathrm{H}$ NMR.

For MALDI-TOF-MS (A) the ratio between Gal-PEG-acrylate and DHB was 1:2. The spectrum was recorded on Voyager-DE RP (PerSeptive Biosystems Inc., MA). For ${ }^{1} \mathrm{H}$ NMR (B), samples were dissolved in $\mathrm{D}_{2} \mathrm{O}$ and the spectra were recorded on a Bruker ARX-300 MHz NMR spectrophotometer at $25^{\circ} \mathrm{C}$. 


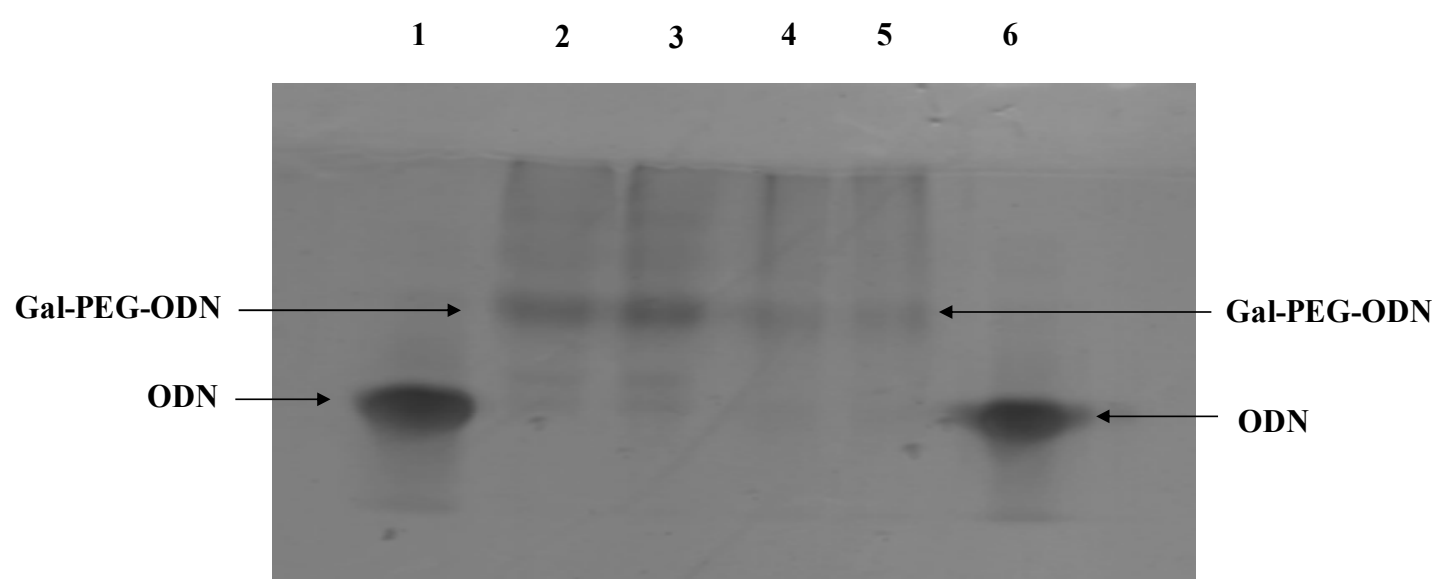

Figure 4.4 Identification of Gal-PEG-ODN by PAGE.

The gel was running at $80 \mathrm{v}$ for $100 \mathrm{~min}$, followed by staining with methylene blue for one night. Lane 1 and 6: ODN $2 \mu \mathrm{g}$; lane 2 and 3: Gal-PEG-ODN $2 \mu \mathrm{g}$; lane 4 and 5:

Gal-PEG-ODN $1 \mu \mathrm{g}$. 

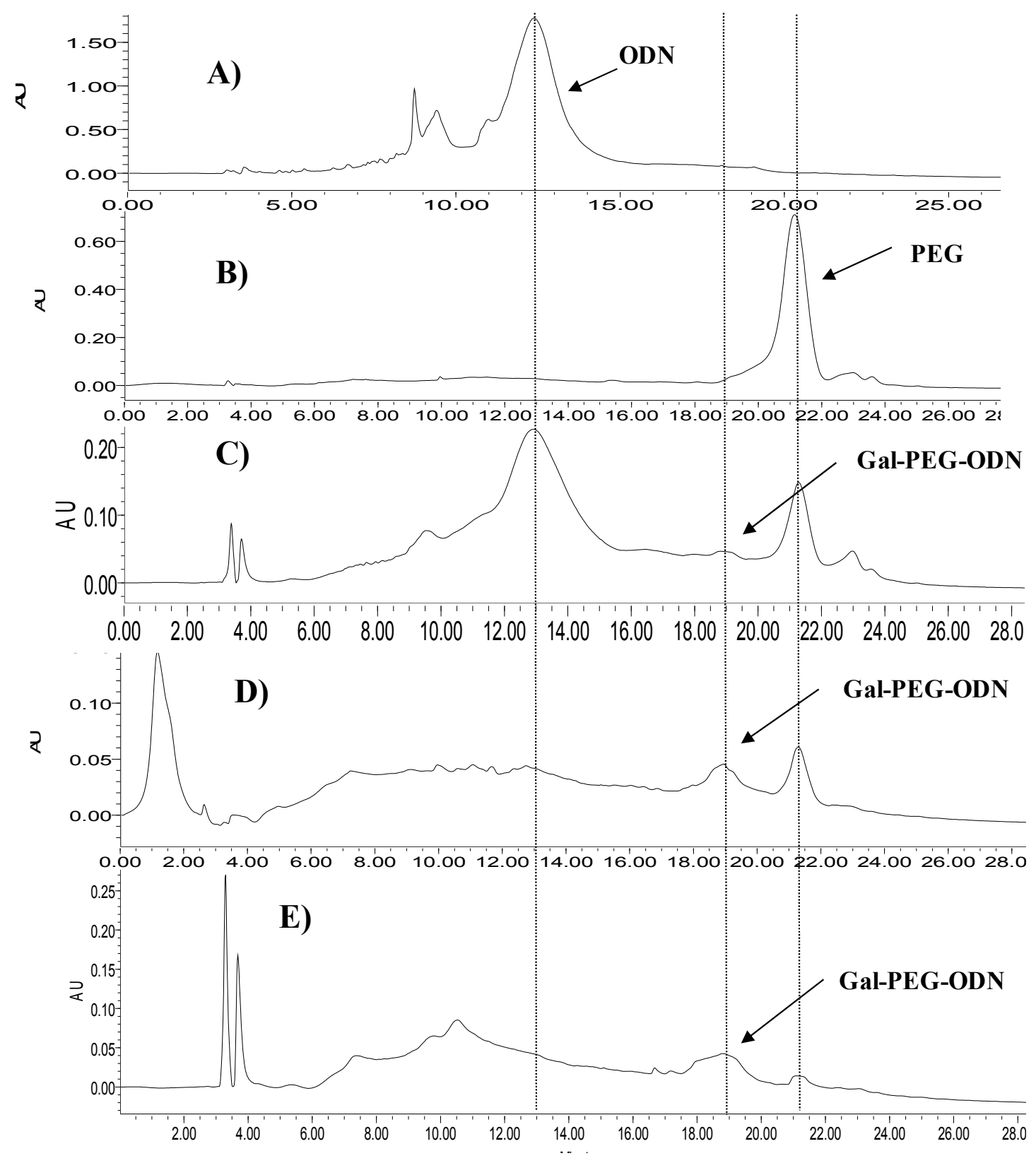

Figure 4.5 HPLC chromatograms of ODN (A), PEG (B), reaction mixture (C), during purification (D) and after purification (E) of Gal-PEG-ODN. 

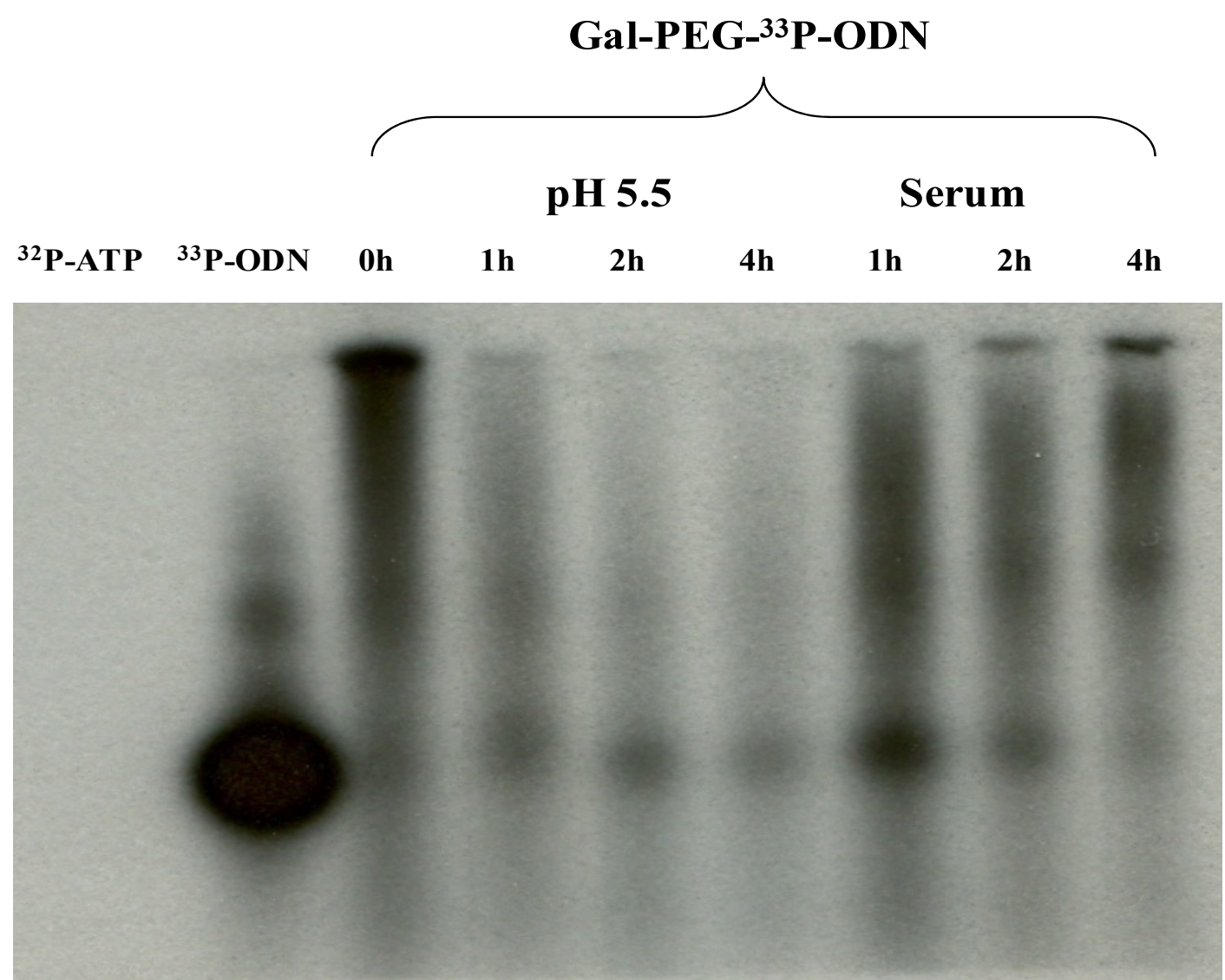

Figure 4.6 Dissociation and stability study of Gal-PEG- ${ }^{33}$ P-ODN.

Dissociation of ${ }^{33} \mathrm{P}-\mathrm{ODN}$ from Gal-PEG- ${ }^{33} \mathrm{P}-\mathrm{ODN}$ was determined by incubating the conjugate at $37^{\circ} \mathrm{C}$ in $\mathrm{pH} 5.5$ buffer, while its stability was determined by incubating the conjugate at $37^{\circ} \mathrm{C}$ in rat serum. The band for Gal-PEG- ${ }^{33} \mathrm{P}-\mathrm{ODN}$ decrease with time when incubate at acidic $\mathrm{pH}$. 
least $4 \mathrm{~h}$. The result suggests that the conjugate was fairly stable in serum, but its acid labile ester linkage can be cleaved at acidic $\mathrm{pH}$. Our study also confirmed the previous report about this kind of conjugates by Oishi et al. (196).

\subsubsection{Biodistribution of Gal-PEG-ODN Conjugate}

Following synthesis and purification of Gal-PEG and then conjugation to ${ }^{33} \mathrm{P}-$ ODN, we determined the biodistribution of Gal-PEG- ${ }^{33} \mathrm{P}-\mathrm{ODN}$ at $2.5,5,15,30,90,240$ and 1440 min post injection into the tail vein of rats. Figure 4.7A shows the time course of radioactivity in the plasma, urine, liver, kidney, lung, heart and spleen (radioactivity in muscle was too low, not shown here). Gal-PEG- ${ }^{33} \mathrm{P}-\mathrm{ODN}$ was rapidly cleared from the circulation with less than $10 \%$ of radioactivity detected in the plasma at 30 min postinjection. Correspondingly hepatic uptake of Gal-PEG- ${ }^{33} \mathrm{P}-\mathrm{ODN}$ increased with time and reached its peak at $30 \mathrm{~min}$ post administration and then decreased with time. To compare the biodistribution profiles of Gal-PEG- ${ }^{33} \mathrm{P}-\mathrm{ODN},{ }^{33} \mathrm{P}-\mathrm{ODN}$ was also injected into rats, and ODN accumulation and concentration in different organs were determined at $30 \mathrm{~min}$ post-injection. Figure 4.7B shows the tissue concentration of Gal-PEG- ${ }^{33} \mathrm{P}-\mathrm{ODN}$ in the plasma $(\mu \mathrm{g} / \mathrm{mL})$ and tissues $(\mu \mathrm{g} / \mathrm{g})$ after tail vein injection into rats, while the conjugation of ODN with Gal-PEG significantly increased the accumulation of radioactivity ( $\%$ of dose) in the liver, as compared to that of ${ }^{33} \mathrm{P}-\mathrm{ODN}$. Gal-PEG- ${ }^{33} \mathrm{P}-\mathrm{ODN}$ concentration was high not only in the liver, but also in the spleen and kidney (Figure 4.7). Almost $60.2 \%$ (about $2.88 \mu \mathrm{g}$ ODN/g liver tissue) of the conjugate accumulated in the liver compared to about $40 \%$ (data not shown) (about $2.01 \mu \mathrm{g}$ ODN/g liver tissue) accumulation by free ODNs at 30 min post administration. Plasma elimination of Gal-PEG- ${ }^{33} \mathrm{P}-\mathrm{ODN}$ was biphasic with a distribution half-life $\left(\mathrm{t}_{1 / 2 \alpha}\right)$ of $4.38 \pm 0.36 \mathrm{~min}$ and elimination half-life $\left(t_{1 / 2 \beta}\right)$ of $118.61 \pm 22.06 \mathrm{~min}$. Figure 4.8 summarized the pharmacokinetic parameters such as AUC, $\mathrm{V}_{\mathrm{d}}, \mathrm{CL}$ and MRT. Consistent with rapid clearance $(0.37 \pm 0.09 \mathrm{~mL} / \mathrm{min})$, Gal-PEG- ${ }^{33} \mathrm{P}-\mathrm{ODN}$ had a large $\mathrm{V}_{\mathrm{d}}$ of $35.98 \pm 2.64 \mathrm{~mL}$. Table 4.1 summarizes the AUC, tissue uptake rate index and organ clearance for representative organs after systemic administration of ${ }^{33} \mathrm{P}-\mathrm{ODN}$ and Gal-PEG- ${ }^{33} \mathrm{P}-\mathrm{ODN}$ in rats. The liver uptake rate index and clearance of Gal-PEG ${ }^{33} \mathrm{P}-\mathrm{ODN}$ were significantly higher than those of ${ }^{33} \mathrm{P}-\mathrm{ODN}$ : $2663.27 \pm 56.63$ versus $376.15 \pm 38.34 \mu \mathrm{L} \cdot \mathrm{h}^{-1} \cdot \mathrm{g}^{-1}$ and $16674.22 \pm 354.55$ versus 2218.09 $\pm 205.68 \mu \mathrm{L} \cdot \mathrm{h}^{-1} \cdot \mathrm{g}^{-1}$, respectively. The spleen was in the second place with the tissue uptake rate index of $969.26 \pm 51.79$ versus $204.73 \pm 9.64 \mu \mathrm{L} \cdot \mathrm{h}^{-1} \cdot \mathrm{g}^{-1}$ and $\mathrm{CL}_{\text {org }}$ of $395.84 \pm$ 21.15 versus $82.85 \pm 7.32 \mu \mathrm{L} \cdot \mathrm{h}^{-1}$. The tissue uptake rate indices and organ clearances of heart, kidney and lung were significantly higher than those of ${ }^{33} \mathrm{P}-\mathrm{ODN}$, possibly due to increased in vivo stability of ODN upon conjugation with Gal-PEG.

\subsubsection{Competition in Hepatic Uptake of Gal-PEG- $-{ }^{33}$ P-ODN}

The role of asialoglycoprotein receptor on biodistribution of Gal-PEG- ${ }^{33} \mathrm{P}-\mathrm{ODN}$ in rats was assessed by determining the effect of excess Gal-BSA on the accumulation of Gal-PEG- ${ }^{33} \mathrm{P}-\mathrm{ODN}$ in the liver. Galactosylated proteins or polymeric systems are known to be taken up by asialoglycoprotein receptor-mediated endocytosis. We have previously 
A)
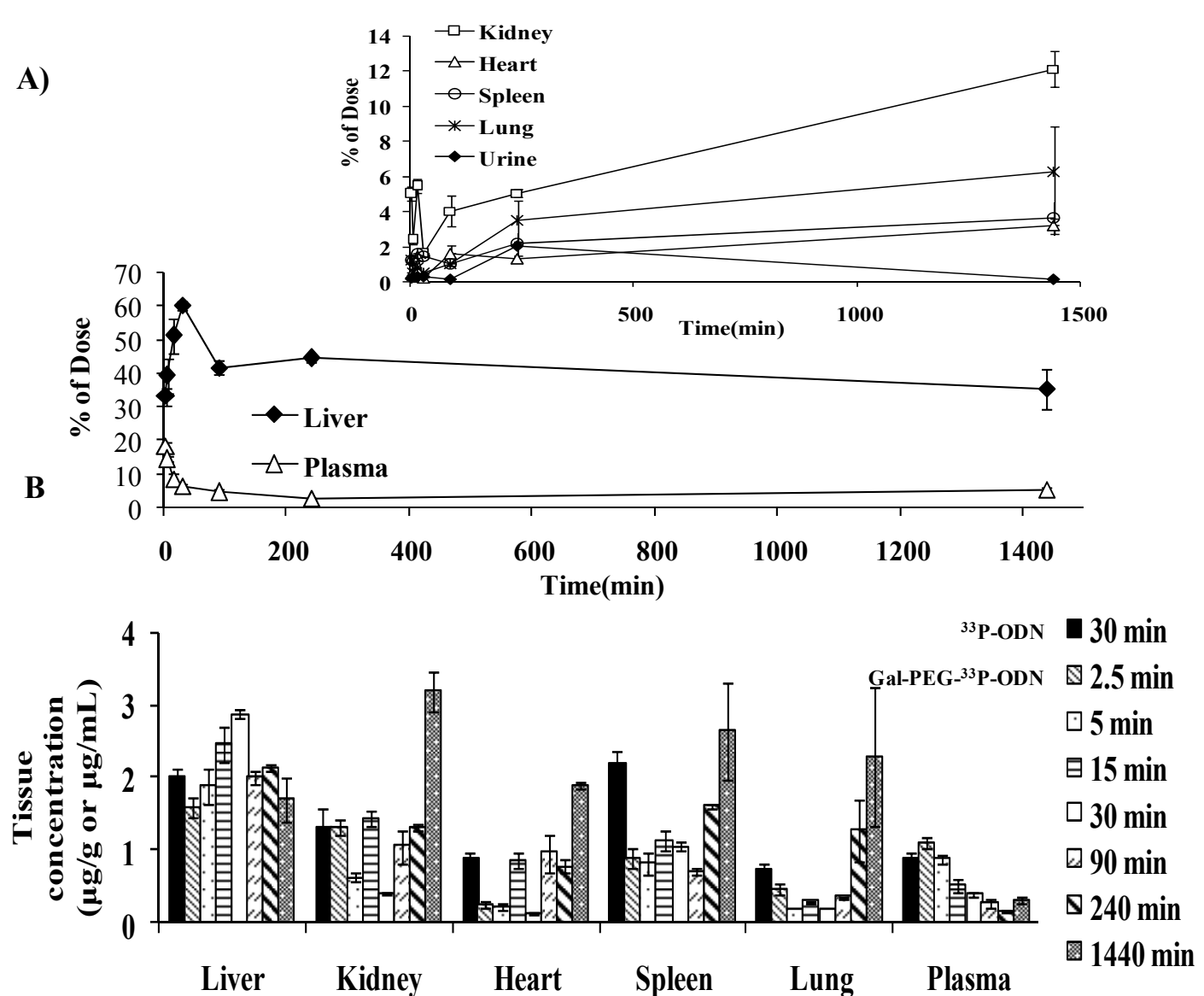

Figure 4.7 Accumulation (A) and concentration (B) of Gal-PEG- ${ }^{33}$ P-ODN after tail vein injection into rats at a dose of $0.2 \mathrm{mg} O D N / \mathrm{Kg}$ of body weight.

To compare the biodistribution profiles of Gal-PEG- ${ }^{33} \mathrm{P}-\mathrm{ODN},{ }^{33} \mathrm{P}-\mathrm{ODN}$ was also injected, and ODN accumulation and concentration in different tissues were determined at $30 \mathrm{~min}$ post-injection. Following blood collection by cardiac puncture and urine collection from the bladder, the tissues were isolated, digested and subjected to radioactivity measurement. The amounts of Gal-PEG- ${ }^{33} \mathrm{P}-\mathrm{ODN}$ and ${ }^{33} \mathrm{P}-\mathrm{ODN}$ were converted from there radioactivity, $1 \times 10^{6} \mathrm{cpm} / \mathrm{mg}$. Results are presented as the mean \pm S.D. $(n=4)$. 


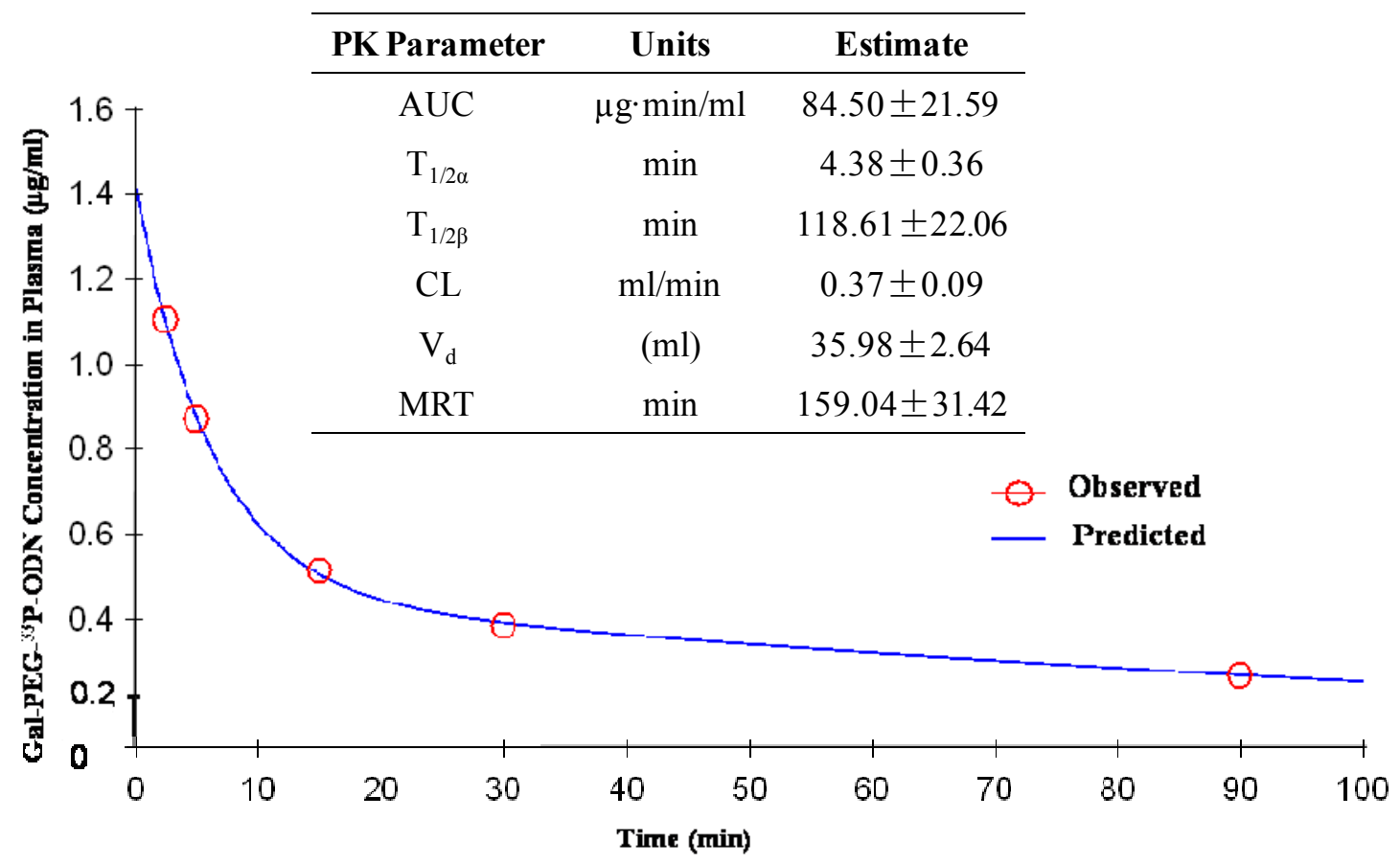

Figure 4.8 Plasma data was analyzed using a two compartment model with WinNonlin Professional (version 5.0.1) software.

The amount of Gal-PEG- ${ }^{33} \mathrm{P}-\mathrm{ODN}$ was converted from its radioactivity, $1 \times 10^{6} \mathrm{cpm} / \mathrm{mg}$. Data are represented as the mean $\pm \operatorname{SD}(n=4)$. 
Table 4.1 Tissue uptake rate index and clearance of ${ }^{33} \mathrm{P}-\mathrm{ODN}$ and Gal-PEG- ${ }^{33} \mathrm{P}-\mathrm{ODN}$ after systemic administration into rats.

\begin{tabular}{|c|c|c|c|c|c|c|c|c|c|c|c|}
\hline \multirow{2}{*}{ Samples } & \multirow{2}{*}{$\begin{array}{c}A U C^{*} \\
(\mu \mathrm{g} \cdot \mathrm{min} / \mathrm{mL})\end{array}$} & \multicolumn{5}{|c|}{ Tissue uptake rate index $\left(\mu \mathrm{L} \cdot \mathrm{h}^{-1} \cdot \mathrm{g}^{-1}\right)$} & \multicolumn{5}{|c|}{ Organ clearance $\left(\mu L \cdot h^{-1}\right)$} \\
\hline & & Liver & Kidney & Heart & Spleen & Lung & Liver & Kidney & Heart & Spleen & Lung \\
\hline $\begin{array}{l}{ }^{33} \mathrm{P}- \\
\text { ODN }\end{array}$ & $\begin{array}{l}95.15 \\
\pm 5.11\end{array}$ & $\begin{array}{l}376.15 \\
\pm 38.34\end{array}$ & $\begin{array}{l}235.23 \\
\pm 29.39\end{array}$ & $\begin{array}{l}48.76 \\
\pm 3.42\end{array}$ & $\begin{array}{c}204.73 \\
\pm 9.64\end{array}$ & $\begin{array}{l}55.28 \\
\pm 8.90\end{array}$ & $\begin{array}{l}2218.09 \\
\pm 205.68\end{array}$ & $\begin{array}{l}241.00 \\
\pm 41.08\end{array}$ & $\begin{array}{l}22.96 \\
\pm 1.94\end{array}$ & $\begin{array}{l}82.85 \\
\pm 7.32\end{array}$ & $\begin{array}{l}42.21 \\
\pm 8.44\end{array}$ \\
\hline $\begin{array}{c}\text { Gal- } \\
\text { PEG- } \\
{ }^{33} \mathrm{P}- \\
\text { ODN }\end{array}$ & $\begin{array}{c}84.50 \\
\pm 21.59\end{array}$ & $\begin{array}{l}2663.27 \\
\pm 56.63\end{array}$ & $\begin{array}{l}376.52 \\
\pm 11.16\end{array}$ & $\begin{array}{l}119.24 \\
\pm 10.81\end{array}$ & $\begin{array}{l}969.26 \\
\pm 51.79\end{array}$ & $\begin{array}{l}161.16 \\
\pm 7.00\end{array}$ & $\begin{array}{l}16674.22 \\
\pm 354.55\end{array}$ & $\begin{array}{l}428.81 \\
\pm 12.71\end{array}$ & $\begin{array}{l}59.67 \\
\pm 5.41\end{array}$ & $\begin{array}{l}395.84 \\
\pm 21.15\end{array}$ & $\begin{array}{l}131.22 \\
\pm 5.70\end{array}$ \\
\hline
\end{tabular}

* The amount of Gal-PEG- ${ }^{33} \mathrm{P}-\mathrm{ODN}$ was converted from its radioactivity, $1 \times 10^{6} \mathrm{cpm} / \mathrm{mg}$. 
demonstrated that one minute pre-injection of excess Gal-BSA can saturate asialoglycoprotein receptors present on the surface of hepatocytes, resulting in decreased hepatic uptake of Gal-PLL/ODN complexes. Staud et al. (1999) also injected galactosylated superoxide dismutase (Gal-SOD) two minute post-injection of excess GalBSA and demonstrated significant decrease in the hepatic uptake of Gal-SOD (189). Therefore, 2 min interval between the intravenous injections of Gal-BSA and Gal-PEGODN is reasonable for the competition study. Systemic administration of excess GalBSA is known to saturate the asialoglycoprotein receptor of the Hepatocytes (203). Prior administration of Gal-BSA at a dose of $10 \mathrm{mg} / \mathrm{Kg}$ caused a significant decrease in the hepatic uptake of Gal-PEG- ${ }^{33} \mathrm{P}-\mathrm{ODN}$, but increase in the radioactivity in plasma and other organs at $30 \mathrm{~min}$ post injection. The hepatic uptake of Gal-PEG- ${ }^{33} \mathrm{P}-\mathrm{ODN}$ decreased from $60.2 \%$ to $35.9 \%$ (Figure 4.9 ). This suggests the involvement of asialoglycoprotein receptor in their hepatic uptake.

\subsubsection{Hepatic Cellular Localization}

To determine the intrahepatic localization of Gal-PEG- ${ }^{33} \mathrm{P}-\mathrm{ODN}$ and to determine whether the uptake of this conjugate by hepatocytes is mediated by asialoglycoprotein receptors, the liver was perfused at $30 \mathrm{~min}$ post tail vein injection of ${ }^{33} \mathrm{P}-\mathrm{ODN}$ or GalPEG- ${ }^{33} \mathrm{P}-\mathrm{ODN}$, and different types of liver cells were isolated for determining the amount of radioactivity in these cells. As shown in Figure 4.10, the hepatocytes were the major site for the uptake of Gal-PEG- ${ }^{33} \mathrm{P}-\mathrm{ODN}$. At $30 \mathrm{~min}$ about $58 \%$ of the total liver recovery was in the hepatocytes compared to only $30 \%$ for the ${ }^{33} \mathrm{P}-\mathrm{ODNs}$ (Figure 4.10 ). Accordingly, the uptake of Gal-PEG- ${ }^{33} \mathrm{P}-\mathrm{ODN}$ in the liver non-parenchymal cells (NPC) was $42 \%$ compared to $70 \%$ for ${ }^{33} \mathrm{P}-\mathrm{ODN}$. This suggests that a large $\%$ of the injected Gal- PEG- ${ }^{33} \mathrm{P}-\mathrm{ODN}$ was taken up by the liver via asialoglycoprotein receptor-mediated endocytosis.

\subsection{DISCUSSION}

Systemic delivery of ODNs is promising for treating both genetic and acquired diseases. Phosphorothioate (PS) ODNs are by far the most extensively studied, and significant progress has been made which resulted in one commercial product (Vitravene) as well as several promising clinical trials (204). To enhance the cellular uptake of ODNs by HepG2.2.15 cells which are stably transfected with hepatitis B virus (HBV), Wu and Wu conjugated asialoorosomucoid to poly(L-lysine) and then formed complex with 21 mer ODN complementary to a portion of human HBV. There was significant increase in ODNs uptake by HepG 2.2.15 cells, and the concentration of Hepatitis B Surface Antigen (HBsAg) was $80 \%$ lower than controls after $24 \mathrm{~h}$ (205). However, these authors did not determine the biodistribution of asialooromucoid-PLL/ODN complexes after systemic administration in rodents.

We have previously shown that although complex formation with Gal-PLL enhances ODN uptake by hepatocytes after systemic administration in mice, the 


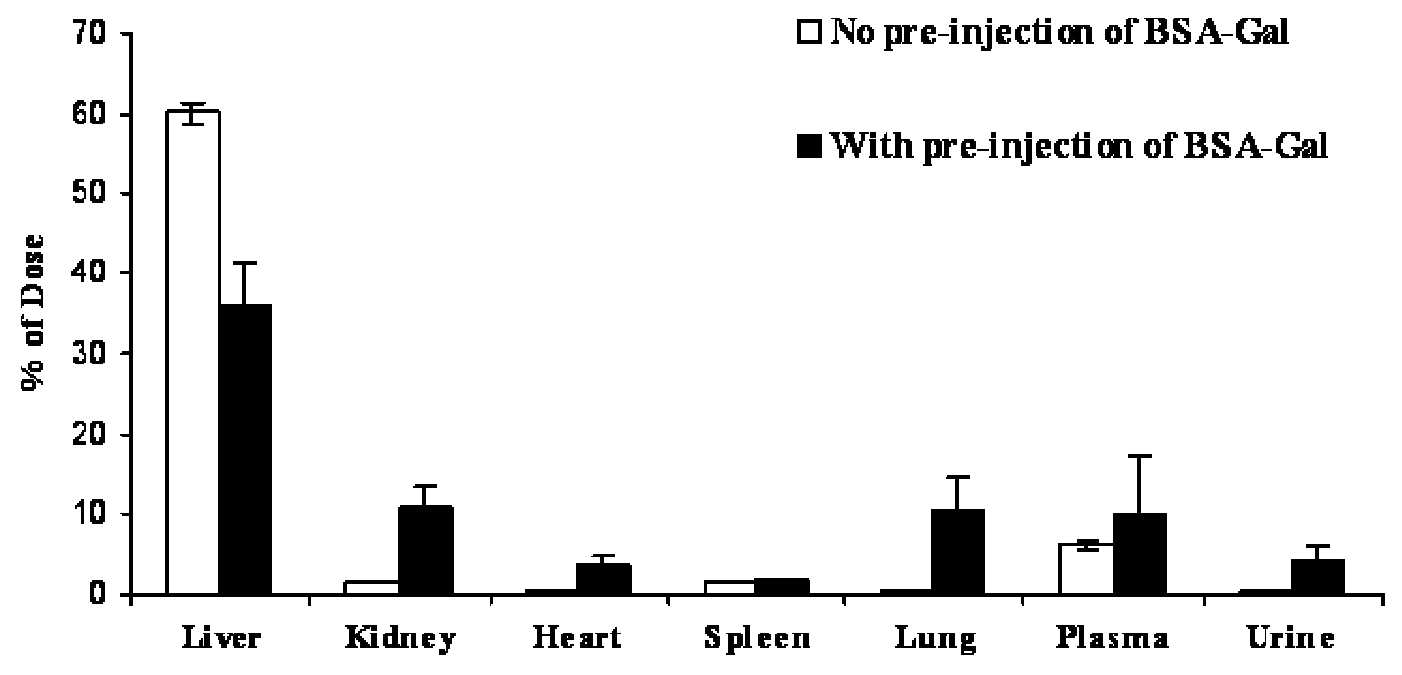

Figure 4.9 Effect of Gal-BSA on biodistribution of Gal-PEG- $-{ }^{33}$ P-ODN after systemic administration into rats.

Gal-BSA $(10 \mathrm{mg} / \mathrm{Kg})$ was injected intravenously into rats 2 minutes before the injection of Gal-PEG- ${ }^{33} \mathrm{P}-\mathrm{ODN}$ at a dose of $0.2 \mathrm{mg} / \mathrm{Kg}$. At 30 minute post injection, rats were sacrificed, major organs were isolated and radioactivity was determined. Data are represented as the mean $\pm \operatorname{SD}(n=4)$. 


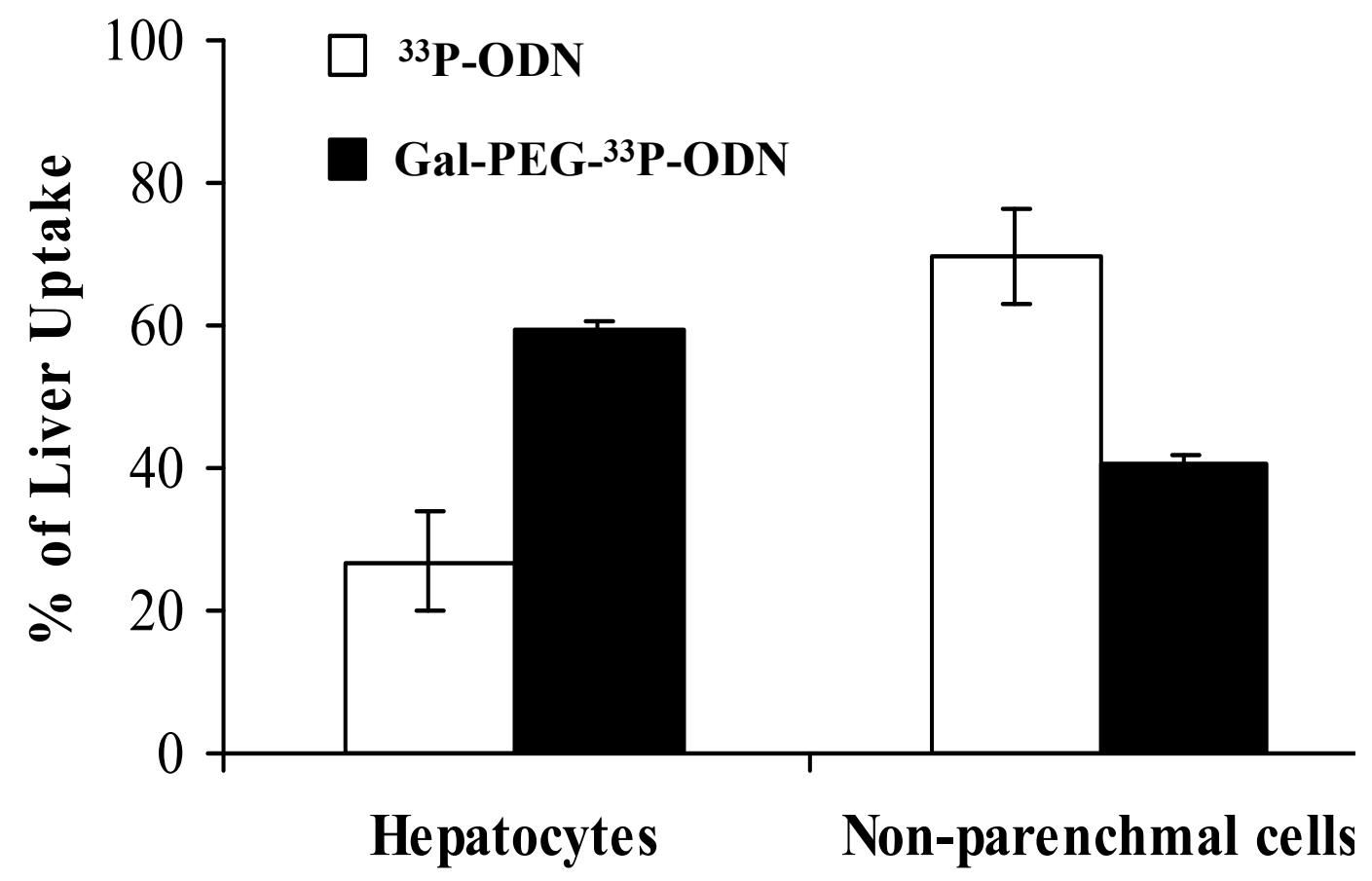

Figure 4.10 Hepatic cellular localization of ${ }^{33}$ P-ODN and Gal-PEG- ${ }^{33}$ P-ODN.

The liver was perfused by collagenase/pronase digestion at $30 \mathrm{~min}$ post injection of ${ }^{33} \mathrm{P}$ ODN or Gal-PEG- ${ }^{33} \mathrm{P}-\mathrm{ODN}$ at a dose of $0.2 \mathrm{mg} / \mathrm{Kg}$. Parenchymal and non-parenchymal cells were separated and the associated radioactivity was measured. Values are the mean \pm S.D. of 4 rats. 
difference in the intracellular distribution of Gal-PLL/ODN and ODN was only moderate, possibly because of the non-specific ionic interaction due to polycations (12). Therefore, in this study, we conjugated ODN to Gal-PEG via an acid labile ester linkage of $\beta$ thiopropionate, which will be cleaved in response to a $\mathrm{pH}$ decrease in the endosome. Oishi et al. (2003) demonstrated the hydrolysis of $\beta$-thiopropionate linkage (ester linkage) of the PEG-ODN conjugate at $\mathrm{pH} 5.5$, but not at $\mathrm{pH} 7.4$ even after incubation at $37^{\circ} \mathrm{C}$ for $24 \mathrm{~h}(196)$.

Consistent with our results on Gal-PLL/ODN complexes (12), the plasma kinetic disposition of Gal-PEG- ${ }^{33} \mathrm{P}-\mathrm{ODN}$ was characterized by rapid distribution to most peripheral tissues, with the highest disposition in the liver (Figures 4.7A and 4.7B). Bioconjugation with Gal-PEG decreased the urinary clearance of ODNs to a great extent (12). The liver accumulation of Gal-PEG- ${ }^{33} \mathrm{P}-\mathrm{ODN}$, including radioactivity and ODN concentration, significantly increased within a short time and reached its peak at $30 \mathrm{~min}$ post administration. Generally, after the peak time point the accumulation of the radioactivity and the concentration should decrease along the time. However, in the present study both of them showed slight increase in the hepatic uptake at $240 \mathrm{~min}$ and then decreased, while in other organs the accumulation and concentration of ODNs increased significantly until $24 \mathrm{~h}$. The possible reason for this phenomenon is that after endocytosis of Gal-PEG-ODN by the liver cells the $\beta$-thiopropionate linkage becomes not stable and ODN will be released from conjugate gradually. The degradation reaction makes the cell an ODN depot. Then some of ODNs can distribute to all over the body.

We determined the role of the asialoglycoprotein receptors on biodistribution of Gal-PEG- ${ }^{33} \mathrm{P}-\mathrm{ODN}$ in rats by the competition effect of excess Gal-BSA on the hepatic uptake of ODNs. There was significant decrease in ODN deposition to the liver, but increase in its accumulation to other organs and tissues, suggesting that Gal-PEG-ODN was taken up by hepatocytes via the galactose-specific asialoglycoprotein receptor mediated endocytosis (Figure 4.9). The higher uptake of ODNs in hepatocytes compared with non-parenchymal cells in the cellular distribution (Figure 4.10) and the highest accumulation of ODNs in liver compared with other organs in whole body level biodistribution after ODN conjugated with Gal-PEG (Figure 4.7) further confirmed this result.

In conclusion, in this study we synthesized a Gal-PEG-ODN conjugate for sitespecific delivery to hepatocytes. In contrast to ${ }^{33} \mathrm{P}-\mathrm{ODN}$, Gal-PEG- $-{ }^{33} \mathrm{P}-\mathrm{ODN}$ was efficiently taken up by hepatocytes and less efficiently by non-parenchymal cells (Figure 4.10). Thus, non-ionic Gal-PEG-ODN is a promising delivery system which can be used for targeted delivery of ODN or siRNA into hepatocytes to treat various liver diseases associated with hepatocyte injury and inflammation. 


\section{CHAPTER 5. TARGETED DELIVERY OF SIRNA TO HEPATOCYTES AND HEPATIC STELLATE CELLS}

\section{$5.1 \quad$ INTRODUCTION}

Since they were first discovered, significant progress has been made in enhancing the potency and specificity of RNAi molecules. RNAi molecules include double-stranded RNA (dsRNA) (2), small interfering RNA (siRNA) (19-23 base-pairs) (4), single stranded short hairpin RNA (shRNA) (5) and micro RNA (miRNA) (6). Although they are structurally different, all of these molecules induce sequence specific gene silencing by either degrading or inhibiting the target mRNA via perfect or mismatched binding in the presence of RNA-induced silencing complex $(1,2)$. The simplest and effective strategy of gene silencing is to design and synthesize siRNAs based on the target mRNA sequence. Most recently, the application of RNAi on the biomedical studies successfully demonstrated the potency of synthetic siRNAs as therapeutic agents in the treatment of numerous diseases, including cancer, fibrosis, genetic disorders, and viral infection (206208). However, siRNAs have not been successfully used as clinical therapeutics due to several obstacles, including the poor enzymatic stability, short circulation time in the blood stream, non-specific tissue or cell targeting, and insufficient intracellular transport.

A variety of cationic lipids and polymers has been designed as nucleic acid delivery carriers. Negatively charged siRNAs could be condensed by cationic lipids or polymers via electrostatic interaction to form nano-sized particles which are easy for cells to take up via endocytosis, membrane fusion, or both. After complex formation, siRNAs are protected from enzymatic digestion (209). However, cationic carriers are not the perfect delivery system for in vivo delivery of siRNAs since they may bind to negatively charged serum proteins and aggregate together resulting in undesired distribution, and induce inflammatory cytokines release and activation of the complement system.

PEGylation is a well known technique which can increase the in vitro and in vivo stability of drug molecules as well as improve their pharmacokinetic profiles. In the previous study, we reported that conjugation of galactose (Gal)-poly(ethylene glycol) (PEG) to oligonucleotide (ODN) using an acid-labile ester linker successfully stabilized ODN, prolonged its circulation time, and specifically delivered ODN to hepatocytes (134). It was also demonstrated that the cleavable linkage between ODN and PEG could be cleaved at $\mathrm{pH} 5.5$ (endosomal $\mathrm{pH}$ ) and free ODN could be released. We also proved that mannose-6-phosphate (M6P) as a ligand could significantly increase accumulation of ODN in hepatic stellate cells (HSCs) in rats. Here we used the similar strategy as GalPEG-ODN conjugate to design two siRNA delivery systems, Gal-PEG-siRNA and M6PPEG-siRNA. Gal-PEG-siRNA could targeted deliver siRNA to hepatocytes via asialoglycoprotein receptor mediated endocytosis, while M6P-PEG-siRNA could specifically deliver siRNA to HSCs via M6P/insulin-like growth factor-II receptor (M6P/IGF2R) mediated endocytosis. In this study the heterobifunctional PEG, (orthopyridyl) disulfide-poly(ethylene glycol)-N-hydroxysuccinimidyl ester (OPSS-PEG-NHS), was used as a backbone followed by modification with either Gal or M6P at its NHS end 
and with 3'-sense strand of siRNA at its OPSS end via disulfide bond. The conjugates were purified by ion exchange HPLC and verified by gel retardation assay. To study the gene silencing of siRNA conjugates, the luciferase siRNA was designed and used as the model sequence. Finally, the in vitro gene down regulation effects of Gal-PEG-siRNA and M6P-PEG-siRNA were evaluated in HepG2 cells and HSCs respectively.

\subsection{MATERIALS AND METHODS}

\subsubsection{Materials}

OPSS-PEG-NHS (MW: $3400 \mathrm{Da}$ ) was purchased from Creative PEGWorks (Winston Salem, NC). Palladium (10 $\mathrm{wt} \%$ on activated carbon), thiophosgene, dithiothreitol (DTT), L-Glutathione (GSH) reduced, p-aminophenyl $\beta$-Dgalactopyranoside, Ethidium Bromide (EtBr), p-nitrophenyl- $\alpha$-D-mannopyranoside, dimethylformamide (DMF), and deuterium oxide $\left(\mathrm{D}_{2} \mathrm{O}\right)$ were purchased from SigmaAldrich Chemicals Limited (St. Louis, MO). Sodium chloride, acetic acid, and HPLC grade water were purchased from Fisher Chemical (Fair Lawn, NJ). Luciferase Assay Kit, TE buffer, $6 \times$ gel loading buffer, and Tris-hydrochloride were purchased from Promega (Madison, WI). Dialysis tubing (MWCO $1000 \mathrm{Da}$ ) was purchased from Spectrum Laboratories, Inc. (Houston, TX). Zeba Spin Desalting Columns (MWCO: 7000 Da) was purchased from Thermo Scientific (Rockford, IL). Dulbecco's modified Eagle's medium (DMEM), penicillin streptomycin solution $(100 \times)$, Phosphate buffered saline (PBS), trypsin-EDTA, Agarose and Lipofectamine 2000 were purchased from Invitrogen Corporation (Carlsbad, CA). Bovine serum albumin (BSA) (fraction V, purity > 98\%) was purchased from Atlanta Biologicals (Lawrenceville, GA). Pyridinium cationic liposomes containing pyridinium lipid (C16:1, amide linker, trans)/DOPE (1:1 mol/mol) cationic liposomes were prepared by Zhu et al. (30).

\subsubsection{Small Interfering RNAs (siRNAs)}

Luciferase siRNA sequence was obtained from literature (sense strand: CUUACGCUGAGUACUUCGA[dT][dT], antisense strand: UCGAAGUACUCAGCGUAAG[dT][dT]) and corresponding annealed synthetic siRNA was purchased from Invitrogen Corporation. For the conjugation purpose, the sense strand of the siRNA was modified with a thiol group $\left(-\left(\mathrm{CH}_{2}\right)_{3}-\mathrm{S}-\mathrm{S}-\left(\mathrm{CH}_{2}\right)_{3}-\mathrm{OH}-3\right.$ ') at its 3 '-end by Invitrogen Corporation. 


\subsubsection{Synthesis of Gal-PEG-siRNA and M6P-PEG-siRNA}

\subsubsection{Synthesis of Ligands (Gal and M6P)}

The ligand galactose residue (Gal) was synthesized according to our previous study (134). Briefly, p-nitrophenyl $\beta$-D-galactopyranoside was reduced with $10 \%$ palladium on activated carbon under hydrogen $(1 \mathrm{~atm})$ in a 1:1 $(\mathrm{v} / \mathrm{v})$ ethanol-water mixture for $2 \mathrm{~h}$. The product, $\mathrm{p}$-aminophenyl $\beta$-D-galactopyranoside, was concentrated by solvent evaporation and characterized by ${ }^{1} \mathrm{H}$ NMR and mass spectrometry after dissolving in $\mathrm{D}_{2} \mathrm{O}$.

The ligand M6P was synthesized according to our previous study (197). Briefly, p-nitrophenyl- $\alpha$-D-mannopyranoside (pnpM) $(0.3 \mathrm{~g}, 1 \mathrm{mmol})$ was dissolved in acetonitrile, pyridine and water mixture $(1 / 0.4 / 0.04, \mathrm{v} / \mathrm{v} / \mathrm{v})$. Phosphorus oxide chloride $(0.4 \mathrm{~mL}, 4.4 \mathrm{mmol})$ was added, and stirred for $1 \mathrm{~h}$ on an ice-water bath. The reaction mixture was poured onto $20 \mathrm{~g}$ of ice. After the ice melted, the $\mathrm{pH}$ was adjusted to 7.0 by slowly adding $2.5 \mathrm{M} \mathrm{NaOH}$, and the solution was evaporated to dryness. The solid material was dissolved in water and crystallized at $4{ }^{\circ} \mathrm{C}$ overnight. The crystals were filtered and washed with $5 \mathrm{~mL}$ of absolute ethanol. The compound was recrystallized in a mixture of $1 \mathrm{~mL}$ of water and $10 \mathrm{~mL}$ of ethanol, redissolved in water, and lyophilized to give p-nitrophenyl-6-phospho- $\alpha$-D-mannopyranoside (pnpM6P). PnpM6P was reduced with $100 \mathrm{mg}$ of $10 \%$ palladium on activated carbon under $\mathrm{H}_{2}(1 \mathrm{~atm})$ in a $4: 1(\mathrm{v} / \mathrm{v})$ methanol-water mixture for $2 \mathrm{~h}$. After filtration, the residue was redissolved in water and lyophilized to give p-aminophenyl-6-phospho- $\alpha$-D-mannopyranoside (papM6P). The product was characterized using ${ }^{1} \mathrm{H}$ NMR and mass spectrometry.

\subsubsection{Synthesis of Gal-PEG-OPSS and M6P-PEG-OPSS}

OPSS-PEG-NHS (50 mg) and galactose (Gal) $(50 \mathrm{mg})$ were dissolved separately in $0.4 \mathrm{~mL}$ of DMF, mixed together, and stirring for $6 \mathrm{~h}$ at room temperature under $\mathrm{N}_{2}$ protection in the dark. The reaction mixture was dialyzed against distilled water for $48 \mathrm{~h}$ with MWCO 1000 to remove the unreacted Gal. The product Gal-PEG-OPSS was freeze dried and characterized by ${ }^{1} \mathrm{H}$ NMR after dissolving it in $\mathrm{D}_{2} \mathrm{O}$.

OPSS-PEG-NHS (50 mg) were dissolved in $0.4 \mathrm{~mL}$ of DMF, and papM6P $(50 \mathrm{mg})$ was dissolved in 0.4 distilled water. Then mixed them dramatically, and stirred for $6 \mathrm{~h}$ at room temperature under $\mathrm{N}_{2}$ protection in the dark. The reaction mixture was dialyzed against distilled water for $48 \mathrm{~h}$ with MWCO 1000 to remove the unreacted papM6P. The product M6P-PEG-OPSS was freeze dried and characterized by ${ }^{1} \mathrm{H}$ NMR after dissolving it in $\mathrm{D}_{2} \mathrm{O}$.

\subsubsection{Synthesis of Gal-PEG-siRNA and M6P-PEG-SiRNA}

The lyophilized 3' thiol-siRNA was reconstituted in TE buffer ( $\mathrm{pH} 8.3-8.5)$ at a concentration of approximately $100 \mathrm{~A} 260$ units $/ \mathrm{mL}$. siRNA solution was then treated with $0.1 \mathrm{M}$ DTT aqueous solution at room temperature for 30 minutes. The excess DTT 
was removed by gel filtration and 3'-sulfhydryl siRNA was stored under $\mathrm{N}_{2}$ to avoid oxidative dimerization to the disulfide before the conjugation reaction. 3'-sulfhydryl siRNA and Gal-PEG-OPSS (or M6P-PEG-OPSS) were dissolved in 0.5 mL PBS (pH7.5) at a molar ratio of 1:100, and stirred under nitrogen protection at room temperature for 6 $\mathrm{h}$. The reaction mixture was analyzed and purified by ion exchange high performance liquid chromatography (ion exchange HPLC), which was carried on a Resource Q ion exchange column (GE Healthcare Life Sciences, Piscataway, NJ) by an HPLC system (Waters, Milford, MA) with detection at $260 \mathrm{~nm}$ using a gradient starting from $0 \% \mathrm{~B}$ to $80 \%$ B (A: $20 \mathrm{mM}$ Tris-HCl buffer, B: $0.1 \mathrm{M}$ sodium chloride buffer) at a flow rate of 1 $\mathrm{mL} / \mathrm{min}$ at $25^{\circ} \mathrm{C}$. The purified Gal-PEG-siRNA and M6P-PEG-siRNA were desalted using Zeba Spin Desalting Column by centrifuge at the speed of $2000 \mathrm{~g}$ and dried by freeze drier.

\subsubsection{Characterization of Gal-PEG-OPSS and M6P-PEG-OPSS}

The concentration of siRNA and siRNA conjugate solutions were quantitated by UV spectrophotometer. For determination of the cleavage of disulfide bond and siRNA dissociation from Gal-PEG-siRNA and M6P-PEG-siRNA, $2 \mu \mathrm{g}$ siRNA and the conjugates containing $2 \mu \mathrm{g}$ siRNA were incubated in $50 \mathrm{mM}$ DTT aqueous buffer for 40 min at room temperature respectively. The DTT treated samples and controls (non-treated siRNA and siRNA conjugate) were mixed with $6 \times$ gel loading buffer and applied on the $1 \%$ agarose gel and run at $10 \mathrm{~V} / \mathrm{cm}$ for $60 \mathrm{~min}$ at room temperature followed by $\mathrm{EtBr}$ staining and visualization under UV light.

\subsubsection{Cell Cultures and Transfections}

HepG2 cells were maintained in a complete growth medium containing DMEM medium supplemented with $10 \% \mathrm{FBS}, 100 \mathrm{IU} / \mathrm{mL}$ penicillin, and $100 \mu \mathrm{g} / \mathrm{mL}$ streptomycin at $37{ }^{\circ} \mathrm{C}$ in a $5 \% \mathrm{CO}_{2}$ humidified atmosphere. HSC-T6 cells, kindly provided by Dr. Scott Friedman (Mount Sinai School of Medicine, New York), were maintained in the same condition as HepG2 cells. Before transfection, the cells were seeded in 24-well plates and maintained in $0.5 \mathrm{~mL}$ of complete growth medium at $37^{\circ} \mathrm{C}$ for $24 \mathrm{~h}$. The cell number was about $4 \times 10^{4}$ cells per well.

Luciferase expression plasmid (pDNA3-Luc) was first transfected with cells by pyridinium cationic liposomes. Briefly, $0.4 \mu \mathrm{g} /$ well luciferase plasmid and pyridinium cationic liposomes were diluted to $25 \mu \mathrm{L}$ by Opti-MEM I medium, respectively, and incubated for $5 \mathrm{~min}$ at room temperature. Lipoplexes were prepared by mixing plasmid and liposomes in equal volume, and incubated for $20 \mathrm{~min}$ at room temperature to allow complex formation. Immediately before transfection, the media was removed, and cells were washed gently with sterile phosphate buffered saline. Lipoplexes were added to each well, diluted to $0.5 \mathrm{~mL}$ by Opti-MEM I medium, and the plate was incubated under $5 \% \mathrm{CO}_{2}$ at $37^{\circ} \mathrm{C}$ for $6 \mathrm{~h}$. Following transfection, the culture medium was replaced with complete growth medium and maintained overnight before further treatment. 
To transfect luciferase siRNA and its conjugate, two methods were used. In the method one, siRNAs and its conjugate were added directly into cell cultures without the assistance of cationic liposomes. In the method two, siRNA and its conjugate mixed with cationic liposomes to form the lipoplexes before adding into cell cultures (the same procedure as the transfection of luciferase plasmid). The transfection time of siRNA and its conjugate was $6 \mathrm{~h}$. Then the medium was replaced with the complete growth medium and incubated for another $42 \mathrm{~h}$.

To determine the luciferase gene expression, the cells were collected and lysed. The cell lysate was measured for luciferase gene expression by Luciferase Assay Kit (Promega, Madison, WI). The total protein concentration was measured by bicinchoninic acid (BCA) protein assay reagent (Pierce, Rockford, IL). Luciferase activity was normalized by the total protein content and expressed as relative light unit (RLU) per $\mu \mathrm{g}$

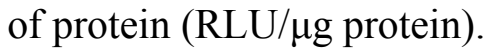

\subsection{RESULTS}

\subsubsection{Synthesis of Gal-PEG-siRNA and M6P-PEG-siRNA}

The synthesis scheme of Gal-PEG-siRNA and M6P-PEG-siRNA was shown in Figure 5.1. Before conjugation reaction, the ligands were synthesized. $p$-Nitrophenyl $\beta$ D-galactopyranoside was reduced to $p$-aminophenyl $\beta$-D-galactopyranoside. ESI-MS and ${ }^{1} \mathrm{H}$ NMR results of this intermediate product were not shown and could be found in our previous paper (134). p-Nitrophenyl- $\alpha$-D-mannopyranoside (pnpM) was phosphorylated to p-nitrophenyl-6-phospho- $\alpha$-D-mannopyranoside (pnpM6P) and pnpM6P was reduced to p-aminophenyl-6-phospho- $\alpha$-D-mannopyranoside (papM6P). ESI-MS and ${ }^{1} \mathrm{H}$ NMR results of this intermediate product are shown in Figure 5.2.

Gal-PEG-OPSS and M6P-PEG-OPSS were synthesized from heterofunctional PEG derivative, NHS-PEG-OPSS and identified by ${ }^{1} \mathrm{H}$ NMR. NHS group is an easygoing group which is ready to react with amine group. After reaction with Gal or M6P, the two peaks ( $\mathrm{a}$ and $\mathrm{b}$ positions) of the benzene ring were found in the NMR spectrum. The data indicated that Gal and M6P reacted with NHS group and linked with PEG (Figure 5.3). Gal-PEG-OPSS and M6P-PEG-OPSS were then conjugated to 3'-sulfhydryl siRNA by disulfide exchange reaction between sulfhydryl and OPSS groups. For the purification process, ion exchange HPLC was used to monitor the conjugation reaction and purify the final products. The ion exchange HPLC chromatograms of siRNAs, Gal-PEG-OPSS, M6P-PEG-OPSS, Gal-PEG-siRNA and M6P-PEG-siRNA conjugate were shown in Figure 5.4. Gal-PEG-OPSS or M6P-PEG-OPSS first eluted since it has no charge and could not bind to anion exchange resin; free siRNAs are negatively charged molecules and bound to anion exchange resin and eluted last; after conjugation, the charge of siRNA was partially blocked by the flexible long chain of PEG and eluted between PEG and siRNA. Gal-PEG-siRNA and M6P-PEG-siRNA were also identified by $1 \%$ agarose gel electrophoresis and visualization under UV light (Figure 5.5). 


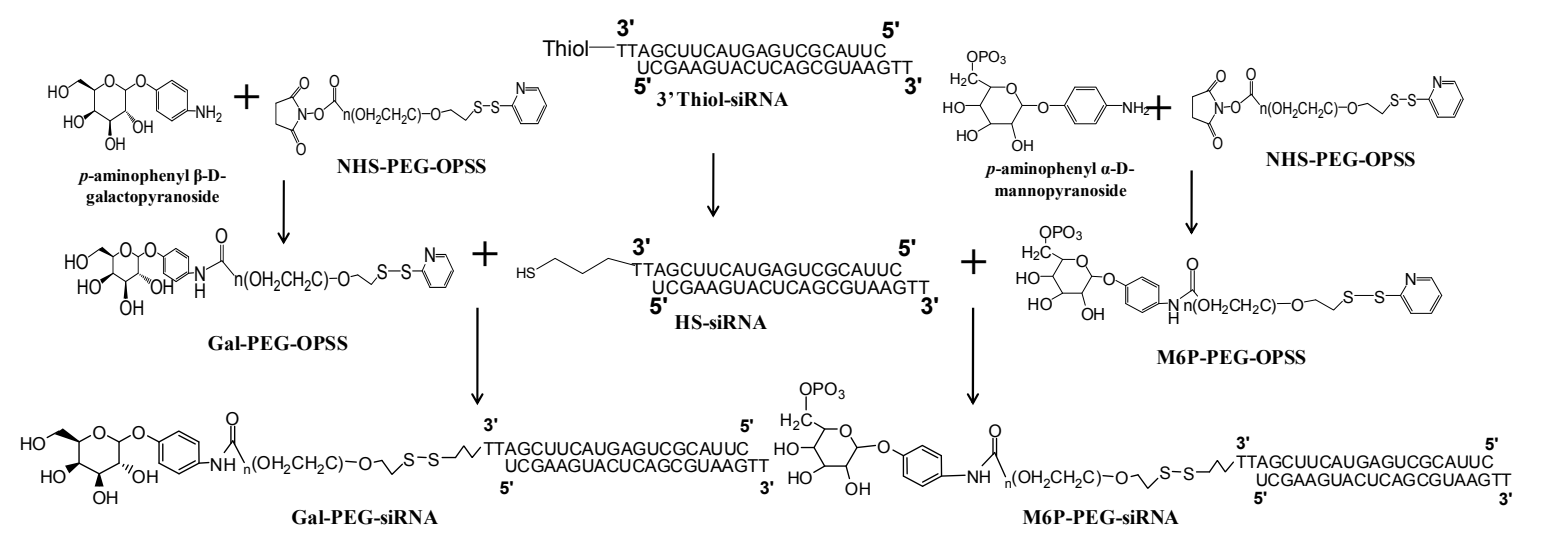

Figure 5.1 Synthesis scheme of Gal-PEG-siRNA and M6P-PEG-siRNA. 
(A)

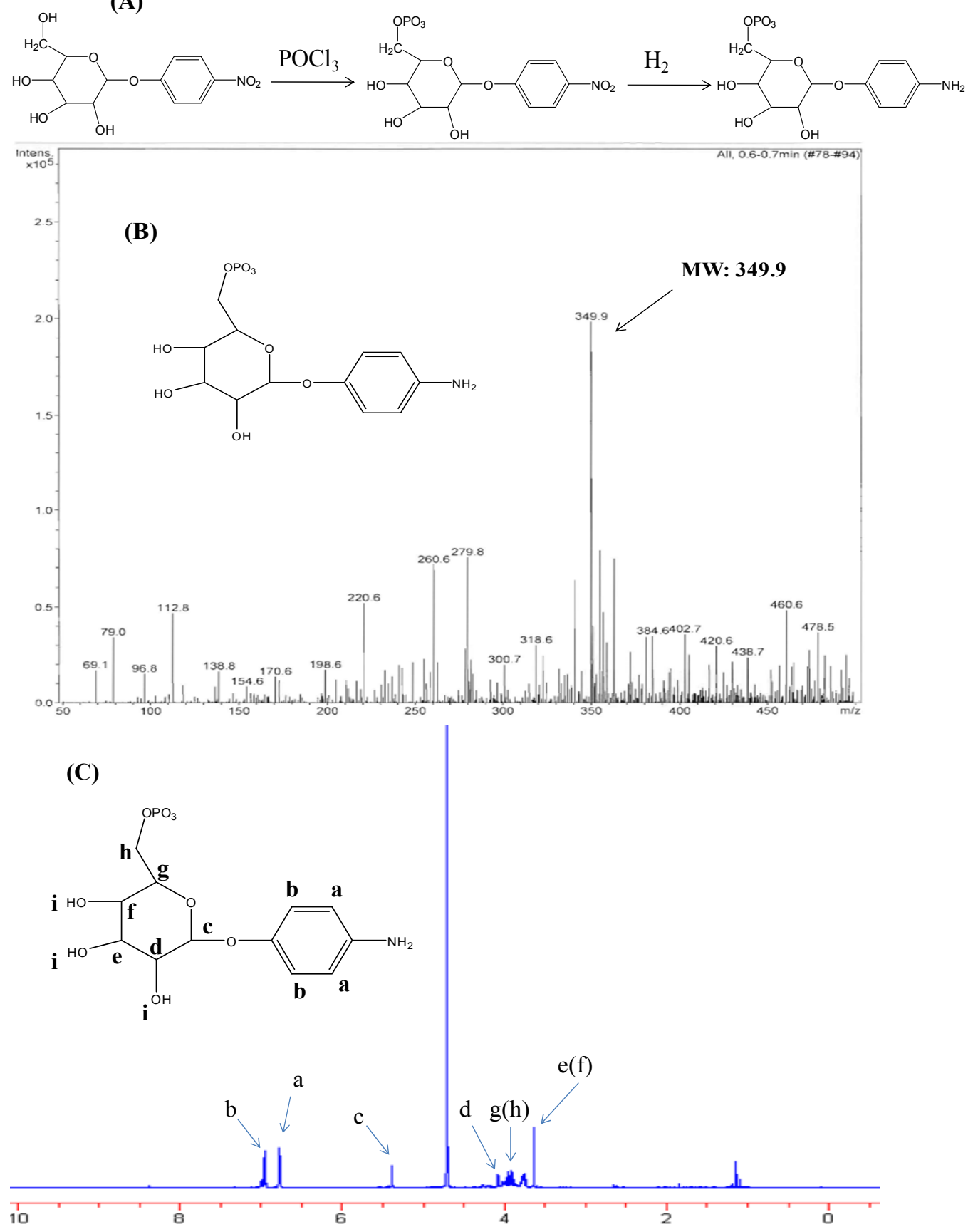

Figure 5.2 Characterization of p-aminophenyl-6-phospho- $\alpha$-D-mannopyranoside with ESI-MS and ${ }^{1}$ H NMR.

Synthesis scheme of p-aminophenyl-6-phospho- $\alpha$-D-mannopyranoside (A). Electron spray ionization mass spectra (B) were obtained after dissolving the product in a $4: 1(\mathrm{v} / \mathrm{v})$ methanol-water mixture on an ESQUIRE-LC Ion Trap LC/MS system in negative mode. For ${ }^{1} \mathrm{H}$ NMR (C), samples were dissolved in $\mathrm{D}_{2} \mathrm{O}$ and the spectra were recorded on a Bruker ARX-500 MHz NMR spectrometer at $25^{\circ} \mathrm{C}$. 


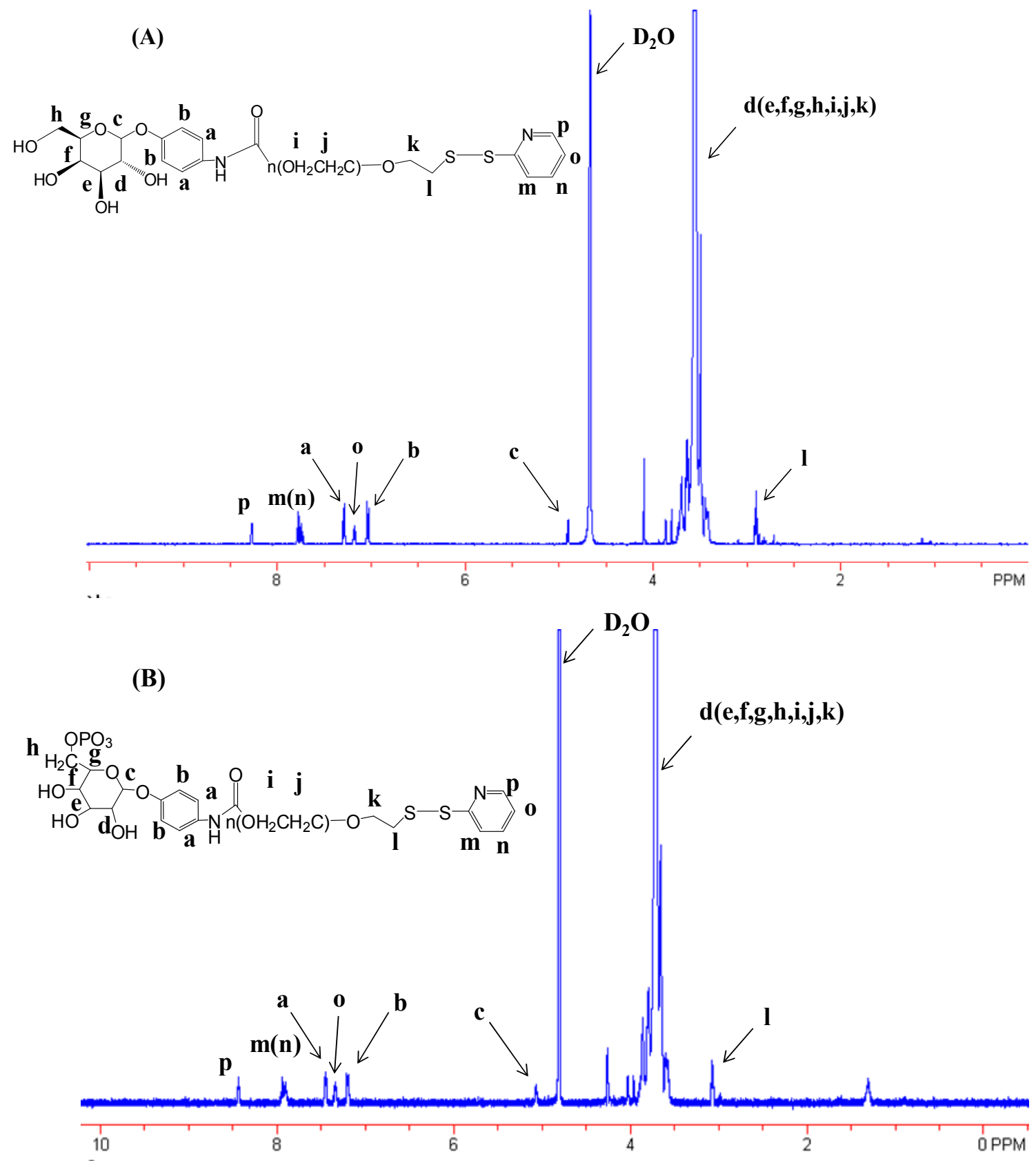

Figure 5.3 Characterization of Gal-PEG-OPSS (A) and M6P-PEG-OPSS (B) with ${ }^{1}$ H NMR.

The samples were dissolved in $\mathrm{D}_{2} \mathrm{O}$ and the spectra were recorded on a Bruker ARX-500 $\mathrm{MHz}$ NMR spectrometer at $25^{\circ} \mathrm{C}$. 


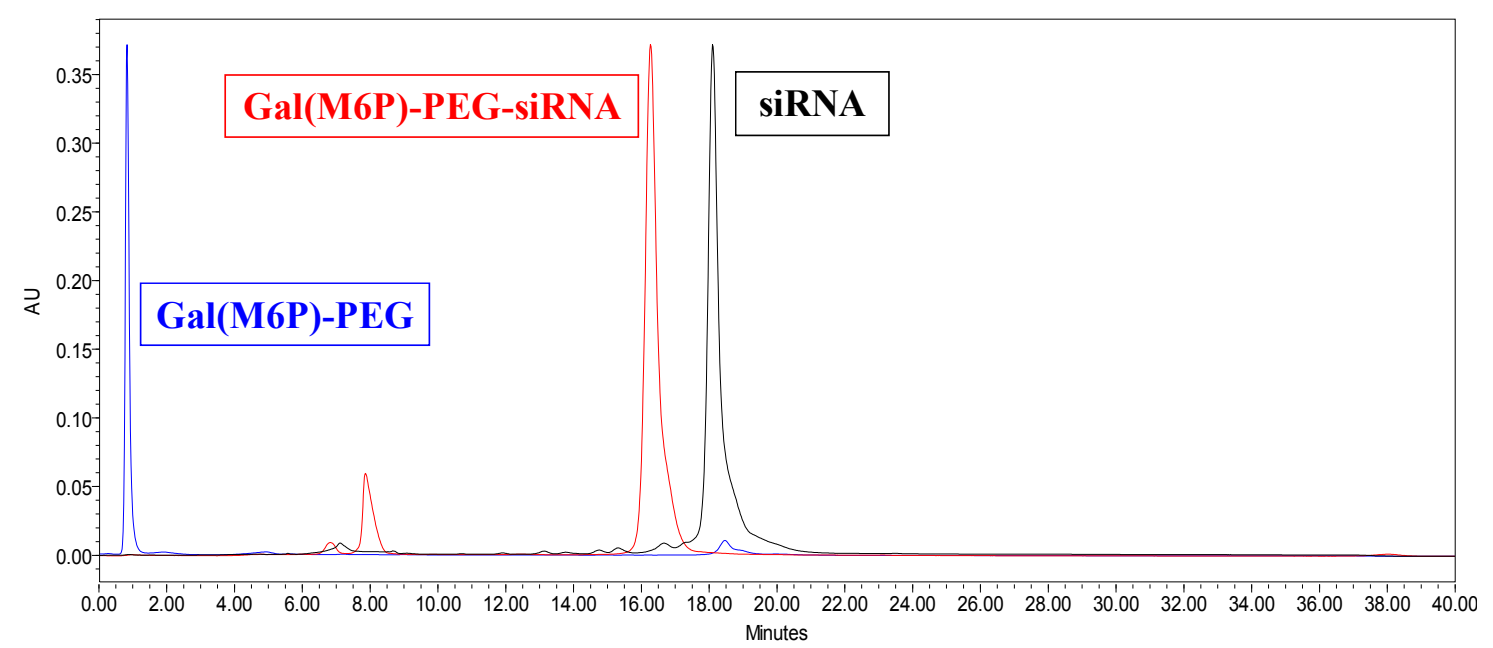

Figure 5.4 Purification of Gal-PEG-siRNA and M6P-PEG-siRNA by Ion Exchange Chromatography.

The reaction mixture was carried on a Resource ${ }^{\mathrm{TM}} \mathrm{Q}$ ion exchange column (GE Healthcare Life Sciences, Piscataway, NJ) by an HPLC system (Waters, Milford, MA) with detection at $260 \mathrm{~nm}$ using a gradient starting from $0 \% \mathrm{~B}$ to $80 \% \mathrm{~B}$ (A: $20 \mathrm{mM}$ Tris$\mathrm{HCl}$ buffer, $\mathrm{B}: 0.1 \mathrm{M}$ sodium chloride buffer) at a flow rate of $1 \mathrm{~mL} / \mathrm{min}$ at $25^{\circ} \mathrm{C}$. 


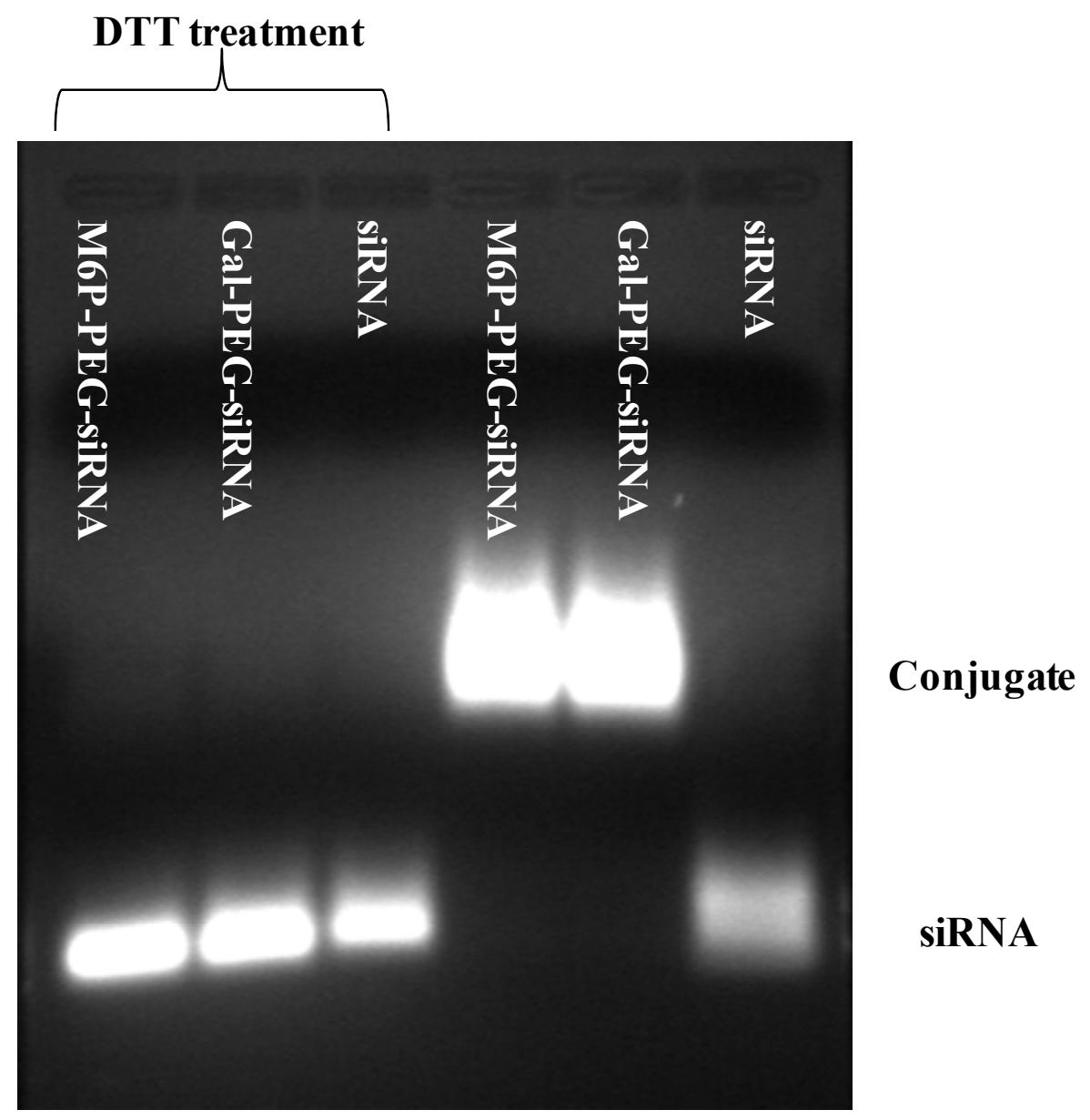

Figure 5.5 Identification of siRNA conjugates by gel retardation assay. Two micrograms of siRNAs, Gal-PEG-siRNA, and M6P-PEG-siRNA were incubated with $50 \mathrm{mM}$ DTT at the room temperature for $40 \mathrm{~min}$. The treated samples and nontreated controls were applied on $1 \%$ agarose gel and run at $10 \mathrm{~V} / \mathrm{cm}$ for $60 \mathrm{~min}$ followed by EtBr staining, then visualized under UV light. 


\subsubsection{Dissociation of siRNAs from Gal-PEG-siRNA and M6P-PEG-siRNA}

To determine that the disulfide bond between PEG and siRNA was cleavable and free siRNA could be released, siRNA and its conjugate were first precisely quantitated by nanodrop $u v$ spectrophotometer (Thermo Scientific, Rockford, IL). Then two microgram of siRNA, Gal-PEG-siRNA, and M6P-PEG-siRNA were treated with DTT aqueous buffer $(50 \mathrm{mM})$ at the room temperature for $40 \mathrm{~min}$ and analyzed by gel retardation assay which was carried on $1 \%$ agarose gel at $10 \mathrm{~V} / \mathrm{cm}$ for $60 \mathrm{~min}$ and visualized under UV light. Agarose gel electrophoresis data showed that siRNA conjugate migrate slower than free siRNA. And after treatment of DTT for 40min, disulfide bond was completely cleaved and free siRNA was released and migrated at the same speed as that of siRNA control (Figure 5.5).

\subsubsection{Gene Down-regulation Study}

Exogenous firefly luciferase plasmid was transfected into both HepG2 and HSC cells using previously optimized pyridinium cationic liposomes at the charge ratio of $3: 1$ $(\mathrm{N} / \mathrm{P})$. The transfection efficiency of pyridinium cationic liposomes was well studied by Zhu et al.. (30) The gene down-regulation effects of siRNA conjugates were studied after transfection of luciferase gene. Figure 5.6A showed the luciferase gene down regulation effect of Gal-PEG-siRNA conjugate in HepG2 cells without transfection reagent, pyridinium cationic liposomes. Without cationic liposomes, Gal-PEG-siRNA conjugate could down-regulate the gene expression of luciferase up to about $45 \%$ at the dose of 400 nM compared to the naked siRNA group and the group (plasmid group) without siRNA treatment. Addition of excessive amount of Gal-PEG into HepG2 cells before transfection of siRNA conjugate abolished the gene down-regulation effect of Gal-PEGsiRNA conjugate. Figure 5.6B showed the gene down regulation of luciferase siRNA and Gal-PEG-siRNA. After complex formation with pyridinium cationic liposomes, the gene silencing effect of Gal-PEG-siRNA significantly increased and reached about $90 \%$ even at the dose of $100 \mathrm{nM}$, while the gene silencing effect of luciferase siRNA was just about $60 \%$ at the same dose. Figure 5.6C showed the gene down-regulation effect of M6PPEG-siRNA in HSC cells without pyridinium cationic liposomes. M6P-PEG-siRNA could down-regulate the luciferase gene expression at the similar level as that of GalPEG-siRNA. Pre-treatment of HSC cells with excessive amount of M6P-PEG before transfection of siRNA conjugate abolished the gene down-regulation effect of M6P-PEGsiRNA conjugate too. The gene down-regulation effect of both Gal-PEG-siRNA and M6P-PEG-siRNA was dose dependent in both absence and presence of pyridinium cationic liposomes.

\subsection{DISCUSSION}

To effectively deliver siRNA to the specific types of cells in vivo is critical for a successful siRNA therapeutic. The current studies of siRNA delivery systems are more focused on cationic particulate delivery systems since negatively charged siRNAs 
(A)

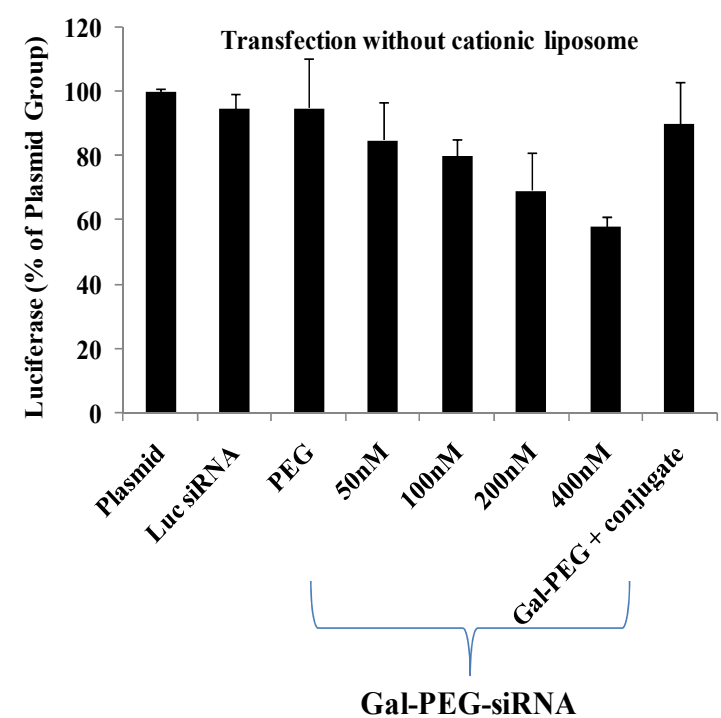

(C)

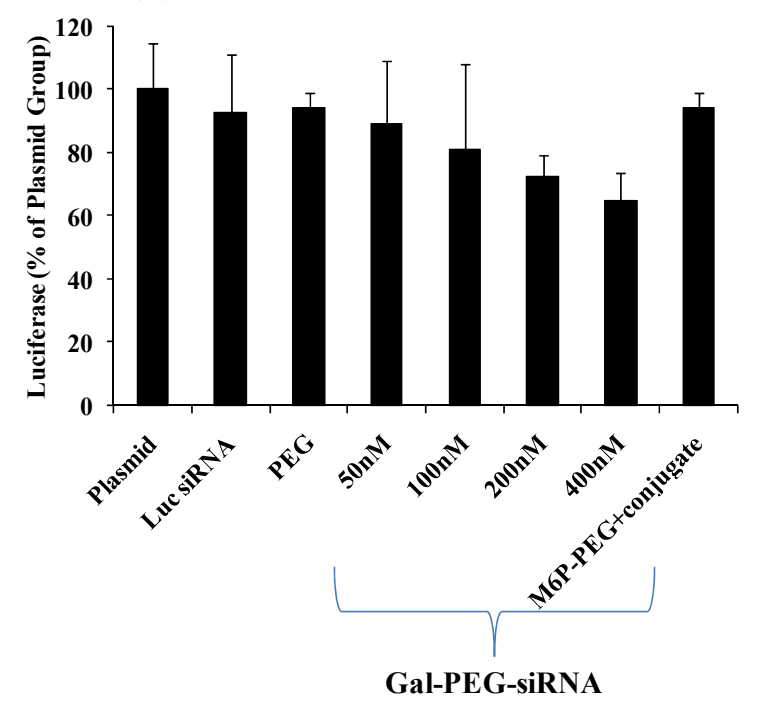

(B)

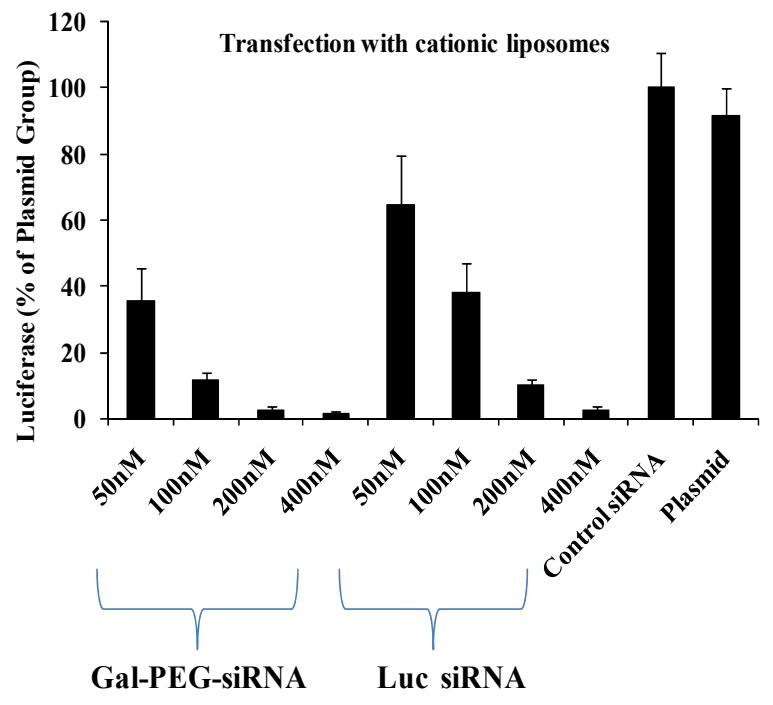


are easily condensed by or incorporated into positively charged liposomal or polymeric carriers. These carriers are shown to protect siRNAs from degradation as well as enhance siRNAs' cellular uptake. However, an ideal delivery carrier should be a cation-free system since the positive charge may cause the immune response and non expected distribution. A lot of non-cationic carriers are designed to deliver nucleic acids. Among them, water soluble macromolecular delivery systems are found to be potential since they are small and thermodynamically stable, and have less undesired protein binding and immune response.

It was reported that nucleic acids are cleared rapidly from blood circulation and mostly accumulated in the peripheral tissues, especially in liver and kidney $(12,13,186)$. However, the in vivo activity of a therapeutic partly depends on its pharmacokinetic behavior, especially the rate of excretion and degradation. PEGylation is known to significantly enhance nucleic acids' stability against exonucleases and reduce renal clearance compared to unmodified nucleic acids (194), which may improve the bioactivity of nucleic acids by increasing plasma residence time and decreasing nuclease degradation. The flexible PEG chains also shield the inherent negative charge of nucleic acids, thereby possibly facilitating cellular uptake of the conjugated nucleic acids.

In a previous study we successfully conjugated ODN to Gal-PEG via an acid labile linkage and demonstrated that Gal-PEG significantly increased ODNs' accumulation in hepatocytes via galactose-asialoglycoprotein receptor mediated endocytosis after systemic administration of Gal-PEG-ODN in rats (134). In another study, M6P was also successfully linked to BSA followed by conjugation with ODN. The M6P-BSA-ODN conjugate increased the accumulation of ODNs in HSCs via M6P ligand-M6P/IGF2R mediated endocytosis compared to other types of liver cells after i.v. injection of it in rats (197). In the present study, we investigated the application of PEG based macromolecular delivery system using two different ligands for siRNA delivery. Since disulfide bond was proven to be cleaved by reducing agents in cytoplasm and was extensively used in drug delivery systems $(138,141,210,211)$, here we used cleavable disulfide bond as the linkage between siRNA and PEG to ensure intact siRNA molecules release from the conjugates in the reducing environment in cytoplasm where RNAi takes action after endocytosis.

Liver fibrosis is one of the most difficult cure diseases and has limit number of effective therapeutics in the clinics. It is a result of the excessive accumulation of extracellular matrix (ECM) proteins in liver and originates from chronic liver injury and inflammation of hepatocytes (major cells in liver) or other hepatic cells. In fibrotic liver, hepatic stellate cells is activated and transformed to proliferative myofibroblast-like cells, which is believed the major source of ECM synthesis. To treat liver fibrosis, design of drug delivery system to targeted deliver therapeutic agents to both hepatocytes and HSCs can enhance the efficacy and decrease the side effects of drug molecules. Excessive ECM causes the loss of sinusoidal fenestrae (212), suggesting that liposomal and other particulate delivery systems may not be suitable for siRNA delivery to hepatic cells. Compared to particulate delivery systems, the water soluble delivery system, Gal-PEGsiRNA or M6P-PEG-siRNA, is much more attractive to deliver therapeutics to hepatic 
cells in fibrotic liver. Firefly luciferase gene was one of the mostly used exogenous reporter gene in the biological studies. In present study we first transfected luciferase plasmid and allowed luciferase gene expression in both HepG2 and HSC cells. Then the gene silencing effects of siRNA conjugates were determined in these luciferase expression cells.

Since siRNAs are relatively smaller and easier to be produced and handled than plasmids, they are readily modified by other functional molecules directly to improve their stability and pharmacokinetic behaviors (134). siRNAs can be covalently linked with functional molecules via either non-cleavable or cleavable linkage, such as acidlabile ester $(134,139)$ and reducible disulfide bond $(140,141)$. For single-stranded oligonulceotides, both 3'- and 5'-terminus of these molecules are reported to be used as the functional sites for the conjugation reaction $(134,142)$. For siRNA duplex, however, it is known that antisense strand of siRNA plays a key role and works as the template in RISC to perform RNAi. Improper modification of antisense strand may cause the loss of RNAi function (213). It was further shown that 5'-terminus of antisense strand was more important than 3'-terminus and determined RNAi activity (143-145). Compared to antisense strand, manipulation of sense strand of siRNA is relatively safe and effective. Both 3'- and 5'-end of sense strand can be used to make a conjugation (121).

In this study, 3'-thiol modifier, was first reduced to 3'-sulfhydryl group which was active and could form a disulfide bond with (ortho-pyridyl) disulfide (OPSS) group by disulfide exchange reaction in PBS. The disulfide bond was expected to be cleaved and free siRNAs were released after treatment with reducing agent DTT. This was confirmed by the result of gel retardation assay that the released siRNAs migrated at the same rate as those of unmodified siRNAs after treatment with DTT. This indicated that the MW and structure of duplex siRNA molecules probably didn't change. The luciferase gene down-regulation of siRNA conjugates indicated that siRNAs didn't lose their RNAi function during conjugation and after dissociation from siRNA conjugates (Figure 5.6). siRNA conjugates just had about $40 \%$ down-regulation of luciferase gene at the dose of $400 \mathrm{nM}$ in both HepG2 and HSCs in the absence of cationic liposomes (Figures 5.6A and 5.6C), while the luciferase gene was almost completely silenced in the presence of cationic liposomes at the same condition (Figure 5.6B). Without condensation with cationic liposomes, the flexible hydrophilic PEG chain surrounds and shields siRNA or the ligand on it from accessing cell membrane, thereby decreasing both specific and nonspecific endocytosis. After complex formation with cationic liposomes, the lipoplexes were slightly positively charged and easy for cells to take up (non-specific) and had high gene silencing effects. Furthermore, combination of ligand-receptor mediated specific endocytosis, siRNA conjugates showed higher gene silencing effect compared to naked siRNAs (Figure 5.6B). However, in the in vivo situation, pegylated siRNAs will be retained in blood circulation and cleared very slow compared to naked siRNAs. Our previous studies showed that pegylated ODN could significantly prolong the elimination half life $\left(\mathrm{t}_{1 / 2 \beta}\right)$ of ODN up to $118.61 \pm 22.06 \mathrm{~min}$ (134) compared to only $34.60 \pm 4.32$ min of naked ODN after i.v. injection in rats (197). The longer residence will provide the sufficient time for siRNA conjugates to access their target cells and initiate the ligandreceptor mediated endocytosis. In Figures 5.6A and 5.6C, pre-addition of excessive 
amount of Gal-PEG or M6P-PEG significantly inhibited gene down-regulation effect of corresponding siRNA conjugates, which indicated that the cellular uptake of siRNA conjugates was ligand-receptor mediated endocytosis, but not non-specific endocytosis. So in vivo we can predict that cation-free Gal-PEG-siRNA and M6P-PEG-siRNA will be specifically accumulated in hepatocytes or HSCs and minimize the non specific distribution and immunostimulatory effect.

In conclusion, we successfully conjugated siRNA with Gal-PEG-OPSS or M6PPEG-OPSS via disulfide bond. The siRNA conjugates were purified and characterized by gel retardation assay. The gene silencing effects of Gal-PEG-siRNA and M6P-PEGsiRNA were observed in HepG2 and HSCs. Gal-PEG-siRNA and M6P-PEG-siRNA may be a suitable delivery system for targeted delivery of siRNAs to hepatocytes and HSCs. 


\section{CHAPTER 6. SUMMARY AND PRESPECTIVES}

Nucleic acids are unstable macromolecules which are difficult for target cells to take up due to biological barriers. In this dissertation we designed the lipid and polymeric carriers for in vitro and in vivo nucleic acid delivery.

In Chapter 3, pyridinium lipids which contain a heterocyclic ring and a nitrogen atom were synthesized. These pyridinium lipids were characterized by measuring their phase transition temperatures and melting points, and corresponding cationic liposomes were characterized by their particle sizes and zeta potentials. The structure-activity relationship and formulation of corresponding cationic liposomes were studied using luciferase and GFP plasmid as reporter genes in CHO cells. Based on these studies, we found the best formulation (C16:1 trans-isomer and DOPE) and verified it in hepatocarcinoma and prostate cancer cells. The optimized formulation was further investigated in the delivery of siRNAs and showed higher gene silencing effect at the low dose of siRNAs compared to Lipofectamine 2000.

To design an in vivo delivery system, in Chapter 4 we successfully synthesized a non-cationic water soluble macromolecular delivery system Gal-PEG-ODN via an acidlabile ester linkage of $\beta$-thiopropionate. The conjugate was purified by RP-HPLC and verified by polyacrylamide gel electrophoresis. PEGylation of ODN significantly increased its circulation time and protected ODN from enzymatic digestion. ODN was dissociated from Gal-PEG-ODN at low $\mathrm{pH}$. The biodistribution, competition and hepatic cellular localization data showed that Gal-PEG-ODN could targeted deliver its payload to hepatocytes after i.v. injection.

Use the similar strategy of Gal-PEG-ODN, in Chapter 5 we designed PEG based siRNA conjugates, Gal-PEG-siRNA and M6P-PEG-siRNA. After conjugation reaction, the conjugate was purified by ion exchange HPLC and verified by agarose gel electrophoresis. Disulfide bond between PEG and siRNA could be cleaved by DTT, thereafter intact siRNA was released. To evaluate their RNAi functions, an effective luciferase siRNA sequence was designed and conjugated with Gal-PEG and M6P-PEG. Both conjugates could down-regulate luciferase gene expression for about $40 \%$ without any transfection reagents, while the gene down-regulation level reached more than $98 \%$ with the help of cationic liposomes at the same dose.

In conclusion, we synthesized a series of pyridinium lipids and studied their SAR and corresponding liposomal formulations. We found pyridinium lipids showed high transfection efficiency and have the potential to be used as transfection reagents in vitro. However, to make them more effective and less toxic especially in vivo, the more structures should be studied including different fatty acid chains (such as branched chain or more double bonds), different type of hydrophobic groups (such as cholesterol), and different linkers (such as ether and carbamate). Pyridinium lipids should be also modified by polymers or peptides to enhance their transfection efficiencies and decrease their side effects. For in vivo delivery of nucleic acids, since positive surface charge prompt non- 
specific ionic interaction with plasma proteins and other tissues, leading to complement system activation or toxicity, PEGylation can block the positive charge of cationic liposomes and decrease the non-specific distribution and unexpected immune response. For specific delivery of nucleic acids, we have demonstrated that the non-cationic polymeric conjugates, Gal-PEG-ODN, Gal-PEG-siRNA and M6P-PEG-siRNA, could targeted deliver nucleic acids to hepatic cells. They are more suitable for in vivo delivery of nucleic acids because of their long circulation time and enhanced targeting efficiency. However, in our studies, only the reporter genes were targeted, which is not sufficient to evaluate the nucleic acid delivery systems. In the future, the therapeutic genes will be used as the target genes to test these delivery systems. In short, the research in this dissertation strengthened the development of lipid and polymeric carriers as the effective nucleic acid delivery systems. 


\section{LIST OF REFERENCES}

(1) Montgomery, M. K., Xu, S., and Fire, A. (1998) RNA as a target of doublestranded RNA-mediated genetic interference in Caenorhabditis elegans. Proc Natl Acad Sci U S A 95, 15502-7.

(2) Fire, A., Xu, S., Montgomery, M. K., Kostas, S. A., Driver, S. E., and Mello, C. C.(1998) Potent and specific genetic interference by double-stranded RNA in Caenorhabditis elegans. Nature 391, 806-11.

(3) Napoli, C., Lemieux, C., and Jorgensen, R. (1990) Introduction of a chimeric chalcone synthase gene into petunia results in reversible co-suppression of homologous genes in trans. Plant Cell 2, 279-89.

(4) Caplen, N. J., Parrish, S., Imani, F., Fire, A., and Morgan, R. A. (2001) Specific inhibition of gene expression by small double-stranded RNAs in invertebrate and vertebrate systems. Proc Natl Acad Sci U S A 98, 9742-7.

(5) Paddison, P. J., Caudy, A. A., Bernstein, E., Hannon, G. J., and Conklin, D. S. (2002) Short hairpin RNAs (shRNAs) induce sequence-specific silencing in mammalian cells. Genes Dev 16, 948-58.

(6) Lee, R. C., Feinbaum, R. L., and Ambros, V. (1993) The C. elegans heterochronic gene lin-4 encodes small RNAs with antisense complementarity to lin-14. Cell 75, $843-54$.

(7) Castanotto, D., and Rossi, J. J. (2009) The promises and pitfalls of RNAinterference-based therapeutics. Nature 457, 426-33.

(8) Bramsen, J. B., Laursen, M. B., Nielsen, A. F., Hansen, T. B., Bus, C., Langkjaer, N., Babu, B. R., Hojland, T., Abramov, M., Van Aerschot, A., Odadzic, D., Smicius, R., Haas, J., Andree, C., Barman, J., Wenska, M., Srivastava, P., Zhou, C., Honcharenko, D., Hess, S., Muller, E., Bobkov, G. V., Mikhailov, S. N., Fava, E., Meyer, T. F., Chattopadhyaya, J., Zerial, M., Engels, J. W., Herdewijn, P., Wengel, J., and Kjems, J. (2009) A large-scale chemical modification screen identifies design rules to generate siRNAs with high activity, high stability and low toxicity. Nucleic Acids Res 37, 2867-81.

(9) Gao, X., Kim, K. S., and Liu, D. (2007) Nonviral gene delivery: what we know and what is next. Aaps $J$ 9, E92-104.

(10) Judge, A. D., Sood, V., Shaw, J. R., Fang, D., McClintock, K., and MacLachlan, I.(2005) Sequence-dependent stimulation of the mammalian innate immune response by synthetic siRNA. Nat Biotechnol 23, 457-62. 
(11) Song, Y. K., Liu, F., Chu, S., and Liu, D. (1997) Characterization of cationic liposome-mediated gene transfer in vivo by intravenous administration. Hum Gene Ther 8, 1585-94.

(12) Mahato, R. I., Rolland, A., and Tomlinson, E. (1997) Cationic lipid-based gene delivery systems: pharmaceutical perspectives. Pharm Res 14, 853-9.

(13) Santel, A., Aleku, M., Keil, O., Endruschat, J., Esche, V., Fisch, G., Dames, S., Loffler, K., Fechtner, M., Arnold, W., Giese, K., Klippel, A., and Kaufmann, J. (2006) A novel siRNA-lipoplex technology for RNA interference in the mouse vascular endothelium. Gene Ther 13, 1222-34.

(14) Liu, F., Song, Y., and Liu, D. (1999) Hydrodynamics-based transfection in animals by systemic administration of plasmid DNA. Gene Ther 6, 1258-66.

(15) Suda, T., and Liu, D. (2007) Hydrodynamic gene delivery: its principles and applications. Mol Ther 15, 2063-9.

(16) Wolff, J. A., Malone, R. W., Williams, P., Chong, W., Acsadi, G., Jani, A., and Felgner, P. L. (1990) Direct gene transfer into mouse muscle in vivo. Science 247, $1465-8$.

(17) Gill, H. S., and Prausnitz, M. R. (2007) Coated microneedles for transdermal delivery. $J$ Control Release 117, 227-37.

(18) Li, S., Xia, X., Zhang, X., and Suen, J. (2002) Regression of tumors by IFN-alpha electroporation gene therapy and analysis of the responsible genes by cDNA array. Gene Ther 9, 390-7.

(19) Barker, G. A., and Diamond, S. L. (2008) RNA interference screen to identify pathways that enhance or reduce nonviral gene transfer during lipofection. Mol Ther 16, 1602-8.

(20) Yang, N. S., and Sun, W. H. (1995) Gene gun and other non-viral approaches for cancer gene therapy. Nat Med 1, 481-3.

(21) Suzuki, R., Takizawa, T., Negishi, Y., Utoguchi, N., and Maruyama, K. (2008) Effective gene delivery with novel liposomal bubbles and ultrasonic destruction technology. Int $J$ Pharm 354, 49-55.

(22) Felgner, P. L., Gadek, T. R., Holm, M., Roman, R., Chan, H. W., Wenz, M., Northrop, J. P., Ringold, G. M., and Danielsen, M. (1987) Lipofection: a highly efficient, lipid-mediated DNA-transfection procedure. Proc Natl Acad Sci U S A 84, 7413-7. 
(23) Farhood, H., Bottega, R., Epand, R. M., and Huang, L. (1992) Effect of cationic cholesterol derivatives on gene transfer and protein kinase $\mathrm{C}$ activity. Biochim Biophys Acta 1111, 239-46.

(24) Behr, J. P., Demeneix, B., Loeffler, J. P., and Perez-Mutul, J. (1989) Efficient gene transfer into mammalian primary endocrine cells with lipopolyamine-coated DNA. Proc Natl Acad Sci U S A 86, 6982-6.

(25) Rose, J. K., Buonocore, L., and Whitt, M. A. (1991) A new cationic liposome reagent mediating nearly quantitative transfection of animal cells. Biotechniques $10,520-5$.

(26) Porteous, D. J., Dorin, J. R., McLachlan, G., Davidson-Smith, H., Davidson, H., Stevenson, B. J., Carothers, A. D., Wallace, W. A., Moralee, S., Hoenes, C., Kallmeyer, G., Michaelis, U., Naujoks, K., Ho, L. P., Samways, J. M., Imrie, M., Greening, A. P., and Innes, J. A. (1997) Evidence for safety and efficacy of DOTAP cationic liposome mediated CFTR gene transfer to the nasal epithelium of patients with cystic fibrosis. Gene Ther 4, 210-8.

(27) Gao, X., and Huang, L. (1991) A novel cationic liposome reagent for efficient transfection of mammalian cells. Biochem Biophys Res Commun 179, 280-5.

(28) San, H., Yang, Z. Y., Pompili, V. J., Jaffe, M. L., Plautz, G. E., Xu, L., Felgner, J. H., Wheeler, C. J., Felgner, P. L., Gao, X., and et al. (1993) Safety and short-term toxicity of a novel cationic lipid formulation for human gene therapy. Hum Gene Ther 4, 781-8.

(29) Scheule, R. K., St George, J. A., Bagley, R. G., Marshall, J., Kaplan, J. M., Akita, G. Y., Wang, K. X., Lee, E. R., Harris, D. J., Jiang, C., Yew, N. S., Smith, A. E., and Cheng, S. H. (1997) Basis of pulmonary toxicity associated with cationic lipid-mediated gene transfer to the mammalian lung. Hum Gene Ther 8, 689-707.

(30) Zhu, L., Lu, Y., Miller, D. D., and Mahato, R. I. (2008) Structural and formulation factors influencing pyridinium lipid-based gene transfer. Bioconjug Chem 19, 2499-512.

(31) van der Woude, I., Wagenaar, A., Meekel, A. A., ter Beest, M. B., Ruiters, M. H., Engberts, J. B., and Hoekstra, D. (1997) Novel pyridinium surfactants for efficient, nontoxic in vitro gene delivery. Proc Natl Acad Sci U S A 94, 1160-5.

(32) Ilies, M. A., Seitz, W. A., Johnson, B. H., Ezell, E. L., Miller, A. L., Thompson, E.B., and Balaban, A. T. (2006) Lipophilic pyrylium salts in the synthesis of efficient pyridinium-based cationic lipids, gemini surfactants, and lipophilic oligomers for gene delivery. J Med Chem 49, 3872-87. 
(33) Vigneron, J. P., Oudrhiri, N., Fauquet, M., Vergely, L., Bradley, J. C., Basseville, M., Lehn, P., and Lehn, J. M. (1996) Guanidinium-cholesterol cationic lipids: efficient vectors for the transfection of eukaryotic cells. Proc Natl Acad Sci U S A 93, 9682-6.

(34) Ilies, M. A., Seitz, W. A., Ghiviriga, I., Johnson, B. H., Miller, A., Thompson, E. B., and Balaban, A. T. (2004) Pyridinium cationic lipids in gene delivery: a structure-activity correlation study. J Med Chem 47, 3744-54.

(35) Heyes, J. A., Niculescu-Duvaz, D., Cooper, R. G., and Springer, C. J. (2002) Synthesis of novel cationic lipids: effect of structural modification on the efficiency of gene transfer. $J$ Med Chem 45, 99-114.

(36) Kumar, V. V., Pichon, C., Refregiers, M., Guerin, B., Midoux, P., and Chaudhuri, A. (2003) Single histidine residue in head-group region is sufficient to impart remarkable gene transfection properties to cationic lipids: evidence for histidinemediated membrane fusion at acidic pH. Gene Ther 10, 1206-15.

(37) Miller, C. R., Bondurant, B., McLean, S. D., McGovern, K. A., and O'Brien, D. F. (1998) Liposome-cell interactions in vitro: effect of liposome surface charge on the binding and endocytosis of conventional and sterically stabilized liposomes. Biochemistry 37, 12875-83.

(38) Tseng, Y. C., Mozumdar, S., and Huang, L. (2009) Lipid-based systemic delivery of siRNA. Adv Drug Deliv Rev 61, 721-31.

(39) Pinnaduwage, P., Schmitt, L., and Huang, L. (1989) Use of a quaternary ammonium detergent in liposome mediated DNA transfection of mouse L-cells. Biochim Biophys Acta 985, 33-7.

(40) Byk, G., Dubertret, C., Escriou, V., Frederic, M., Jaslin, G., Rangara, R., Pitard, B., Crouzet, J., Wils, P., Schwartz, B., and Scherman, D. (1998) Synthesis, activity, and structure--activity relationship studies of novel cationic lipids for DNA transfer. $J$ Med Chem 41, 229-35.

(41) Gaucheron, J., Wong, T., Wong, K. F., Maurer, N., and Cullis, P. R. (2002) Synthesis and properties of novel tetraalkyl cationic lipids. Bioconjug Chem 13, 671-5.

(42) Sankaram, M. B., Powell, G. L., and Marsh, D. (1989) Effect of acyl chain composition on salt-induced lamellar to inverted hexagonal phase transitions in cardiolipin. Biochim Biophys Acta 980, 389-92.

(43) Szule, J. A., Fuller, N. L., and Rand, R. P. (2002) The effects of acyl chain length and saturation of diacylglycerols and phosphatidylcholines on membrane monolayer curvature. Biophys J 83, 977-84. 
(44) Heyes, J., Palmer, L., Bremner, K., and MacLachlan, I. (2005) Cationic lipid saturation influences intracellular delivery of encapsulated nucleic acids. $J$ Control Release 107, 276-87.

(45) Felgner, J. H., Kumar, R., Sridhar, C. N., Wheeler, C. J., Tsai, Y. J., Border, R., Ramsey, P., Martin, M., and Felgner, P. L. (1994) Enhanced gene delivery and mechanism studies with a novel series of cationic lipid formulations. $J$ Biol Chem $269,2550-61$.

(46) McGregor, C., Perrin, C., Monck, M., Camilleri, P., and Kirby, A. J. (2001) Rational approaches to the design of cationic gemini surfactants for gene delivery. $J$ Am Chem Soc 123, 6215-20.

(47) Takahashi, T., Kojima, C., Harada, A., and Kono, K. (2007) Alkyl chain moieties of polyamidoamine dendron-bearing lipids influence their function as a nonviral gene vector. Bioconjug Chem 18, 1349-54.

(48) Israelachvili, J., Mitchell, D.J., and Ninham,B. (1976) Theory of self-assembly of hydrocarbon amphiphiles into micelles and bilayers. J. Chem. Soc., Faraday Trans. 2 72, 1525-68.

(49) Kumar, V. V. (1991) Complementary molecular shapes and additivity of the packing parameter of lipids. Proc Natl Acad Sci U S A 88, 444-8.

(50) Koltover, I., Salditt, T., Radler, J. O., and Safinya, C. R. (1998) An inverted hexagonal phase of cationic liposome-DNA complexes related to DNA release and delivery. Science $281,78-81$.

(51) Scarzello, M., Chupin, V., Wagenaar, A., Stuart, M. C., Engberts, J. B., and Hulst, R. (2005) Polymorphism of pyridinium amphiphiles for gene delivery: influence of ionic strength, helper lipid content, and plasmid DNA complexation. Biophys $J$ $88,2104-13$.

(52) Mahato, R. I., Smith, L. C., and Rolland, A. (1999) Pharmaceutical perspectives of nonviral gene therapy. Adv Genet 41, 95-156.

(53) Ghosh, Y. K., Visweswariah, S. S., and Bhattacharya, S. (2000) Nature of linkage between the cationic headgroup and cholesteryl skeleton controls gene transfection efficiency. FEBS Lett 473, 341-4.

(54) Aberle, A. M., Tablin, F., Zhu, J., Walker, N. J., Gruenert, D. C., and Nantz, M. H.(1998) A novel tetraester construct that reduces cationic lipid-associated cytotoxicity. Implications for the onset of cytotoxicity. Biochemistry 37, 6533-40. 
(55) Nagasaki, T., Taniguchi, A., and Tamagaki, S. (2003) Photoenhancement of transfection efficiency using novel cationic lipids having a photocleavable spacer. Bioconjug Chem 14, 513-6.

(56) Boomer, J. A., Thompson, D. H., and Sullivan, S. M. (2002) Formation of plasmid-based transfection complexes with an acid-labile cationic lipid: characterization of in vitro and in vivo gene transfer. Pharm Res 19, 1292-301.

(57) Tang, F., and Hughes, J. A. (1998) Introduction of a disulfide bond into a cationic lipid enhances transgene expression of plasmid DNA. Biochem Biophys Res Commun 242, 141-5.

(58) Spagnou, S., Miller, A. D., and Keller, M. (2004) Lipidic carriers of siRNA: differences in the formulation, cellular uptake, and delivery with plasmid DNA. Biochemistry 43, 13348-56.

(59) Boussif, O., Lezoualc'h, F., Zanta, M. A., Mergny, M. D., Scherman, D., Demeneix, B., and Behr, J. P. (1995) A versatile vector for gene and oligonucleotide transfer into cells in culture and in vivo: polyethylenimine. Proc Natl Acad Sci U S A 92, 7297-301.

(60) von Harpe, A., Petersen, H., Li, Y., and Kissel, T. (2000) Characterization of commercially available and synthesized polyethylenimines for gene delivery. $J$ Control Release 69, 309-22.

(61) Sonawane, N. D., Szoka, F. C., Jr., and Verkman, A. S. (2003) Chloride accumulation and swelling in endosomes enhances DNA transfer by polyamineDNA polyplexes. $J$ Biol Chem 278, 44826-31.

(62) Behr, J. P. (1997) The proton sponge:a trick to enter cells the viruses did not exploit. CHIMIA, International Journal for Chemistry 57, 34-6.

(63) Akinc, A., Thomas, M., Klibanov, A. M., and Langer, R. (2005) Exploring polyethylenimine-mediated DNA transfection and the proton sponge hypothesis. $J$ Gene Med 7, 657-63.

(64) Ogris, M., Steinlein, P., Kursa, M., Mechtler, K., Kircheis, R., and Wagner, E. (1998) The size of DNA/transferrin-PEI complexes is an important factor for gene expression in cultured cells. Gene Ther 5, 1425-33.

(65) Fischer, D., Bieber, T., Li, Y., Elsasser, H. P., and Kissel, T. (1999) A novel nonviral vector for DNA delivery based on low molecular weight, branched polyethylenimine: effect of molecular weight on transfection efficiency and cytotoxicity. Pharm Res 16, 1273-9. 
(66) Godbey, W. T., Wu, K. K., and Mikos, A. G. (1999) Size matters: molecular weight affects the efficiency of poly(ethylenimine) as a gene delivery vehicle. $J$ Biomed Mater Res 45, 268-75.

(67) Shin, J. Y., Suh, D., Kim, J. M., Choi, H. G., Kim, J. A., Ko, J. J., Lee, Y. B., Kim,J. S., and Oh, Y. K. (2005) Low molecular weight polyethylenimine for efficient transfection of human hematopoietic and umbilical cord blood-derived CD34+ cells. Biochim Biophys Acta 1725, 377-84.

(68) Neu, M., Fischer, D., and Kissel, T. (2005) Recent advances in rational gene transfer vector design based on poly(ethylene imine) and its derivatives. J Gene Med 7, 992-1009.

(69) Kircheis, R., Wightman, L., Schreiber, A., Robitza, B., Rossler, V., Kursa, M., and Wagner, E. (2001) Polyethylenimine/DNA complexes shielded by transferrin target gene expression to tumors after systemic application. Gene Ther 8, 28-40.

(70) Reschel, T., Konak, C., Oupicky, D., Seymour, L. W., and Ulbrich, K. (2002) Physical properties and in vitro transfection efficiency of gene delivery vectors based on complexes of DNA with synthetic polycations. J Control Release 81, 201-17.

(71) Wightman, L., Kircheis, R., Rossler, V., Carotta, S., Ruzicka, R., Kursa, M., and Wagner, E. (2001) Different behavior of branched and linear polyethylenimine for gene delivery in vitro and in vivo. J Gene Med 3, 362-72.

(72) Thomas, M., Lu, J. J., Ge, Q., Zhang, C., Chen, J., and Klibanov, A. M. (2005) Full deacylation of polyethylenimine dramatically boosts its gene delivery efficiency and specificity to mouse lung. Proc Natl Acad Sci U S A 102, 5679-84.

(73) Hassani, Z., Lemkine, G. F., Erbacher, P., Palmier, K., Alfama, G., Giovannangeli,C., Behr, J. P., and Demeneix, B. A. (2005) Lipid-mediated siRNA delivery down-regulates exogenous gene expression in the mouse brain at picomolar levels. J Gene Med 7, 198-207.

(74) Fischer, D., Li, Y., Ahlemeyer, B., Krieglstein, J., and Kissel, T. (2003) In vitro cytotoxicity testing of polycations: influence of polymer structure on cell viability and hemolysis. Biomaterials 24, 1121-31.

(75) Zintchenko, A., Philipp, A., Dehshahri, A., and Wagner, E. (2008) Simple modifications of branched PEI lead to highly efficient siRNA carriers with low toxicity. Bioconjug Chem 19, 1448-55. 
(76) Lee, M. K., Chun, S. K., Choi, W. J., Kim, J. K., Choi, S. H., Kim, A., Oungbho, K., Park, J. S., Ahn, W. S., and Kim, C. K. (2005) The use of chitosan as a condensing agent to enhance emulsion-mediated gene transfer. Biomaterials 26, 2147-56.

(77) Liu, X., Howard, K. A., Dong, M., Andersen, M. O., Rahbek, U. L., Johnsen, M. G., Hansen, O. C., Besenbacher, F., and Kjems, J. (2007) The influence of polymeric properties on chitosan/siRNA nanoparticle formulation and gene silencing. Biomaterials 28, 1280-8.

(78) Katas, H., and Alpar, H. O. (2006) Development and characterisation of chitosan nanoparticles for siRNA delivery. J Control Release 115, 216-25.

(79) Borchard, G. (2001) Chitosans for gene delivery. Adv Drug Deliv Rev 52, 145-50.

(80) Kim, T. H., Jiang,H.L., Jere,D., Park,I.K., Cho, M.H., Nah, J.W., Choi,Y.J., Akaike, T. and Cho, C.S. (2007) Chemical modification of chitosan as a gene carrier in vitro and in vivo. Prog. Polym. Sci. 32, 726-53.

(81) Mumper, R. J., Wang,J.J., Claspell,J.M. and Rolland,A.P. (1995) Novel polymeric condensing carriers for gene delivery. Proc Int Symp Control Rel Bioact Mater 22, 178-9.

(82) MacLaughlin, F. C., Mumper, R. J., Wang, J., Tagliaferri, J. M., Gill, I., Hinchcliffe, M., and Rolland, A. P. (1998) Chitosan and depolymerized chitosan oligomers as condensing carriers for in vivo plasmid delivery. $J$ Control Release $56,259-72$.

(83) Huang, M., Fong, C. W., Khor, E., and Lim, L. Y. (2005) Transfection efficiency of chitosan vectors: effect of polymer molecular weight and degree of deacetylation. J Control Release 106, 391-406.

(84) Kiang, T., Wen, J., Lim, H. W., and Leong, K. W. (2004) The effect of the degree of chitosan deacetylation on the efficiency of gene transfection. Biomaterials 25, 5293-301.

(85) Li, X. W., Lee, D. K., Chan, A. S., and Alpar, H. O. (2003) Sustained expression in mammalian cells with DNA complexed with chitosan nanoparticles. Biochim Biophys Acta 1630, 7-18.

(86) Yang, X., Yuan, X., Cai, D., Wang, S., and Zong, L. (2009) Low molecular weight chitosan in DNA vaccine delivery via mucosa. Int J Pharm 375, 123-32.

(87) Liu, W., Sun, S., Cao, Z., Zhang, X., Yao, K., Lu, W. W., and Luk, K. D. (2005) An investigation on the physicochemical properties of chitosan/DNA polyelectrolyte complexes. Biomaterials 26, 2705-11. 
(88) Ishii, T., Okahata, Y., and Sato, T. (2001) Mechanism of cell transfection with plasmid/chitosan complexes. Biochim Biophys Acta 1514, 51-64.

(89) Aiba, S. (1989) Studies on chitosan: 2. Solution stability and reactivity of partially $\mathrm{N}$-acetylated chitosan derivatives in aqueous media. Int J Biol Macromol 11, 24952.

(90) Tomihata, K., and Ikada, Y. (1997) In vitro and in vivo degradation of films of chitin and its deacetylated derivatives. Biomaterials 18, 567-75.

(91) Kas, H. S. (1997) Chitosan: properties, preparations and application to microparticulate systems. J Microencapsul 14, 689-711.

(92) Szejtli, J. (1998) Introduction and general overview of cyclodextrin chemistry. Chem Rev 98, 1743-54.

(93) Uekama, K., Hirayama, F., and Irie, T. (1998) Cyclodextrin drug carrier systems. Chem Rev 98, 2045-76.

(94) Gonzalez, H., Hwang, S. J., and Davis, M. E. (1999) New class of polymers for the delivery of macromolecular therapeutics. Bioconjug Chem 10, 1068-74.

(95) Yang, C., Li, H., Goh, S. H., and Li, J. (2007) Cationic star polymers consisting of alpha-cyclodextrin core and oligoethylenimine arms as nonviral gene delivery vectors. Biomaterials 28, 3245-54.

(96) Pun, S. H., Bellocq, N. C., Liu, A., Jensen, G., Machemer, T., Quijano, E., Schluep, T., Wen, S., Engler, H., Heidel, J., and Davis, M. E. (2004) Cyclodextrin-modified polyethylenimine polymers for gene delivery. Bioconjug Chem 15, 831-40.

(97) Li, J., Yang,C.,Li,H., Wang,X., Goh,S. H. , Ding,J. L.,Wang,D. Y., Leong, K. W. (2006) Cationic supramolecules composed of multiple oligoethylenimine-grafted -cyclodextrins threaded on a polymer chain for efficient gene delivery. Advanced Materials 18, 2969-74.

(98) Yang, C., Li, H., Wang, X., and Li, J. (2009) Cationic supramolecules consisting of oligoethylenimine-grafted alpha-cyclodextrins threaded on poly(ethylene oxide) for gene delivery. J Biomed Mater Res A 89, 13-23.

(99) Li, J., and Loh, X. J. (2008) Cyclodextrin-based supramolecular architectures: syntheses, structures, and applications for drug and gene delivery. Adv Drug Deliv Rev 60, 1000-17. 
(100) Dufes, C., Uchegbu, I. F., and Schatzlein, A. G. (2005) Dendrimers in gene delivery. Adv Drug Deliv Rev 57, 2177-202.

(101) Zinselmeyer, B. H., Mackay, S. P., Schatzlein, A. G., and Uchegbu, I. F. (2002) The lower-generation polypropylenimine dendrimers are effective gene-transfer agents. Pharm Res 19, 960-7.

(102) Gebhart, C. L., and Kabanov, A. V. (2001) Evaluation of polyplexes as gene transfer agents. $J$ Control Release 73, 401-16.

(103) Hollins, A. J., Benboubetra, M., Omidi, Y., Zinselmeyer, B. H., Schatzlein, A. G., Uchegbu, I. F., and Akhtar, S. (2004) Evaluation of generation 2 and 3 poly(propylenimine) dendrimers for the potential cellular delivery of antisense oligonucleotides targeting the epidermal growth factor receptor. Pharm Res 21, $458-66$.

(104) Malik, N., Wiwattanapatapee, R., Klopsch, R., Lorenz, K., Frey, H., Weener, J. W., Meijer, E. W., Paulus, W., and Duncan, R. (2000) Dendrimers: relationship between structure and biocompatibility in vitro, and preliminary studies on the biodistribution of 125I-labelled polyamidoamine dendrimers in vivo. J Control Release 65, 133-48.

(105) Kihara, F., Arima, H., Tsutsumi, T., Hirayama, F., and Uekama, K. (2002) Effects of structure of polyamidoamine dendrimer on gene transfer efficiency of the dendrimer conjugate with alpha-cyclodextrin. Bioconjug Chem 13, 1211-9.

(106) Taratula, O., Garbuzenko, O. B., Kirkpatrick, P., Pandya, I., Savla, R., Pozharov, V. P., He, H., and Minko, T. (2009) Surface-engineered targeted PPI dendrimer for efficient intracellular and intratumoral siRNA delivery. $J$ Control Release 140, 284-93.

(107) Schatzlein, A. G., Zinselmeyer, B. H., Elouzi, A., Dufes, C., Chim, Y. T., Roberts,C. J., Davies, M. C., Munro, A., Gray, A. I., and Uchegbu, I. F. (2005) Preferential liver gene expression with polypropylenimine dendrimers. J Control Release 101, 247-58.

(108) Braun, C. S., Vetro, J. A., Tomalia, D. A., Koe, G. S., Koe, J. G., and Middaugh, C. R. (2005) Structure/function relationships of polyamidoamine/DNA dendrimers as gene delivery vehicles. J Pharm Sci 94, 423-36.

(109) Litzinger, D. C., and Huang, L. (1992) Phosphatidylethanolamine liposomes: drug delivery, gene transfer and immunodiagnostic applications. Biochim Biophys Acta $1113,201-27$. 
(110) Farhood, H., Serbina, N., and Huang, L. (1995) The role of dioleoyl phosphatidylethanolamine in cationic liposome mediated gene transfer. Biochim Biophys Acta 1235, 289-95.

(111) Smisterova, J., Wagenaar, A., Stuart, M. C., Polushkin, E., ten Brinke, G., Hulst, R., Engberts, J. B., and Hoekstra, D. (2001) Molecular shape of the cationic lipid controls the structure of cationic lipid/dioleylphosphatidylethanolamine-DNA complexes and the efficiency of gene delivery. J Biol Chem 276, 47615-22.

(112) Crook, K., Stevenson, B. J., Dubouchet, M., and Porteous, D. J. (1998) Inclusion of cholesterol in DOTAP transfection complexes increases the delivery of DNA to cells in vitro in the presence of serum. Gene Ther 5, 137-43.

(113) Han, S., Mahato, R. I., and Kim, S. W. (2001) Water-soluble lipopolymer for gene delivery. Bioconjug Chem 12, 337-45.

(114) Wang, D. A., Narang, A. S., Kotb, M., Gaber, A. O., Miller, D. D., Kim, S. W., and Mahato, R. I. (2002) Novel branched poly(ethylenimine)-cholesterol watersoluble lipopolymers for gene delivery. Biomacromolecules 3, 1197-207.

(115) Ambegia, E., Ansell, S., Cullis, P., Heyes, J., Palmer, L., and MacLachlan, I. (2005) Stabilized plasmid-lipid particles containing PEG-diacylglycerols exhibit extended circulation lifetimes and tumor selective gene expression. Biochim Biophys Acta 1669, 155-63.

(116) Morrissey, D. V., Lockridge, J. A., Shaw, L., Blanchard, K., Jensen, K., Breen, W., Hartsough, K., Machemer, L., Radka, S., Jadhav, V., Vaish, N., Zinnen, S., Vargeese, C., Bowman, K., Shaffer, C. S., Jeffs, L. B., Judge, A., MacLachlan, I., and Polisky, B. (2005) Potent and persistent in vivo anti-HBV activity of chemically modified siRNAs. Nat Biotechnol 23, 1002-7.

(117) Kabanov, A. V., Batrakova, E. V., and Alakhov, V. Y. (2002) Pluronic block copolymers as novel polymer therapeutics for drug and gene delivery. J Control Release 82, 189-212.

(118) Lemieux, P., Guerin, N., Paradis, G., Proulx, R., Chistyakova, L., Kabanov, A., and Alakhov, V. (2000) A combination of poloxamers increases gene expression of plasmid DNA in skeletal muscle. Gene Ther 7, 986-91.

(119) Murata, N., Takashima, Y., Toyoshima, K., Yamamoto, M., and Okada, H. (2008) Anti-tumor effects of anti-VEGF siRNA encapsulated with PLGA microspheres in mice. $J$ Control Release 126, 246-54.

(120) Jensen, D. M., Cun, D., Maltesen, M. J., Frokjaer, S., Nielsen, H. M., and Foged, C. (2009) Spray drying of siRNA-containing PLGA nanoparticles intended for inhalation. J Control Release 142, 138-45 
(121) Jeong, J. H., Mok, H., Oh, Y. K., and Park, T. G. (2009) siRNA conjugate delivery systems. Bioconjug Chem 20, 5-14.

(122) Ozato, K., Ziegler, H. K., and Henney, C. S. (1978) Liposomes as model membrane systems for immune attack. I. Transfer of antigenic determinants to lymphocyte membranes after interactions with hapten-bearing liposomes. $J$ Immunol 121, 1376-82.

(123) Sessa, G., and Weissmann, G. (1970) Incorporation of lysozyme into liposomes. A model for structure-linked latency. J Biol Chem 245, 3295-301.

(124) Klibanov, A. L., Maruyama, K., Torchilin, V. P., and Huang, L. (1990) Amphipathic polyethyleneglycols effectively prolong the circulation time of liposomes. FEBS Lett 268, 235-7.

(125) Mukherjee, K., Sen, J., and Chaudhuri, A. (2005) Common co-lipids, in synergy, impart high gene transfer properties to transfection-incompetent cationic lipids. FEBS Lett 579, 1291-300.

(126) Ma, B., Zhang, S., Jiang, H., Zhao, B., and Lv, H. (2007) Lipoplex morphologies and their influences on transfection efficiency in gene delivery. J Control Release 123, 184-94.

(127) Zuhorn, I. S., Oberle, V., Visser, W. H., Engberts, J. B., Bakowsky, U., Polushkin,E., and Hoekstra, D. (2002) Phase behavior of cationic amphiphiles and their mixtures with helper lipid influences lipoplex shape, DNA translocation, and transfection efficiency. Biophys J 83, 2096-108.

(128) Wiethoff, C. M., Gill, M. L., Koe, G. S., Koe, J. G., and Middaugh, C. R. (2002) The structural organization of cationic lipid-DNA complexes. J Biol Chem 277, 44980-7.

(129) Felgner, P. L., and Ringold, G. M. (1989) Cationic liposome-mediated transfection. Nature 337, 387-8.

(130) Sato, Y., Murase, K., Kato, J., Kobune, M., Sato, T., Kawano, Y., Takimoto, R., Takada, K., Miyanishi, K., Matsunaga, T., Takayama, T., and Niitsu, Y. (2008) Resolution of liver cirrhosis using vitamin A-coupled liposomes to deliver siRNA against a collagen-specific chaperone. Nat Biotechnol 26, 431-42.

(131) Meyer, O., Kirpotin, D., Hong, K., Sternberg, B., Park, J. W., Woodle, M. C., and Papahadjopoulos, D. (1998) Cationic liposomes coated with polyethylene glycol as carriers for oligonucleotides. J Biol Chem 273, 15621-7. 
(132) Abu-Lila, A., Suzuki, T., Doi, Y., Ishida, T., and Kiwada, H. (2009) Oxaliplatin targeting to angiogenic vessels by PEGylated cationic liposomes suppresses the angiogenesis in a dorsal air sac mouse model. J Control Release 134, 18-25.

(133) Zimmermann, T. S., Lee, A. C., Akinc, A., Bramlage, B., Bumcrot, D., Fedoruk, M. N., Harborth, J., Heyes, J. A., Jeffs, L. B., John, M., Judge, A. D., Lam, K., McClintock, K., Nechev, L. V., Palmer, L. R., Racie, T., Rohl, I., Seiffert, S., Shanmugam, S., Sood, V., Soutschek, J., Toudjarska, I., Wheat, A. J., Yaworski, E., Zedalis, W., Koteliansky, V., Manoharan, M., Vornlocher, H. P., and MacLachlan, I. (2006) RNAi-mediated gene silencing in non-human primates. Nature 441, 111-4.

(134) Zhu, L., Ye, Z., Cheng, K., Miller, D. D., and Mahato, R. I. (2008) Site-specific delivery of oligonucleotides to hepatocytes after systemic administration. Bioconjug Chem 19, 290-8.

(135) Cheng, K., Ye, Z., Guntaka, R. V., and Mahato, R. I. (2006) Enhanced hepatic uptake and bioactivity of type alpha1(I) collagen gene promoter-specific triplexforming oligonucleotides after conjugation with cholesterol. J Pharmacol Exp Ther 317, 797-805.

(136) Soutschek, J., Akinc, A., Bramlage, B., Charisse, K., Constien, R., Donoghue, M., Elbashir, S., Geick, A., Hadwiger, P., Harborth, J., John, M., Kesavan, V., Lavine, G., Pandey, R. K., Racie, T., Rajeev, K. G., Rohl, I., Toudjarska, I., Wang, G., Wuschko, S., Bumcrot, D., Koteliansky, V., Limmer, S., Manoharan, M., and Vornlocher, H. P. (2004) Therapeutic silencing of an endogenous gene by systemic administration of modified siRNAs. Nature 432, 173-8.

(137) Yang, N., Ye, Z., Li, F., and Mahato, R. I. (2009) HPMA polymer-based sitespecific delivery of oligonucleotides to hepatic stellate cells. Bioconjug Chem 20, 213-21.

(138) Derfus, A. M., Chen, A. A., Min, D. H., Ruoslahti, E., and Bhatia, S. N. (2007) Targeted quantum dot conjugates for siRNA delivery. Bioconjug Chem 18, 13916.

(139) Oishi, M., Nagasaki, Y., Itaka, K., Nishiyama, N., and Kataoka, K. (2005) Lactosylated poly(ethylene glycol)-siRNA conjugate through acid-labile betathiopropionate linkage to construct $\mathrm{pH}$-sensitive polyion complex micelles achieving enhanced gene silencing in hepatoma cells. J Am Chem Soc 127, 16245.

(140) Muratovska, A., and Eccles, M. R. (2004) Conjugate for efficient delivery of short interfering RNA (siRNA) into mammalian cells. FEBS Lett 558, 63-8. 
(141) Kim, S. H., Jeong, J. H., Lee, S. H., Kim, S. W., and Park, T. G. (2006) PEG conjugated VEGF siRNA for anti-angiogenic gene therapy. J Control Release 116, 123-9.

(142) Harrison, J. G., and Balasubramanian, S. (1998) Synthesis and hybridization analysis of a small library of peptide-oligonucleotide conjugates. Nucleic Acids Res 26, 3136-45.

(143) Schwarz, D. S., Hutvagner, G., Du, T., Xu, Z., Aronin, N., and Zamore, P. D. (2003) Asymmetry in the assembly of the RNAi enzyme complex. Cell 115, 199208.

(144) Khvorova, A., Reynolds, A., and Jayasena, S. D. (2003) Functional siRNAs and miRNAs exhibit strand bias. Cell 115, 209-16.

(145) Schwarz, D. S., Hutvagner, G., Haley, B., and Zamore, P. D. (2002) Evidence that siRNAs function as guides, not primers, in the Drosophila and human RNAi pathways. Mol Cell 10, 537-48.

(146) Kim, S. H., Jeong, J. H., Lee, S. H., Kim, S. W., and Park, T. G. (2008) LHRH receptor-mediated delivery of siRNA using polyelectrolyte complex micelles selfassembled from siRNA-PEG-LHRH conjugate and PEI. Bioconjug Chem 19, 2156-62.

(147) Oishi, M., Nagasaki, Y., Nishiyama, N., Itaka, K., Takagi, M., Shimamoto, A., Furuichi, Y., and Kataoka, K. (2007) Enhanced growth inhibition of hepatic multicellular tumor spheroids by lactosylated poly(ethylene glycol)-siRNA conjugate formulated in PEGylated polyplexes. ChemMedChem 2, 1290-7.

(148) Kim, S. H., Jeong, J. H., Lee, S. H., Kim, S. W., and Park, T. G. (2008) Local and systemic delivery of VEGF siRNA using polyelectrolyte complex micelles for effective treatment of cancer. J Control Release 129, 107-16.

(149) Waeckerle-Men, Y., and Groettrup, M. (2005) PLGA microspheres for improved antigen delivery to dendritic cells as cellular vaccines. Adv Drug Deliv Rev 57, $475-82$.

(150) Jiang, W., Gupta, R. K., Deshpande, M. C., and Schwendeman, S. P. (2005) Biodegradable poly(lactic-co-glycolic acid) microparticles for injectable delivery of vaccine antigens. Adv Drug Deliv Rev 57, 391-410.

(151) Ravi Kumar, M. N., Bakowsky, U., and Lehr, C. M. (2004) Preparation and characterization of cationic PLGA nanospheres as DNA carriers. Biomaterials 25, $1771-7$. 
(152) Takashima, Y., Saito, R., Nakajima, A., Oda, M., Kimura, A., Kanazawa, T., and Okada, H. (2007) Spray-drying preparation of microparticles containing cationic PLGA nanospheres as gene carriers for avoiding aggregation of nanospheres. Int $J$ Pharm 343, 262-9.

(153) Patil, Y., and Panyam, J. (2009) Polymeric nanoparticles for siRNA delivery and gene silencing. Int J Pharm 367, 195-203.

(154) Walter, E., Moelling, K., Pavlovic, J., and Merkle, H. P. (1999) Microencapsulation of DNA using poly(DL-lactide-co-glycolide): stability issues and release characteristics. J Control Release 61, 361-74.

(155) Capan, Y., Woo, B. H., Gebrekidan, S., Ahmed, S., and DeLuca, P. P. (1999) Preparation and characterization of poly (D,L-lactide-co-glycolide) microspheres for controlled release of poly(L-lysine) complexed plasmid DNA. Pharm Res 16, 509-13.

(156) Maruyama, A., Ishihara, T., Kim, J. S., Kim, S. W., and Akaike, T. (1997) Nanoparticle DNA carrier with poly(L-lysine) grafted polysaccharide copolymer and poly(D,L-lactic acid). Bioconjug Chem 8, 735-42.

(157) Hartikka, J., Bozoukova, V., Ferrari, M., Sukhu, L., Enas, J., Sawdey, M., Wloch, M. K., Tonsky, K., Norman, J., Manthorpe, M., and Wheeler, C. J. (2001) Vaxfectin enhances the humoral immune response to plasmid DNA-encoded antigens. Vaccine 19, 1911-23.

(158) Hermanson, G., Whitlow, V., Parker, S., Tonsky, K., Rusalov, D., Ferrari, M., Lalor, P., Komai, M., Mere, R., Bell, M., Brenneman, K., Mateczun, A., Evans, T., Kaslow, D., Galloway, D., and Hobart, P. (2004) A cationic lipid-formulated plasmid DNA vaccine confers sustained antibody-mediated protection against aerosolized anthrax spores. Proc Natl Acad Sci US A 101, 13601-6.

(159) Mahato, R. I. (2005) Water insoluble and soluble lipids for gene delivery. $A d v$ Drug Deliv Rev 57, 699-712.

(160) Tu, Y., and Kim, J. S. (2008) A fusogenic segment of glycoprotein H from herpes simplex virus enhances transfection efficiency of cationic liposomes. J Gene Med 10, 646-54.

(161) Leventis, R., and Silvius, J. R. (1990) Interactions of mammalian cells with lipid dispersions containing novel metabolizable cationic amphiphiles. Biochim Biophys Acta 1023, 124-32.

(162) Gao, H., and Hui, K. M. (2001) Synthesis of a novel series of cationic lipids that can act as efficient gene delivery vehicles through systematic heterocyclic substitution of cholesterol derivatives. Gene Ther 8, 855-63. 
(163) Blubaugh, L. V., BoTTs, C. W., and Gerwe, E. G. (1940) A study of the germicidal properties of cetyl pyridinium chloride. The Journal of Bacteriology $39,51$.

(164) Gopal, V., Prasad, T. K., Rao, N. M., Takafuji, M., Rahman, M. M., and Ihara, H. (2006) Synthesis and in vitro evaluation of glutamide-containing cationic lipids for gene delivery. Bioconjug Chem 17, 1530-6.

(165) Ilies, M. A., Johnson, B. H., Makori, F., Miller, A., Seitz, W. A., Thompson, E. B.,and Balaban, A. T. (2005) Pyridinium cationic lipids in gene delivery: an in vitro and in vivo comparison of transfection efficiency versus a tetraalkylammonium congener. Arch Biochem Biophys 435, 217-26.

(166) Mahato, R. I., Anwer, K., Tagliaferri, F., Meaney, C., Leonard, P., Wadhwa, M. S., Logan, M., French, M., and Rolland, A. (1998) Biodistribution and gene expression of lipid/plasmid complexes after systemic administration. Hum Gene Ther 9, 2083-99.

(167) Mahato, R. I., Kawabata, K., Nomura, T., Takakura, Y., and Hashida, M. (1995) Physicochemical and pharmacokinetic characteristics of plasmid DNA/cationic liposome complexes. J Pharm Sci 84, 1267-71.

(168) Lee, E. R., Marshall, J., Siegel, C. S., Jiang, C., Yew, N. S., Nichols, M. R., Nietupski, J. B., Ziegler, R. J., Lane, M. B., Wang, K. X., Wan, N. C., Scheule, R. K., Harris, D. J., Smith, A. E., and Cheng, S. H. (1996) Detailed analysis of structures and formulations of cationic lipids for efficient gene transfer to the lung. Hum Gene Ther 7, 1701-17.

(169) Srilakshmia GV, S. J., Chaudhuria A, Ramadasb Y and Rao NM. (2002) Anchordependent lipofection with non-glycerol based cytofectins containing single 2hydroxyethyl head groups. Biochim Biophys Acta - Biomembranes 1559, 87-95

(170) Venkata Srilakshmi, G., Sen, J., Chaudhuri, A., Ramadas, Y., and Madhusudhana Rao, N. (2002) Anchor-dependent lipofection with non-glycerol based cytofectins containing single 2-hydroxyethyl head groups. Biochim Biophys Acta 1559, 87-95.

(171) Takafuji, M., Ishiodori, A., Yamada, T., Sakurai, T., and Ihara, H. (2004) Stabilization of enhanced chirality from pyrene-containing l-glutamide lipid in methyl methacrylate by photo-induced polymerization. Chem Commun (Camb), 1122-3.

(172) Simberg, D., Weiss, A., and Barenholz, Y. (2005) Reversible mode of binding of serum proteins to DOTAP/cholesterol Lipoplexes: a possible explanation for intravenous lipofection efficiency. Hum Gene Ther 16, 1087-96. 
(173) Singh, R. S., Mukherjee, K., Banerjee, R., Chaudhuri, A., Hait, S. K., Moulik, S. P., Ramadas, Y., Vijayalakshmi, A., and Rao, N. M. (2002) Anchor dependency for non-glycerol based cationic lipofectins: mixed bag of regular and anomalous transfection profiles. Chemistry 8, 900-9.

(174) Smyth Templeton, N. (2003) Cationic liposomes as in vivo delivery vehicles. Curr Med Chem 10, 1279-87.

(175) Madaan, P., and Tyagi, V. K. (2008) Quaternary pyridinium salts: a review. $J$ Oleo Sci 57, 197-215.

(176) Haldar, J., Kondaiah, P., and Bhattacharya, S. (2005) Synthesis and antibacterial properties of novel hydrolyzable cationic amphiphiles. Incorporation of multiple head groups leads to impressive antibacterial activity. J Med Chem 48, 3823-31.

(177) Tucker, S. J., McClelland, D., Jaspars, M., Sepcic, K., MacEwan, D. J., and Scott, R. H. (2003) The influence of alkyl pyridinium sponge toxins on membrane properties, cytotoxicity, transfection and protein expression in mammalian cells. Biochim Biophys Acta 1614, 171-81.

(178) Scott, R. H., Whyment, A. D., Foster, A., Gordon, K. H., Milne, B. F., and Jaspars,M. (2000) Analysis of the structure and electrophysiological actions of halitoxins: 1,3 alkyl-pyridinium salts from Callyspongia ridleyi. J Membr Biol $176,119-31$.

(179) Kabanov, A. V., Astafieva, I. V., Maksimova, I. V., Lukanidin, E. M., Georgiev, G. P., and Kabanov, V. A. (1993) Efficient transformation of mammalian cells using DNA interpolyelectrolyte complexes with carbon chain polycations. Bioconjug Chem 4, 448-54.

(180) Liu, F., Yang, J., Huang, L., and Liu, D. (1996) New cationic lipid formulations for gene transfer. Pharm Res 13, 1856-60.

(181) Goula, D., Remy, J. S., Erbacher, P., Wasowicz, M., Levi, G., Abdallah, B., and Demeneix, B. A. (1998) Size, diffusibility and transfection performance of linear PEI/DNA complexes in the mouse central nervous system. Gene Ther 5, 712-7.

(182) Benns, J. M., Choi, J. S., Mahato, R. I., Park, J. S., and Kim, S. W. (2000) pHsensitive cationic polymer gene delivery vehicle: N-Ac-poly(L-histidine)-graftpoly(L-lysine) comb shaped polymer. Bioconjug Chem 11, 637-45.

(183) De Smedt, S. C., Demeester, J., and Hennink, W. E. (2000) Cationic polymer based gene delivery systems. Pharm Res 17, 113-26. 
(184) Mahato, R. I., Cheng, K., and Guntaka, R. V. (2005) Modulation of gene expression by antisense and antigene oligodeoxynucleotides and small interfering RNA. Expert Opin Drug Deliv 2, 3-28.

(185) Temsamani, J., Roskey, A., Chaix, C., and Agrawal, S. (1997) In vivo metabolic profile of a phosphorothioate oligodeoxyribonucleotide. Antisense Nucleic Acid Drug Dev 7, 159-65.

(186) Graham, M. J., Crooke, S. T., Monteith, D. K., Cooper, S. R., Lemonidis, K. M., Stecker, K. K., Martin, M. J., and Crooke, R. M. (1998) In vivo distribution and metabolism of a phosphorothioate oligonucleotide within rat liver after intravenous administration. $J$ Pharmacol Exp Ther 286, 447-58.

(187) Rusckowski, M., Qu, T., Roskey, A., and Agrawal, S. (2000) Biodistribution and metabolism of a mixed backbone oligonucleotide (GEM 231) following single and multiple dose administration in mice. Antisense Nucleic Acid Drug Dev 10, $333-45$.

(188) Graham, M. J., Crooke, S. T., Lemonidis, K. M., Gaus, H. J., Templin, M. V., and Crooke, R. M. (2001) Hepatic distribution of a phosphorothioate oligodeoxynucleotide within rodents following intravenous administration. Biochem Pharmacol 62, 297-306.

(189) Staud, F., Nishikawa, M., Takakura, Y., and Hashida, M. (1999) Liver uptake and hepato-biliary transfer of galactosylated proteins in rats are determined by the extent of galactosylation. Biochim Biophys Acta 1427, 183-92.

(190) Attie, A. D., Pittman, R. C., and Steinberg, D. (1980) Metabolism of native and of lactosylated human low density lipoprotein: evidence for two pathways for catabolism of exogenous proteins in rat hepatocytes. Proc Natl Acad Sci U S A 77, 5923-7.

(191) Biessen, E. A., Beuting, D. M., Vietsch, H., Bijsterbosch, M. K., and Van Berkel, T. J. (1994) Specific targeting of the antiviral drug 5-iodo 2'-deoxyuridine to the parenchymal liver cell using lactosylated poly-L-lysine. J Hepatol 21, 806-15.

(192) Ye, Z., Cheng, K., Guntaka, R. V., and Mahato, R. I. (2006) Receptor-mediated hepatic uptake of M6P-BSA-conjugated triplex-forming oligonucleotides in rats. Bioconjug Chem 17, 823-30.

(193) Rajur, S. B., Roth, C. M., Morgan, J. R., and Yarmush, M. L. (1997) Covalent protein-oligonucleotide conjugates for efficient delivery of antisense molecules. Bioconjug Chem 8, 935-40. 
(194) Healy, J. M., Lewis, S. D., Kurz, M., Boomer, R. M., Thompson, K. M., Wilson, C., and McCauley, T. G. (2004) Pharmacokinetics and biodistribution of novel aptamer compositions. Pharm Res 21, 2234-46.

(195) Bonora, G. M., Ivanova, E., Zarytova, V., Burcovich, B., and Veronese, F. M. (1997) Synthesis and characterization of high-molecular mass polyethylene glycol-conjugated oligonucleotides. Bioconjug Chem 8, 793-7.

(196) Oishi, M., Sasaki, S., Nagasaki, Y., and Kataoka, K. (2003) pH-responsive oligodeoxynucleotide (ODN)-poly(ethylene glycol) conjugate through acid-labile beta-thiopropionate linkage: preparation and polyion complex micelle formation. Biomacromolecules 4, 1426-32.

(197) Ye, Z., Cheng, K., Guntaka, R. V., and Mahato, R. I. (2005) Targeted delivery of a triplex-forming oligonucleotide to hepatic stellate cells. Biochemistry 44, 446676.

(198) Guicciardi, M. E., and Gores, G. J. (2005) Apoptosis: a mechanism of acute and chronic liver injury. Gut 54, 1024-33.

(199) Monsigny, M., Roche, A. C., and Midoux, P. (1984) Uptake of neoglycoproteins via membrane lectin(s) of L1210 cells evidenced by quantitative flow cytofluorometry and drug targeting. Biol Cell 51, 187-96.

(200) Sando, G. N., and Karson, E. M. (1980) p-Isothiocyanatophenyl 6-phospho-alphaD-mannopyranoside coupled to albumin. A model compound recognized by the fibroblast lysosomal enzyme uptake system. 1. Chemical synthesis and characterization. Biochemistry 19, 3850-5.

(201) Monsigny, M., Petit, C., and Roche, A. C. (1988) Colorimetric determination of neutral sugars by a resorcinol sulfuric acid micromethod. Anal Biochem 175, 52530 .

(202) Hendriks, H. F., Brouwer, A., and Knook, D. L. (1990) Isolation, purification, and characterization of liver cell types. Methods Enzymol 190, 49-58.

(203) Terada, T., Nishikawa, M., Yamashita, F., and Hashida, M. (2006) Analysis of the molecular interaction of glycosylated proteins with rabbit liver asialoglycoprotein receptors using surface plasmon resonance spectroscopy. J Pharm Biomed Anal 41, 966-72.

(204) Orr, R. M., and Dorr, F. A. (2005) Clinical studies of antisense oligonucleotides for cancer therapy. Methods Mol Med 106, 85-111. 
(205) Wu, G. Y., and Wu, C. H. (1992) Specific inhibition of hepatitis B viral gene expression in vitro by targeted antisense oligonucleotides. J Biol Chem 267, 12436-9.

(206) Song, E., Lee, S. K., Wang, J., Ince, N., Ouyang, N., Min, J., Chen, J., Shankar, P., and Lieberman, J. (2003) RNA interference targeting Fas protects mice from fulminant hepatitis. Nat Med 9, 347-51.

(207) de Fougerolles, A., Vornlocher, H. P., Maraganore, J., and Lieberman, J. (2007) Interfering with disease: a progress report on siRNA-based therapeutics. Nat Rev Drug Discov 6, 443-53.

(208) Oh, Y. K., and Park, T. G. (2009) siRNA delivery systems for cancer treatment. Adv Drug Deliv Rev 61, 850-62.

(209) Herringson, T. P., and Altin, J. G. (2009) Convenient targeting of stealth siRNAlipoplexes to cells with chelator lipid-anchored molecules. J Control Release 139, 229-38.

(210) Rozema, D. B., Lewis, D. L., Wakefield, D. H., Wong, S. C., Klein, J. J., Roesch, P. L., Bertin, S. L., Reppen, T. W., Chu, Q., Blokhin, A. V., Hagstrom, J. E., and Wolff, J. A. (2007) Dynamic PolyConjugates for targeted in vivo delivery of siRNA to hepatocytes. Proc Natl Acad Sci U S A 104, 12982-7.

(211) Al-Abd, A. M., Lee, S. H., Kim, S. H., Cha, J. H., Park, T. G., Lee, S. J., and Kuh, H. J. (2009) Penetration and efficacy of VEGF siRNA using polyelectrolyte complex micelles in a human solid tumor model in-vitro. J Control Release 137, $130-5$.

(212) Bataller, R., and Brenner, D. A. (2005) Liver fibrosis. J Clin Invest 115, 209-18.

(213) Chiu, Y. L., and Rana, T. M. (2003) siRNA function in RNAi: a chemical modification analysis. Rna 9, 1034-48. 


\section{VITA}

Mr. Lin Zhu, son of Mr. Xianzhong Zhu and Mrs. Jinhua Li, was born in Kaifeng, Henan Province, China on February 14, 1975. He was admitted to College of Pharmacy, China Pharmaceutical University, (Nanjing, Jiangsu Province, China) in September 1993. Mr. Lin Zhu graduated with a Bachelor of Engineering in pharmaceuitcs in June 1997. In September 1997, he joined the Department of Pharmaceutical Sciences, School of Pharmacy, Henan University (Kaifeng, Henan Province, China) as a lecturer, where he taught pharmaceutics theory and practice courses for undergraduate students and did research on formulation and drug delivery. In September 2000, he was admitted in College of Pharmacy, China Pharmaceutical University again and graduated with a Master of Science in pharmaceutics in June 2003. In September 2003, he joined Department of Pharmaceutical Sciences, China Pharmaceutical University as a senior lecturer. Besides of teaching and research, he worked as the co-advisor for 2 graduate students and advisor for 2 undergraduate students.

Mr. Lin Zhu enrolled in the Doctor of Philosophy program at the University of Tennessee Health Science Center in August 2005 and received a Graduate Teaching Assistantship. At the same time, he joined Dr. Ram I Mahato's group in the Department of Pharmaceutical Sciences.

Mr. Lin Zhu is a member of the American Association of Pharmaceutical Scientists and the Controlled Release Society.

\section{LIST OF PUBLICATIONS}

\section{Papers}

1. Zhu, L., Huo, Z., Wang, L., Tong, X., Xiao, Y., and Ni, Y. (2009) Targeted delivery of methotrexate to skeletal muscular tissue by thermosensitive magnetoliposomes, International Journal of Pharmaceutics, 370 (1-2), 136-43.

2. Zhu, L., Lu, Y., Miller, D.D., and Mahato, R.I. (2008) Structural and formulation factors influencing pyridinium lipid-based gene transfer, Bioconjugate Chemistry, 19 (12), 2499-512.

3. Cheng, G., Zhu, L., and Mahato, R.I. (2008) Caspase-3 gene silencing for inhibiting apoptosis in insulinoma cells and human islets, Molecular Pharmaceutics, 5 (6), 1093-102.

4. Tu, Y., Zhu, L., Wang, G., Zhao, L., and Xiang, B. (2008) Development and validation of a LC-ESI-MS Assay for determination of Icariin in rat plasma after administration of Herba Epimedii. Chromatographia, 67 (7-8), 591-7. 
5. Zhu, L., Ye, Z., Cheng, K., Miller, D.D., and Mahato, R.I. (2008) Site-specific delivery of oligonucleotides to hepatocytes after systemic administration. Bioconjugate Chemistry, 19 (1), 290-8.

6. Huo, Z., Zhu, L., Xiao, Y., Tong, X., and Ni, K. (2008) The study of the preparation and targeting effect of thermosensitive magneto-liposomes, Strait Pharmaceutical Journal, 20 (7), 14-7.

7. Wang, L., Zhu, L., Ni, K., Tu, Y., and Peng, G. (2006) Study on the tissue distribution of methotrexate magnetoliposomes in mice by HPLC, Chinese Pharmaceutical Journal, 41 (20), 1572-5.

8. Zhu, L., Wang, L., Ni, K., Tong, X., and Dai, L. (2006) Preparation of stable magnetoliposomes with high encapsulation efficiency of methotrexate, Chinese Pharmaceutical Journal, 41 (17), 1324-17.

\section{Reviews}

9. Zhu, L. and Mahato, R. (2010) Lipid and polymeric carrier mediated nucleic acid delivery, Expert Opinion on Drug Delivery, 7(10), 1-18.

\section{Abstracts and Presentations}

10. Zhu L, Lu Y, Ye Z, Cheng K, Miller DD, Mahato RI, Design of lipid and polymeric carriers for nucleic acid delivery, AAPS Annual, Los Angeles, CA, Nov 8-12, 2009. (Podium presentation)

11. Zhu L, Lu Y, Miller DD, Mahato RI, Pyridinium cationic lipid based gene and siRNA delivery, AAPS Annual, Los Angeles, CA, Nov 8-12, 2009. (Poster presentation)

12. Zhu L, Lu Y, Miller DD, Mahato RI, Enhancing gene delivery using pyridinium cationic lipids, AAPS Annual, Atlanta, GA, Nov 16-20, 2008. (Poster presentation)

13. Zhu L, Lu Y, Miller DD, Mahato RI, Effect of structure and formulation factors of pyridinium cationic lipids on gene delivery, AAPS PharmForum, Little Rock, AR, May 18-20, 2008. (Podium presentation)

14. Zhu L, Lu Y, Miller DD, Mahato RI, Synthesis and characterization of pyridinium cationic lipids for nucleic acid delivery, AAPS Annual, San Diego, CA, Nov 11-15, 2007. (Poster presentation)

15. Zhu L, Ye Z, Cheng K, Miller DD, Mahato RI, Site-specific delivery of oligonucleotides to hepatocytes. Controlled Release Society Annual, Long Beach, CA, July 07-11, 2007. (Poster presentation)

16. Zhu L, Lu Y, Miller DD, Mahato RI, Synthesis and characterization of 
pyridinium cationic lipids for nucleic acid delivery. AAPS PharmForum, Memphis, TN, May 30-31, 2007. (Poster presentation)

17. Zhu L, Ye Z, Miller DD, Mahato RI, Site-specific delivery of short interfering RNA to hepatocytes, AAPS Annual, San Antonio, TX, Oct 29-Nov 02, 2006. (Poster presentation) 